PEDRO HENRIQUE RIBEIRO FERREIRA

PROJETO E OTIMIZAÇÃO DE ÁRVORES DE MANIVELAS 
PEDRO HENRIQUE RIBEIRO FERREIRA

\section{PROJETO E OTIMIZAÇÃO DE ÁRVORES DE MANIVELAS}

Dissertação apresentada à Escola Politécnica da Universidade de São Paulo para obtenção do título de Mestre em Engenharia

Área de concentração:

Engenharia Mecânica

Orientadora: Profa. Dra.

Larissa Driemeier 


\section{FICHA CATALOGRÁFICA}

\section{Ferreira, Pedro Henrique Ribeiro}

Projeto e otimização de árvores de manivelas / P.H.R. Ferreira. -- São Paulo, 2008.

$138 \mathrm{p}$.

Dissertação (Mestrado) - Escola Politécnica da Universidade de São Paulo. Departamento de Engenharia Mecânica.

1. Motores de combustão interna (Componentes) 2. Árvores de manivelas 3. Análise estrutural 4. Análise dinâmica 5. Otimização I. Universidade de São Paulo. Escola Politécnica. Departamento de Engenharia Mecânica II. t. 
DEDICATÓRIA

Dedico este trabalho a meus pais e à minha companheira Elen. 


\section{AGRADECIMENTOS}

À professora Dra. Larissa Driemeier, pela orientação e pelo constante estímulo transmitido durante todo o trabalho.

A meus pais, Vicente Policarpo Buck Ferreira e Valquíria Cação Ribeiro Ferreira pela dedicação, apoio e educação, fundamentais para o meu crescimento e desenvolvimento em todas as etapas da minha vida.

À minha companheira Elen Haruka Miyabara por todo amor, atenção e compreensão.

A meus irmãos Antônio Paulo Ribeiro Ferreira e João Vicente Ribeiro Ferreira pelo incentivo, apoio e auxílio.

Ao colegas de trabalho da ThyssenKrupp Metalúrgica Campo Limpo, Luis Antônio Fonseca Galli, Alex de Souza Rodrigues, Rafael Augusto de Lima e Silva, Robson Ferreira da Cruz e Sergio Gradella Villalva, pela amizade, oportunidade e colaboração técnica.

A todos que colaboraram direta ou indiretamente na execução deste trabalho. 
"Grandes realizações não são feitas por impulso, mas por uma soma de pequenas realizações." Vincent Van Gogh 


\section{SUMÁRIO}

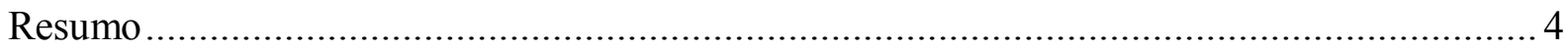

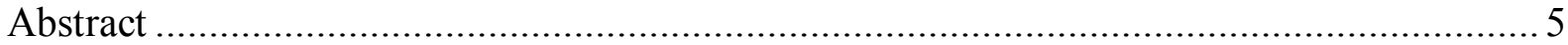

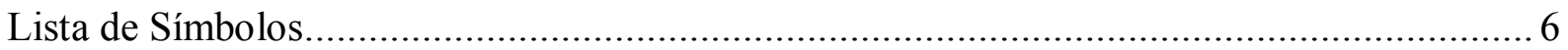

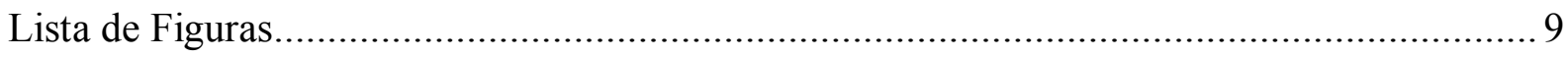

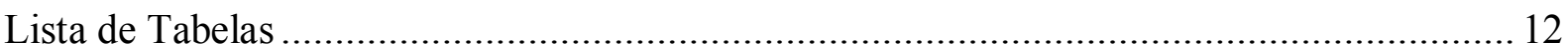

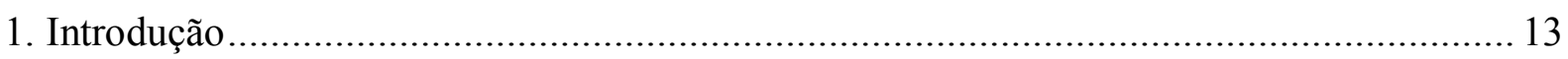

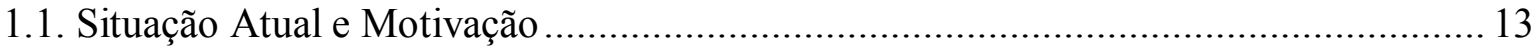

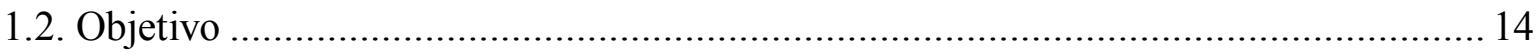

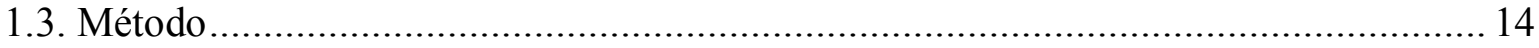

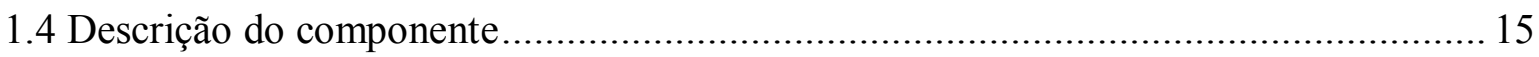

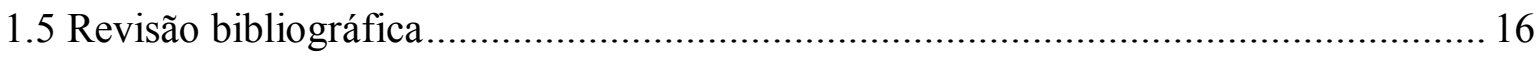

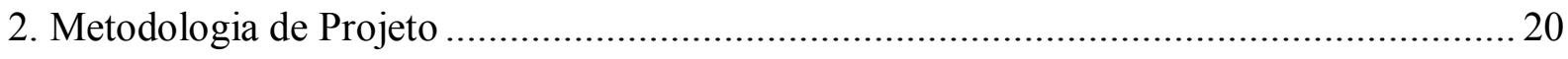

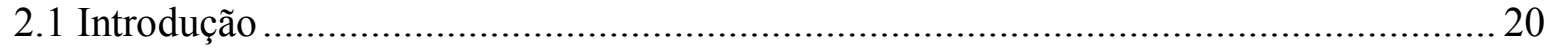

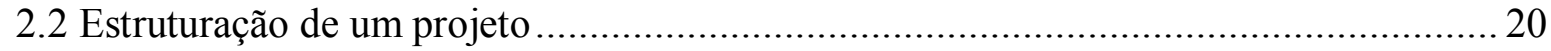

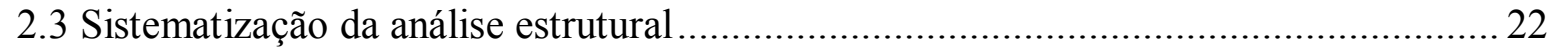

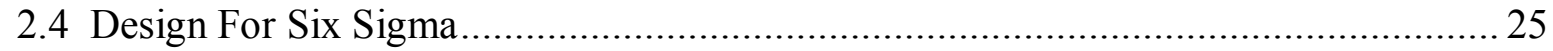

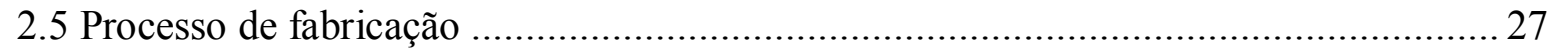

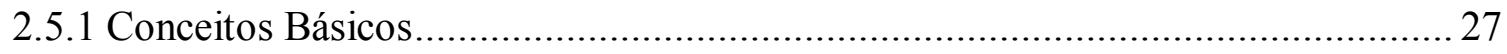

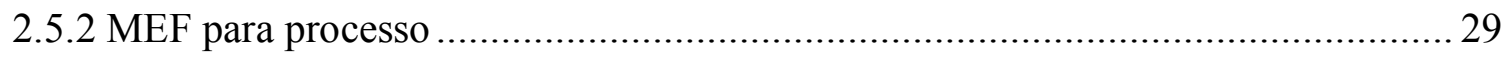

3. Análise do Carregamento Atuante no Sistema …........................................................ 32

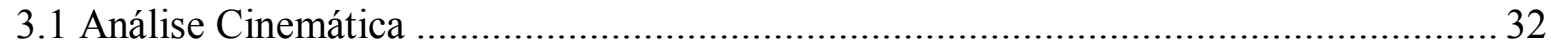

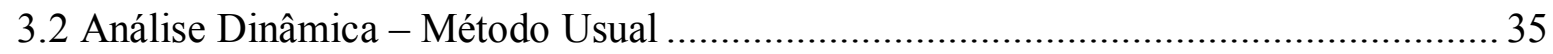

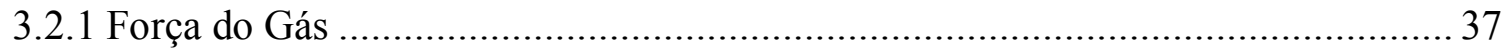

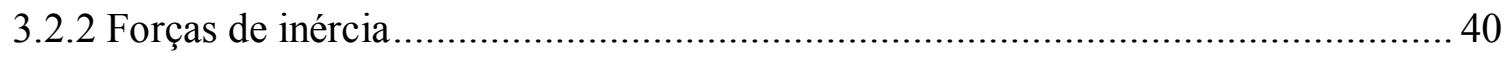

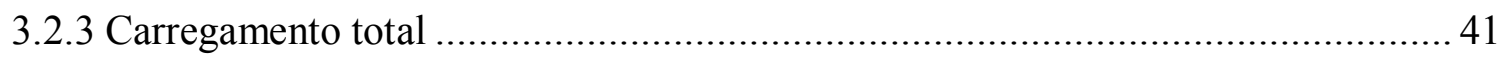

3.3 Análise Dinâmica - Método de Newton................................................................. 42

3.4 Comparação dos métodos de cálculo do carregamento............................................. 46

3.5 Esforços nos mancais / análise hidrodinâmica.............................................................. 49

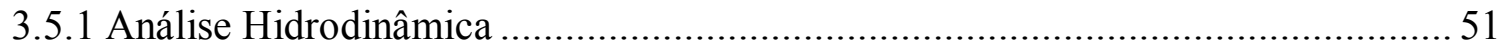

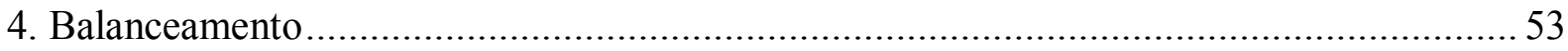

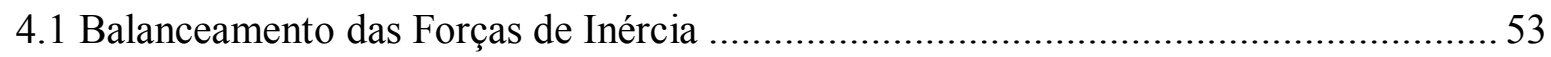




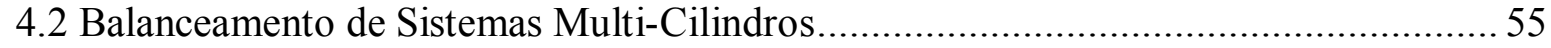

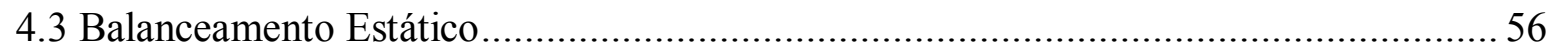

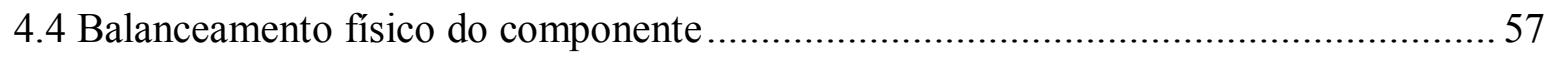

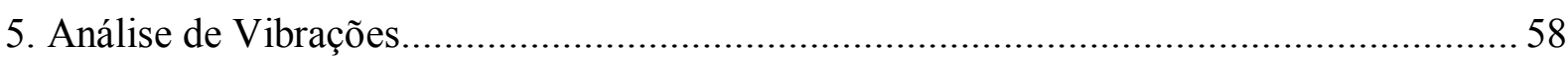

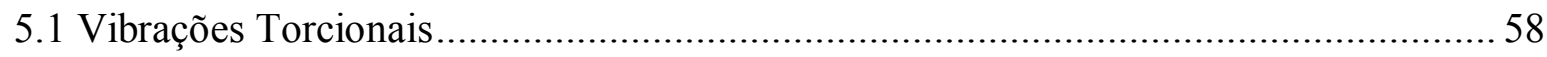

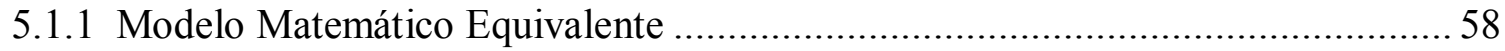

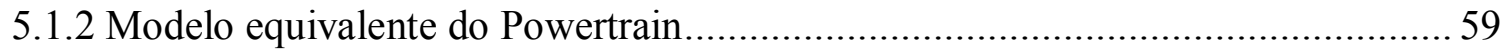

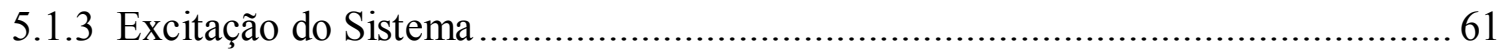

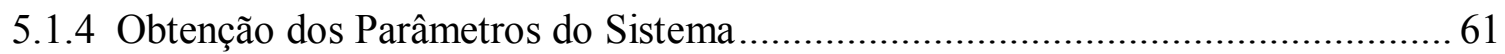

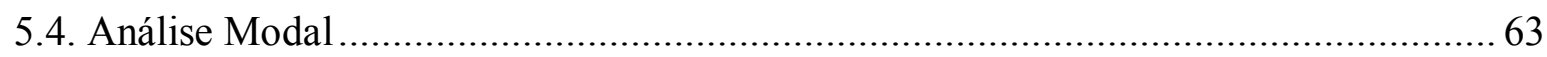

5.4.2 Análise modal em diferentes níveis (motor e conjunto de transmissão) ................ 64

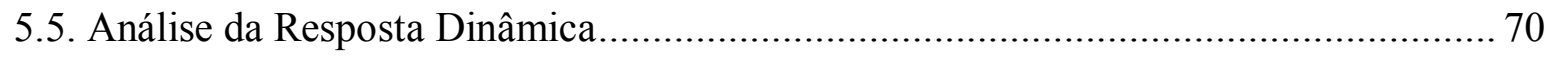

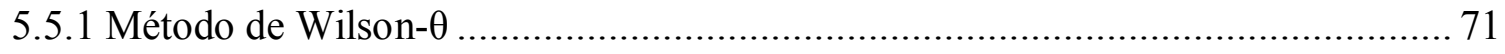

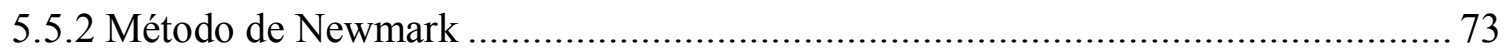

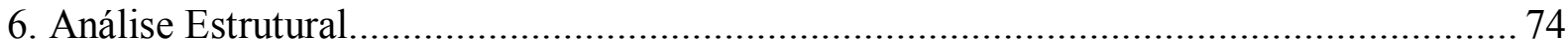

6.1 Cálculo dos Coeficientes de Segurança.................................................................. 77

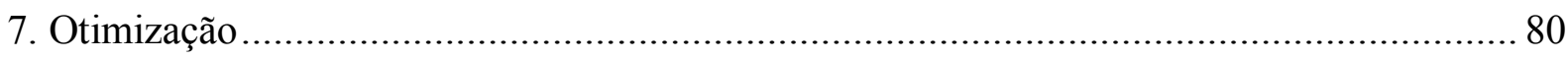

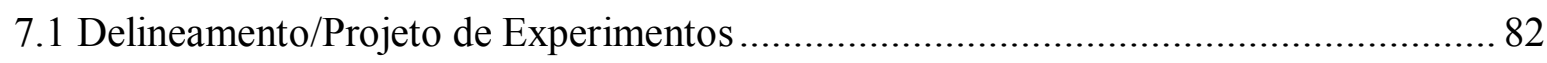

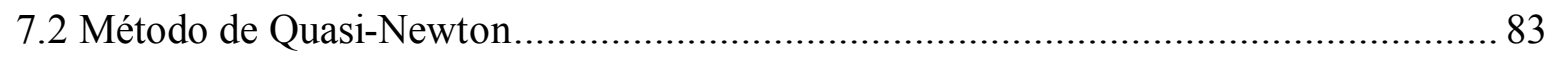

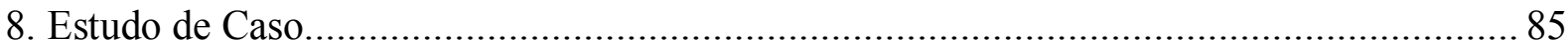

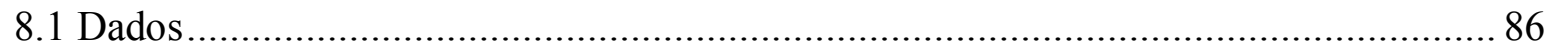

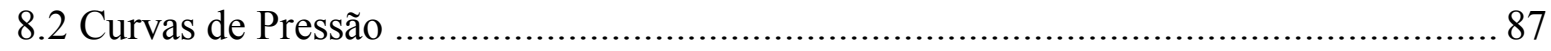

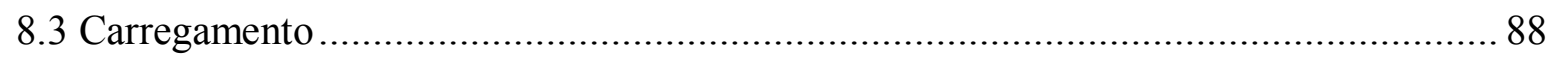

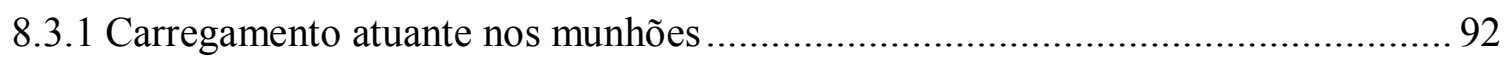

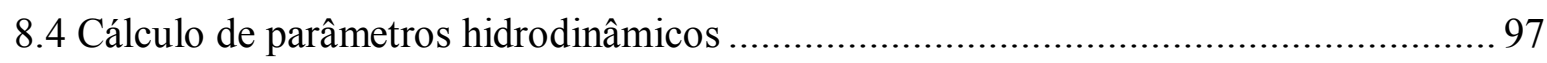

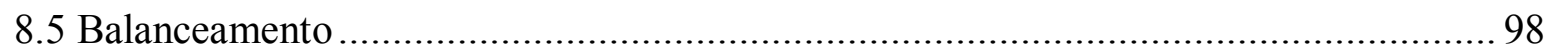

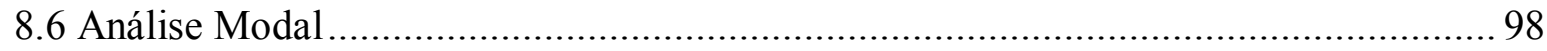

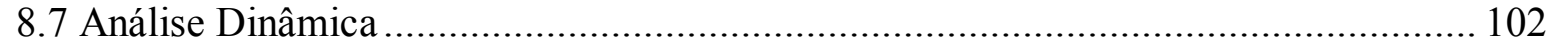

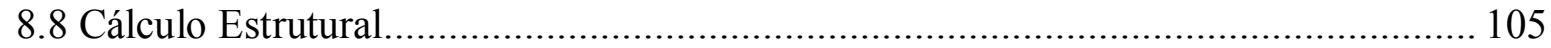

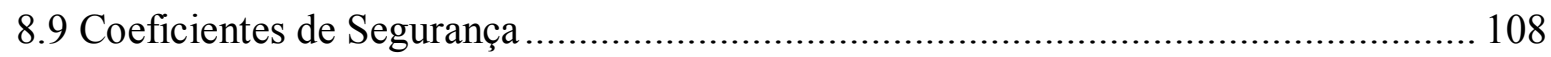

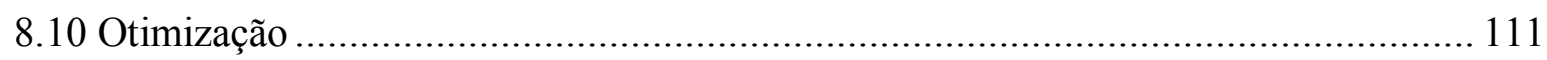

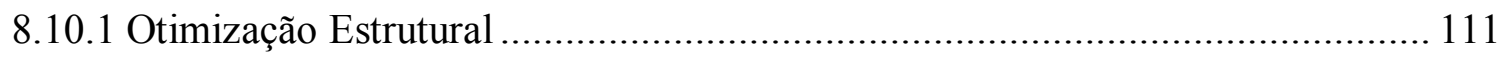

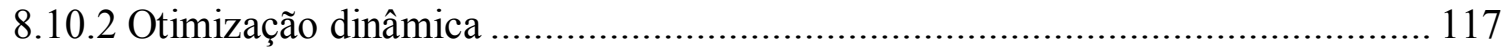

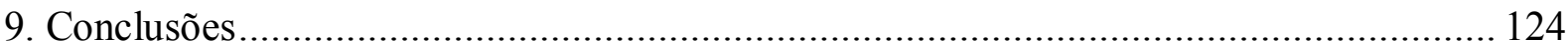


APÊNDICE A: PROGRAMA EM MATLAB PARA BALANCEAMENTO 130 APÊNDICE B: PROGRAMA EM MATLAB PARA CÁLCULO DO CARREGAMENTO,

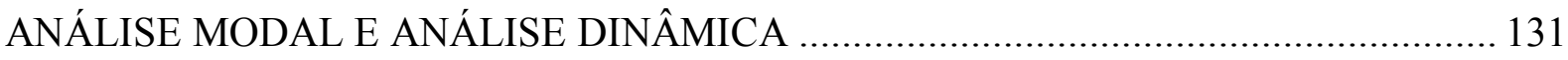
APÊNDICE C: PROGRAMA EM MATLAB PARA OTIMIZAÇÃO …………………..... 138 


\section{Resumo}

O presente trabalho objetivou ilustrar procedimentos de análise auxiliada por computador e metodologia de desenvolvimento para árvores de manivela tendo-se como meta sugestões de boas práticas de projeto visando à otimização de componentes segundo necessidades ditadas pelos clientes, competidores e legislações vigentes. Ilustrou-se uma lista das etapas principais do projeto e desenvolvimento de virabrequins com foco na análise dinâmica e estrutural do componente. Para estas etapas específicas, resumiu-se a teoria básica envolvida nos cálculos e análises necessários e, para casos de abordagens consagradas distintas na resolução de um mesmo problema, realizou-se uma comparação de precisão e custo envolvidos. Posteriormente, aplicou-se o conjunto de ferramentas analisadas em um estudo de caso com uma árvore de manivelas de quatro cilindros em linha, obtendo-se o desempenho estrutural e dinâmico do componente seguido de uma otimização paramétrica. Observou-se um potencial de ganho de precisão desde o cálculo do carregamento aplicado no componente à otimização do mesmo, com o uso de métodos clássicos aplicados à nova tecnologia de software e hardware disponível. Concluiu-se que a organização adequada e utilização específica das ferramentas disponíveis trazem benefícios expressivos na qualidade dos resultados, melhor utilização dos recursos disponíveis e visão global do vínculo de diferentes parâmetros de desempenho.

Palavras-chave: Motores de combustão interna. Árvore de manivelas. Análise estrutural. Análise dinâmica. Otimização 


\section{Abstract}

In the current dissertation it was aimed to illustrate procedures regarding computer aided analysis and methodology for development of crankshafts seeking best practices suggestions to design and focusing on component optimization. These methods must adequate component design to customer, competitors and laws demands. Main development and design tasks for crankshafts were shown centering attention on dynamic and structural analysis. The basic needed theory for these specific tasks with calculus and analyses was summarized and, when more than one common approach was applicable, a cost and precision comparison was performed. Afterward, these tools were applied in a case study where main performance parameters for an inline four cylinder engine crankshaft were obtained. The component was analyzed structurally and dynamically for a subsequent parametric optimization. A potential benefit in precision was observed from applied loads calculation to the mentioned optimization by using available classic methods and modern software and hardware technology mutually. It was concluded that, with an adequate project organization and specific usage of available methods, expressive results can be obtained in results quality, best resources employment and general understanding of performance parameter's links.

Keywords: Internal combustion engines. Crankshaft. Structural analysis. Dynamic analysis. Optimization. 


\section{Lista de Símbolos}

$\beta$ - ângulo entre o eixo do pistão e a linha que cruza os centros dos olhais da biela

$\alpha$ - posição angular da árvore de manivelas

L - distância entre centros dos olhais

L1 - distância entre centro do olhal menor e centro de gravidade da biela

L2 - distância entre centro do olhal maior e centro de gravidade da biela

$r$ - meio-curso do virabrequim

$\lambda$ - relação $L / r$

$\omega$ - velocidade angular da árvore de manivelas

$x$ - posição do pistão na direção de seu eixo

$a_{p}$ - aceleração do pistão

$a_{A}, a_{B}, a_{C}$ e $a_{D}$

$\mathrm{x}_{\mathrm{a}}$ - posição do pistão adimensionalisada $(\mathrm{x} / \mathrm{r})$

$A_{i}$ - coeficientes das equações resultantes de expansão por séries de Fourier

$F_{p}$ - força no pistão

$\mathrm{F}_{\mathrm{N}}$ - força normal (pistão-cilindro)

$F_{\mathrm{s}}$ - força na chamada direção do eixo da biela

$F_{T}$ - força tangencial no virabrequim

$F_{R}$ - força radial no virabrequim

$F_{o x i}$ - força no munhão $i$, na direção do eixo $x$

$F_{\text {oyi }}$ - força no munhão i, na direção do eixo y

$F_{A x}$ - força no moente, na direção do eixo $x$

$F_{A y}$ - força no moente, na direção do eixo y

$\mathrm{m}_{\mathrm{Ma}}$ - massa da manivela

$F_{B x}$ - força no pistão, na direção do eixo $x$

$F_{\mathrm{By}}$ - força no pistão, na direção do eixo y

$F_{m i}$ - força no munhão i ,resultante na direção do eixo $x$

$\mathrm{m}_{\mathrm{b}}$ - massa da biela

$\mathrm{m}_{\mathrm{p}}$ - massa do pistão

$D_{p}$ - diâmetro do pistão

$\mathrm{n}_{\mathrm{cil}}$ - número de cilindros

$r_{v}$ - taxa de compressão 
$P_{m}$ - potência do motor

$\eta_{T}$ - eficiência mecânica do motor

k - coeficiente de Fp máximado ar

$p_{\text {at }}$ - pressão atmosférica

PMS - ponto morto superior

PMI - ponto morto inferior

pme - pressão média efetiva

pmi - pressão média indicada

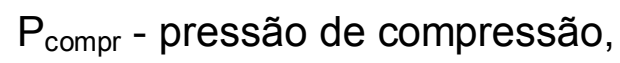

$P_{\text {adm - pressão de admissão }}$

$V_{\text {pmi }}$ - volume no ponto morto inferior

$V_{\text {pms }}$ - volume no ponto morto superior

$\mathrm{P}_{\mathrm{Ma}}$ - peso da manivela

$\mathrm{m}_{\mathrm{Ma}}$ - massa da manivela

$r_{i}$ - distância do centro de gravidade de um volume do virabrequim ao eixo do munhão

$m_{\circ}$ - massas oscilantes do conjunto de potência

$\mathrm{m}_{\mathrm{r}}$ - massas rotativas do conjunto de potência

$F_{1 z}$ - força livre de inércia de $1^{a}$ ordem na direção $z$

$\mathrm{m}_{\mathrm{G}}$ - massa do contrapeso

$\mathrm{Kt}_{\mathrm{i}}$ - rigidez torcional equivalente de cada seção do virabrequim

$\mathrm{I}_{i}$ - inércia equivalente de cada seção do virabrequim

$\mathrm{Ca}_{\mathrm{i}}$ - amortecimento absoluto entre anéis do pistão e cilindro

$\tau$ - incremento no tempo para métodos de integração - resposta dinâmica

$\theta$ - constante para método Wilson- $\theta$

$A_{w}$ e $L_{w}$ - matrizes de constantes para o método Wilson- $\theta$

$\delta_{n}$ e $\alpha_{n}$ - parâmetros para o método de Newmark

w - frequência natural de vibração

$\lambda_{1}$-quadrado da frequência natural de vibração

$\mathrm{S}_{\mathrm{u}}$ - resistência à ruptura

Se - tensão limite de fadiga

$\sigma_{1}$ - tensão máxima principal

$\sigma_{3}$ - tensão mínima principal

$\mathrm{M}$ - amatriz de massa ou de inércia do sistema 
$\mathrm{K}$ - matriz de rigidez do sistema

C - matriz de amortecimento do sistema

$\mathrm{Q}$ - vetor de deslocamentos do sistema

$P$ - vetor de carregamentos externos

s - direção para iterações no algoritmo de otimização

$\mathrm{H}$ - matriz Hessiana 


\section{Lista de Figuras}

Figura 1: Árvore de Manivelas

Figura 2: Metodologia de projeto proposta por Pahl \& Beitz3 em 1996

Figura 3: Ex. de metodologia para análise estrutural.

Figura 4: Principais etapas no processo de forjamento e usinagem de virabrequins

Figura 5: Simulação do processo de laminação (esquerda) e forma final (direita)

Figura 6: Simulação do processo de conformação (pré-forma)

Figura 7: Componentes do Powertrain

Figura 8: Ângulos e dimensões para o sistema biela-manivela

Figura 9: Esforços atuantes no sistema biela-manivela

Figura 10: Gráfico típico da curva Pressão x ângulo

Figura 11: Diagramas para um ciclo Diesel ideal

Figura 12: Exemplo de medição do centro de gravidade em uma biela

Figura 13: Forças atuantes na manivela

Figura 14: Forças atuantes na biela

Figura 15: Forças atuantes no pistão

Figura 16: Forças atuantes na manivela (máxima pressão)

Figura 17: Forças atuantes na manivela (máxima velocidade)

Figura 18: Cálculo do carregamento nos munhões

Figura 19: Mancal hidrodinâmico radial

Figura 20: Representação vetorial das forças de inércia oscilantes

Figura 21: Forças de inércia para diferentes tamanhos de contrapesos

Figura 22: Manivelas para $1^{\mathrm{a}}$ e $2^{\mathrm{a}}$ Ordem para Motores em Linha (4 tempos) com 3 a 6 cilindros

Figura 23: Modelo equivalente para um motor de quatro cilindros

Figura 24:Componentes do trem de transmissão

Figura 25:Modelos para cálculo de rigidez equivalente

Figura 26:Modelos para cálculo das inércias equivalentes do virabrequim

Figura 27: Modelo com eixo comando e componentes para Fp mínima dianteira no software AVL EXCITE $®$

Figura 28: Valores utilizados no exemplo com software AVL EXCITE $®$ 
Figura 29: Curvas de pressão do gás para o exemplo com software AVL EXCITE®

Figura 30: Modos de vibrar conjunto motor (amortecedor ao volante)

Figura 31: Modos de vibrar conjunto amortecedor às rodas

Figura 32: Modos de vibrar conjunto amortecedor às rodas (cont.)

Figura 33: Condições de contorno para análise estrutural - máxima flexão

Figura 34: Condições de contorno para análise estrutural - máxima torção

Figura 35: Diagrama de Goodman mdificado

Figura 36: Modelos tridimensionais utilizados para aquisição de dados

Figura 37: Curvas da pressão de gás pela posição angular do virabrequim

Figura 38: Deslocamento do pistão pelo ângulo do virabrequim

Figura 39: Velocidade do pistão pelo ângulo do virabrequim

Figura 40: Aceleração do pistão pelo ângulo do virabrequim

Figura 41: Força do gás pelo ângulo do virabrequim

Figura 42: Força de inércia pelo ângulo do virabrequim

Figura 43: Força total tangencial pelo ângulo do virabrequim

Figura 44 Força total radial pelo ângulo do virabrequim

Figura 45 Força total tangencial pelo ângulo do virabrequim

Figura 46: Forças verticais atuantes nos munhões

Figura 47: Forças horizontais atuantes nos munhões

Figura 48: Forças totais atuantes no munhão 1

Figura 49: Forças totais atuantes no munhão 2

Figura 50: Forças totais atuantes no munhão 3

Figura 51: Forças totais atuantes no munhão 4

Figura 52: Forças totais atuantes no munhão 5

Figura 53: Desbalanceamento para o estudo de caso

Figura 54: Modos e freqüências naturais de torção

Figura 55: Modos e freqüências naturais de torção (AVL/EXCITE®)

Figura 56: Velocidades críticas da árvore de manivelas

Figura 57: Resposta Dinâmica - Aceleração Constante

Figura 58: Resposta Dinâmica - Aceleração Linear

Figura 59: Resposta Dinâmica - Aproximação (MMQ) na região de regime permanente

Figura 60: Condições de contorno para carregamento combinado

Figura 61: Máxima tensão principal para Fp máximano caso 1 
Figura 62: Tensão equivalente de Von Mises no caso 1

Figura 63: Diagrama de Goodman mdificado para o estudo de caso

Figura 64: Condições de contorno para estudo de otimização

Figura 65: Dimensões analisadas na otimização

Figura 66: Estudo de sensibilidade $-\sigma 1 \times$ comprimento $x$ largura

Figura 67: Estudo de sensibilidade - massa $x$ comprimento $x$ largura

Figura 68: Estudo de sensibilidade - massa $\times$ comprimento $\times$ largura

Figura 69: Candidatos para os valores de mínima massa sem restrição para a tensão

Figura 70: Candidatos para os valores de mínima massa com restrição para a tensão

Figura 71: Estudo de sensibilidade Rigidez,Massa e Inércia x Espessura (largura do braço)

Figura 72: Combinações estudadas na primeira abordagem com DOE

Figura 73: Diagrama de Pareto na primeira abordagem com DOE

Figura 74: Efeitos principais na segunda abordagem com DOE

Figura 75: Interações na segunda abordagem com DOE 


\section{Lista de Tabelas}

Tabela 1: Descrição das Atividades do DFSS

Tabela 2: Vantagens e Desvantagens dos Pocessos de Fabricação de Virabrequins

Tabela 3: Descrição das forças e momentos atuantes nos motores

Tabela 4: Freqüências naturais do conjunto eixo comando às rodas

Tabela 5: Combinações de carregamento utilizadas na análise estrutural

Tabela 6: Carregamento utilizado no estudo

Tabela 7: Tensões para os dois casos no ponto crítico

Tabela 8: Tensões alternadas e médias para os dois casos no ponto crítico

Tabela 9: Tensões equivalentes e fatores de segurança para os dois casos no ponto

Tabela 10: Estrutura de confundimento da análise fracionada

Tabela 11: Dimensões para solução ótima 


\section{Introdução}

\subsection{Situação Atual e Motivação}

A necessidade constante de redução do tempo no projeto de componentes na indústria automotiva dada a evolução de competidores, o advento de leis de emissões mais rígidas e a crescente exigência de desempenho por parte dos consumidores, tornam obrigatória uma política de melhoria contínua destes fatores viabilizando a garantia de vantagens competitivas.

Particularmente, para motores de combustão interna, fatores como peso, resistência estrutural, vibração, ruído e tempo de entrega dos componentes devem ser otimizados concomitantemente, com o máximo de precisão possível.

Pressões por parte do mercado, limitações dos processos de fabricação e requisitos diversos por parte dos clientes finais influenciam significativamente o direcionamento dos projetos de componentes atuais. Portanto, todo o processo de desenvolvimento de componentes deve ser revisto com a inclusão de novas ferramentas desenvolvidas no ambiente competitivo citado, incluindo uma sistemática atualizada e dinâmica.

A utilização de uma metodologia de projeto é fundamental por envolver procedimentos ordenados que visem organizar os conhecimentos. Pode-se desta forma construir uma estrutura de pensamento conduzindo o projeto com objetividade, eficácia e baixo custo ${ }^{1}$.

Através de um sistema de projeto robusto, pode-se minimizar o número de iterações desnecessárias da fase de desenvolvimento à produção final do componente. Potenciais erros corrigidos nas fases iniciais do projeto de componentes podem inclusive evitar problemas maiores nas suas fases subseqüentes. Ferramentas de alta tecnologia disponíveis para dimensionamento, modelagem, simulações, gerenciamento e análises diversas reduzem consideravelmente o tempo consumido no ciclo do projeto e a probabilidade de ocorrência destes erros. 


\subsection{Objetivo}

O objetivo do presente trabalho é a ilustração de métodos para o uso de ferramentas de engenharia assistida por computador no projeto de árvores de manivela. São feitas sugestões de boas práticas de análise e desenvolvimento visando à otimização de componentes segundo as necessidades de redução de tempo e desempenho de uma maneira geral. Deste modo, são mostradas as etapas principais do projeto e desenvolvimento de virabrequins com foco na análise dinâmica e estrutural do componente.

Para estas etapas específicas, pretende-se comparar técnicas já consagradas com outras, propostas na literatura recente, definindo vantagens e desvantagens de diferentes métodos para uma mesma aplicação.

\subsection{Método}

Pretende-se seguir no presente trabalho uma seqüência de análises estruturais e dinâmicas típicas no desenvolvimento de árvores de manivelas. Métodos clássicos e alternativos de cálculo do carregamento atuante no sistema estudado, otimização, além de análises modal, dinâmica e estrutural, serão feitos de modo ordenado para que dados necessários em cada análise específica sejam calculados no momento oportuno.

Assim, numa das possíveis ordens lógicas das etapas, a definição do carregamento e condições de contorno, necessários para a análise dinâmica, é seguida pela análise modal. Esta pode ser pré-requisito na resolução das equações de movimento. A análise de vibração, por sua vez, fornece informações que podem ser utilizadas numa análise estrutural mais completa. Finalmente, na otimização podese resumir informações de todos estes estudos, dependendo da função objetivo, condições de contorno e variáveis de projeto. O presente trabalho segue, tanto para ilustração da teoria quanto para o estudo de caso, esta ordem lógica mencionada.

O capítulo 1 apresenta uma revisão da bibliografia atual. No segundo capítulo, sistemáticas de projeto são sugeridas, contendo as principais etapas dentro do ciclo de projeto. O objetivo principal da ilustração de metodologia geral para gerenciamento de projetos é demonstrar onde as etapas de análise estudadas se 
encaixam no ciclo de desenvolvimento do produto. A fundamental importância de utilização ordenada e inteligente dos recursos disponíveis deve ser considerada, portanto, desde a organização do projeto como um todo a análises específicas como as examinadas neste trabalho.

Um estudo do carregamento atuante em árvores de manivelas é então executado no capítulo 3 para análises estruturais e dinâmicas posteriores, de fundamental importância para a otimização do componente. O quarto capítulo inicia este estudo dinâmico com a teoria de balanceamento de componentes. O quinto capítulo traz a teoria de vibrações e análise dinâmica.

O comportamento estrutural do componente é então analisado no capítulo 6 . No sétimo capítulo são ilustradas técnicas básicas de otimização.

Um estudo de caso em uma árvore de manivelas de um motor real de quatro cilindros em linha é finalmente realizado no oitavo capítulo para a conclusão do trabalho no tópico seguinte.

\subsection{Descrição do componente}

Uma árvore de manivelas, ou virabrequim, é o componente do motor responsável pela transformação do movimento de translação produzido pela força do gás exercida no pistão durante a combustão em movimento rotativo. Conforme a figura 1, um virabrequim é normalmente dividido em braços e moentes, que formam as manivelas e munhões que correspondem às superfícies de contato do virabrequim com o bloco do motor. Uma das extremidades é denominada de espiga, onde é normalmente montado um amortecedor dinâmico ou polias e a outra de flange, onde um volante é usualmente acoplado. 


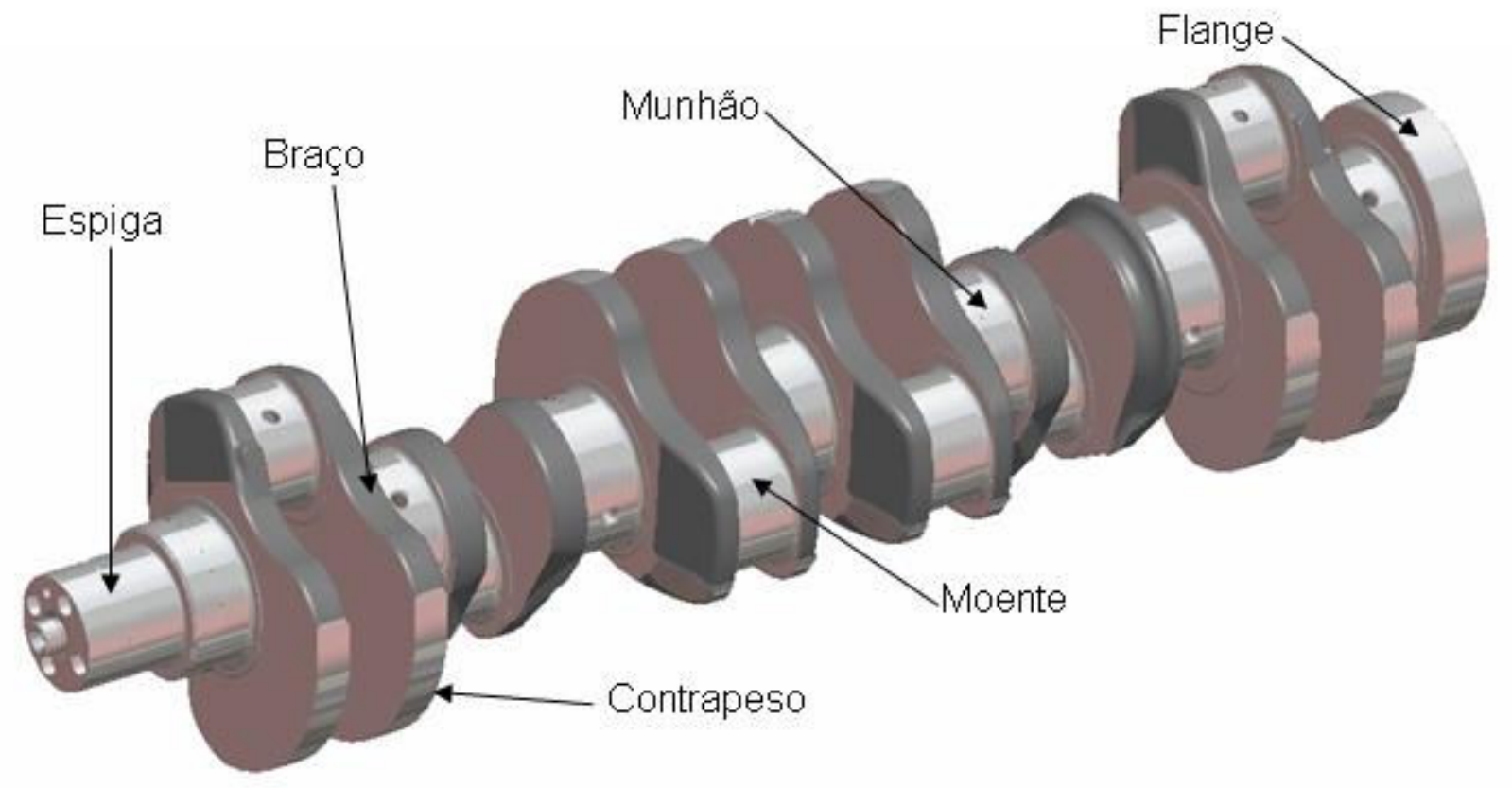

Figura 1: Árvore de Manivelas

\subsection{Revisão bibliográfica}

De maneira geral, ASIMOV 2 e Pahl e Beitz ${ }^{3}$ mostram estudos de metodologias de projetos com conceitos básicos e clássicos de gerenciamento de projeto, seus componentes, planejamento, métodos para auxiliar no desenvolvimento de novas idéias e sistematização de todo o ciclo de projeto. Hubka e Eder ${ }^{4}$ utilizam a teoria de gerenciamento de projetos para estudos de caso em desenvolvimento de máquinas e componentes. Além dos estudos de sistematização de projetos clássicos, a crescente utilização pela nova metodologia de Design for Six Sigma detalhada mais adiante foi estudada por diversos autores, dentre eles WERKEMA ${ }^{41}$ mostra a organização mais comum desta metodologia sendo que outros autores ${ }^{57,58}$ descrevem de modo mais profundo o funcionamento de ferramentas estatísticas normalmente utilizadas nela.

Tendo organizadas as etapas de desenvolvimento de produto em diferentes níveis, das atividades genéricas às de análises estruturais e dinâmicas do componente, resta estudar, vantagens e aplicações dos diferentes procedimentos dentro da organização estabelecida. Assim, são estudados métodos e modelos para os diferentes estudos. 
A complexidade inerente às árvores de manivelas torna em muitos casos, sua análise custosa tanto em termos numéricos quanto experimentais. A utilização de modelos simplificados do componente para análises específicas tende a acelerar substancialmente o tempo despendido nas mesmas, muitas vezes sem grandes perdas de precisão.

Particularmente para árvores de manivelas, diversos modelos simplificados para análises técnicas foram desenvolvidos na literatura corrente, com características que diferem segundo aplicação específica e com vantagens e desvantagens diversas. Todos, porém com a finalidade de representar as características de inércia, rigidez e amortecimento com o comportamento mais próximo possível do fenômeno que se deseja estudar.

MOURELATOS ${ }^{5}$ propõe uma subestruturação dinâmica com vetores de Ritz na análise de virabrequins para permitir maior precisão na representação dinâmica. Em uma subestruturação dinâmica a estrutura é dividida em partes, que são analisadas independentemente e, subseqüentemente, sintetizadas em ordem para determinar a resposta de toda a estrutura. Essa análise é similar à técnica convencional de síntese modal usando autovetores ${ }^{6}$. Em outro trabalho de aplicação mais abrangente, MOURELATOS ${ }^{7}$ utiliza também uma abordagem sistêmica para associação da dinâmica estrutural da árvore de manivelas, a lubrificação hidrodinâmica dos munhões e a rigidez do bloco do motor com a mesma técnica de subestruturação citada.

Para a dedução das fórmulas que descrevem a cinemática e dinâmica de uma árvore de manivelas, existe um grande número de referências, da literatura clássica à documentação de softwares comerciais de dinâmica e estruturas. TAYLOR ${ }^{8}, \mathrm{AVL}^{9}$ e $\mathrm{BOSCH}^{10}$ compilaram grande parte dos métodos utilizados sendo que no handbook da $\mathrm{BOSCH}^{10}$ mostram-se ainda, a teoria para balanceamento, extrapolação das formulações estudadas para diversas configurações de motores e teoria geral para motores de combustão interna como noções de combustão, projeto em diversos níveis de detalhamento de componentes, esforços e testes experimentais. $O$ balanceamento e sua teoria são mais bem estudados por HARTOG ${ }^{61}$ e COELHO ${ }^{60}$. B.I.C.E.R.A. ${ }^{11}$ e KER ${ }^{12}$ trazem uma abordagem mais detalhada no que diz respeito à vibração torcional, com a teoria necessária para o cálculo de momentos de inércia e rigidez das diversas partições de uma árvore de manivelas, conceitos de projeto e 
operação para redução de vibrações e instrumentação geral para ensaios experimentais.

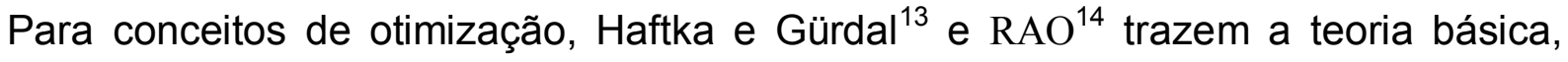
com o detalhamento das ferramentas clássicas como o cálculo variacional, o método dos multiplicadores de Lagrange, teoria de programação linear, otimização com e sem restrições, métodos para estudos de sensibilidade, critérios de optimalidade e outros métodos específicos como o de Quasi-Newton, utilizado no presente trabalho. $\mathrm{Na}$ indústria é comum a utilização de métodos de experimentação inteligentes como - DOE (design of experiments) para a análise de sensibilidade necessária para a otimização de parâmetros de desempenho e de processo obtidos através de ensaios $^{57}$. Na análise computacional utilizam-se com freqüência, módulos de otimização já inseridos nos softwares de análise comerciais como o ANSYS ${ }^{\circledR}$, também empregado neste trabalho.

No desenvolvimento de árvores de manivelas, ensaios experimentais são essenciais tanto para a obtenção de fatores de correção e limite de resistência no cálculo da falha por fadiga do componente quanto para análises dinâmicas.

Para o primeiro conjunto de ensaios, DURELLI et al. ${ }^{15}$ mostra os conceitos fundamentais de medição de deformação, métodos estatísticos e outras técnicas de análise experimental relacionadas à medição de tensões. WRIGHT ${ }^{17}$ escreve os conceitos básicos necessários para instrumentação e sistemas de medição com noções de sensores, funções de transferência, equipamentos e sistemas de medição, análise, amostragem e aquisição de dados.

No caso da análise modal, EWINS ${ }^{18}$ traz a teoria básica necessária para a análise espectral, instrumentação e obtenção dos parâmetros modais de estruturas. Já MEIROVITCH ${ }^{19}$ mostra de uma maneira bastante completa, técnicas de abordagem para vários tipos de problemas relacionados à teoria de vibrações lineares.

Após o cálculo das reações nos mancais, o comportamento do filme de óleo atuante nos mesmos deve ser analisado para garantir a inexistência de contato entre as superfícies metálicas entre a árvore de manivelas e o bloco do motor, e entre a primeira e as bielas do conjunto.

DUARTE $J R^{20}$ resume o conhecimento teórico necessário para o entendimento dos mecanismos físicos que regem o comportamento de mancais hidrodinâmicos sob condições reais de operação, modelagem matemática e projeto de mancais com características operacionais otimizadas. 
O método industrial utilizado para a produção do componente deve ser sempre analisado cuidadosamente no seu desenvolvimento. As restrições de fabricação definem muitas das condições de contorno do projeto e limitações da geometria que devem ser respeitadas para a viabilidade comercial e técnica do componente.

A bibliografia para a obtenção de informações relacionadas aos métodos de fabricação de árvores de manivelas é bastante extensa. Tanto para o processo de forjamento como para o de fundição, usualmente utilizados, existem livros generalistas como resumem KALPAKJIAN e SCHMID ${ }^{21}$. Especificamente para o processo do objeto de estudo de caso, forjamento, sugere-se como referência ASM $\mathrm{Int}^{22}$, onde se encontram de uma forma relativamente completa a teoria básica e nomenclaturas de diferentes processos de forjamento, características de diferentes materiais para a conformação, teoria de lubrificação, cisalhamento, projeto e instrumentação.

Ressalta-se a utilização de novas teorias e métodos que aplicam a tecnologia de hardwares e softwares amplamente desenvolvida nos últimos anos. Alguns permitindo a utilização direta de condições de contorno específicas para árvores de manivela como o AVL-Excite ${ }^{\circledR}$, uns para simulações diversas como o ANSYS ${ }^{\circledR}$, MscPATRAN $^{\circledR}$, ABAQUS $^{\circledR}$ e outros que permitem a sua customização através de programação como, por exemplo, o Pro/Engineer ${ }^{\circledR}$. A literatura sugerida para o melhor aproveitamento dessa tecnologia citada encontra-se dos próprios manuais destes softwares. 


\section{Metodologia de Projeto}

\subsection{Introdução}

Um projeto pode ser definido como um esforço temporário exercido para a criação de um produto ou serviço ${ }^{23}$.

Neste capítulo, resume-se um estudo da sistematização de projetos e, particularmente para o projeto de virabrequins. $O$ estudo abaixo foi baseado no procedimento metodológico feito por FONSECA ${ }^{6}$ e na teoria citada em PAHL e BEITZ ${ }^{3}$ além de WERKEMA ${ }^{41}$ e CREVELING et al. ${ }^{58}$.

\subsection{Estruturação de um projeto}

A estruturação clássica do projeto, como o mostrado na Figura 2, é dividida em fases de planejamento, projeto conceitual, preliminar e detalhado. A sistematização é bastante útil na organização do projeto, embora nem sempre seja possível delinear uma fronteira entre estas fases principais.

No planejamento e esclarecimento da tarefa é feita uma análise detalhada do projeto, com a definição do seu escopo. Esta etapa resulta na demarcação das entradas necessárias, com seus requisitos, e na definição mais precisa do problema proposto.

Os requisitos da entrada nada mais são que as especificações do produto, provenientes das exigências dos clientes traduzidas em parâmetros técnicos, das condições de contorno impostas pelo processo de fabricação escolhido e da tecnologia disponível. Eles devem conter aspectos relacionados a custo, manufatura, montagem, funcionabilidade, manutenção e descarte.

O projeto conceitual tem como objetivo o esboço da solução. O mesmo pode ser alcançado através da abstração dos problemas essenciais, estabelecimento da estrutura da função, que consiste em uma formulação abstrata da tarefa, relacionando entradas e saídas de modo a descrever e solucionar problemas de projeto. Em seguida é feita uma pesquisa pelos princípios de operação convenientes e então combinação dos mesmos princípios em uma estrutura de trabalho. Nesta fase é estabelecida a concepção que melhor atende às especificações do projeto. 


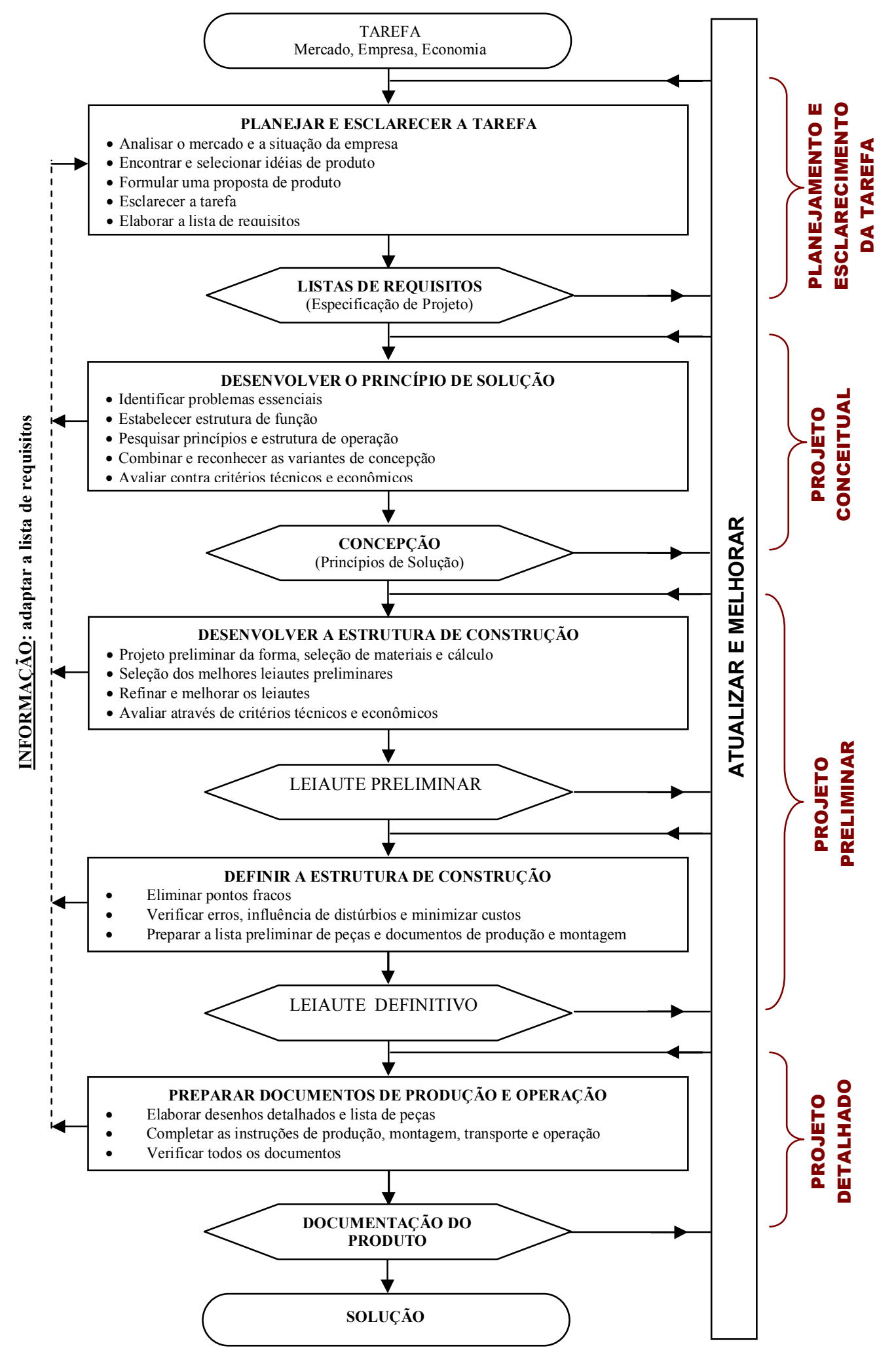

Figura 2: Metodologia de projeto proposta por Pahl e Beitz em 1996

O projeto preliminar consiste na caracterização do produto com a análise e validação das características que definirão o produto final. Nesta fase, os requisitos e restrições de projetos são avaliados de forma mais detalhada, obtendo os 
parâmetros quantitativos e qualitativos do produto.

As etapas do projeto preliminar iniciam-se com o desenho do produto, passando pelas tarefas de cálculo, dimensionamento dos componentes, da eliminação de inconsistências, especificação dos componentes, adequação aos processos de produção disponíveis, análises experimentais, construção e testes em protótipos, otimização, entre outras atividades. Nesta fase o uso de modelos e simulações tende a ser bastante intensivo, geralmente demandando o emprego de ferramentas computacionais e procedimentos específicos para a validação do projeto.

A quarta e última fase compreende o detalhamento do projeto com a sistematização de todas as fases anteriores e a geração da documentação necessária para abranger todos os aspectos relacionados à utilização do produto, contendo os desenhos dos componentes, conjunto e montagem, o processo de manufatura, a lista de componentes, as instruções de montagem, testes, embalagem e transporte, aspectos de qualidade e segurança, instruções de uso ou manual do usuário, entre outros.

No presente trabalho pretende-se listar ferramentas focadas nas fases de projeto conceitual e preliminar. As etapas de análise mercadológica e esclarecimento da tarefa devem certamente direcionar a utilização da metodologia em questão, assim como o projeto definitivo será a documentação dos resultados da mesma.

\subsection{Sistematização da análise estrutural}

Principalmente na etapa de projeto preliminar, como ferramenta numérica, o método dos elementos finitos é largamente utilizado na análise estrutural de componentes automotivos. No caso da árvore de manivelas, fatores que determinam o desempenho do componente, relacionados ao balanceamento, análise modal, resposta em freqüência, análise dinâmica, limites de resistência e otimização podem ser resolvidos com velocidade e precisão através deste método.

Detalhes sobre a utilização e teoria envolvidas na simulação numérica de estruturas serão mostrados no capítulo 6 . Ainda assim é válido mencionar como este tipo de abordagem se insere na sistemática de projeto.

De modo geral, pode-se dividir uma análise estrutural genérica em três fases:

1 Pré-Processamento 


\section{Solução}

\section{Pós-Processamento}

No pré-processamento, o modelo que simulará as condições reais é definido pelo engenheiro, com as simplificações e hipóteses que considerar necessárias e factíveis. Nesta fase, são definidos os tipos de elementos que serão utilizados na discretização do componente, as propriedades do material, as condições de contorno, o tipo de análise a ser executado, o carregamento e as demais opções necessárias para a resolução das equações do sistema de acordo com o tipo de análise escolhido.

A segunda fase é auto-explicativa, e pode conter a maior parte do tempo despendido na análise, dependendo do tipo de estudo realizado. Análises não lineares como contato, grandes deformações e outras normalmente resultam em um processamento mais demorado por serem iterativas.

No pós-processamento, os resultados obtidos numericamente são avaliados, validados e documentados.

Para o caso do objeto de estudo, a obtenção dos dados de entrada das fases de pré-processamento gera a necessidade de uma etapa inicial que consiste em um estudo do carregamento no componente, bem como suas fontes. Nesta etapa, denominada aqui de linha de base ou projeto informacional, considerações iniciais são feitas como, por exemplo, a existência ou não de pré-tensões resultantes de tratamento térmico, montagem de componentes e outros, as condições críticas de análise e dimensionamento de acordo com as especificações de tolerância, acabamento superficial e outros fatores que definirão o pré-processamento.

A figura 3 mostra a união da metodologia para análise estrutural citada com a sistemática para o projeto de virabrequins. Vale lembrar que esta estruturação não é fixa e serve apenas como uma referência contendo as principais características dos procedimentos seguidos na prática como, por exemplo, o caráter iterativo. Ainda assim, cada empresa ou centro de pesquisa deve desenvolver a estrutura de trabalho que melhor representa suas necessidades. 


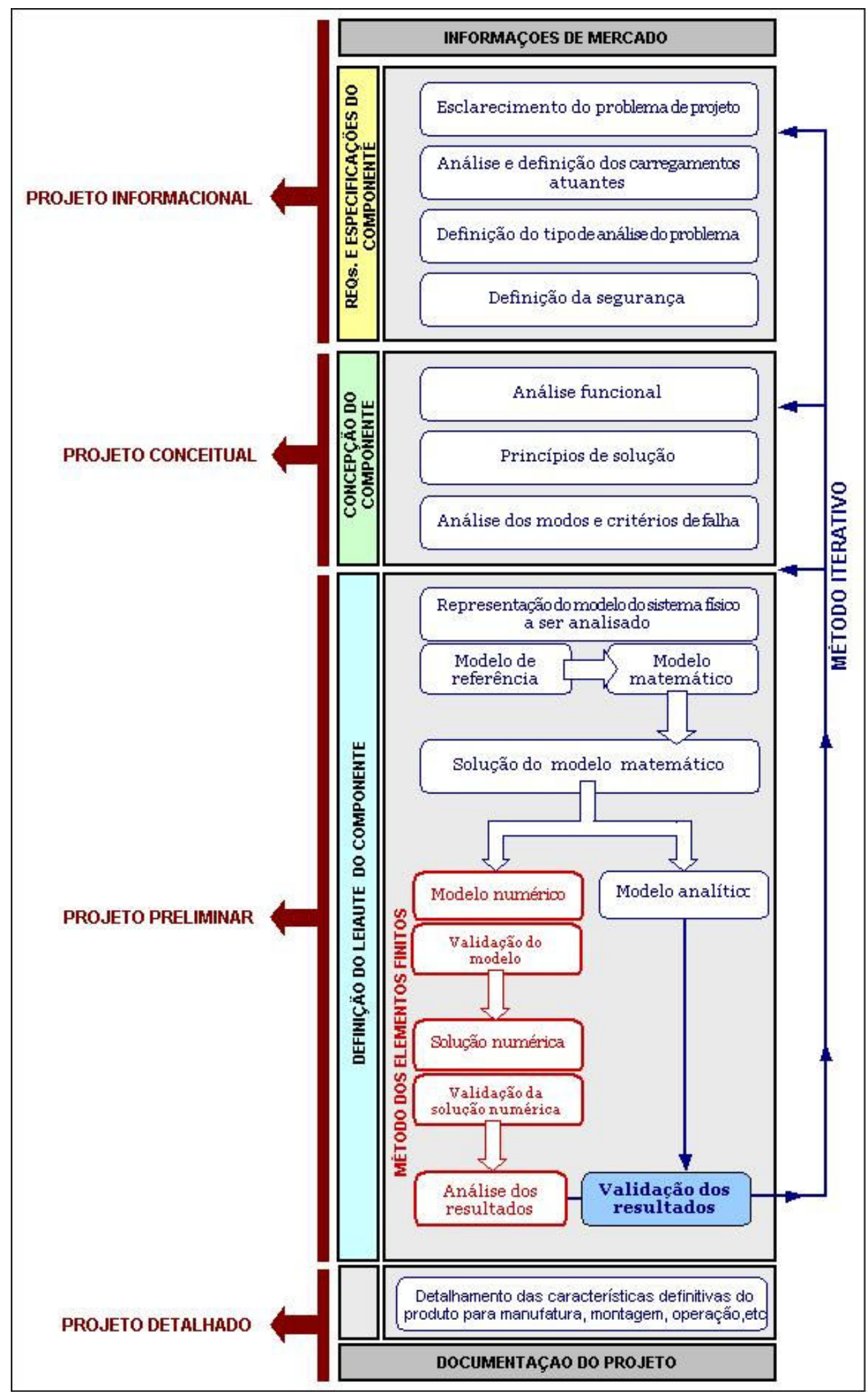

Figura 3: Ex. de metodologia para análise estrutural. ${ }^{6}$ 


\subsection{Design For Six Sigma}

Apesar da metodologia de projeto clássica citada ser ainda largamente utilizada, em indústrias de diversos segmentos pode-se observar um crescimento grande da aceitação nos centros de desenvolvimento da metodologia de design for six sigma. Muito deste sucesso baseia-se nos bons resultados já obtidos durante mais de 20 anos de utilização da metodologia 6 Sigma em processos.

A metodologia 6 Sigma consiste num conjunto de ferramentas de melhoria diversas já existentes nas indústrias, atreladas à ferramentas estatísticas aplicadas de uma maneira sistemática a fim de minimizar a variação do processo em projetos com metas normalmente arrojadas e de curto prazo.

Esta metodologia surgiu na década de 80 , quando Robert Galvin, CEO da Motorola estabelece metas agressivas de melhoria de desempenho, lançando a base para o desenvolvimento da filosofia do Seis Sigma. Bill Smith, um cientista do sistema de comunicações da mesma empresa, foi um dos primeiros responsáveis no estudo da melhoria da qualidade e redução de custos utilizando ferramentas estatísticas.

Em 1984, o Dr. Mike Harry, na divisão GEG (Government Electronics Group) da Motorola, desenvolve metodologia integrada para melhoria contínua utilizando técnicas estatísticas.

O Design for Six Sigma (DFSS) é uma extensão do Seis Sigma para o projeto de produtos (bens ou serviços) e processos, que surgiu na General Electric (GE) no final da década de $1990^{41}$. O DFSS pode ser definido como uma abordagem metodológica sistemática caracterizada pela utilização conjunta de métodos estatísticos e de engenharia.

A metodologia citada é normalmente implantada seguindo um sistema inicialmente utilizado pela GE, constituído por cinco etapas: Define, Measure, Analyze, Design, e Verify. Uma breve descrição destas etapas, que devem ser executadas por uma equipe multifuncional, é apresentada na Tabela 1. 


\begin{tabular}{ll}
\hline Definir claramente o novo produto & - Justificativa para o desenvolvimento do projeto \\
ou processo a ser projetado. & - Análise preliminar da viabilidade técnica \\
- Análise preliminar da viabilidade econômica & - Previsão da data de conclusão do projeto \\
& - Estimativa dos recursos necessários
\end{tabular}

Tabela 1- Descrição das Atividades do DFSS ${ }^{41}$

Apesar de a Tabela 1 ilustrar conceitos que se assemelham mais à concepção de produtos, qualquer bem ou serviço em qualquer etapa, da concepção ao desenvolvimento e otimização pode ser trabalhado através desta metodologia generalista.

Nesta nova metodologia, o projeto do presente trabalho se concentraria na fase de Design. Algumas empresas aplicam as mesmas ferramentas do DFSS sistematizadas nas etapas Concept, Design, Optimize, Verify. Neste caso, a aplicação das ferramentas estatísticas é bastante semelhante, diferenciando somente do agrupamento das mesmas. Assim, o projeto do presente trabalho nas novas definições dos termos citados se concentraria na fase Optimize. 


\subsection{Processo de fabricação}

O processo de fabricação do componente determina muitas das condições de contorno do seu projeto ou sua otimização. Limitações de geometria, material, tolerâncias e acabamento superficial são únicas de cada processo e um bom projeto tem como premissa básica o conhecimento das condições de contorno impostas pelo método de fabricação escolhido.

\subsubsection{Conceitos Básicos}

Árvores de manivela são normalmente fabricadas através do forjamento ou fundição, dependendo das condições de operação desejadas, propriedades mecânicas esperadas, complexidade da geometria, e do preço aceitável definido pelo cliente. Pode-se encontrar facilmente dados comparativos sobre os dois processos sendo possível a troca de processo de fabricação escolhido para um determinado componente durante sua concepção de acordo com as vantagens e desvantagens de cada processo que, de uma forma geral se resumem à tabela abaixo ${ }^{28}$ :

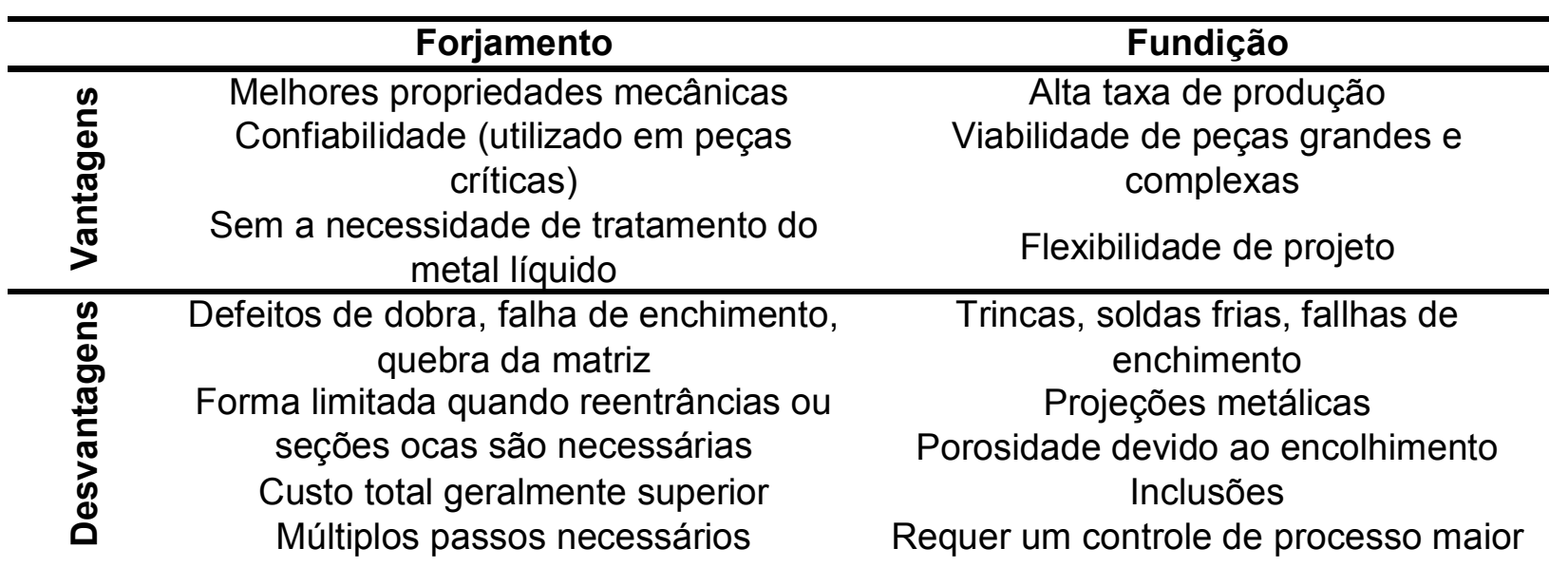

Tabela 2 - Vantagens e Desvantagens dos Pocessos de Fabricação de Virabrequins

Do exposto na Tabela 2, pode-se entender a razão de normalmente, árvores de manivelas projetadas para motores de automóveis serem fundidas e as projetadas para caminhonetes e caminhões serem forjadas dada a diferença de magnitude dos carregamentos impostos nos diferentes ciclos de combustão, taxa de compressão e 
aplicação.

O virabrequim selecionado para o estudo de caso, é fabricado através de forjamento, cujas etapas principais são listadas na Figura 4. A figura mostra de uma maneira superficial, as fases do processo de forjamento e usinagem de árvores de manivela. Faz-se necessário lembrar que o processo completo inclui detalhes que não serão mencionados por não serem foco do presente trabalho.

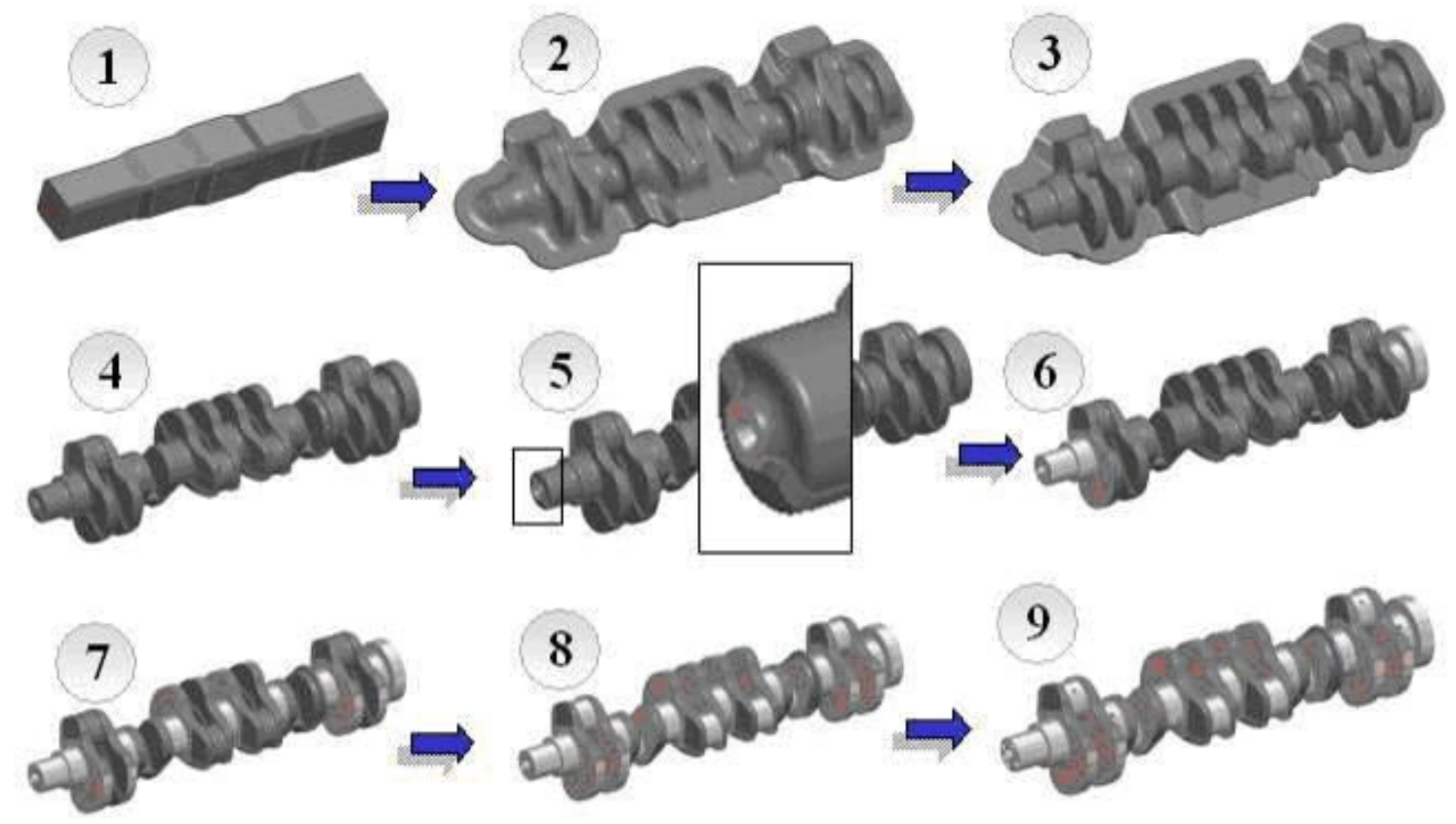

Figura 4: Principais etapas no processo de forjamento e usinagem de virabrequins

O processo de forjamento corresponde à conformação plástica de material em diferentes etapas de modo que ao seu final, o material se encontre com a forma desejada. Este processo pode ser executado em prensas hidráulicas, prensas excêntricas ou martelos hidráulicos.

Tendo especificado o material, barras de aço com bitola calculada quadrada ou redonda são fornecidas. Elas passam por um processo de corte e são então aquecidas em um forno de indução.

A primeira conformação plástica (etapa 1) é normalmente feita através de um rolo laminador, com a divisão do material em volumes que auxiliarão as etapas subseqüentes. Na etapa 2 , é feita uma pré-forma do material seguida da etapa 3 onde o material se encontra com as dimensões finais. Estas três primeiras etapas definem os ângulos de saída e raios mínimos necessários na forma do produto 
forjado final, e são dependentes do equipamento utilizado, do lubrificante e do material. Uma alteração no projeto de um virabrequim pode resultar em aumento da força de prensagem quando altera a forma dos braços do mesmo, por exemplo, e isso pode ocasionalmente prejudicar ou inviabilizar a sua conformação.

Na etapa 4 é realizado o processo denominado de rebarbação.

A etapa 5 comporta a atividade de faceamento das extremidades e execução do furo de centro. A centragem pode ser executada geometricamente ou por massa, onde o centro de inércia da árvore de manivelas é encontrado através de um equipamento que gira a mesma medindo os esforços em mancais que a sustentam, para a execução do furo de centro nos pontos desejados. A análise do balanceamento do componente é critica para esta etapa dado que dependendo da distribuição de massa do virabrequim o processo pode ser prejudicado.

A usinagem de desbaste da espiga e do flange (etapa 6) e dos munhões e/ou contrapesos (etapa 7) é executada seguida pelo desbaste dos moentes (etapa 8).

Após tratamento térmico são feitos os furos de lubrificação e os furos nas extremidades para a montagem de componentes. A árvore de manivelas passa, finalmente, por etapas de acabamento e proteção superficial.

O tipo de tratamento térmico em conjunto com a disposição dos furos de lubrificação e acabamento determinam pontos onde pode haver concentração de tensões, e por isso devem ser analisados na definição das condições de contorno do projeto ou otimização do componente.

\subsubsection{MEF para processo}

A utilização de simulações via método dos elementos finitos para o processo, tende

a acelerar consideravelmente o projeto de componentes, com ganhos em redução de custo incluídos na medida em que testes, ajustes e custo com protótipos são minimizados com o pré-conhecimento das características do processo de cada componente específico.

Existem muitos programas comerciais destinados à simulação de processos da fundição ou forjamento à usinagem. Além dos softwares de CAM (Computer Aided Manufacturing), que auxiliam no projeto dos programas de processo, existem softwares que utilizam o método dos elementos finitos para a simulação das etapas da fabricação. 
Como exemplos de softwares para esta aplicação, pode-se citar programas como o DFORM $^{\circledR}$, o Plasticine ${ }^{\circledR}$ o FORGE ${ }^{\circledR}$, que consistem em soluções para a otimização de forjamento frio ou quente de materiais metálicos. Podendo-se simular todas as etapas desde a conformação em matrizes abertas ou fechadas à retirada da rebarba através da extrusão e os tratamentos térmicos seqüentes. Eles trabalham com técnicas de reconstrução automática da malha à medida que o material se deforma. Muitas publicações tratam do uso de simulações numéricas para processos de fabricação. FUJIKAWA ${ }^{29}$ citou em seu trabalho três exemplos de aplicação de otimização do processo de forjamento via utilização de programas comerciais aplicados na Nissan Motor Company. O primeiro exemplo mostra uma simulação via método dos elementos finitos e um programa comercial, visando a redução do material utilizado no forjamento de um virabrequim. O segundo exemplo é de um estudo de aumento de vida de matrizes e o terceiro mostra a aplicação de CAE (Computer Aided Engineering) para o desenvolvimento de um sistema de forjamento inteligente para prevenção de defeitos de forjamento.

As Figuras 5 e 6 mostram, duas imagens que exemplificam a utilização de simulação de forjamento em árvores de manivela através de programa comercial, no caso, o FORGE $^{\circledR}$.

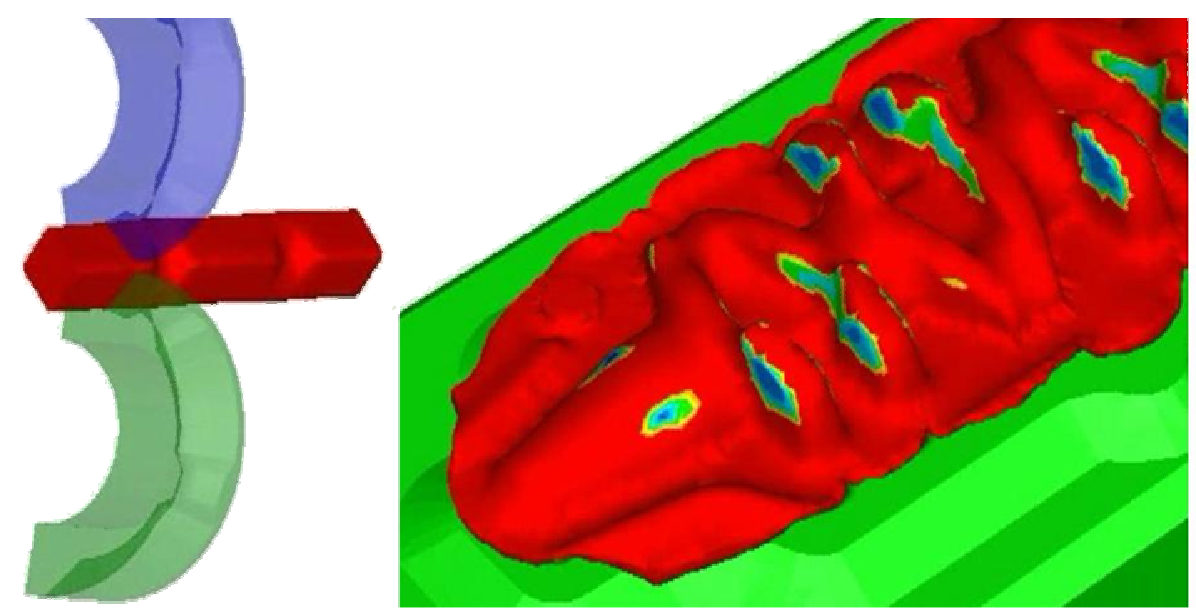

Figura 5: Simulação do processo de laminação (esquerda) e forma final (direita) 


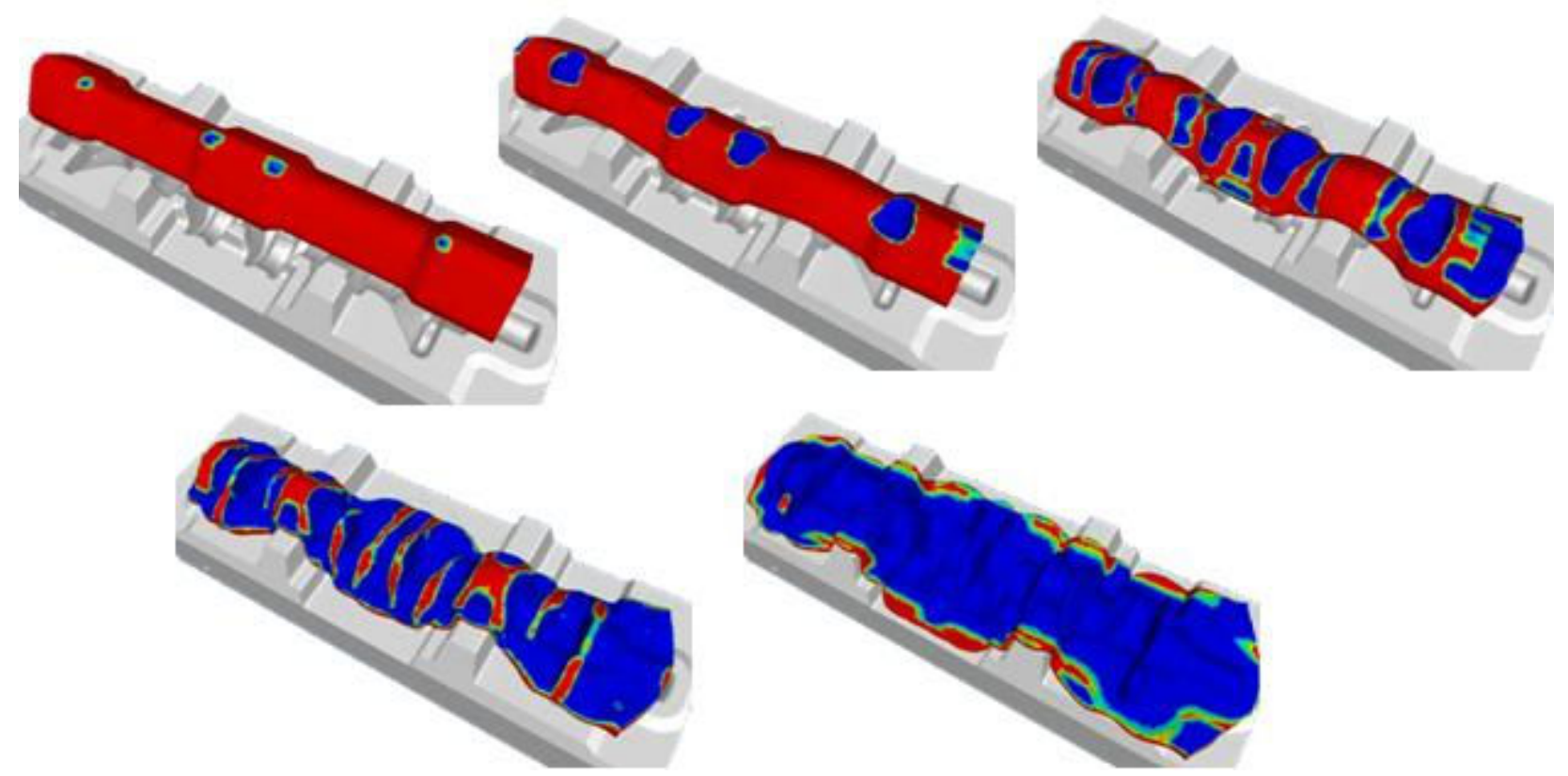

Figura 6: Simulação do processo de conformação (pré-forma) 


\section{Análise do Carregamento Atuante no Sistema}

O primeiro passo para entendimento das condições de trabalho do componente é a análise do seu comportamento cinemático e dinâmico. Através do cálculo dos carregamentos que atuam nos componentes estudados, pode-se definir pontos críticos de estudo, influência da variação de parâmetros no desempenho do componente, condições de contorno na otimização do mesmo e finalmente, coeficientes de segurança de falha em operação.

\subsection{Análise Cinemática}

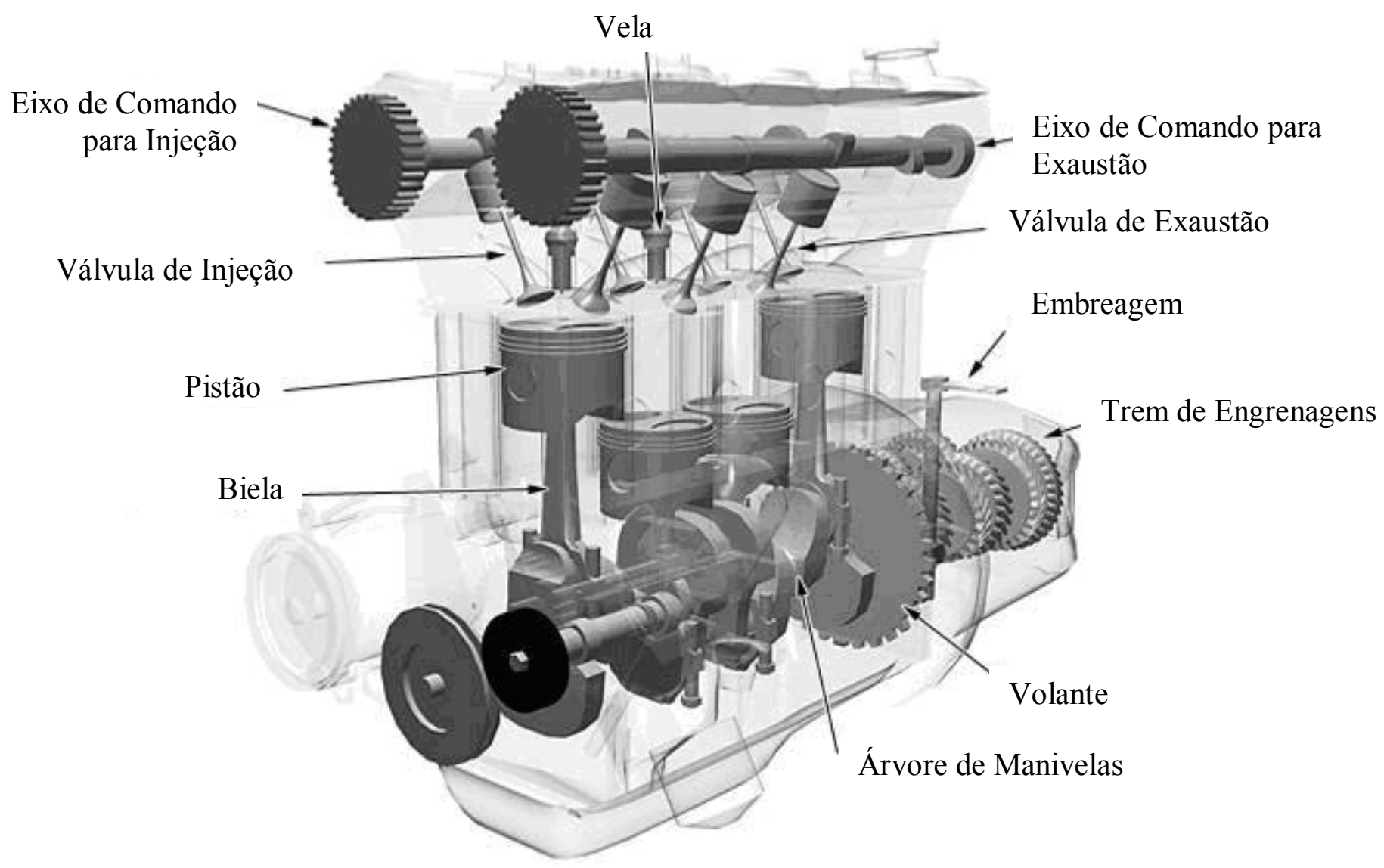

Figura 7: Componentes do Powertrain ${ }^{21}$

Para a análise estrutural no projeto de árvores de manivela o carregamento atuante pode ser dividido em uma parcela devido à inércia dos componentes constituintes do conjunto de potência powertrain (árvore de manivela, bielas e pistões) mostrados na 
Figura 7, e uma segunda parcela decorrente da força resultante da explosão na combustão.

Para a determinação das forças de inércia é conveniente equacionar a aceleração dos componentes em função do ângulo de rotação do virabrequim (ângulo $\alpha$ na Figura 8).

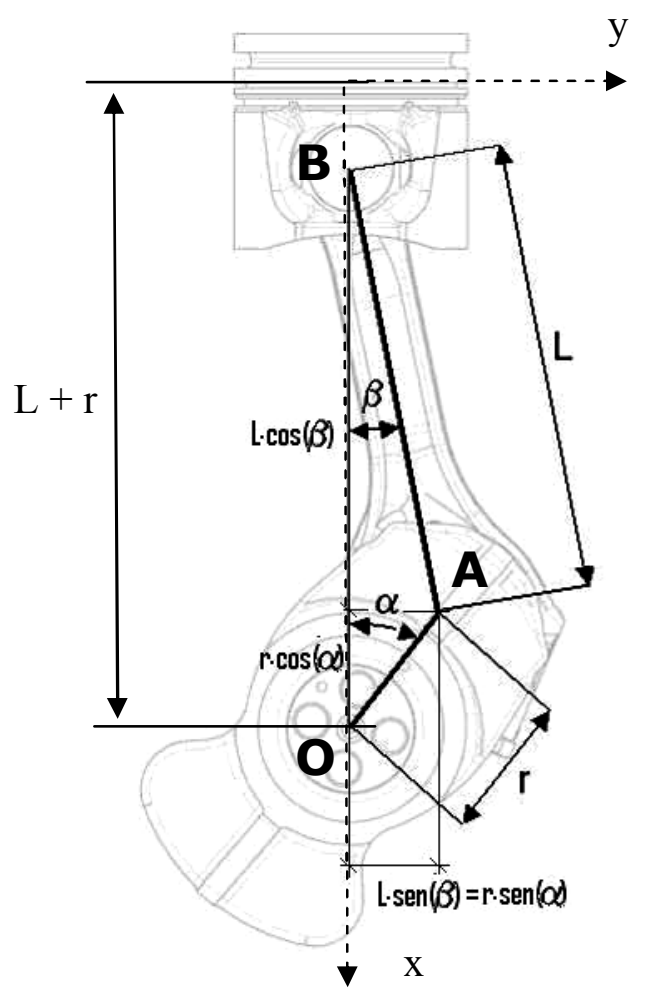

Figura 8: Ângulos e dimensões para o sistema biela-manivela

Torna-se válido lembrar que todas as análises mostradas neste capítulo referem-se ao sistema estaticamente determinado, ou seja, todos os componentes são aqui considerados rígidos.

Pela análise geométrica do sistema biela-manivela mostrado na Figura 5 chega-se facilmente nas seguintes relações:

$$
L \cdot \operatorname{sen}(\beta)=r \cdot \operatorname{sen}(\alpha) \Rightarrow \operatorname{sen}(\beta)=\lambda \cdot \operatorname{sen}(\alpha) \Rightarrow \cos (\beta)=\sqrt{1-\lambda^{2} \cdot \operatorname{sen}(\alpha)^{2}}
$$


Onde $\lambda=\mathrm{L} / \mathrm{r}$, $\beta$ é o ângulo entre o eixo do pistão e a linha que cruza os centros dos olhais da biela, $L$ é a distância entre centros dos olhais da biela e $r$ é o meio-curso do pistão.

Sendo que a posição do pistão no sistema de coordenadas indicado é dada por:

$$
\begin{aligned}
& x=L+r-L \cdot \cos (\beta)-r \cdot \cos (\alpha)=(1-\cos (\beta)) \cdot L+(1-\cos (\alpha)) \cdot r \\
& x=(1-\cos (\alpha)) \cdot r+\left(1-\sqrt{1-\lambda^{2} \cdot \operatorname{sen}(\alpha)^{2}}\right) \cdot L
\end{aligned}
$$

Reescrevendo a equação anterior através do termo adimensionalisado $x_{a} e$ expandindo a mesma equação através de séries de Fourier $\left(\mathrm{x}_{\mathrm{t}}\right)$, temos ${ }^{9}$ :

$$
\begin{aligned}
& \mathrm{x}_{\mathrm{a}}=\frac{\mathrm{x}}{\mathrm{r}}=1-\cos (\alpha)+\frac{1}{\lambda}-\frac{1}{\lambda} \cdot \sqrt{1-\lambda^{2} \cdot \operatorname{sen}(\alpha)^{2}} \\
& \mathrm{x}_{\mathrm{t}}=\mathrm{A}_{0}-\mathrm{A}_{1} \cdot \cos (\alpha)-\frac{\mathrm{A}_{2}}{4} \cdot \cos (2 \cdot \alpha)-\frac{\mathrm{A}_{4}}{16} \cdot \cos (4 \cdot \alpha)-\frac{\mathrm{A}_{6}}{36} \cdot \cos (6 \cdot \alpha)-. . \\
& \mathrm{A}_{0}=1+\frac{1}{4} \cdot \lambda+\frac{3}{64} \cdot \lambda^{3}+\frac{5}{256} \cdot \lambda^{5}+. . \quad \mathrm{A}_{1}=1 \quad \mathrm{~A}_{2}=\lambda+\frac{1}{4} \cdot \lambda^{3}+\frac{15}{128} \cdot \lambda^{5}+. . \\
& \mathrm{A}_{4}=\frac{-1}{4} \cdot \lambda^{3}+\frac{3}{16} \cdot \lambda^{5} \quad \mathrm{~A}_{6}=\frac{9}{128} \cdot \lambda^{5}+. .
\end{aligned}
$$

Onde $A_{i}$ são os coeficientes obtidos após a expansão em séries.

Assumindo conforme $\mathrm{TAYLOR}^{8}, \lambda$ menor que 1/3, vemos que a série acima converge rapidamente e a posição adimensionalisada pode ser reescrita como:

$$
\mathrm{x}_{\mathrm{a}}=1+\frac{\lambda}{4}-\cos (\alpha)-\frac{\lambda}{4} \cdot \cos (2 \cdot \alpha)
$$

A velocidade angular $(\omega)$ é dada por:

$$
\omega=\frac{\mathrm{d}}{\mathrm{dt}} \alpha
$$

Considerando-se a velocidade angular constante e derivando (3.2) no tempo, temos a velocidade do pistão: 


$$
\frac{\mathrm{d}}{\mathrm{dt}} \mathrm{x}_{\mathrm{a}}=\frac{1}{\omega \cdot \mathrm{r}} \cdot\left(\frac{\mathrm{d}}{\mathrm{dt}} \mathrm{x}\right)=\operatorname{sen}(\alpha)+\frac{\lambda \cdot \operatorname{sen}(\alpha) \cdot \cos (\alpha)}{\sqrt{1-\lambda^{2} \cdot \operatorname{sen}(\alpha)}}
$$

Ou, se expressa em séries e desprezados os termos de alta ordem:

$$
\frac{\mathrm{d}}{\mathrm{dt}} \mathrm{x}_{\mathrm{a}}=\mathrm{A}_{1} \cdot \operatorname{sen}(\alpha)-\frac{\mathrm{A}_{2}}{2} \cdot \operatorname{sen}(2 \cdot \alpha)-\frac{\mathrm{A}_{4}}{4} \cdot \operatorname{sen}(4 \cdot \alpha)-\frac{\mathrm{A}_{6}}{6} \cdot \operatorname{sen}(6 \cdot \alpha)+. .=\operatorname{sen}(\alpha)+\frac{\lambda}{2} \cdot \operatorname{sen}(2 \cdot \alpha)
$$

A aceleração pode então ser obtida derivando-se a equação anterior:

$$
\frac{\mathrm{d}^{2}}{\mathrm{dt}^{2}} \mathrm{x}_{\mathrm{a}}=\frac{1}{\omega^{2} \cdot \mathrm{r}} \cdot \frac{\mathrm{d}^{2}}{\mathrm{dt}^{2}} \mathrm{x}=\cos (\alpha)+\frac{\lambda \cdot \cos (\alpha)^{2}-\lambda \cdot \operatorname{sen}(\alpha)^{2}+\lambda^{3} \cdot \operatorname{sen}(\alpha)^{4}}{\left(1-\lambda^{2} \cdot \operatorname{sen}(\alpha)^{2}\right)^{1.5}}
$$

Expandindo em séries novamente, para os mesmos coeficientes $A_{i}$ temos:

$$
\frac{\mathrm{d}^{2}}{\mathrm{dt}^{2}} \mathrm{x}_{\mathrm{a}}=\mathrm{A}_{1} \cos (\alpha)+\mathrm{A}_{2} \cdot \cos (2 \alpha)
$$

\subsection{Análise Dinâmica - Método Usual}

Das referências utilizadas pelo presente trabalho que trazem o cálculo do carregamento atuante em árvores de manivelas ${ }^{8,9,10}$ e 32 e da prática observada na indústria observa-se que o método mais utilizado para tal dedução, aqui denominado de método usual, traz hipóteses simplificadoras que poderiam afetar ou não a precisão do cálculo do carregamento. Dentre estas hipóteses, podemos destacar a separação da massa da biela em duas componentes, uma rotativa e outra oscilante e a não utilização da inércia da biela no cálculo das forças do mecanismo.

A Figura 9 mostra a decomposição das forças atuantes em uma das manivelas do virabrequim. Nela podemos observar a força $F_{p}$ que representa a soma das forças de inércia e de gás atuantes no pistão cujo detalhamento será executado posteriormente e a força normal $F_{N}$, que consiste basicamente da reação na direção horizontal resultante do mecanismo biela-manivela entre o pistão e a camisa. As outras forças são derivadas da força no pistão, sendo $F_{s}$ a força na chamada direção do eixo da biela (linha que cruza os centros dos olhais), $F_{\mathrm{T}}$ a força tangencial no 
virabrequim e $F_{R}$ a força radial no mesmo.

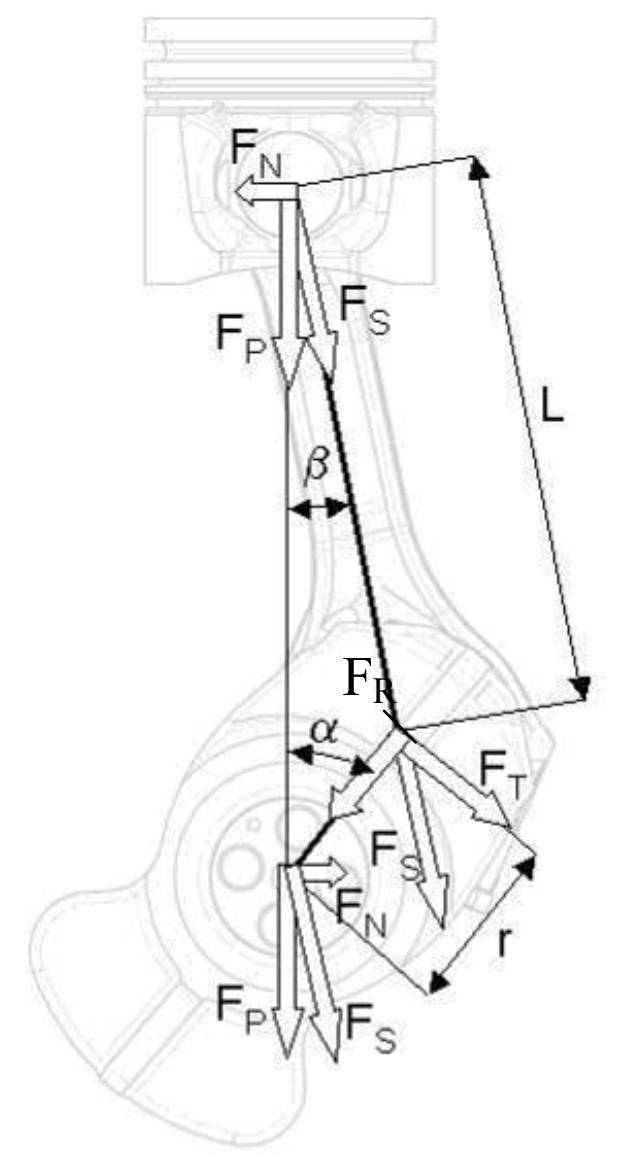

Figura 9: Esforços atuantes no sistema biela-manivela

$$
\begin{aligned}
& \mathrm{F}_{\mathrm{s}}=\frac{\mathrm{F}_{\mathrm{p}}}{\cos (\beta)}=\frac{\mathrm{F}_{\mathrm{p}}}{\sqrt{1-\lambda^{2} \cdot \operatorname{sen}(\alpha)^{2}}} \quad \mathrm{~F}_{\mathrm{n}}=\mathrm{F}_{\mathrm{p}} \cdot \tan (\beta)=\mathrm{F}_{\mathrm{p}} \cdot \frac{\lambda \cdot \operatorname{sen}(\alpha)}{\sqrt{1-\lambda^{2} \cdot \operatorname{sen}(\alpha)^{2}}} \\
& \gamma=90-(\alpha+\beta) \quad \mathrm{F}_{\mathrm{r}}=\mathrm{F}_{\mathrm{s}} \cdot \operatorname{sen}(\gamma)=\mathrm{F}_{\mathrm{p}} \cdot \frac{\cos (\alpha+\beta)}{\cos (\beta)}=\left(\cos (\alpha)-\frac{\lambda \cdot \operatorname{sen}(\alpha)^{2}}{\sqrt{1-\lambda^{2} \cdot \operatorname{sen}(\alpha)^{2}}}\right) \cdot \mathrm{F}_{\mathrm{p}} \\
& \mathrm{F}_{\mathrm{t}}=\mathrm{F}_{\mathrm{p}} \cdot \frac{\operatorname{sen}(\alpha+\beta)}{\cos (\beta)}=\left(\operatorname{sen}(\alpha)+\frac{\lambda \cdot \operatorname{sen}(\alpha) \cdot \cos (\alpha)}{\sqrt{1-\lambda^{2} \cdot \operatorname{sen}(\alpha)^{2}}}\right) \cdot \mathrm{F}_{\mathrm{p}}
\end{aligned}
$$




\subsubsection{Força do Gás}

Normalmente a curva de pressão do gás no interior do cilindro em função do ângulo da árvore de manivelas é medida através da utilização de um transdutor de pressão instalado no cabeçote do motor e de um sensor de rotações para que se obtenha o ângulo instantâneo da árvore de manivelas em relação ao ponto morto superior do pistão.

A Figura 10 traz um gráfico teórico da curva citada:

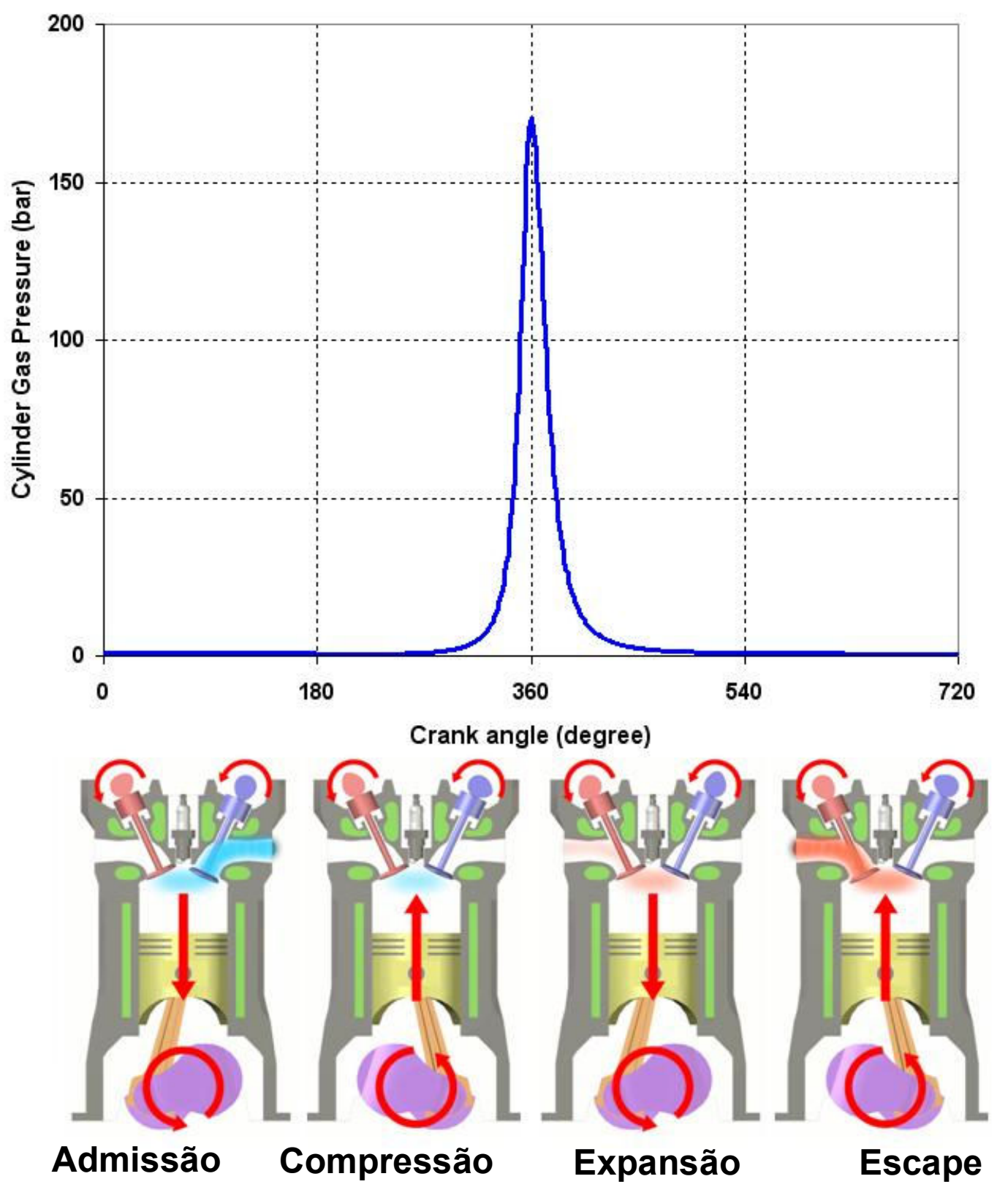

Figura 10: Gráfico típico da curva Pressão x ângulo 
Em algumas situações, a curva da pressão não é conhecida, tendo-se disponíveis somente os valores da pressão máxima e do ângulo onde a mesma ocorrre além de informações básicas de desempenho do motor. Nestes casos, pode-se estimar o comportamento da pressão pelo ângulo de rotação da árvore de manivelas através do ciclo de combustão ideal conforme diagrama pressão versus volume da Figura 11, onde pode-se observar ainda a posição do pistão no cilindro nas diferentes fases do ciclo. O chamado ponto morto superior (PMS) corresponde à posição do pistão quando $\alpha$ e $\beta$ são zero, ou seja, a origem do sistema de coordenadas descrito na Figura 8. O ponto morto inferior corresponde à situação onde $\alpha$ e $\beta$ são respectivamente 0 e $180^{\circ}$, portanto, quando a posição x é igual ao curso do pistão, $2 r$.

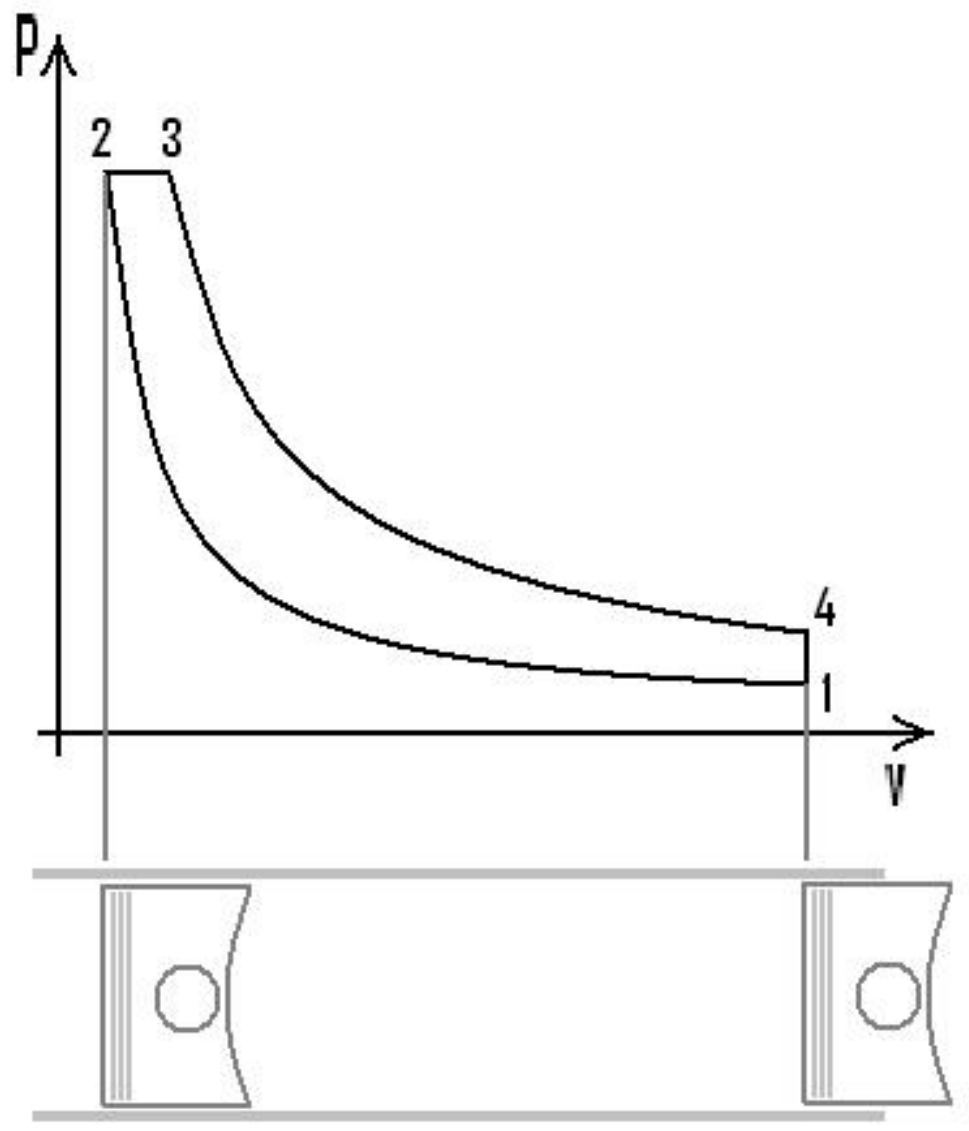

Figura 11: Diagramas para um ciclo Diesel ideal

A explosão num ciclo diesel ideal é considerada isobárica (pressão constante). Este processo corresponde à injeção e queima do combustível no motor Diesel real. Como o gás expande durante a transferência de calor no ciclo padrão a ar, a transferência de calor deve ser apenas o suficiente para manter a pressão constante. Quando se atinge o estágio 3, a transferência de calor cessa e o calor 
sofre uma expansão adiabática (processo 3-4) até que o pistão atinja o ponto morto inferior. A rejeição de calor, é isocórica com o pistão no mesmo ponto. Esta rejeição simula os processos de descarga e de admissão do motor real ${ }^{22}$.

Sabendo-se, por exemplo, que na injeção e exaustão a pressão se iguala à atmosférica, conhecidos os volumes no ponto morto inferior e no ponto morto superior e utilizando-se da relação adiabática entre os processos 1-2 e 3-4, temos todas as propriedades dinâmicas conhecidas para os quatro pontos do cilclo ideal. Assim, podemos estimar a curva da pressão do gás pelo ângulo da árvore de manivela.

Tendo como entradas o diâmetro e curso do pistão $\left(D_{p}\right.$ e $\left.2 r\right)$, o número de cilindros $\left(\mathrm{n}_{\text {cli }}\right)$, comprimento da biela $(L)$, taxa de compressão $\left(r_{v}\right)$, potência do motor $\left(P_{m}\right)$, eficiência mecânica $\left(\eta_{\mathrm{T}}\right)$, coeficiente de compressão do ar $(k)$, a pressão atmosférica $\left(p_{a t}\right)$ e a velocidade angular $(\omega)$, pode-se estimar a curva de pressão do gás pelo ângulo da árvore de manivelas seguindo o procedimento abaixo.

A pressão média efetiva (pme) é definida como a pressão em regime na qual, se a plicada em cada pistão durante cada curso de expansão forneceria a potência medida do motor. Assim:

$$
\text { pme }=\frac{\frac{\mathrm{Pm}}{\mathrm{n}_{\mathrm{cil}}}}{2 \cdot \mathrm{r} \cdot\left[\pi \cdot \frac{\left(\mathrm{D}_{\mathrm{p}}\right)^{2}}{4}\right] \cdot \frac{\omega}{60}}
$$

A pressão média indicada (pmi) representa a pressão idealmente aplicada no pistão, ou seja, sem considerar a perda de eficiência mecância. Ela é definida como a pressão hipotética constante que seria necessária no interior do cilindro, durante o curso de expansão para desenvolver potência igual à indicada.

$$
\mathrm{pmi}=\frac{\mathrm{pme}}{\eta_{\mathrm{t}}}
$$

Para a definição da pressão durante o ciclo, basta utilizar-se das propriedades termodinâmicas e do conhecimento que temos sobre o ciclo Diesel teórico descrito. Assim, sabemos antecipadamente o valor da pressão na fase de admissão que 
representa basicamente a pressão atmosférica. A compressão é então definida através da segunda lei da termodinâmica:

$$
\frac{\mathrm{P}_{\text {compr }}}{\text { Padm }}=\left(\frac{\mathrm{V}_{\text {pmi }}}{\mathrm{V}_{\text {pms }}}\right)^{\mathrm{k}}
$$

Onde $\mathrm{P}_{\text {compr }}$ é a pressão de compressão, $\mathrm{P}_{\mathrm{adm}}$ representa a pressão de admissão, $\mathrm{V}_{\text {pmi }} \mathrm{O}$ volume no ponto morto inferior e $\mathrm{V}_{\text {pms }} \mathrm{O}$ volume no ponto morto superior.

Como as razões de expansão e de compressão são iguais:

$$
\frac{\mathrm{T}_{\mathrm{esc}}}{\mathrm{T}_{\mathrm{adm}}}=\left(\frac{\mathrm{V}_{\mathrm{pms}}}{\mathrm{V}_{\mathrm{pmi}}}\right)^{\mathrm{k}-1}
$$

Onde $T_{\text {esc }}$ é a temperatura de escape e $T_{\text {adm }}$ é a temperatura de admissão. Portanto, sabendo que a pressão nos pontos 2 e 3 e o volume nos pontos 1 e 4 da Figura 8 são iguais, temos pelo menos duas propriedades termodinâmicas para cada ponto e podemos obter os valores das pressões para todo o ciclo já que para condições entre os pontos 1 e 2 e entre os pontos 3 e 4 basta utilizar as relações (3.4) e (3.5). Finalmente, escrevendo o volume no cilindro em função da posição angular da árvore de manivelas temos a curva de pressão desejada.

Tendo obtido a variação da pressão no cilindro experimentalmente ou pela aproximação do ciclo Diesel ideal, temos a força no pistão dada por:

$$
\mathrm{F}_{\mathrm{g}}=\mathrm{P}_{\mathrm{g}} \cdot \frac{\pi \cdot \mathrm{D}_{\mathrm{p}}}{4}
$$

\subsubsection{Forças de inércia}

A força de inércia atuante em um sistema biela-manivela pode ser dividida em uma componente alternativa, decorrente da dinâmica das massas do pistão e da parte da biela mais próxima do mesmo, com um comportamento majoritariamente oscilante, e uma componente rotativa resultante da inércia da parte da biela próxima ao olhal maior, com comportamento rotativo. 


\section{Componente alternativa}

A componente oscilante para as forças de inércia pode ser escrita, de acordo com as deduções mostradas, como:

$$
\begin{aligned}
& \mathrm{F}_{\mathrm{o}}=\mathrm{m}_{\mathrm{o}} \cdot \mathrm{r} \cdot \omega^{2} \cdot\left(\mathrm{A}_{1} \cdot \cos (\alpha)+\mathrm{A}_{2} \cdot \cos (2 \cdot \alpha)+. .\right) \\
& \mathrm{A}_{1}=1 \quad \mathrm{~A}_{2}=\lambda+\frac{\lambda^{3}}{4}+\frac{15 \cdot \lambda}{128}
\end{aligned}
$$

Onde $\mathrm{m}_{\mathrm{o}}$ representa a massa da parte da biela mencionada acima, próxima ao olhal menor somada à massa do pistão e seus componentes. Para as constantes e a expansão da aceleração acima em séries, foi feita a mesma hipótese de que os efeitos e ordem mais alta são desprezíveis.

\section{Componente rotativa}

A componente rotativa, considerada atuante no moente é dada por:

$$
\mathrm{F}_{\mathrm{r}}=\mathrm{m}_{\mathrm{r}} \cdot \mathrm{r} \cdot \omega^{2}
$$

com suas componentes projetadas nos eixos mostrados na figura 8 sendo:

$$
\mathrm{F}_{\mathrm{cy}}=\mathrm{F}_{\mathrm{c}} \cdot \cos (\alpha) \quad \mathrm{F}_{\mathrm{cx}}=\mathrm{F}_{\mathrm{c}} \cdot \operatorname{sen}(\alpha)
$$

\subsubsection{Carregamento total}

A força no pistão, resultante da somatória das forças de inércia com a de explosão pode ser escrita como: $F_{p}=F_{c y}+F_{o}+F_{g}$

Para um motor com seus cilindros em linha, as resultantes das forças nas direções $\mathrm{x}$ e y são:

$$
\begin{aligned}
& \mathrm{F}_{\mathrm{y}}=-\mathrm{r} \cdot \omega^{2} \cdot\left(\mathrm{m}_{\mathrm{r}} \cdot \cos (\alpha)+\mathrm{m}_{\mathrm{o}} \cdot \cos (\alpha) \cdot \mathrm{A}_{1} \cdot \cos (\alpha)+\mathrm{m}_{\mathrm{o}} \cdot \mathrm{A}_{2} \cdot \cos (2 \cdot \alpha)+. .\right) \\
& \mathrm{F}_{\mathrm{x}}=\mathrm{r} \cdot \omega^{2} \cdot \mathrm{m}_{\mathrm{r}} \cdot \operatorname{sen}(\alpha)
\end{aligned}
$$


A divisão das massas da biela em uma componente oscilante e outra rotativa pode ser feita de diversas maneiras. Alguns usam uma relação de $1 / 3$ da massa total da biela como a parte da mesma que contribui para os esforços oscilantes e os dois terços restantes como a componente rotativa. Como uma alternativa prática e precisa, pode-se utilizar uma relação proporcional à distância do centro de gravidade obtido a partir de um modelo tridimensional (Figura 12).

Assim:

$$
\mathrm{m}_{\mathrm{o}}=\frac{\mathrm{L}_{2}}{\mathrm{~L}_{1}} \cdot \mathrm{m}_{\mathrm{r}} \quad \text { e } \mathrm{m}_{\mathrm{o}}+\mathrm{m}_{\mathrm{r}}=\text { massa da biela }\left(\mathrm{m}_{\mathrm{b}}\right)
$$

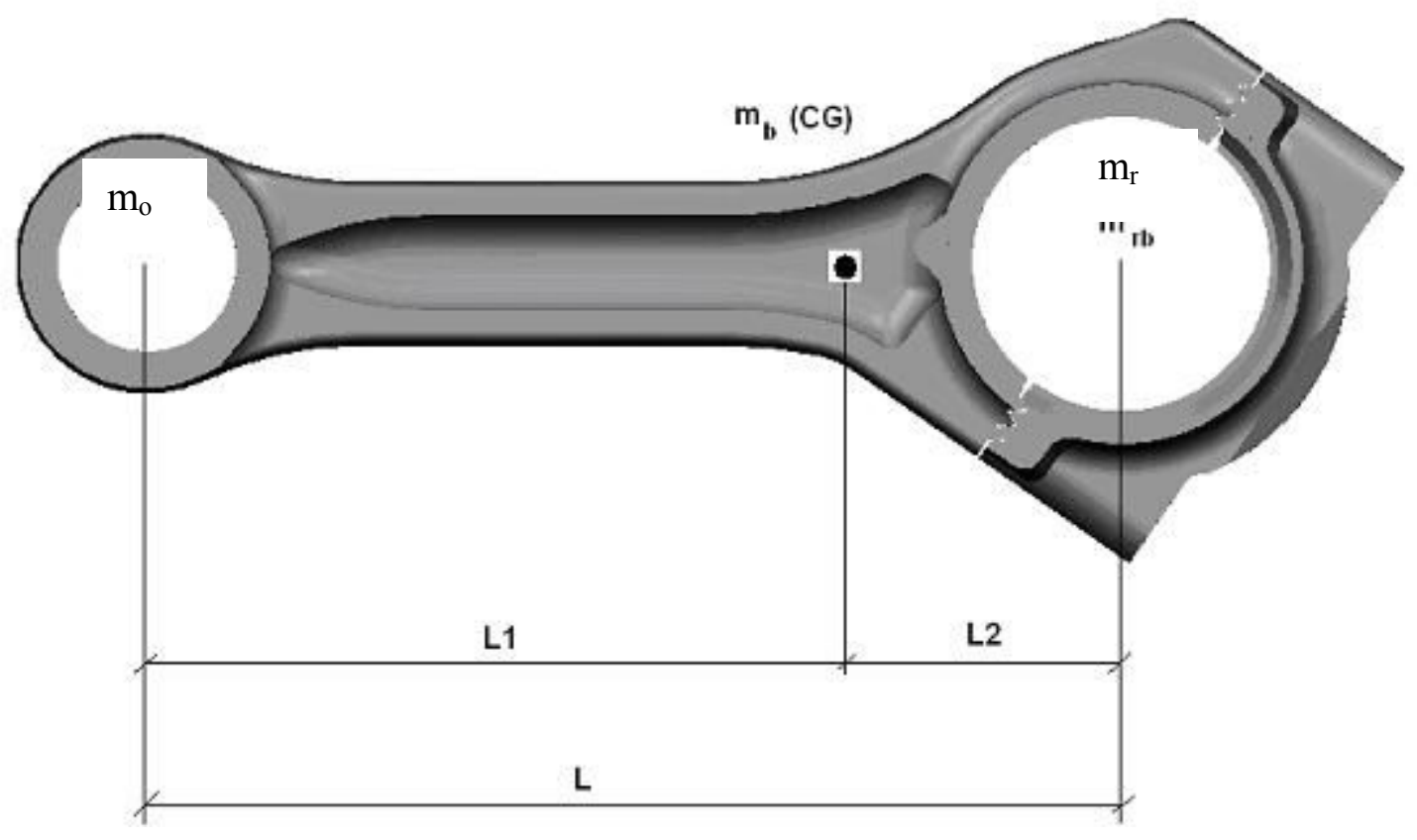

Figura 12: Exemplo de medição do centro de gravidade em uma biela

\subsection{Análise Dinâmica - Método de Newton}

Para a validação do método usual e análise do erro envolvido, foi desenvolvido o cálculo do carregamento pela abordagem clássica do método de Newton sem as hipóteses simplificadoras mencionadas no item 3.2, para a comparação dos resultados obtidos. 
A dedução das forças atuantes no sistema pela dinâmica de múltiplos corpos tradicional trata simplesmente da dedução das equações de equilíbrio de forças nas direções vertical e horizontal segundo um sistema de coordenadas específico, a segunda lei de Newton, e das equações decorrentes do teorema do momento angular, a equação de Euler.

Utilizando como referência a Figura 8, podemos deduzir as velocidades e acelerações dos pontos $A$ (posição do moente das manivelas), C (posição do centro de gravidade da biela) e D (posição do centro de gravidade da manivela) do mesmo modo em que foi deduzida a aceleração no ponto B para o cálculo pelo método usual.

No presente trabalho, a distância do ponto $D$ ao ponto $O$ foi chamada de $R_{D}$. Assim, as acelerações nos pontos $A, B C$ e $D$ respectivamente $a_{A}, a_{B}, a_{C}$ e $a_{D}$ escritas na forma matricial segundo sistema de coordenadas descrito são dadas por:

$$
a_{A}=\left(\begin{array}{c}
a_{p}+L \cdot \frac{d^{2}}{d t^{2}} \beta \cdot \operatorname{sen}(\beta)+L \cdot \frac{d}{d t} \beta \cdot \cos (\beta) \\
-L \cdot \frac{d^{2}}{{d t^{2}}^{2}} \beta \cdot \cos (\beta)-L \cdot \frac{d}{d t} \beta \cdot \operatorname{sen}(\beta) \\
0
\end{array}\right)
$$

Onde $a_{p}$ é a aceleração do pistão:

$$
\begin{aligned}
& a_{p}=\frac{d^{2}}{{d t^{2}}^{2}} \\
& a_{B}=\left(\begin{array}{c}
a_{p} \\
0 \\
0
\end{array}\right) \\
& a_{C}=\left(\begin{array}{c}
a_{p}+L_{1} \cdot \frac{d^{2}}{d^{2}} \beta \cdot \operatorname{sen}(\beta)+L_{1} \cdot \frac{d}{d t} \beta \cdot \cos (\beta) \\
-L_{1} \cdot \frac{d^{2}}{d t^{2}} \beta \cdot \cos (\beta)-L_{1} \cdot \frac{d}{d t} \beta \cdot \operatorname{sen}(\beta) \\
0
\end{array}\right)
\end{aligned}
$$


$\mathrm{a}_{\mathrm{D}}=\left(\begin{array}{c}-\mathrm{R}_{\mathrm{D}} \cdot \omega^{2} \cdot \cos (\alpha) \\ \mathrm{R}_{\mathrm{D}} \cdot \omega^{2} \cdot \operatorname{sen}(\alpha) \\ 0\end{array}\right)$

Analisando separadamente as forças atuantes na manivela temos:

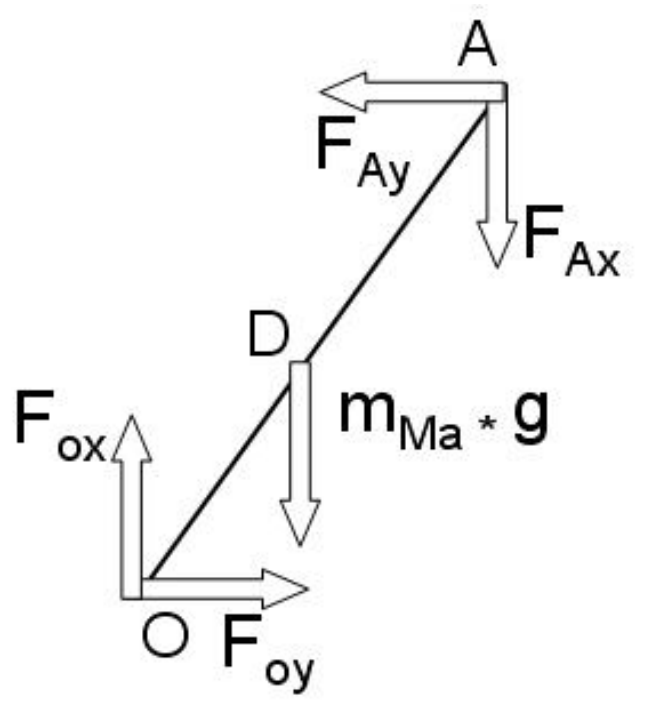

Figura 13: Forças atuantes na manivela

Onde $F_{o y}, F_{o x}, F_{A y}, F_{A x}, m_{M a}$ e g são, respectivamente, a força horizontal no munhão, a força vertical no munhão, a força horizontal no moente, a força vertical no moente, a massa da manivela e a aceleração gravitacional.

O equilíbrio de forças no presente componente traz as equações:

$$
\left(\begin{array}{c}
\mathrm{m}_{\mathrm{Ma}} \cdot \mathrm{g} \\
0 \\
0
\end{array}\right)+\left(\begin{array}{c}
-\mathrm{F}_{\mathrm{ox}} \\
\mathrm{F}_{\mathrm{oy}} \\
0
\end{array}\right)+\left(\begin{array}{c}
\mathrm{F}_{\mathrm{Ax}} \\
-\mathrm{F}_{\mathrm{Ay}} \\
0
\end{array}\right)=\mathrm{m}_{\mathrm{Ma}} \cdot \mathrm{a} \mathrm{D}
$$

Onde $\mathrm{m}_{\mathrm{Ma}}$ é a massa da manivela.

O teorema do momento angular aplicado ao mesmo corpo, onde $M_{o z}$ representa o 
momento de torção aplicado à manivela no ponto $\mathrm{O}$, gera a equação:

$-r \cdot\left(F_{A y} \cdot \cos (\alpha)-F_{A x} \cdot \operatorname{sen}(\alpha)\right)+R_{D} \cdot m_{M a} \cdot g \cdot \operatorname{sen}(\alpha)+M_{O Z}=0$

Analisando separadamente as forças atuantes na biela temos:

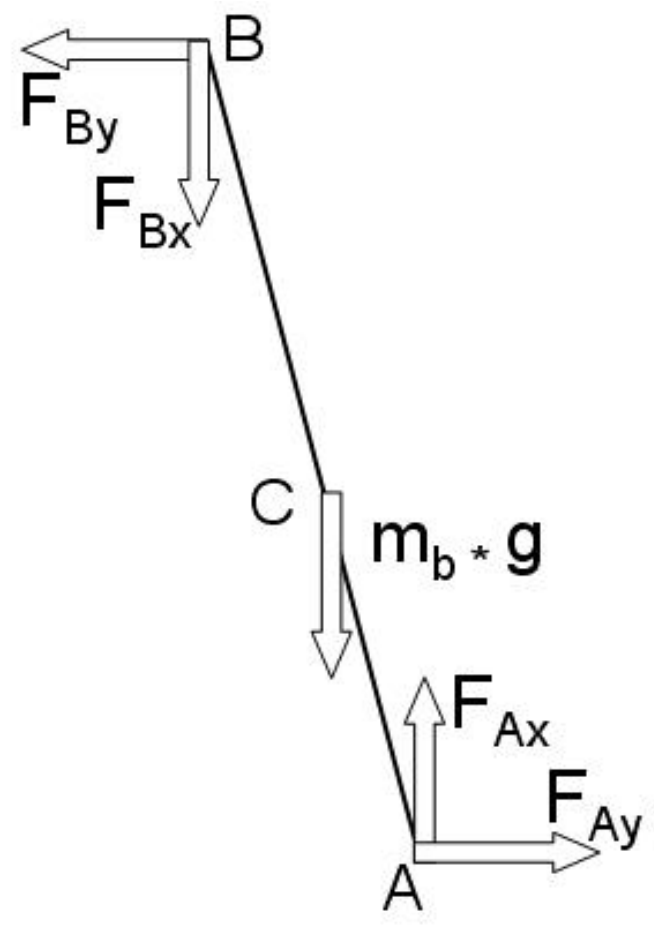

Figura 14: Forças atuantes na biela

Onde $F_{B y}, F_{B x}$ e $m_{b}$ são, respectivamente, a força horizontal no pistão, a força vertical no pistão e a massa da biela.

O equilíbrio de forças na biela traz as equações:

$$
\left(\begin{array}{c}
-\mathrm{mb} \cdot \mathrm{g} \\
0 \\
0
\end{array}\right)+\left(\begin{array}{c}
\mathrm{F}_{\mathrm{Ax}} \\
\mathrm{F}_{\mathrm{Ay}} \\
0
\end{array}\right)+\left(\begin{array}{c}
-\mathrm{F}_{\mathrm{Bx}} \\
-\mathrm{F}_{\mathrm{By}} \\
0
\end{array}\right)=\mathrm{m}_{\mathrm{b}} \cdot \mathrm{aC}
$$

O teorema do momento angular aplicado ao mesmo corpo, onde $I_{z z b}$ representa 0 momento de inércia da biela em relação ao ponto $C$, gera a equação:

$$
\mathrm{L}_{2} \cdot\left(\mathrm{F}_{\mathrm{Ay}} \cdot \cos (\beta)+\mathrm{F}_{\mathrm{Ax}} \cdot \operatorname{sen}(\beta)\right)+\mathrm{L}_{1} \cdot\left(\mathrm{F}_{\mathrm{By}} \cdot \cos (\beta)+\mathrm{F}_{\mathrm{Bx}} \cdot \operatorname{sen}(\beta)\right)+\mathrm{I}_{\mathrm{zzb}} \cdot \frac{\mathrm{d}^{2}}{\mathrm{dt}^{2}} \beta=0
$$


Finalmente, analisando separadamente as forças atuantes no pistão, temos:

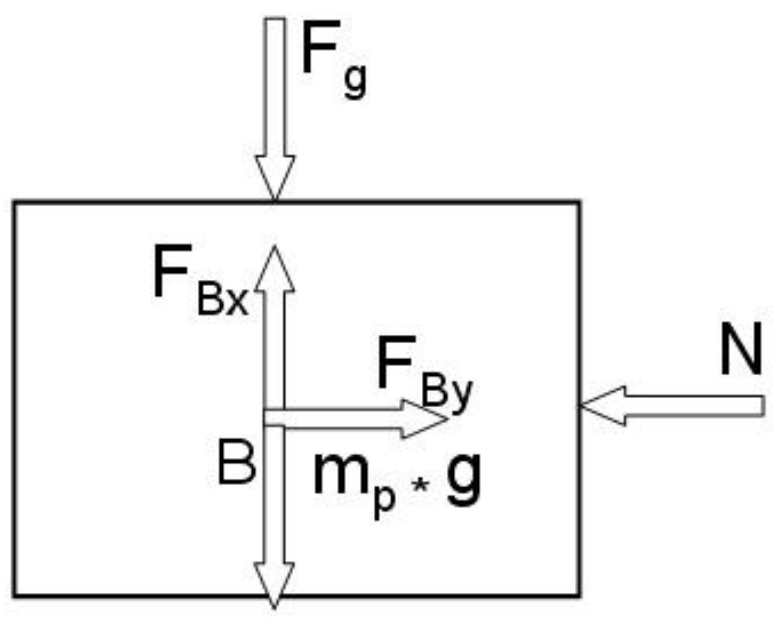

Figura 15: Forças atuantes no pistão

O equilíbrio de forças no pistão traz as equações:

$$
\left(\begin{array}{c}
-\mathrm{m}_{\mathrm{p}} \cdot \mathrm{g} \\
0 \\
0
\end{array}\right)+\left(\begin{array}{c}
0 \\
-\mathrm{N} \\
0
\end{array}\right)+\left(\begin{array}{c}
\mathrm{F}_{\mathrm{Bx}} \\
\mathrm{F}_{\mathrm{By}} \\
0
\end{array}\right)+\left(\begin{array}{c}
-\mathrm{F}_{\mathrm{g}} \\
0 \\
0
\end{array}\right)=\mathrm{m}_{\mathrm{p}} \cdot \mathrm{a}_{\mathrm{B}}
$$

Onde $\mathrm{N}$ é a força normal, ração do bloco com o pistão.

Tendo como incógnitas biela-manivela as forças $F_{o y}, F_{o x}, F_{A y}, F_{A x}, F_{B y}$ e $F_{B x}$ e o momento $M_{o z}$, e equações 3.9 a 3.13 , obtemos um sistema linear que pode ser resolvido para cada posição angular específica. Assim temos as forças nos três componentes resolvidas.

\subsection{Comparação dos métodos de cálculo do carregamento}

Observa-se que as hipóteses utilizadas para o cálculo usual fazem com que não seja necessário resolver um sistema linear a cada posição angular em que se deseja conhecer uma determinada força do sistema. O método usual permite, além disso, a obtenção do valor de forças específicas de modo separado, não sendo necessário calcular carregamentos que não sejam de interesse específico para cada finalidade. O método de Newton por não necessitar de tais hipóteses traz ainda resultados mais 
precisos.

Para a avaliação da precisão do método usual, foram sobrepostos os resultados de carregamento na árvore de manivelas pelos dois métodos, nos casos de máxima pressão na Figura 16, e máxima velocidade na Figura 17.

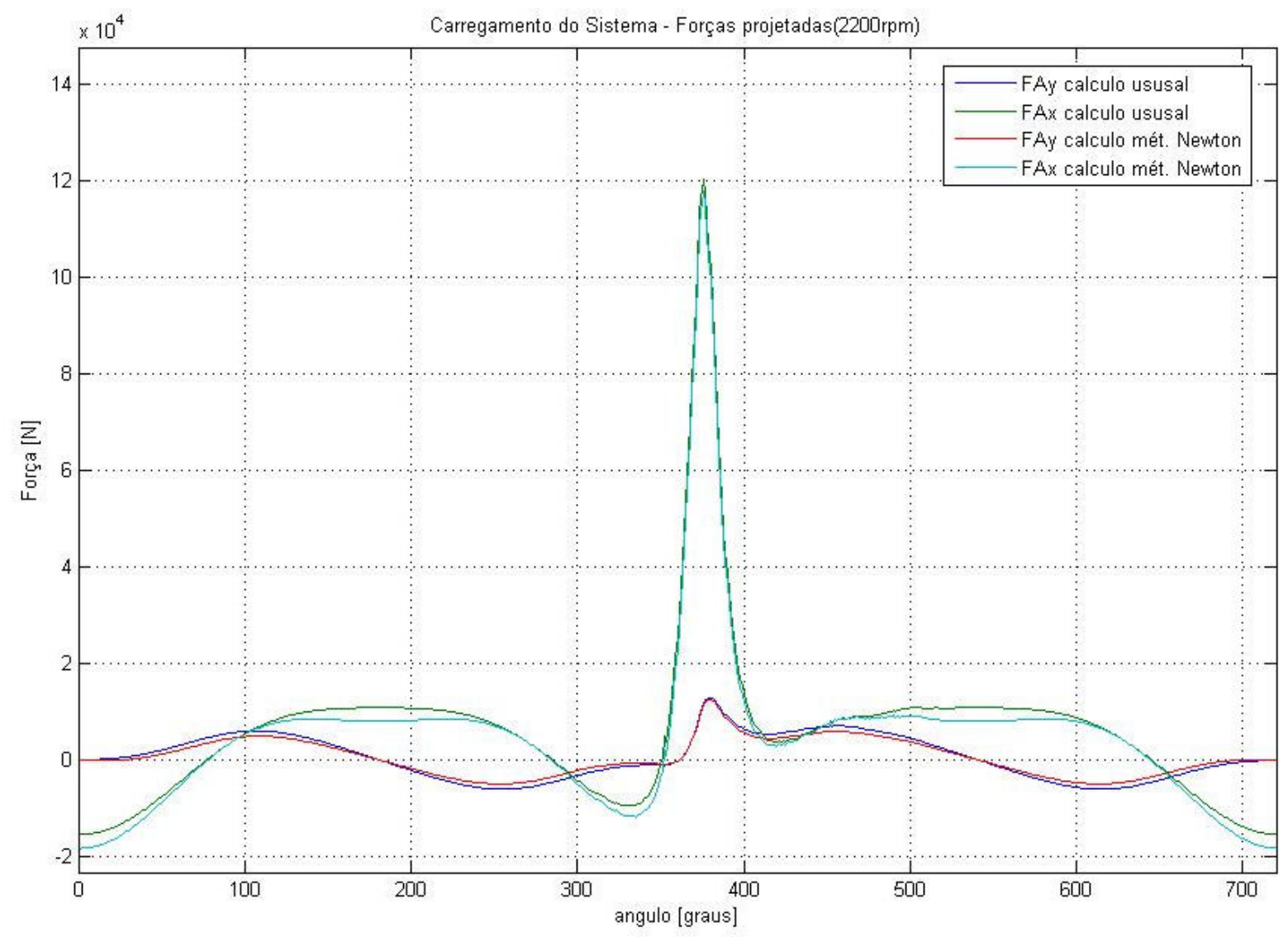

Figura 16: Forças atuantes na manivela (máxima pressão) 


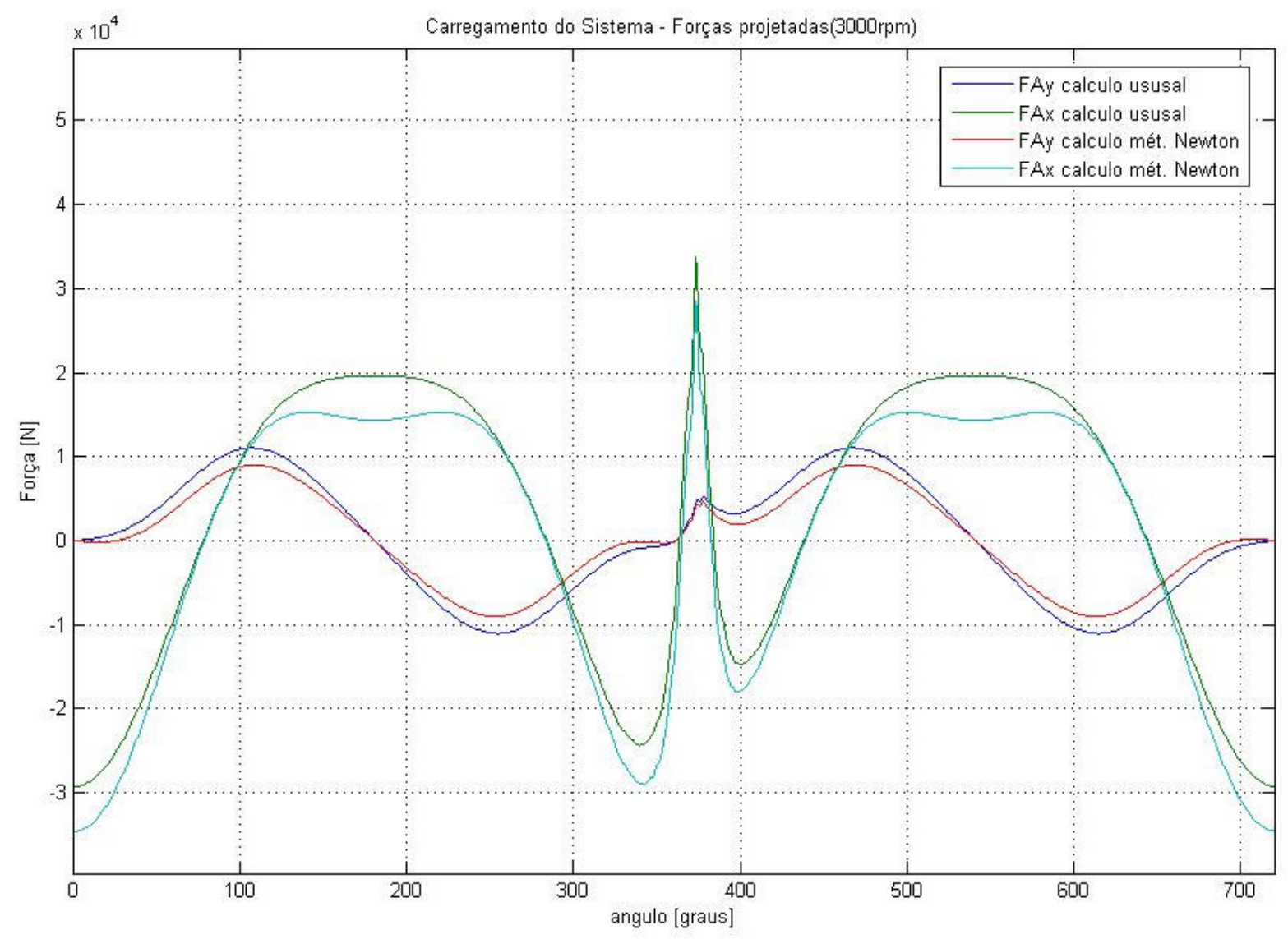

Figura 17: Forças atuantes na manivela (máxima velocidade)

Observa-se uma pequena diferença entre os resultados obtidos para os dois métodos utilizados. Considerando-se as ordens de grandeza da força do gás atuante no sistema, o fato de se necessitar estudar tensões alternadas e médias dado que o componente falha por fadiga, e a pequena diferença percentual dos dois métodos (máximo de aproximadamente $9 \%$ no caso de máxima velocidade e de $2 \%$ no caso de máxima pressão), verifica-se que o custo computacional extra de resolução de um sistema linear a cada valor novo de velocidade e ângulo não justifica, para esta aplicação específica do presente trabalho, a utilização deste método mais preciso.

Para uma análise da resposta dinâmica do sistema ou o caso em que os recursos computacionais sejam limitantes, os resultados obtidos com o método usual são suficientemente satisfatórios.

A diferença entre os dois métodos tende a aumentar com a velocidade conforme também observado por $\mathrm{SHIAO}^{43}$ onde uma terceira abordagem de cálculo de carregamento, pelo método de Lagrange, foi também implementada. Villalva et al. ${ }^{59}$ 
também executam análises semelhantes com a dedução detalhada dos dois métodos observado a diferença de precisão mencionada. A faixa de velocidade de motores Diesel estudada neste trabalho não traz, no entanto, erros significativos. Apesar da maior precisão dos resultados obtidos pelo método de Newton ou de Lagrange, há ainda uma hipótese simplificadora utilizada neste trabalho relacionada ao acoplamento das forças internas do motor para os diferentes cilindros. No presente estudo, foi utilizado o acoplamento em um só sentido, dos componentes em movimento dentro do motor para o bloco. Esta abordagem usualmente empregada não necessariamente garante a conservação de energia, desprezando efeitos giroscópicos de Coriolis. HOFFMAN ${ }^{44}$ estudou a implementação de um modelo totalmente acoplado, considerando os efeitos mencionados, mostrando que para motores balanceados o erro é desprezível. O mesmo autor mostra que para o caso de motores com balanceamento deficitário como é o caso de motores de um cilindro, os erros são maiores.

\subsection{Esforços nos mancais / análise hidrodinâmica}

O cálculo do carregamento no projeto de virabrequins viabiliza além de dados necessários para a análise estrutural e de resposta dinâmica, dados necessários para a análise dos esforços hidrodinâmicos nos mancais e para o dimensionamento dos furos de lubrificação do virabrequim.

$\mathrm{Na}$ análise hidrodinâmica do mancal de deslizamento, características como folga radial e perfil do eixo do virabrequim podem ser determinados através de parâmetros de saída da mesma como máxima pressão do filme de óleo, mínima espessura do filme de óleo e pressão máxima de contato, que normalmente são especificados pelas necessidades de desempenho do motor.

Pode-se calcular também, o dimensionamento ideal dos furos de lubrificação no virabrequim garantindo assim quantidade e pressão do óleo nos mancais para o funcionamento ideal do motor e durabilidade de seus componentes.

Para ambos os estudos mencionados, além de dados relacionados à viscosidade, temperatura, rugosidade, raio e largura do mancal e folga radial, são necessários os valores da força no mancal estudado. Para o caso dos munhões e moentes, basta calcular as forças no mancal por um dos métodos ilustrados acima e, no caso dos munhões, somar a metade dos mesmos carregamentos dos cilindros vizinhos, 
defasados de acordo com a ordem de ignição e projetados em mesmas direções. Assim, o carregamento atuante no primeiro munhão equivale à metade do calculado para o primeiro cilindro, devido às forças de inércia e de gás. $O$ carregamento atuante no segundo munhão equivale à metade do calculado para o primeiro cilindro somado à metade da força atuante no segundo cilindro, defasado de acordo com a ordem de ignição e projetado nas direções $x$ e y. A Figura 18 ilustra um exemplo do cálculo citado para a força $F_{\text {ox }}$ calculada pelo método de Newton. $O$ cálculo para os demais munhões é análogo ao ilustrado na Figura 18.

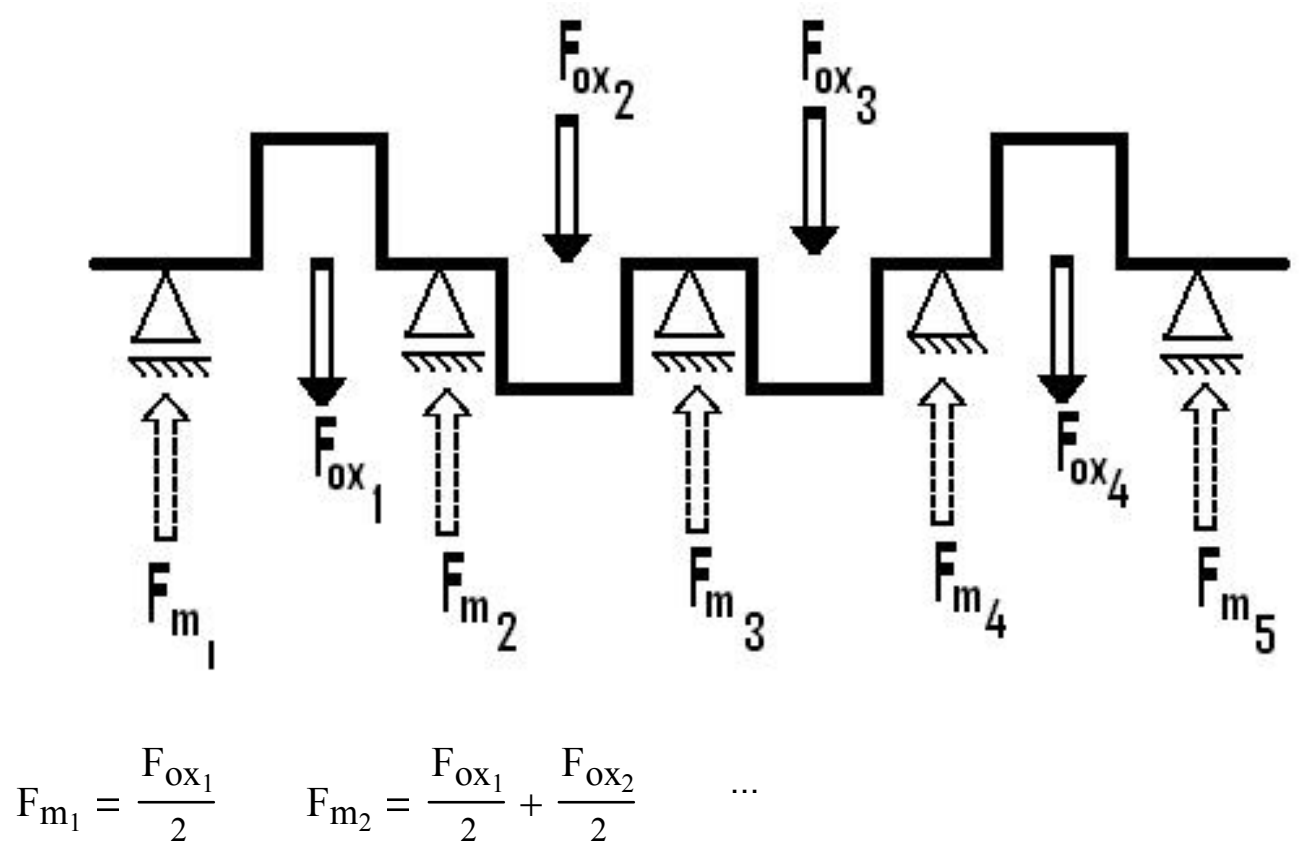

Figura 18: Cálculo do carregamento nos munhões

Análises como as mencionadas para projeto dos furos de lubrificação não são o foco do presente trabalho e podem ser mais bem estudadas através de referência específica ${ }^{20,54}$. O cálculo do carregamento nos munhões foi efetuado no estudo de caso, para ilustrar dados típicos de análise hidrodinâmica em mancais mais bem explicados na seção 3.5.1, e pela transferência de esforços da árvore de manivelas ao bloco se efetuar através dos mesmos.

- Além disso, numa otimização do perfil dos mancais visando um melhor comportamento hidrodinâmico ou mesmo na análise do desempenho dos parâmetros deste estudo específico, como potência de acionamento, vazão do fluido lubrificante e temperatura do mesmo, estes dados seriam novamente necessários. 


\subsubsection{Análise Hidrodinâmica}

Apenas para ilustração de resultados possíveis da análise hidrodinâmica e definições básicas de terminologia aplicada foi aplicado no presente trabalho um programa desenvolvido por DURVAL ${ }^{20}$.

Um mancal hidrodinâmico consiste de um elemento de máquina cuja função é separar duas peças rígidas através da sua capacidade de auto-pressurização. Esta capacidade decorre de dois efeitos: wedge ou efeito cunha, e o efeito squeeze ou de aumento da pressão do filme de óleo mais bem observados na Figura 19, onde e representa a excentricidade do eixo em relação ao alojamento. $O$ primeiro efeito consiste de um gradiente de pressão devido ao movimento das partículas levadas por arraste com a rotação do eixo. O segundo, resulta da velocidade radial do eixo que gera a pressão hidrodinâmica pelo prensamento do fluido.

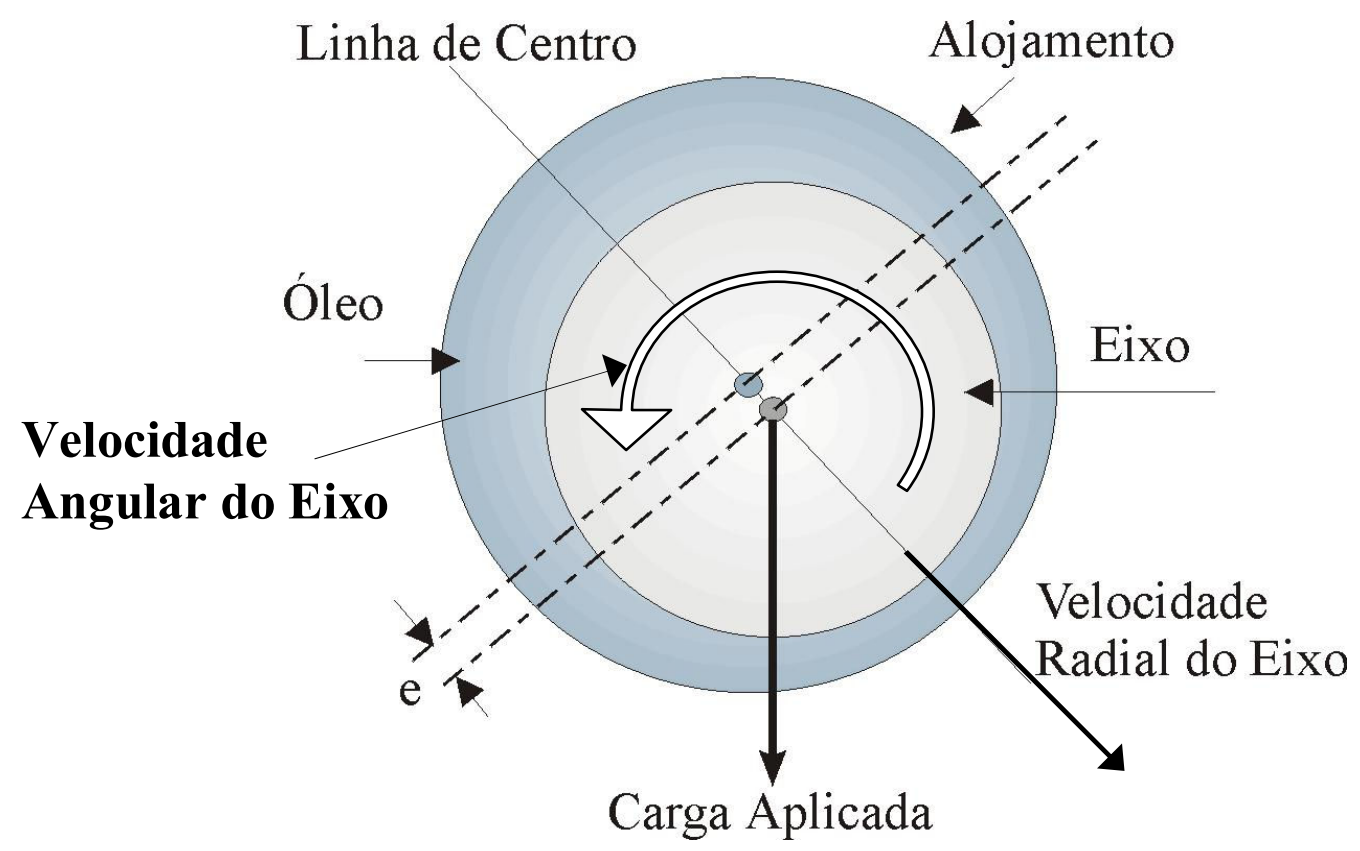

Figura 19: Mancal hidrodinâmico radial ${ }^{54}$

No caso de mancais axiais com superfície plana, o que normalmente ocorre nas superfícies dos virabrequins destinadas à limitação do movimento dos mesmos no sentido axial, normalmente denominadas de espelho guia, não há pressão hidrodinâmica. Já os munhões e moentes, são mancais radiais e possuem o comportamento mostrado na Figura 19.

Os tipos de lubrificação podem ser classificados em: lubrificação marginal, quando a 
distância entre as superfícies deslizantes é menor ou igual à rugosidade das mesmas havendo, portanto, contato entre as faces, lubrificação hidrodinâmica, quando esta distância é maior ou igual a cinco vezes a rugosidade, e lubrificação mista, no caso intermediário.

Resolvendo-se a equação de Reynolds em mancais radiais através de métodos numéricos ou analíticos pode-se obter a distribuição da pressão hidrodinâmica no mancal. Esta pressão pode servir de entrada em análises estruturais na árvore de manivelas e para a definição dos furos de óleo como já foi mencionado.

Além disso, pela análise hidrodinâmica pode-se obter 0 valor da força de sustentação no mancal que consiste da integral desta pressão hidrodinâmica pela área, a potência de acionamento (potência necessária para girar o eixo), a viscosidade média do fluido lubrificante, a quantidade de óleo que o mancal expulsa durante operação, dentre outros fatores.

Detalhes de dedução das equações mencionadas bem como métodos de solução numérica e analítica das mesmas podem ser encontrados em referência específica ${ }^{20}$. Existem ainda análises mais complexas como a elastohidrodinâmica, onde os efeitos de rigidez dos componentes são considerados ou a termoelastohidrodinâmica onde efeitos da temperatura no fluido são também adicionados. 


\section{Balanceamento}

Em qualquer projeto ou alteração de geometria em árvores de manivela que se traduza em alteração da distribuição de massa do componente, uma das primeiras análises de desempenho realizadas é a do balanceamento do componente. A análise do balanceamento é necessária em todas as etapas da fabricação à condição final do componente já que mesmo com a variação inerente ao processo de fabricação do mesmo,deve sempre ser possível realizar o balanceamento do componente durante sua usinagem e o comportamento dinâmico, a ser mais bem detalhado no capítulo 5 , preservado dentro de condições o mais próximas possível das ideais.

\subsection{Balanceamento das Forças de Inércia}

Os principais momentos e forças atuantes no motor, bem como suas causas e efeitos podem ser resumidos na tabela abaixo:

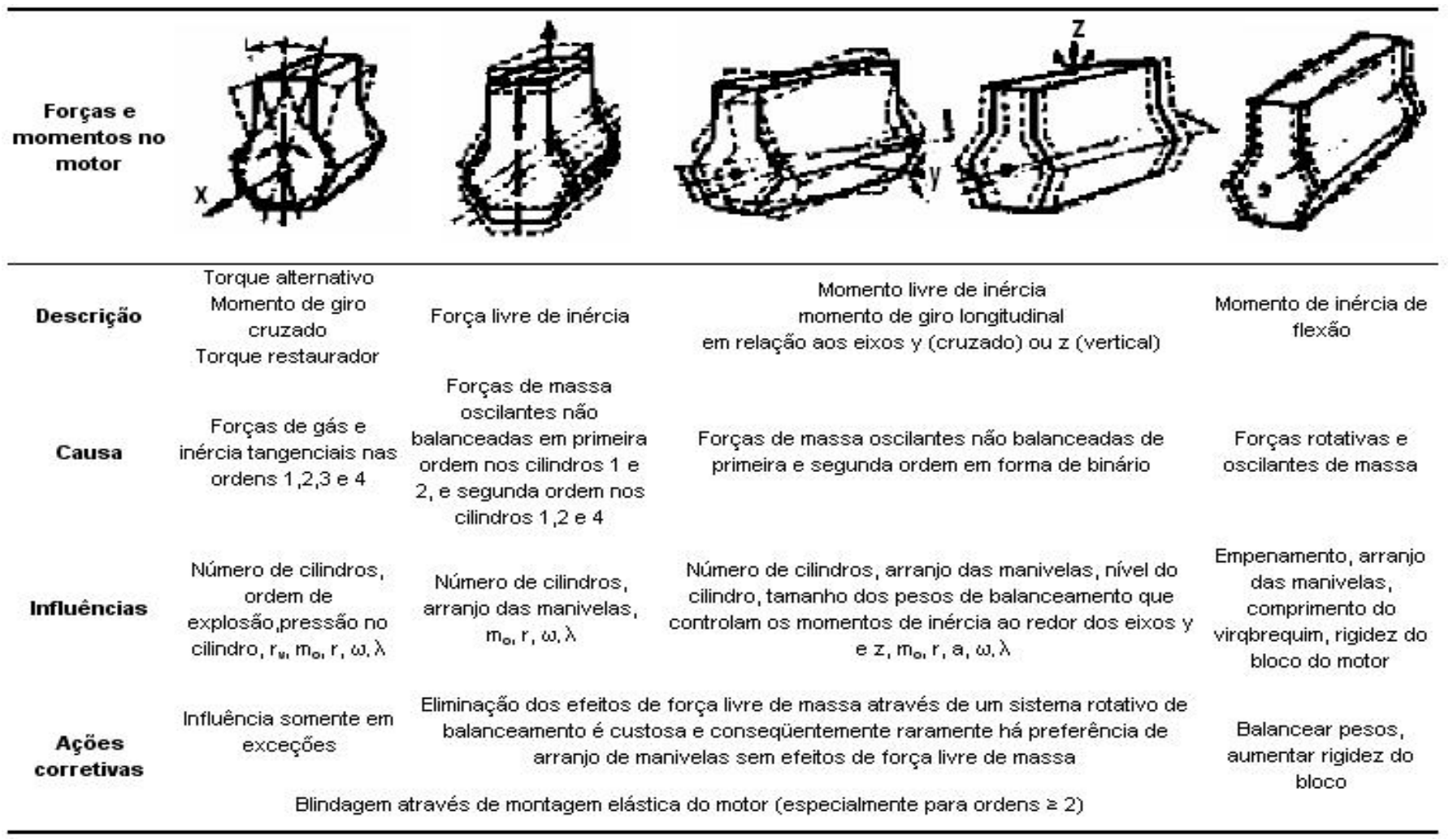

Tabela 3: Descrição das forças e momentos atuantes nos motores ${ }^{10}$ 
As forças de inércia rotativas podem ser totalmente balanceadas através dos contrapesos com a simples alteração dos mesmos de modo que o efeito da força centrífuga gerado é anulado. Já para as forças de inércia oscilantes, o diagrama vetorial da Figura 20 pode ser utilizado para ilustrar o seu processo de balanceamento. Nele, as forças oscilantes de primeira e segunda ordem são substituídas por vetores rotativos com velocidades angulares idênticas e de sinal oposto. O balanceamento total destas forças pode ser obtido com a rotação de sistemas de balanceamento girando na direção oposta com velocidade igual à da árvore de manivelas para as forças de primeira ordem e velocidade duplicada para as de segunda ordem. O vínculo da árvore de manivelas com estes sistemas é feito através de uma engrenagem ligada a um dos braços da mesma, chamada normalmente de "anel sensor". Este tipo de balanceamento é caro e em razão disso, raramente executado ${ }^{9}$.

Outro modo de se reduzir o efeito das forças de inércia oscilantes no motor é a alteração da distância entre centros $(\mathrm{L})$ da biela, alterando assim a massa alternativa $\mathrm{m}_{\mathrm{o}}^{60}$.

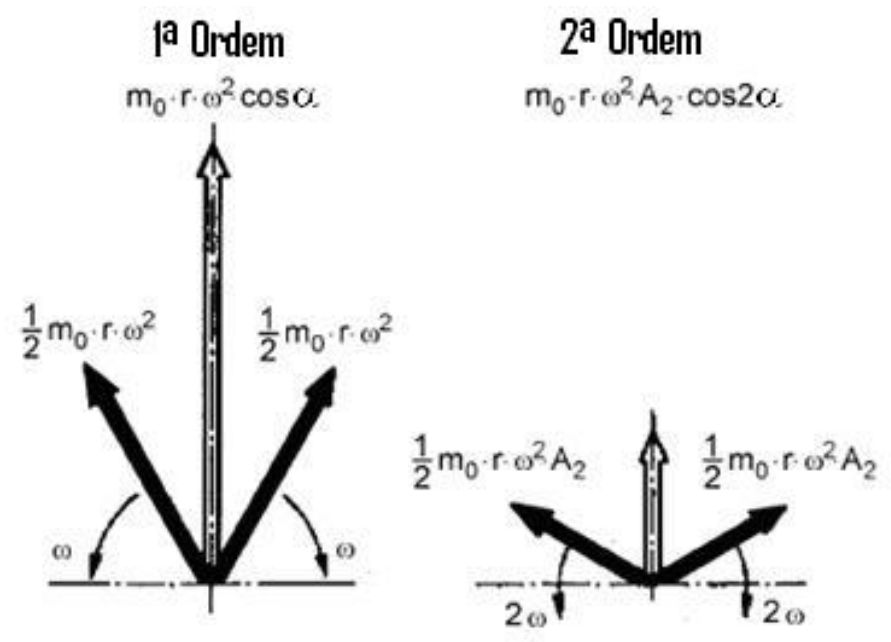

Figura 20: Representação vetorial das forças de inércia oscilantes ${ }^{9}$

Um terceiro método para balanceamento parcial das forças de inércia oscilantes é a adição das massas oscilantes nos contrapesos, o que altera a direção das mesmas transferindo uma parcela das forças antes na direção axial do cilindro para a direção transversal do mesmo. A razão do balanceamento reduzido pelo original gera a chamada "taxa de balanceamento". Alguns autores consideram uma taxa de 50\% como a solução suficiente ${ }^{9}$. 
O balanceamento total pode ser alcançado acrescendo a massa do contrapeso em $\mathrm{m}_{\mathrm{o}} / 2$ e adicionando um eixo rotativo com velocidade igual à da árvore de manivelas, porém de sinal oposto e massa de balanceamento $\mathrm{m}_{\mathrm{o}} / 2$.

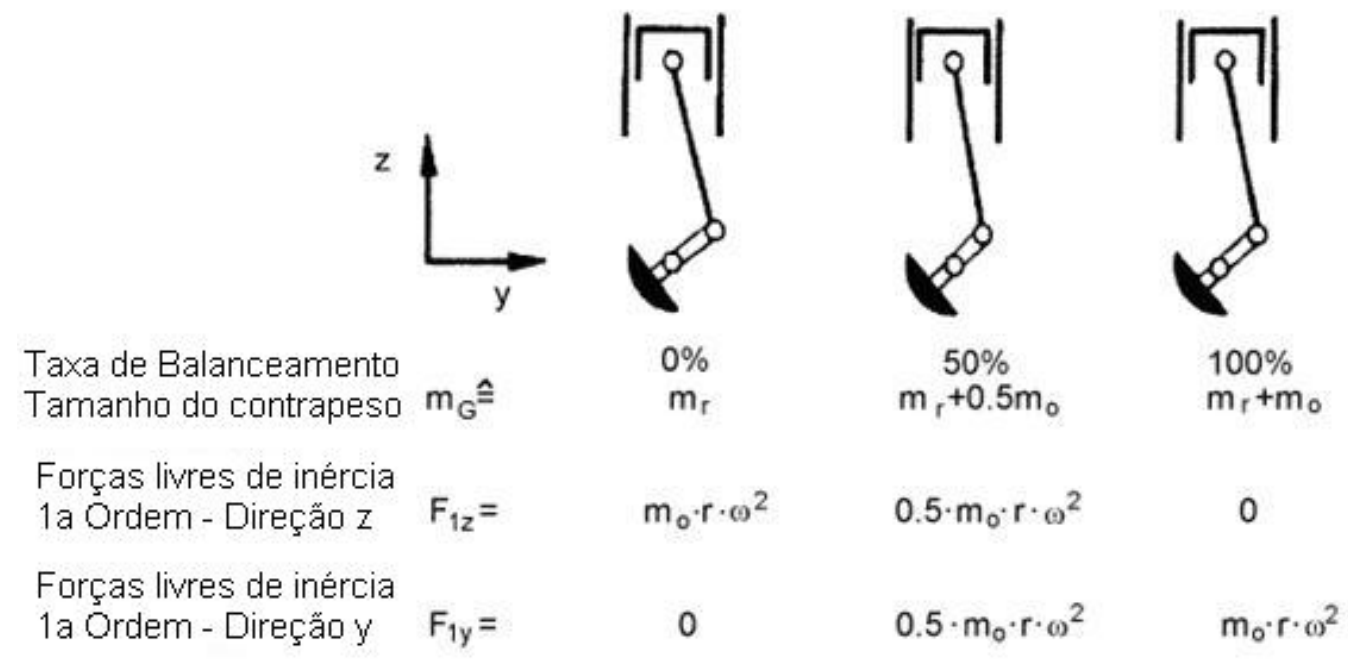

Figura 21: Forças de inércia para diferentes tamanhos de contrapesos

\subsection{Balanceamento de Sistemas Multi-Cilindros}

No caso de sistemas com várias manivelas, pode-se obter o balanceamento das forças de inércia de primeira ordem com o correto espaçamento constante das manivelas e o projeto das mesmas de modo que tenham massas equivalentes. Já para anular os efeitos de segunda ordem, é necessário dobrar o ângulo entre as manivelas e o cilindro conforme ilustrado na Figura 22.
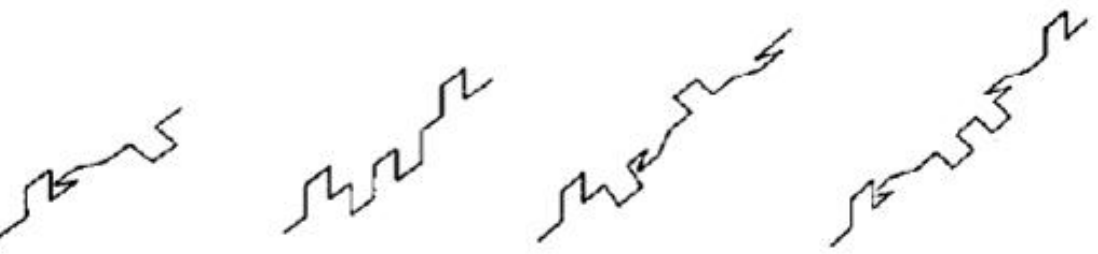

\begin{abstract}
Arranjo de Manivelas $1^{\text {a }}$ Ordem
\end{abstract}<smiles>[R]C(S)I</smiles>

Arranjo de

Manivelas

$2^{\mathrm{a}}$ Ordem
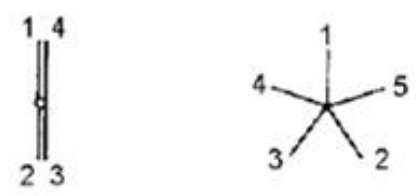<smiles>CC(C)(C)C</smiles>

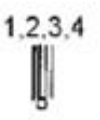<smiles>[2H]C(C)(C)I</smiles><smiles>CC(C)C</smiles>

Figura 22: Manivelas para $1^{a}$ e $2^{a}$ Ordem para Motores em Linha (4 tempos) com 3 a 6 cilindros 


\subsection{Balanceamento Estático}

Após finalizadas as considerações de arranjo das manivelas, da taxa de balanceamento e da utilização ou não de um sistema de balanceamento com anel sensor, o cálculo da distribuição correta de massas no componente é executado.

Para a determinação do desbalanceamento de árvore de manivelas, um modelo 3D gerado por um CAD pode ser utilizado, medindo-se a massa e o centro de massa de diferentes volumes e reduzindo-se o sistema a um conjunto de massas localizadas com distâncias ao eixo de rotação denominadas de braço $\left(r_{i}\right)$ e ângulo em relação à mesma referência do virabrequim.

Normalmente os virabrequins são projetados com um desbalanceamento residual para que mesmo com a dispersão inerente ao processo possam-se executar os furos de balanceamento no produto usinado, com número e posições controlados. Assim, quando se foca no balanceamento do virabrequim, calcula-se a amplitude e o ângulo do desbalanceamento residual. Um mau posicionamento do mesmo resultará em dificuldades de balanceamento no produto na sua fabricação, ou mesmo num comportamento indesejável do componente em operação.

Após a divisão do modelo da árvore de manivelas em massas concentradas nos centros de gravidade de cada volume específico como braços, moentes e munhões, o desbalanceamento e a direção do mesmo é calculado através das expressões:

$$
\text { desb }=m_{i} \cdot r_{i} \quad \operatorname{ang}=\operatorname{atan}\left(\frac{y_{i}}{r_{i}}\right) \quad r_{i}=\sqrt{\left(x_{1}\right)^{2}+\left(y_{i}\right)^{2}}
$$

Como a força centrífuga gerada por cada massa concentrada seria obtida pela simples multiplicação do desbalanceamento citado acima pelo quadrado da velocidade angular, pode-se sem perda de funcionalidade tratar estes desbalanceamentos como forças concentradas, calcular as reações em dois planos distintos (planos de balanceamento) como se a árvore de manivelas estivesse simplesmente apoiada e obter assim o desbalanceamento residual nestes planos. 
Qualquer algoritmo de otimização ou resolução de sistemas pode ser então utilizado para a obtenção dos novos valores de massa e centro de gravidade necessários para o balanceamento do componente.

No Apêndice $A$, pode-se ver com detalhes um programa feito no software MATLAB ${ }^{\circledR}$ para o cálculo do balanceamento citado.

\subsection{Balanceamento físico do componente}

Após a fabricação da árvore de manivelas seja através de fundição ou forjamento, e a subseqüente usinagem do mesmo, torna-se necessário o processo de balanceamento das mesmas. O processo consiste na definição do desbalanceamento do componente através de várias fontes distintas, como através da medição das reações nos mancais ou da deflexão do rotor, por exemplo, seguida pelo cálculo da alteração de massa necessária para os contrapesos e finalizada com a execução de furos nos mesmos para a obtenção do balanceamento desejado. 0 correto cálculo do balanceamento na fase de projeto como descrito na seção 4.3 tende a minimizar os esforços nesta fase de processo, reduzindo paralelamente 0 número de furos e profundidade dos mesmos, utilizados para balancear 0 componente. O conhecimento do processo torna-se então essencial para um bom projeto.

Os métodos de balanceamento podem ser divididos em duas categorias auto explicativas: balanceamento de rotores rígidos e balanceamento de rotores flexíveis. Muitos métodos flexíveis podem ser utilizados em rotores rígidos, não sendo o oposto válido na maior parte das aplicações ${ }^{30}$. Rotores flexíveis são geralmente balanceados em valores próximos às velocidades críticas dentro da faixa de operação do motor. 


\section{Análise de Vibrações}

\subsection{Vibrações Torcionais}

Uma árvore de manivelas está sujeita a vibrações de tração, flexão e torção. Será dada ênfase à análise do último tipo, que compreende um modo crítico de vibrar do componente, dadas às potenciais altas tensões de cisalhamento resultantes da variação da força tangencial, $F_{T}$ na Figura 9 , e consequentemente, do momento de torção distribuído no componente.

Possíveis meios de minimizar o efeito destas vibrações são a utilização de amortecedores ou a adequada alteração da rigidez e inércia da montagem pelo dimensionamento da árvore de manivelas e seus componentes.

Os amortecedores citados são normalmente constituídos de dois discos com inércias específicas, unidos por borracha ou fluido com viscosidade designada, de modo a alterar as freqüências naturais de vibrar do sistema, montados na maior parte das vezes no lado da espiga do virabrequim.

Como solução alternativa pode-se ajustar as curvas de pressão de combustão pela configuração adequada dos sistemas eletrônicos de injeção de combustível, prolongando assim o tempo de atuação da força $\mathrm{F}_{\mathrm{T}}$ e consequentemente reduzindo a amplitude das vibrações ${ }^{32}$.

\subsubsection{Modelo Matemático Equivalente}

A representação clássica do sistema de componentes do motor em um conjunto equivalente onde cada inércia, rigidez e amortecedor equivalente são montados simulando o sistema real de acordo com a Figura 23, onde se pode observar o sistema equivalente para um motor de quatro cilindros com amortecedor, polia, trem de engrenagens e volante. 


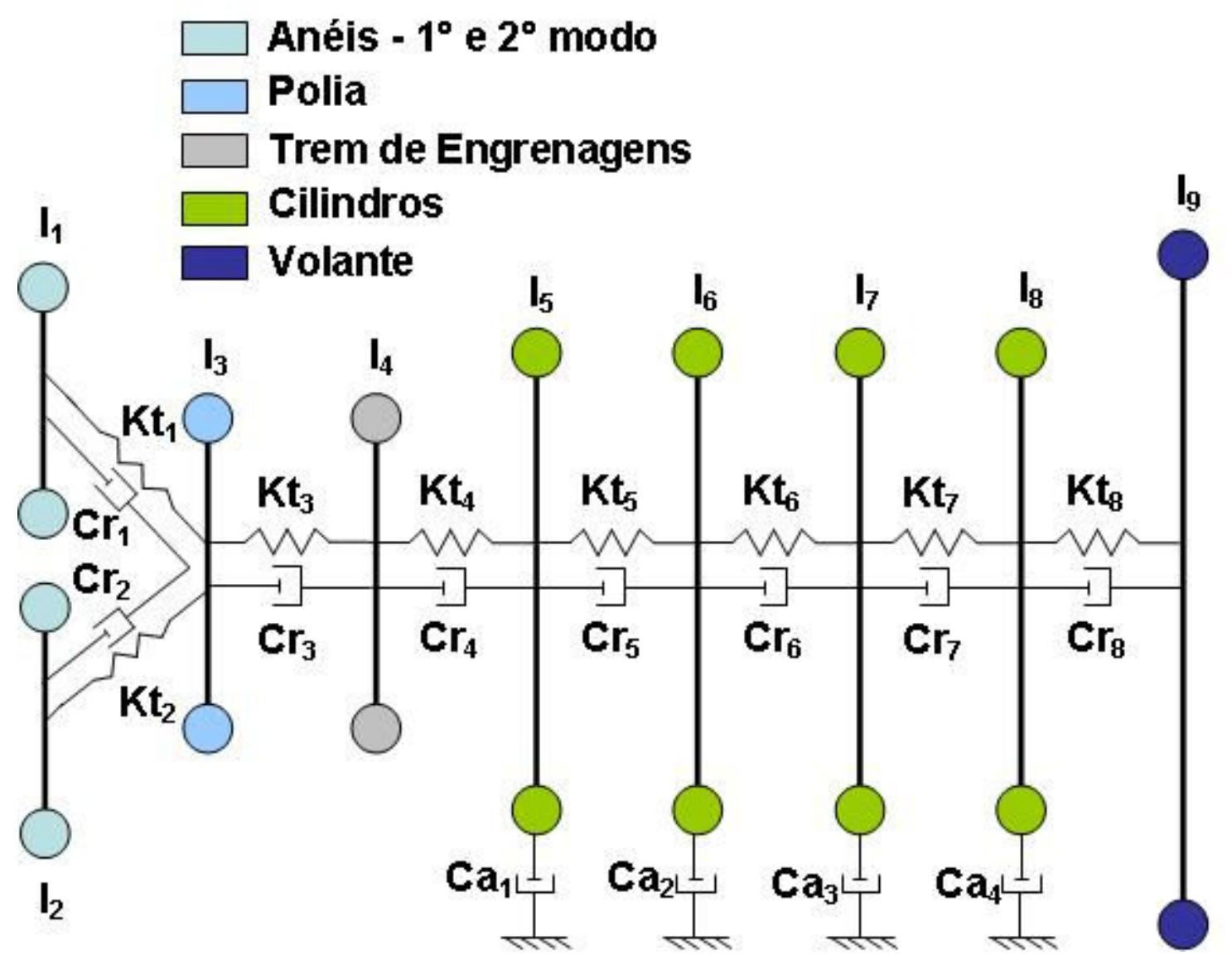

Figura 23: Modelo equivalente para um motor de quatro cilindros

\subsubsection{Modelo equivalente do Powertrain}

Além da possibilidade de adição dos componentes já ilustrados na Figura 7 como o eixo comando e as correias, polias e engrenagens, o chamado trem de transmissão composto pelos componentes ilustrados na Figura 24, componentes do carro do motor às rodas, têm teoricamente influência na análise dinâmica do sistema destacado na seção 5.1.1. Quando engrenado, o sistema como um todo possui distribuição de inércia, amortecimento e rigidez singular tendo cada componente participação ativa no desempenho do conjunto completo. 


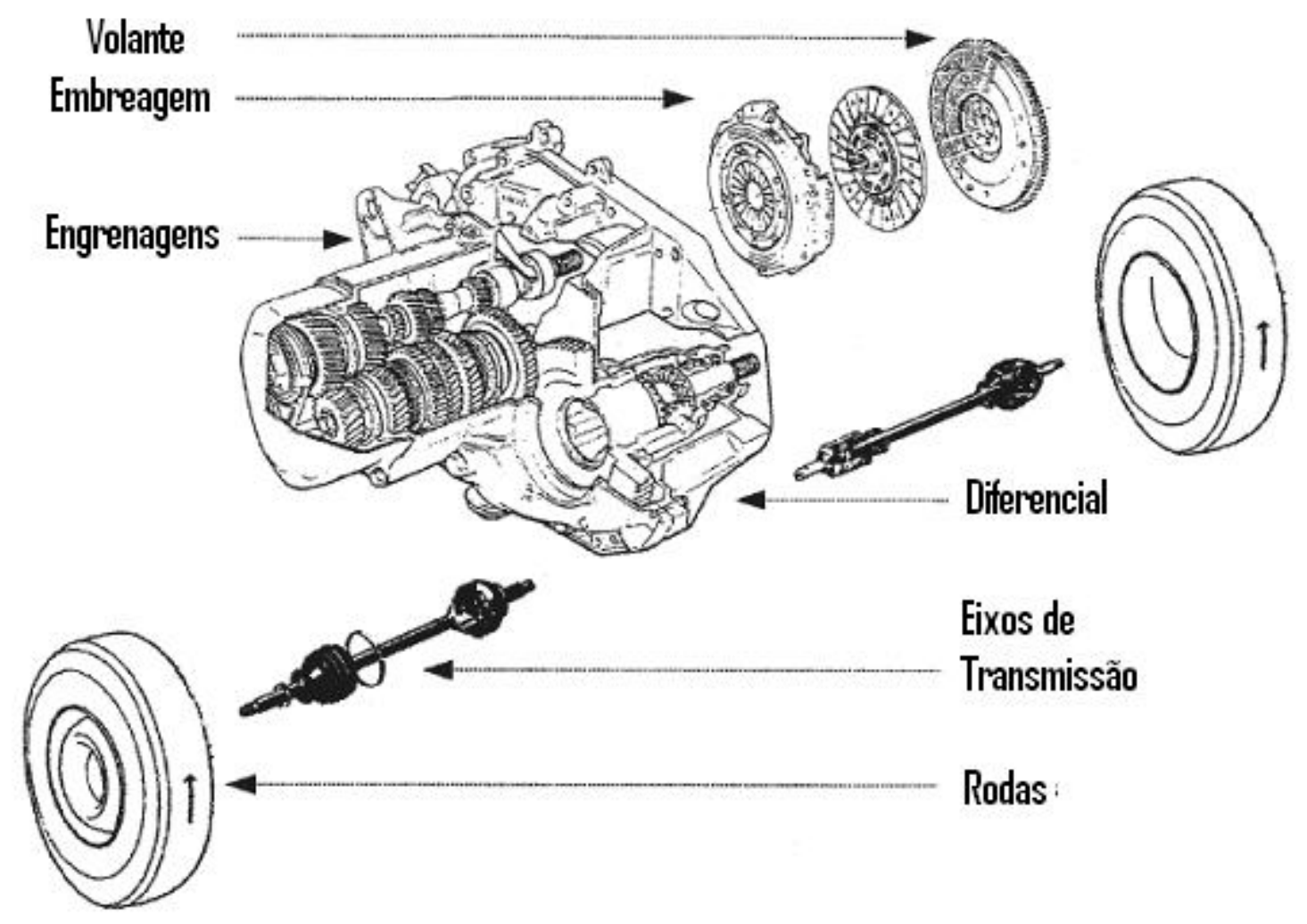

Figura 24: Componentes do trem de transmissão ${ }^{46}$

O aqui chamado trem de transmissão é vinculado pelo volante cuja inércia reduz a magnitude das acelerações angulares decorrentes das irregularidades de torque gerado pelo motor. A embreagem tem como funções principais conectar e desconectar a caixa de engrenagens com o motor, transmitir progressivamente o torque ao eixo de entrada e prover isolamento do conjunto de transmissão em relação à vibração do motor. Em seguida temos o conjunto de engrenagens helicoidais e o diferencial, para transmitir o torque para as rodas.

$\mathrm{O}$ conjunto de transmissão possui dois tipos principais de fontes de vibração ${ }^{46}$. $\mathrm{O}$ primeiro tipo, conhecido por gear rattle consiste da vibração decorrente de esforços impulsivos em razão das folgas, diferenças de rigidez, atrito, histerese entre as engrenagens dentre outros fatores. Esta fonte é bastante estudada quando o foco está localizado no conjunto de transmisão ${ }^{46,47,49}$. A segunda fonte de vibração desse conjunto é a estudada neste trabalho para o conjunto do motor, decorrente da variação de inércia, amortecimento e rigidez dos componentes gerando ruídos quando o conjunto está em funcionamento. A ressonância pode amplificar o movimento gerando necessidade de análise de freqüências.

Apesar da natural maior precisão de uma abordagem completa do conjunto de 
potência do carro na análise de vibração torcional, usualmente estudam-se separadamente o conjunto do motor como o exposto na seção 5.1.1, do volante aos anéis do amortecedor dinâmico ${ }^{7,32,45}$ e o conjunto do trem de transmissão, que tem como entrada a posição angular do volante em função do tempo e foco nos componentes que ligam o motor às rodas com inclusão das mesmas ${ }^{46,47,48}$.

Mesmo para os estudos em que o sistema completo é estudado, como por exemplo ZHANG $^{50}$ e ASSANIS ${ }^{51}$, uma abordagem modular é aplicada. Assim, os modelos do motor e trem de transmissão são desenvolvidos em módulos separados, com ajuda de softwares como SIMULINK ${ }^{\circledR}$ ou Scicos ${ }^{\circledR}$, que facilitam a posterior integração dos diferentes sistemas. Ainda para o sistema simplificado que considera somente o motor, esta abordagem traz resultados práticos e modelos flexíveis quando os diferentes cilindros são estudados separadamente e acoplados de acordo com a estrutura do motor (ex. quatro cilindros em linha, 6 cilindros em $V$ e assim por diante), com módulos montados e alterados de acordo com cada nova configuração de motor.

\subsubsection{Excitação do Sistema}

Conforme já deduzida, a força tangencial resultante da variação da força de gás citada anteriormente pode ser escrita como (eq. 3.3):

$$
\mathrm{F}_{\mathrm{t}}=\mathrm{F}_{\mathrm{p}} \cdot \frac{\operatorname{sen}(\alpha+\beta)}{\cos (\beta)}=\left(\operatorname{sen}(\alpha)+\frac{\lambda \cdot \operatorname{sen}(\alpha) \cdot \cos (\alpha)}{\sqrt{1-\lambda^{2} \cdot \operatorname{sen}(\alpha)^{2}}}\right) \cdot \mathrm{F}_{\mathrm{p}}
$$

Onde $F_{p}$ representa a soma da força do gás, $F_{g}$ (eq. 3.6) e a de inércia na direção do eixo de translação do pistão (eq. 3.7), reescritas abaixo.

$$
\mathrm{F}_{\mathrm{g}}=\mathrm{P}_{\mathrm{g}} \cdot \frac{\pi \cdot \mathrm{D}_{\mathrm{p}}}{4} \quad \mathrm{~F}_{\mathrm{y}}=-\mathrm{r} \cdot \omega^{2} \cdot\left(\mathrm{m}_{\mathrm{r}} \cdot \cos (\alpha)+\mathrm{m}_{\mathrm{O}} \cdot \cos (\alpha) \cdot \mathrm{A}_{1} \cdot \cos (\alpha)+\mathrm{m}_{\mathrm{o}} \cdot \mathrm{A}_{2} \cdot \cos (2 \cdot \alpha)+. .\right)
$$

\subsubsection{Obtenção dos Parâmetros do Sistema}

Através de programas de CAD e CAE pode-se obter rapidamente o valor de cada rigidez $\mathrm{Kt}_{\mathrm{i}}$ e inércia $\mathrm{I}_{\mathrm{i}}$. Outra fonte comum para estes valores são deduções analíticas ou empíricas contidas em referências clássicas como mostra B.I.C.E.R.A. ${ }^{11}$ e AVL ${ }^{9}$. Os chamados amortecimentos absolutos $\mathrm{Ca}_{\mathrm{i}}$, decorrentes do contato entre os anéis 
do pistão e os respectivos cilindros pode ser obtido da literatura ou da prática ${ }^{32}$ assim como os demais parâmetros.

Para o presente trabalho, as propriedades do modelo equivalente foram obtidas da referência ${ }^{32}$ que estuda o mesmo componente e de simulações numéricas baseadas em modelos tridimensionais do virabrequim escolhido para o estudo de caso como o descrito nas Figuras 25 e 26.
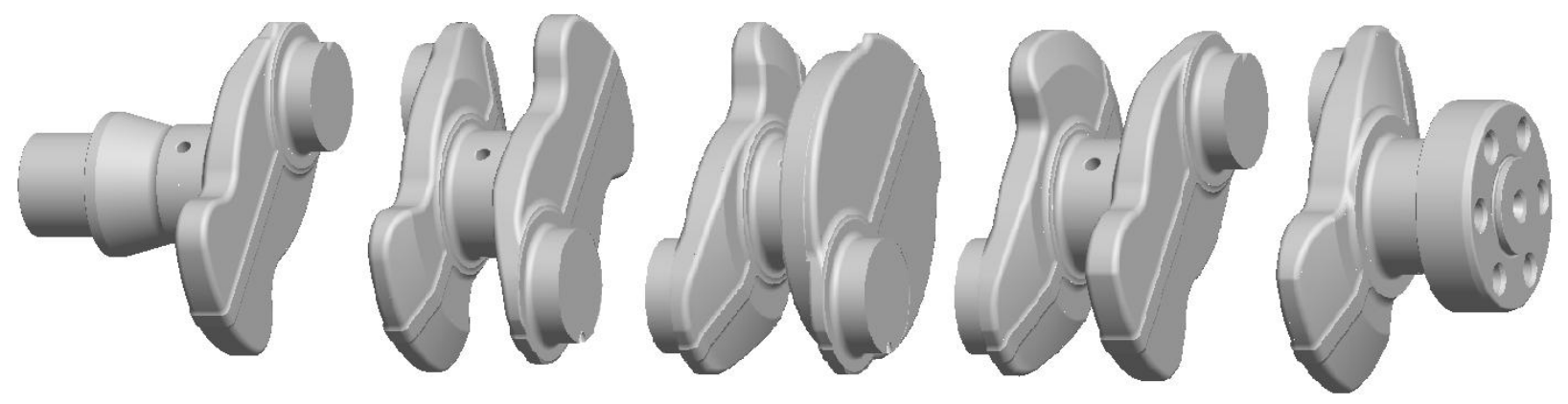

Figura 25: Modelos para cálculo de rigidez equivalente
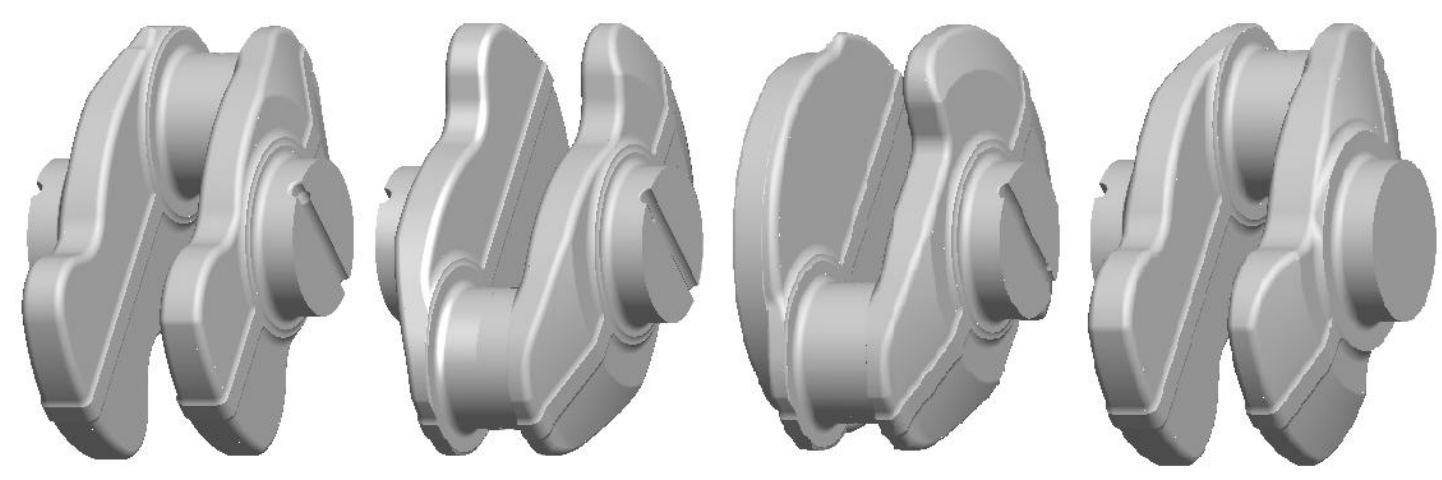

Figura 26: Modelos para cálculo das inércias equivalentes do virabrequim 


\subsection{Análise Modal}

No dimensionamento de árvores de manivela estamos também interessados em conhecer suas freqüências e modos naturais de vibrar para uma eventual maximização das freqüências através da alteração da rigidez e da inércia do componente.

$\mathrm{Na}$ análise modal, o problema que se propõe a resolver é o de vibração livre não amortecida, resumido pela equação abaixo.

$$
\mathrm{M} \cdot \frac{\mathrm{d}^{2}}{\mathrm{dt}^{2}} \mathrm{Q}+\mathrm{K} \cdot \mathrm{Q}=0
$$

Onde $\mathrm{M}$ representa a matriz de massa ou de inércia, $\mathrm{K}$ a matriz de rigidez e $\mathrm{Q}$ o vetor de deslocamentos.

Com as hipóteses de movimento síncrono e a condição de existência de solução não trivial chegamos ao problema clássico generalizado do autovalor:

$$
\operatorname{det}\left(\mathrm{K}-\mathrm{w}^{2} \cdot \mathrm{M}\right)=0 \Rightarrow\left(\mathrm{K}_{\mathrm{i}}-\lambda_{\mathrm{i}} \cdot \mathrm{M}_{\mathrm{i}}\right) \cdot \phi_{\mathrm{i}}=0
$$

Existem vários métodos numéricos aplicáveis na solução do problema proposto como os de iteração polinomial, iteração vetorial, métodos de transformação e métodos que se utilizam da propriedade de seqüência de Sturm ${ }^{36}$.

No presente trabalho, foi utilizada a função eig do software MATLAB ${ }^{\circledR}$ que utiliza o método de Jacobi-Davidson (QZ). Este algoritmo consiste em um método de transformação das matrizes para a solução do problema generalizado do autovalor. Nele, as duas matrizes são primeiramente triangularizadas para então ser aplicado o método de fatoração $Q R$ que diagonaliza a matriz dinâmica $\left(D=K^{-1} M\right)$. Os autovalores podem então ser calculados à partir dos elementos da diagonal da mesma.

Para a execução da análise modal foram criados programas no MATLAB ${ }^{\circledR}$ descritos no Apêndice $B$ para gerar as matrizes de rigidez e inércia do sistema equivalente de torção. Não foram feitos programas para sistemas equivalentes de flexão ou tração, pois, para o primeiro caso o foco no projeto de árvores de manivela está nos mancais conforme calculado no capítulo 3 e para o segundo caso, a magnitude do carregamento neste sentido tem ordem de grandeza desprezível se comparada à 
das outras direções.

\subsubsection{Análise modal em diferentes níveis (motor e conjunto de transmissão)}

Para análise de comportamento do conjunto motor quando acoplado ou não com componentes como os do eixo comando pelo lado da espiga ou os do conjunto de transmissão pelo lado do volante, foi feito um estudo baseado em dados disponíveis na literatura ${ }^{52}$, onde foram feitas análises modais em diferentes níveis de simplificação do sistema.

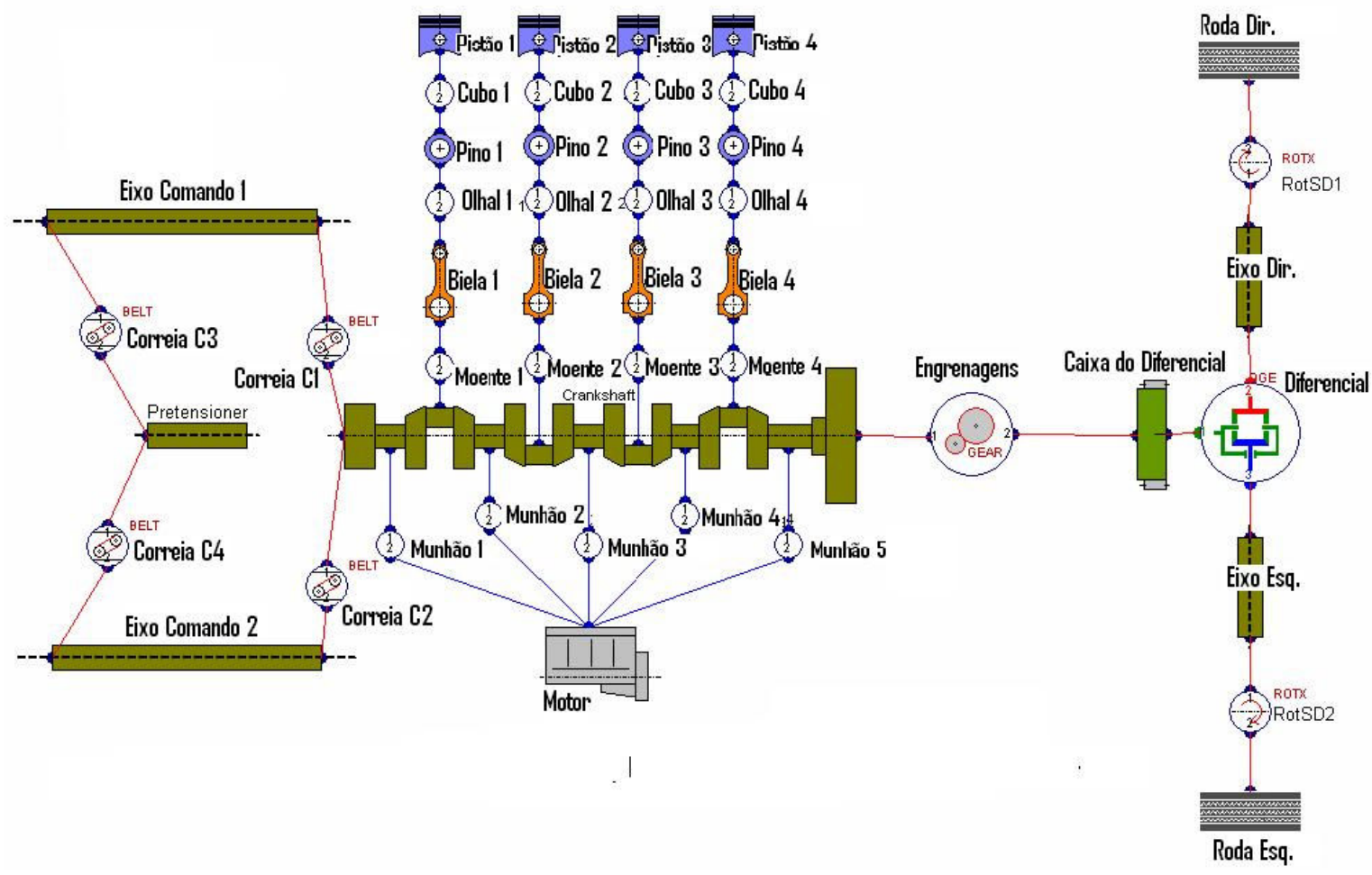

Figura 27: Modelo com eixo comando e componentes para tração dianteira no software AVL EXCITE ${ }^{\circledR}$

No software AVL EXCITE ${ }^{\circledR}$, a análise modal executada é semelhante à desenvolvida neste trabalho, com exceção à forma com a qual a árvore de manivelas é separada na análise da rigidez e inércia equivalente das seções. Neste software, munhões e moentes são separados dos braços, gerando mais graus de liberdade que o proposto neste trabalho. A maior precisão neste caso não altera de forma representativa os resultados para os primeiros modos de vibrar.

Os valores de inércia e rigidez utilizados neste exemplo encontram-se na Figura 28. 


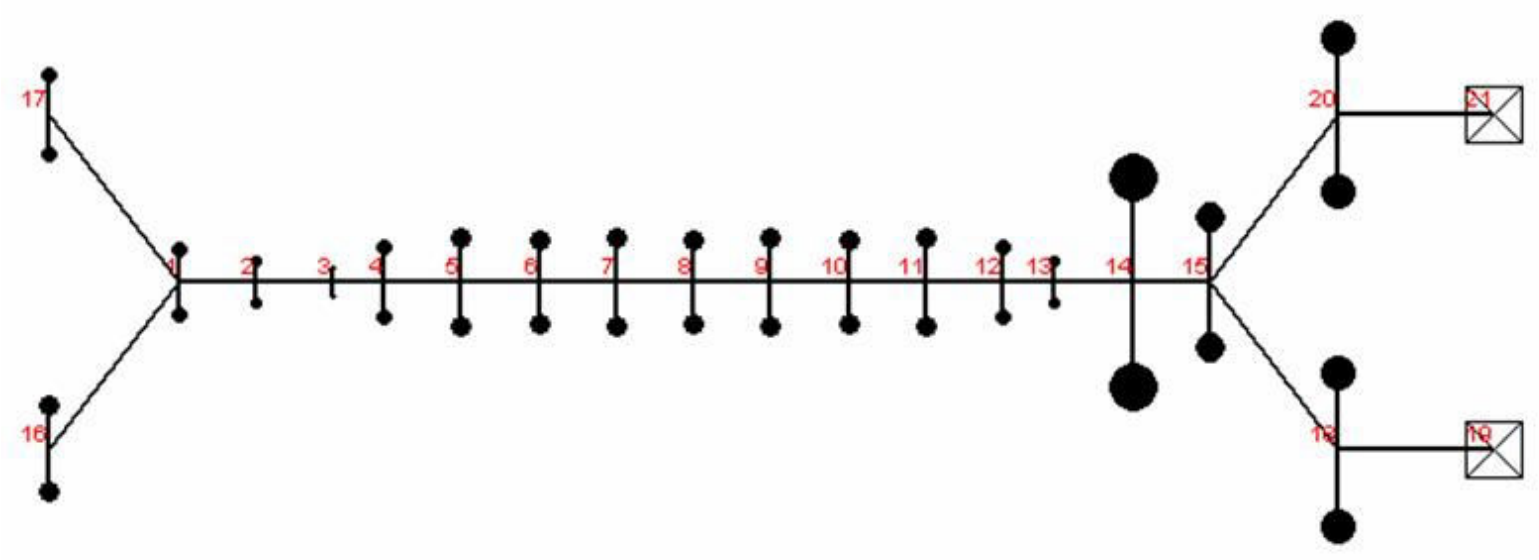

Inércia dos nós [kgm2]

\begin{tabular}{|c|c|c|}
\hline 1 & DampertHub & $1.059 \mathrm{e} \cdot 003$ \\
\hline 2 & Segment1-Segment2 & $1.313 \mathrm{e} \cdot 004$ \\
\hline 3 & Segment2-MainJoumal1 & $7.213 \mathrm{e} \cdot 005$ \\
\hline 4 & MainJournal1 & $1.687 \mathrm{e}-003$ \\
\hline 5 & CrankP in 1 & $5.123 \mathrm{e}-003$ \\
\hline 6 & MainJournal2 & $3.257 \mathrm{e} \cdot 003$ \\
\hline 7 & CrankP in 2 & $5.123 \mathrm{e}-003$ \\
\hline 8 & MainJournal3 & $3.257 \mathrm{e}-003$ \\
\hline 9 & CrankPin 3 & $5.123 \mathrm{e}-003$ \\
\hline 10 & MainJournal4 & $3.257 \mathrm{e}-003$ \\
\hline 11 & CrankPin 4 & $5.123 \mathrm{e} \cdot 003$ \\
\hline 12 & MainJourna15 & $1.687 \mathrm{e}-003$ \\
\hline 13 & MainJourna15.Segment3 & $1.409 \mathrm{e} \cdot 004$ \\
\hline 14 & Flymaheel & $1.592 \mathrm{e} \cdot 001$ \\
\hline 15 & DiftCattief & $2.000 \mathrm{e} \cdot 002$ \\
\hline 16 & DampetRing1 & $3.700 \mathrm{e} \cdot 003$ \\
\hline 17 & DampetRing2 & $2.200 \mathrm{e} \cdot 003$ \\
\hline 18 & RightAxle & $5.000 \mathrm{e} \cdot 002$ \\
\hline 19 & Rightwheel & $2.500 \mathrm{e}-001$ \\
\hline 20 & Leftaxle & $5.000 \mathrm{e} \cdot 002$ \\
\hline 21 & Leftwheel & $2.500 \mathrm{e} \cdot 001$ \\
\hline
\end{tabular}

\begin{tabular}{|c|c|c|}
\hline \multicolumn{3}{|c|}{ Rigidez dos elementos [Nm/rad] } \\
\hline 1.2 & & $1.337 \mathrm{e}+006$ \\
\hline $2 \cdot 3$ & Segment2 & $1.854 e+006$ \\
\hline 3.4 & Half_MainJournal1 & $4.142 \mathrm{e}+006$ \\
\hline 4. 5 & Web1 & $6.129 e+005$ \\
\hline 5.6 & Web2 & $6.129 e+005$ \\
\hline 6. 7 & Web3 & $6.129 e+005$ \\
\hline 7.8 & Web4 & $6.129 e+005$ \\
\hline 8. 9 & Web5 & $6.129 e+005$ \\
\hline $9 \cdot 10$ & Web6 & $6.129 \mathrm{e}+005$ \\
\hline $10 \cdot 11$ & Web7 & $6.129 e+005$ \\
\hline 11.12 & Web8 & $6.129 e+005$ \\
\hline $12 \cdot 13$ & Half_MainJournal5 & $4.142 \mathrm{e}+006$ \\
\hline 13.14 & Segment3 & $1.817 \mathrm{e}+006$ \\
\hline $14 \cdot 15$ & Gear1 & $1.325 e+006$ \\
\hline 1.16 & Damper1 & $2.000 e+004$ \\
\hline 1.17 & Damper2 & $3.000 \mathrm{e}+004$ \\
\hline $15 \cdot 18$ & DiffC arrier-RightAxle & $2.160 \mathrm{e}+004$ \\
\hline 18.19 & RotSD1 & $7.000 \mathrm{e}+002$ \\
\hline $15 \cdot 20$ & DiffC arrier-LeftAxle & $2.160 \mathrm{e}+004$ \\
\hline $20 \cdot 21$ & RotSD2 & $7.000 \mathrm{e}+002$ \\
\hline
\end{tabular}

Figura 28: Valores utilizados no exemplo com software AVL EXCITE ${ }^{\circledR}$

Além dos dados expostos acima, foram utilizadas como entradas para as engrenagens:

- Número de dentes na engrenagem do virabrequim: 40

- Número de dentes na engrenagem do diferencial: 80

- Amortecimento dos dentes: $20 \mathrm{~N}^{*} \mathrm{~s} / \mathrm{mm}$

- Ângulo do hélice: 10 graus

- Ângulo de pressão: 20 graus

Para a caixa do diferencial:

- Amortecimento absoluto: $1 \mathrm{~N}^{*} \mathrm{~mm}^{*} \mathrm{~s} / \mathrm{rad}$

Para as engrenagens do diferencial:

- Amortecimento tangencial: $300 \mathrm{~N}^{*} \mathrm{~s} / \mathrm{mm}$

Para os eixos de transmissão:

- Amortecimento absoluto: $2 \mathrm{~N}^{*} \mathrm{~mm} m^{*} \mathrm{~s} / \mathrm{rad}$ 
Para o amortecedor vinculando eixos de transmissão e rodas:

- Coeficiente de amortecimento proporcional: 1.9

Finalmente, para as rodas:

- Amortecimento absoluto: $10 \mathrm{~N}^{*} \mathrm{~mm}^{*} \mathrm{~s} / \mathrm{rad}$

Como condição de contorno, foi imposta como constante a velocidade angular das rodas.

Os dados do conjunto Virabrequim-Biela-Pistão são:

- Número de cilindros: 4

- Diâmetro do pistão: $75 \mathrm{~mm}$

- Curso: $84,5 \mathrm{~mm}$

- Distância entre centros da biela: $131 \mathrm{~mm}$

- Tipo de motor: quatro tempos

- Massa do conjunto do pistão e pino: $0,45 \mathrm{~kg}$

- Massa oscilante da biela: $0,165 \mathrm{~kg}$

- Massa rotativa da biela: $0,477 \mathrm{~kg}$

- Amortecimento absoluto do conjunto do amortecedor: $0 \mathrm{~N}^{*} \mathrm{~mm}^{*} \mathrm{~s} / \mathrm{rad}$

As curvas de gás para este estudo estão descritas na Figura 29. 


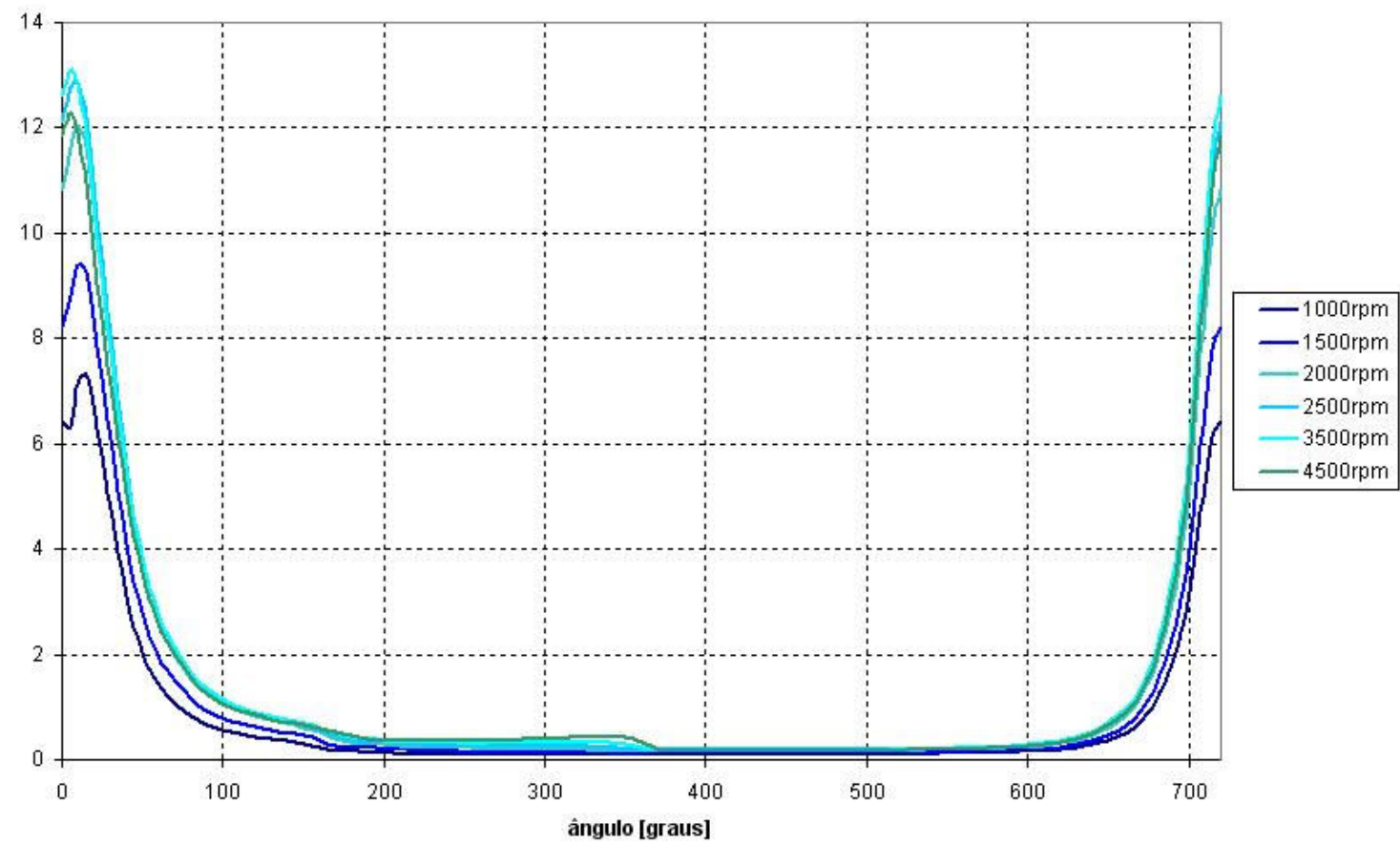

Figura 29: Curvas de pressão do gás para o exemplo com software AVL EXCITE ${ }^{\circledR}$

Para os dados e modelos ilustrados, foram feitas três análises modais: a primeira considerando somente os componentes como o ilustrado na seção 5.1.1, do amortecedor ao volante, a segunda com o sistema do amortecedor às rodas e a terceira, adicionando o conjunto do eixo comando.

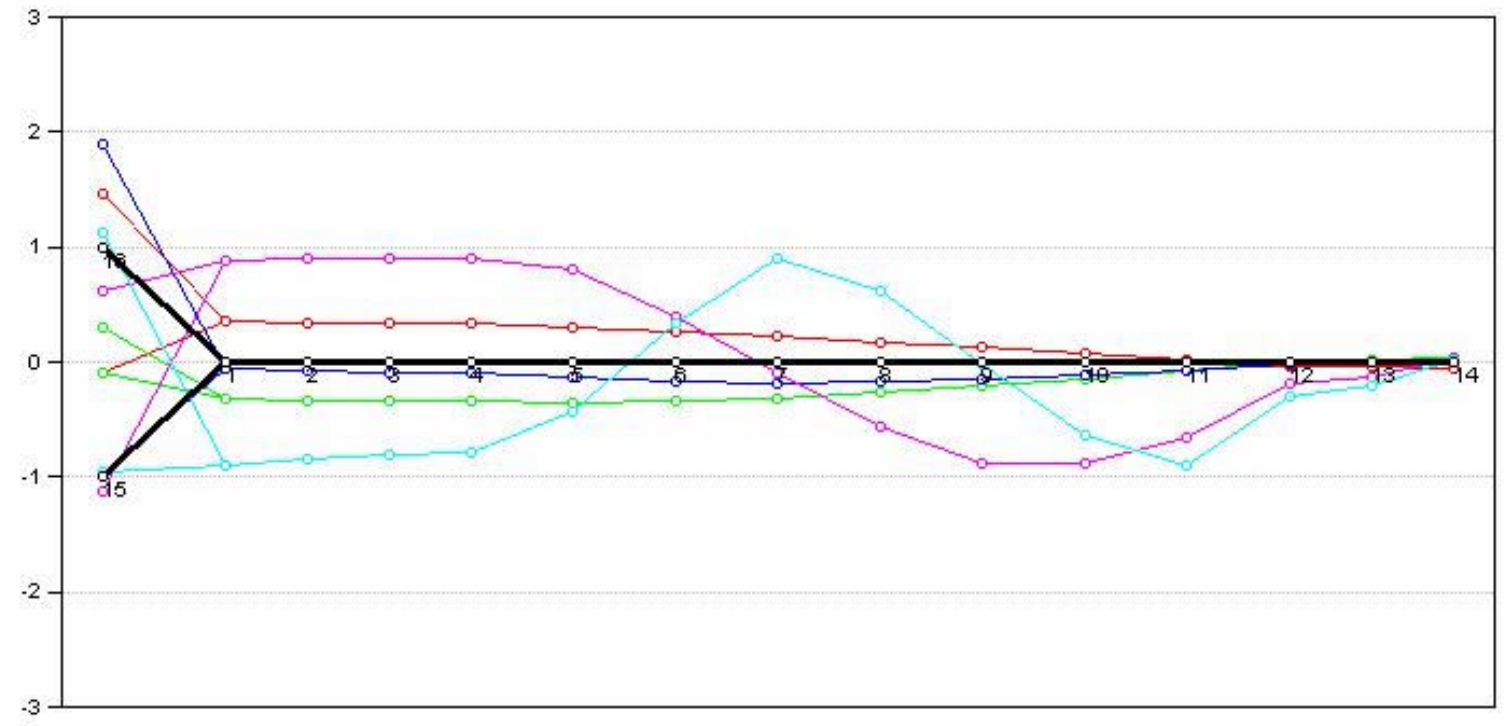

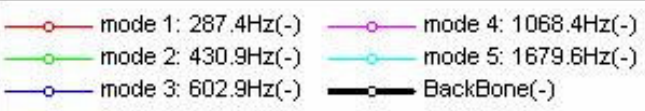

Figura 30: Modos de vibrar conjunto motor (amortecedor ao volante) 

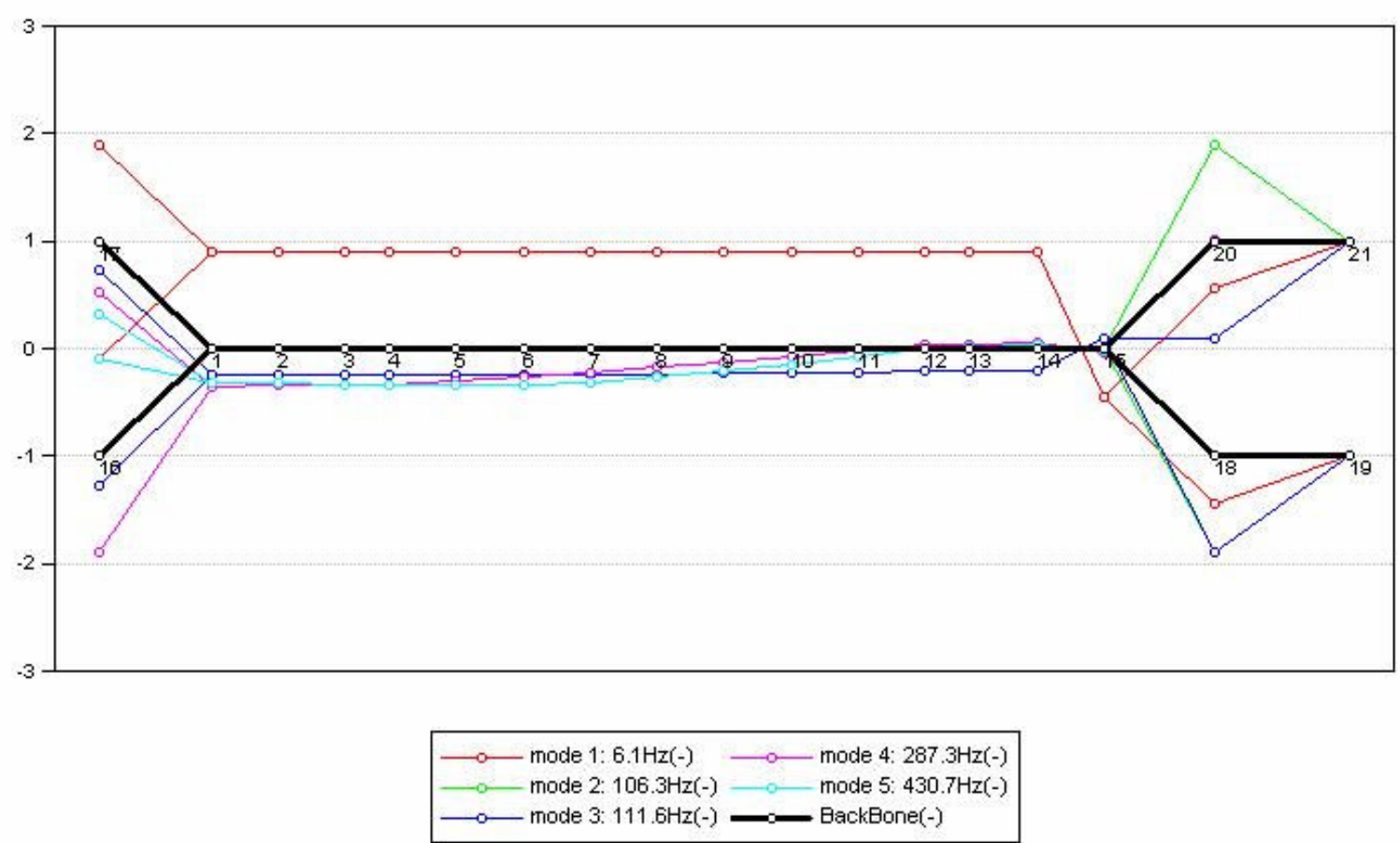

Figura 31: Modos de vibrar conjunto amortecedor às rodas

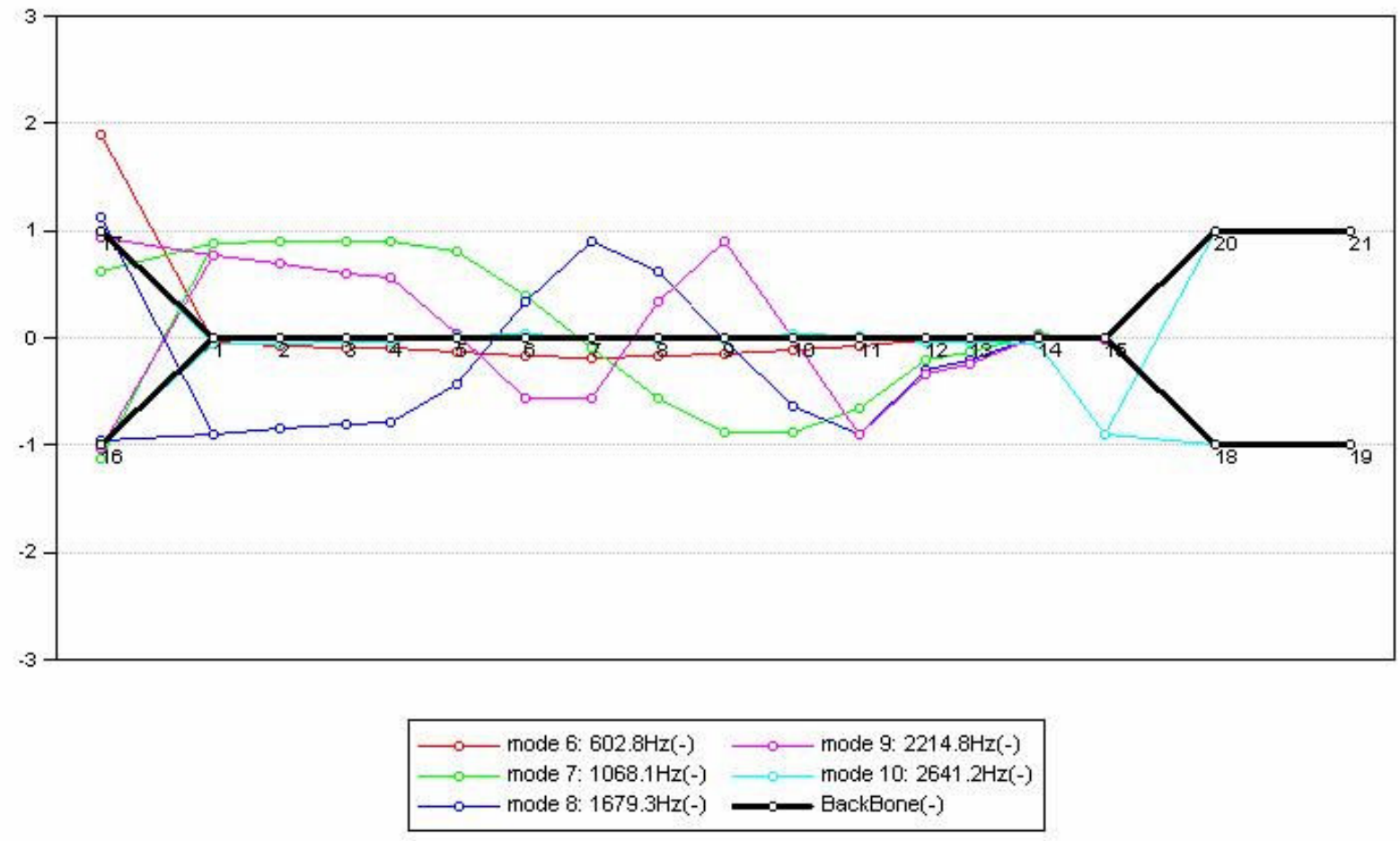

Figura 32: Modos de vibrar conjunto amortecedor às rodas (cont.) 


\begin{tabular}{cc}
\hline $\begin{array}{c}\text { Modo } \\
{[-]}\end{array}$ & $\begin{array}{c}\text { Freqüência } \\
{[\mathrm{Hz}]}\end{array}$ \\
\hline 1 & 6,1 \\
2 & 106,3 \\
3 & 111,6 \\
4 & 281,2 \\
5 & 420,4 \\
6 & 550,6 \\
7 & 604,4 \\
8 & 948,5 \\
9 & 1077,3 \\
\hline
\end{tabular}

Tabela 4: Freqüências naturais do conjunto eixo comando às rodas

Como pode-se observar nas Figuras 30, 31 e 32, os modos e freqüências naturais pouco se alteraram com a adição dos sistemas periféricos principalmente devido à diferença de ordens de grandeza de inércia e rigidez de cada um dos três conjuntos aqui considerados, o de correias e eixo comando de válvulas, o do motor com amortecedor, engrenagens, virabrequim, biela, pistão e volante, e o terceiro conjunto, do volante às rodas.

A obtenção dos parâmetros necessários para a análise do sistema completo, constituído por todos os componentes pertencentes ao sistema, do eixo comando às rodas do veículo normalmente não é simples. Muitas montadoras de veículo utilizam motores desenvolvidos por outras empresas que por sua vez terceirizam o projeto e fabricação de outros componentes. Mesmo para as que desenvolvem o sistema completo, ou para as outras com a tecnologia existente atualmente que permite uma engenharia simultânea com grande troca de informações entre empresas e instituições, na maior parte das vezes é utilizado o modelo da Figura 23 quando o foco está em árvores de manivela.

Além da referência de onde foram obtidos os valores acima ${ }^{52}$ autores como CROWTHER e ZHANG ${ }^{53}$ mostram exemplos de como modelar os componentes do powertrain com não linearidades das conexões de engrenagens e estuturas ramificadas. 


\subsection{Análise da Resposta Dinâmica}

$\mathrm{Na}$ análise da resposta dinâmica, buscamos a solução da equação de equilíbrio na sua forma completa:

$$
M \cdot \frac{\mathrm{d}^{2}}{\mathrm{dt}^{2}} \mathrm{Q}+\mathrm{C} \cdot \frac{\mathrm{d}}{\mathrm{dt}} \mathrm{Q}+\mathrm{K} \cdot \mathrm{Q}=\mathrm{P}
$$

Sendo C a matriz de amortecimento do sistema e $\mathrm{P}$ o vetor de carregamentos externos aplicados ao mesmo.

Este tipo de análise é extremamente útil no desenvolvimento de componentes, quando necessitamos da resposta em freqüência do mesmo ou do comportamento dinâmico do componente quando solicitado por um esforço em função do tempo.

No primeiro caso, buscamos a resposta em regime permanente do sistema dada uma excitação harmônica. Uma vantagem desta abordagem é que os ensaios de resposta em freqüência são normalmente simples e podem ser feitos com velocidade e precisão pelo uso de geradores de sinais senoidais e equipamentos de medição precisos ${ }^{37}$.

Matematicamente, o sistema de equações diferenciais de segunda ordem acima pode ser resolvido por procedimentos clássicos no caso de coeficientes constantes, o que, entretanto, traz um custo computacional elevado ${ }^{36}$. Métodos numéricos mais efetivos, que se utilizam da análise de elementos finitos são normalmente empregados na prática. Existem basicamente dois modos possíveis de solução da equação acima: Integração Direta e Superposição Modal.

Os algoritmos classificados como de integração direta tratam da resolução da equação de equilíbrio sem transformações preliminares. Essencialmente, eles são baseados em duas idéias. A primeira seria a solução da equação completa em intervalos discretos, ao invés de buscar a solução em qualquer tempo t. A segunda idéia é a de existência de uma variação de deslocamentos, velocidades e acelerações dentro de cada intervalo $\Delta t^{36}$. Este intervalo determina o custo e a estabilidade do método numérico utilizado.

Os métodos que utilizam-se da Superposição Modal, podem ser aplicados a qualquer caso de excitação, tendo como resultados a resposta no regime transitório e a resposta em regime permanente. Eles se utilizam da hipótese de Ritz que trata a 
resposta total do sistema como uma somatória dos modos naturais multiplicados por suas respostas normais, baseado na propriedade de ortogonalidade dos modos. Assim, necessita-se primeiramente executar uma análise modal para a obtenção dos modos naturais para então diagonalizar as matrizes de massa, amortecimento e rigidez obtendo componentes generalizadas para as mesmas e para o carregamento. Finalmente, obtemos a resposta do sistema através da solução de $n$ sistemas de um grau de liberdade, que temos grande conhecimento, ao invés de um sistema único de $\mathrm{n}$ graus de liberdade.

No presente trabalho foram utilizados dois métodos de integração direta passo a passo, o Método Implícito de Aceleração Constante e o Método Implícito de Aceleração Linear, cujos programas em MATLAB ${ }^{\circledR}$ se encontram no Apêndice $B$.

O Método Implícito de Aceleração Constante é basicamente uma variação do método de Newmark enquanto que o de Aceleração Linear consiste do Método de Wilson- $\theta$. Os dois métodos citados são mais bem detalhados adiante.

\subsubsection{Método de Wilson- $\theta$}

A hipótese básica do método de Wilson- $\theta$ é que a aceleração varia linearmente dentro do intervalo de $\mathrm{t} a \mathrm{t}+\theta \Delta \mathrm{t}$, onde $\theta \geq 1$ e tem finalidade de determinar as características de estabilidade e precisão ótimas. Pode-se mostrar que para estabilidade incondicional é necessário utilizar $\theta \geq 1.366^{42}$.

Chamemos de $\tau$ o incremento no tempo, onde $\theta \Delta t \geq \tau \geq 0$. Temos então para 0 intervalo de tempo $\mathrm{t}$ a $\mathrm{t}+\theta \Delta \mathrm{t}^{36}$ :

$$
\begin{aligned}
& \left(\frac{\mathrm{d}^{2}}{\mathrm{dt}^{2}} \mathrm{Q}\right)_{\mathrm{t}+\tau}=\left(\frac{\mathrm{d}^{2}}{\mathrm{dt}^{2}} \mathrm{Q}\right)_{\mathrm{t}}+\left[\left(\frac{\mathrm{d}^{2}}{\mathrm{dt}^{2}} \mathrm{Q}\right)_{\mathrm{t}+\Delta \mathrm{t}}-\left(\frac{\mathrm{d}^{2}}{\mathrm{dt}^{2}} \mathrm{Q}\right)_{\mathrm{t}}\right] \cdot \frac{\tau}{\Delta \mathrm{t}} \\
& \left(\frac{\mathrm{d}}{\mathrm{dt}} \mathrm{Q}\right)_{\mathrm{t}+\tau}=\left(\frac{\mathrm{d}}{\mathrm{dt}} \mathrm{Q}\right)_{\mathrm{t}}+\left(\frac{\mathrm{d}^{2}}{\mathrm{dt}^{2}} \mathrm{Q}\right)_{\mathrm{t}} \cdot \tau+\left[\left(\frac{\mathrm{d}^{2}}{\mathrm{dt}^{2}} \mathrm{Q}\right)_{\mathrm{t}+\Delta \mathrm{t}}-\left(\frac{\mathrm{d}^{2}}{\mathrm{dt}^{2}} \mathrm{Q}\right)_{\mathrm{t}}\right] \cdot \frac{\tau^{2}}{2 \cdot \Delta \mathrm{t}} \\
& \mathrm{Q}_{\mathrm{t}+\tau}=\mathrm{Q}_{\mathrm{t}}+\left(\frac{\mathrm{d}}{\mathrm{dt}} \mathrm{Q}\right)_{\mathrm{t}} \cdot \tau+\frac{1}{2} \cdot\left(\frac{\mathrm{d}^{2}}{\mathrm{dt}^{2}} \mathrm{Q}\right)_{\mathrm{t}} \cdot \tau^{2}+\left[\left(\frac{\mathrm{d}^{2}}{\mathrm{dt}^{2}} \mathrm{Q}\right)_{\mathrm{t}+\Delta \mathrm{t}}-\left(\frac{\mathrm{d}^{2}}{\mathrm{dt}^{2}} \mathrm{Q}\right)\right] \cdot \frac{\tau^{3}}{6 \cdot \Delta \mathrm{t}}
\end{aligned}
$$


Em $\mathrm{t}+\Delta \mathrm{t}$, temos:

$$
\begin{aligned}
& \left(\frac{\mathrm{d}}{\mathrm{dt}} \mathrm{Q}\right)_{\mathrm{t}+\Delta \mathrm{t}}=\left(\frac{\mathrm{d}}{\mathrm{dt}} \mathrm{Q}\right)_{\mathrm{t}}+\left[\left(\frac{\mathrm{d}^{2}}{\mathrm{dt}^{2}} \mathrm{Q}\right)_{\mathrm{t}+\Delta \mathrm{t}}+\left(\frac{\mathrm{d}^{2}}{\mathrm{dt}^{2}} \mathrm{Q}\right)_{\mathrm{t}}\right]_{\mathrm{t}} \\
& \mathrm{Q}_{\mathrm{t}+\Delta \mathrm{t}}=\mathrm{Q}_{\mathrm{t}}+\left(\frac{\mathrm{d}}{\mathrm{dt}} \mathrm{Q}\right)_{\mathrm{t}} \cdot \Delta \mathrm{t}+\left[2 \cdot\left(\frac{\mathrm{d}^{2}}{\mathrm{dt}^{2}} \mathrm{Q}\right)_{\mathrm{t}}+\left(\frac{\mathrm{d}^{2}}{\mathrm{dt}^{2}} \mathrm{Q}\right)_{\mathrm{t}+\Delta \mathrm{t}}\right] \cdot \frac{\Delta \mathrm{t}^{2}}{6}
\end{aligned}
$$

O equilíbrio é considerado no tempo $t+\theta \Delta t$ que resulta em:

$$
M\left(\frac{d^{2}}{d^{2}} Q\right)_{t+\theta \cdot \Delta t}+C \cdot\left(\frac{d}{d t} Q\right)_{t+\theta \cdot \Delta t}+K \cdot Q_{t+\theta \cdot \Delta t}=P_{t+\theta \cdot \Delta t}
$$

Reescrevendo as três primeiras equações em $\tau=\theta \Delta$ t para substituir na equação de equilíbrio obtemos uma equação com somente a aceleração em $\mathrm{t}+\Delta \mathrm{t}$ como incógnita. Resolvendo a equação de equilíbrio para a aceleração e substituindo nas equações 7.1 e 7.2 temos:

$$
\left[\begin{array}{c}
\left(\frac{\mathrm{d}^{2}}{\mathrm{dt}^{2}}\right)_{\mathrm{t}+\Delta \mathrm{t}} \\
\left(\frac{\mathrm{d}}{\mathrm{dt}} \mathrm{Q}\right)_{\mathrm{t}+\Delta \mathrm{t}} \\
\mathrm{Q}_{\mathrm{t}+\Delta \mathrm{t}}
\end{array}\right]=\mathrm{Aw} \cdot\left[\begin{array}{c}
\left(\frac{\mathrm{d}^{2}}{\mathrm{dt}^{2}} \mathrm{Q}\right)_{\mathrm{t}} \\
\left(\frac{\mathrm{d}}{\mathrm{dt}} \mathrm{Q}\right)_{\mathrm{t}} \\
\mathrm{Q}_{\mathrm{t}}
\end{array}\right]+\mathrm{Lw} \cdot \mathrm{P}_{\mathrm{t}+\theta \cdot \Delta \mathrm{t}}
$$

Onde Aw e Lw são matrizes em função de $\theta$, w e $\Delta t^{36}$. 


\subsubsection{Método de Newmark}

No esquema de integração de Newmark a equação de equilíbrio é considerada em $\mathrm{t}+\Delta \mathrm{t}:$

$$
M\left(\frac{d^{2}}{{d t^{2}}^{2}} Q\right)_{t+\Delta t}+C \cdot\left(\frac{d}{d t} Q\right)_{t+\Delta t}+K \cdot Q_{t+\Delta t}=P_{t+\Delta t}
$$

O deslocamento e a velocidade são escritos na forma:

$$
\begin{aligned}
& \left(\frac{\mathrm{d}}{\mathrm{dt}} \mathrm{Q}\right)_{\mathrm{t}+\Delta \mathrm{t}}=\left(\frac{\mathrm{d}}{\mathrm{dt}} \mathrm{Q}\right)_{\mathrm{t}}+\left[\delta_{\mathrm{n}}\left(\frac{\mathrm{d}^{2}}{\mathrm{dt}^{2}} \mathrm{Q}\right)_{\mathrm{t}+\Delta \mathrm{t}}+\left(1-\delta_{\mathrm{n}}\right) \cdot\left(\frac{\mathrm{d}^{2}}{\mathrm{dt}^{2}} \mathrm{Q}\right)_{\mathrm{t}}\right] \cdot \Delta \mathrm{t} \\
& \mathrm{Q}_{\mathrm{t}+\Delta \mathrm{t}}=\mathrm{Q}_{\mathrm{t}}+\left(\frac{\mathrm{d}}{\mathrm{dt}} \mathrm{Q}\right)_{\mathrm{t}} \cdot \Delta \mathrm{t}+\left[\alpha_{\mathrm{n}} \cdot\left(\frac{\mathrm{d}^{2}}{\mathrm{dt}^{2}} \mathrm{Q}\right)_{\mathrm{t}}+\left(\frac{1}{2}-\alpha_{\mathrm{n}}\right) \cdot\left(\frac{\mathrm{d}^{2}}{\mathrm{dt}^{2}}\right)_{\mathrm{t}+\Delta \mathrm{t}}\right] \cdot \Delta \mathrm{t}^{2}
\end{aligned}
$$

Onde $\delta_{n}$ e $\alpha_{n}$ são parâmetros escolhidos para obter estabilidade e precisão. Newmark propõe estabilidade incondicional com a escolha destes parâmetros em: $\delta_{n}$ $=1 / 2$ e $\alpha_{n}=1 / 4$, no que resulta o método de aceleração constante.

O método de Newmark pode ter seus parâmetros escolhidos de modo que a aceleração seja linear e, portanto, as mesmas aproximações para os operadores de carregamento são obtidas para os dois métodos citados. 


\section{Análise Estrutural}

Como ilustrado no capítulo 2, durante o projeto preliminar do componente, utiliza-se normalmente o método dos elementos finitos para uma análise estrutural, onde são calculadas as deformações e tensões distribuídas, para a então obtenção dos fatores de segurança de falha por fadiga.

O modelo matemático a ser analisado para esta situação corresponde ao ilustrado abaixo.

$\mathrm{K} \cdot \mathrm{Q}=\mathrm{P}$

As condições de contorno dependerão do tipo de análise que se deseja executar. Pode-se buscar acelerar ensaios experimentais através da simulação numérica repetindo assim as condições de contorno do ensaio no software de análise, simular o carregamento e restrições do componente em operação ou mesmo executar um estudo de rigidez e inércias para as análises de vibração, balanceamento e dinâmica citadas nos capítulos anteriores.

Tanto na definição do modelo tridimensional, completo ou somente uma manivela, a ser utilizado quando se pretende simular o carregamento e restrições do componente em operação, quanto na definição de quais velocidades serão analisadas, observa-se que existem diversas abordagens válidas e comumente executadas. Alguns autores utilizam o modelo completo da árvore de manivelas ${ }^{32,59}$ aplicando um carregamento equivalente em todos os moentes. Outros, para adicionar o efeito da rigidez do bloco utilizam-se de métodos de subestruturação $0^{5,7}$, simplificando sistema pra então adicionar esta condição mais complexa. Há ainda a possibilidade de análise dos fatores de concentração de tensão nas manivelas através de tabelas empíricas ${ }^{11}$ e então utilização, num modelo simplificado equivalente, para diminuir assim o custo computacional ${ }^{9,59}$. Fatores como condições de contato, distribuição da pressão hidrodinâmica e rigidez dos componentes do motor podem introduzir uma complexidade ainda maior na análise. Neste trabalho foi utilizada uma abordagem visando otimizar o custo computacional onde cada manivela é analisada separadamente. Pode-se ajustar este modelo para a obtenção de resultados mais realistas através da comparação com resultados empíricos e adequação das condições de contorno. Esta abordagem pode, portanto, trazer resultados semelhantes aos dos modelos mais complexos com um custo reduzido 
como observado por Piraner et al. ${ }^{62}$, onde foram comparadas as abordagens acima. Neste trabalho, os autores definem numa relação de custo e benefício a possibilidade de análise de somente uma manivela, desprezando a rigidez do bloco e outros componentes e obtendo resultados próximos aos de análises mais completas.

Para o dimensionamento de virabrequins, devemos executar no mínimo duas análises simulando as condições mais críticas de funcionamento: quando a força de gás é máxima (Figura 33), e quando a força tangencial é máxima (Figura 34), o que gera a condição de máximas tensões de cisalhamento. Neste caso, pode-se executar as duas análises de forma separada calculando posteriormente 0 coeficiente de segurança para o carregamento combinado ${ }^{34}$.

Pode-se por outro lado aplicar o carregamento combinado numa mesma análise estrutural obtendo o tensor de tensões para os pontos mais críticos.

Assim, para a análise do componente pelo primeiro método, são necessárias pelo menos oito simulações: máxima força $F_{p}$ e mínima força $F_{p}$ na rotação em que a força de gás é máxima e para as mesmas configurações de $F_{p}$ quando a força de inércia é máxima, com estas quatro condições sendo analisadas para as duas condições de contorno mencionadas, flexão e torção.

Já no segundo método, são necessárias quatro simulações, para os casos de máxima e mínima força $F_{p}$ nas rotações de máxima força do gás e máxima força de inércia. Conforme mostrado na Tabela 5.

\begin{tabular}{ccc}
\hline Caso & Fp & Condiçäo \\
\hline 1 & Maxima & Maxima força do gás \\
2 & Mínima & Maxima força do gás \\
3 & Maxima & Maxima força de inércia \\
4 & Minima & Máma força de inércia \\
\hline
\end{tabular}

Tabela 5: Combinações de carregamento utilizadas na análise estrutural Em árvores de manivelas usualmente utilizam-se as condições de máxima potência, máxima rotação e máximo torque como condições críticas a serem abordadas numa análise estrutural $^{32,59}$. Certamente, não há como de antemão definir qual é a condição mais crítica de operação antes de um estudo mais aprofundado que deve inclusive considerar outras condições de operação. 


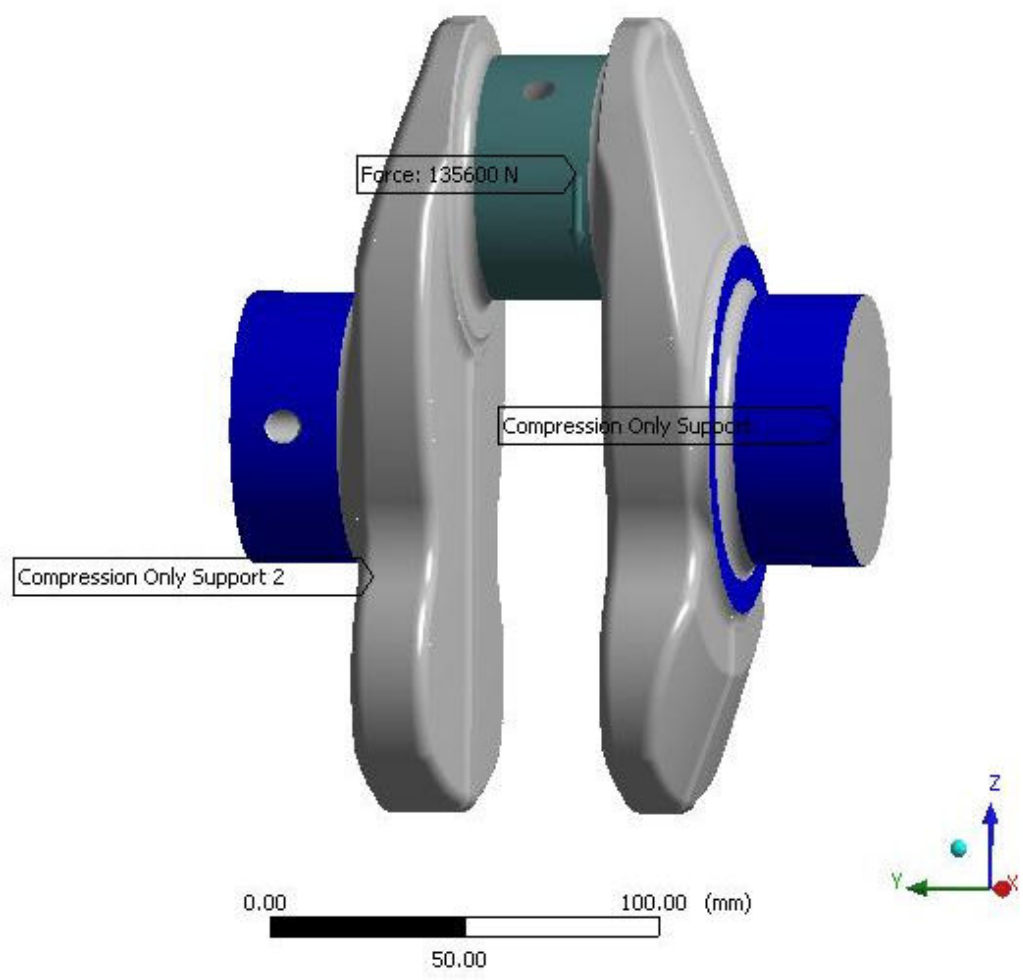

Figura 33: Condições de contorno para análise estrutural - máxima flexão

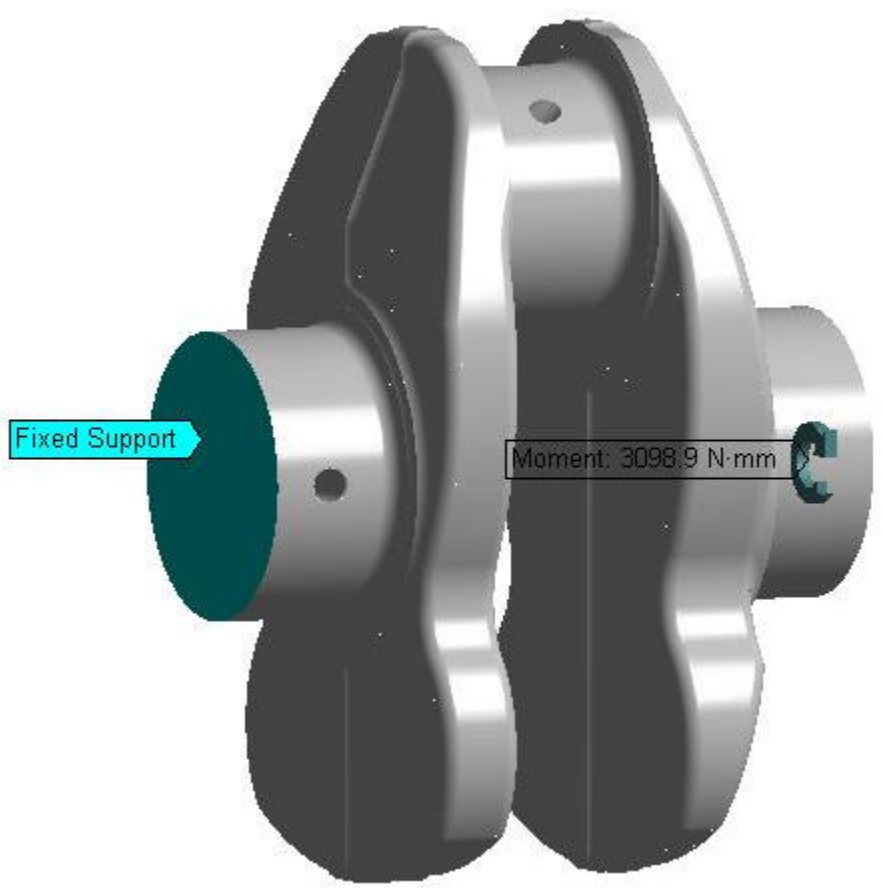

Figura 34: Condições de contorno para análise estrutural - máxima torção

As simulações citadas se fazem necessárias pela necessidade de cálculo dos esforços alternados no componente para análise de falha por fadiga, a ser mais bem explicada na sessão seguinte. 


\subsection{Cálculo dos Coeficientes de Segurança}

Após a geração do modelo numérico equivalente e a obtenção da distribuição das tensões principais, é executado o cálculo dos coeficientes de segurança de falha por fadiga, dada a natureza variável do carregamento atuante em árvores de manivelas. Ainda hoje, a mais usual teoria existente para explicar a natureza da falha por fadiga consiste na chamada Strain-life Theory, que pode ser utilizada para estimar a resistência de componentes tendo todavia a adição de algumas incertezas aos resultados devido às idealizações inerentes à mesma ${ }^{34}$. Estudos experimentais mostram a dificuldade de prevenção com precisão de falhas geradas por fadiga, principalmente quando defeitos metalúrgicos locais e de acabamento superficial existem ${ }^{35}$.

Usualmente utilizam-se métodos de análise de tensões em diagramas específicos para o cálculo dos coeficientes de segurança. Neste trabalho será ilustrado superficialmente o diagrama de Goodman modificado, escolhido para o posterior estudo de caso. O diagrama citado tem a tensão média no ponto estudado mostrada no eixo das abscissas e todos os outros componentes ilustrados no eixo das ordenadas. A resistência à ruptura $\left(S_{u}\right)$ e a tensão limite de fadiga $\left(S_{e}\right)$ são mostrados acima e abaixo da origem conforme a Figura 35.

Para o cálculo da tensão limite de fadiga $\left(S_{\mathrm{e}}\right)$ ainda hoje se utilizam com freqüência ensaios experimentais com corpos de prova e fatores modificadores visando a adaptação da situação experimental para a real ${ }^{34,56}$.

$$
S_{e}=k_{a} \cdot k_{b} \cdot k_{c} \cdot k_{d} \cdot k_{e} \cdot S_{u t}
$$

Onde $k_{a}$ representa o fator de superfície dado por:

$$
\mathrm{k}_{\mathrm{a}}=\mathrm{a} \cdot\left(\mathrm{S}_{\mathrm{ut}}\right)^{\mathrm{b}}
$$

Com a e $b$ tabelados para diferentes acabamentos superficiais ${ }^{34}$.

O fator $\mathrm{k}_{\mathrm{b}}$ correspode ao fator de tamanho, dado por:

$$
\mathrm{k}_{\mathrm{b}}=\left(\frac{\mathrm{d}}{7,62}\right)^{-0,1133}
$$

Para diâmetros d entre $2,79 \mathrm{~mm}$ e $51 \mathrm{~mm}$. No caso de diâmetros maiores, utilizam-se valores entre 0,6 e 0,75.

O fator de carga $k_{c}$, possui valores: 0,923 para carregamento axial e tensões de 
ruptura menores que 1520 MPa e 1 para tensões limite de ruptura maiores, 1 para flexão e 0,577 para torção e cisalhamento.

$\mathrm{O}$ fator de temperatura $\mathrm{k}_{\mathrm{c}}$ é tabelado em referência específica e tende a traduzir efeitos na resistência do material quando o mesmo encontra-se fora da temperatura ambiente.

Finalmente, o fator $k_{e}$ corresponde a efeitos miscelâneos desde corrosão, tratamentos com deposição de materiais, concentração de tensões e outros.

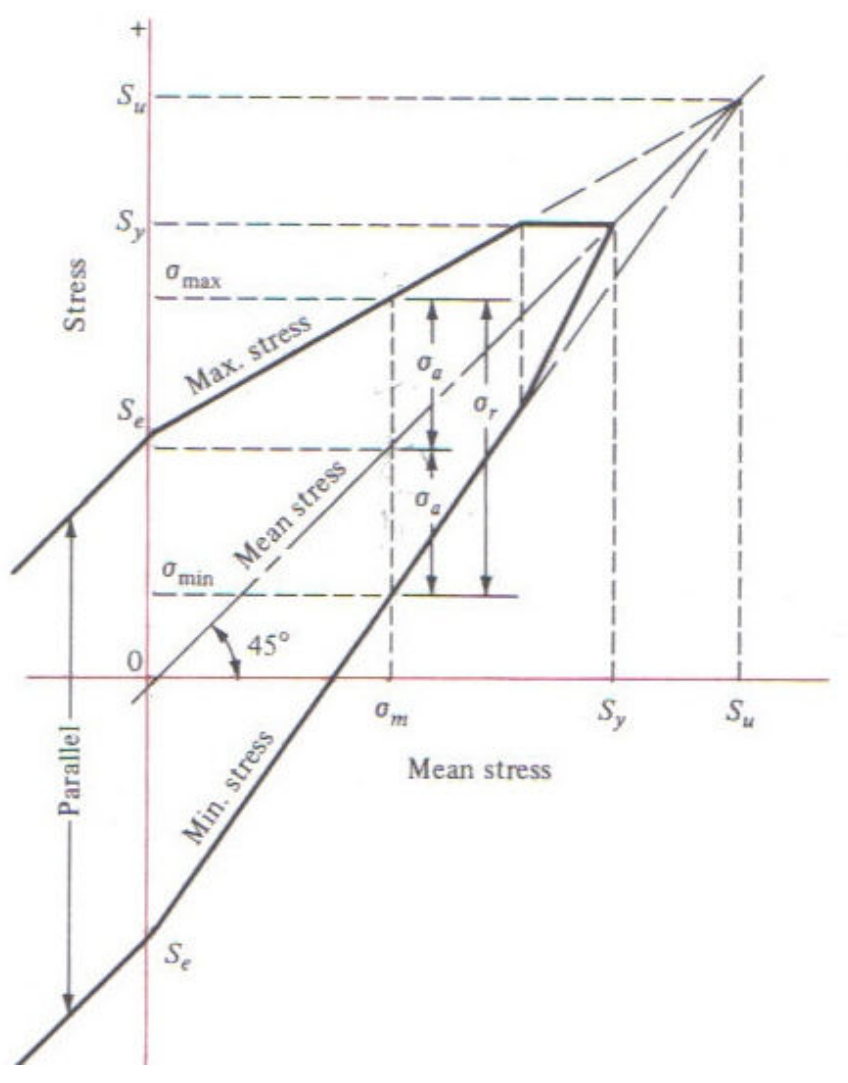

Figura 35: Diagrama de Goodman modificado

O coeficiente de segurança nada mais é que a divisão da tensão alternada limite ilustrada $\left(\sigma_{a}\right)$ pela tensão alternada efetiva no mesmo ponto.

As tensões média e alternada para cada caso analisado no início do capítulo foram calculadas segundo o sugerido na literatura ${ }^{34,55}$ com a utilização do tensor de tensões resultante no mesmo ponto crítico nas situações de Fp mínima e Fp máxima do componente num ciclo completo em mesma rotação, seguindo para todos os componentes do tensor a regra básica: 


$$
\begin{aligned}
\sigma_{\mathrm{ija}} & =\frac{\sigma_{i j_{\text {máx }}}-\sigma_{i j_{\text {mín }}}}{2} \\
\sigma_{i j_{\mathrm{m}}} & =\frac{\sigma_{i j_{\text {máx }}}+\sigma_{i j_{\text {mín }}}}{2}
\end{aligned}
$$

Onde $\sigma_{\mathrm{ija}}$ e $\sigma_{\mathrm{ijm}}$ são, respectivamente, a componente de tensão $\mathrm{ij}(\mathrm{i}, \mathrm{j}=1,2,3)$ alternada e a componente média do tensor de tensões no ponto crítico.

Para os dois tensores, alternado e médio, pode-se calcular as duas tensões (alternada e média) equivalentes de Von Mises a serem utilizadas no cálculo do coeficiente segurança ${ }^{34,55}$.

Equação da tensão equivalente de Von Mises:

$$
\sigma_{\mathrm{vM}}=\sqrt{\frac{\left(\sigma_{\mathrm{xx}}-\sigma_{\mathrm{yy}}\right)^{2}+\left(\sigma_{\mathrm{yy}}-\sigma_{\mathrm{zz}}\right)^{2}+\left(\sigma_{\mathrm{zz}}-\sigma_{\mathrm{xx}}\right)^{2}+6 \cdot\left(\sigma_{\mathrm{xy}}\right)^{2}+6 \cdot\left(\sigma_{\mathrm{yz}}\right)^{2}+6 \cdot\left(\sigma_{\mathrm{xz}}\right)^{2}}{2}}
$$




\section{Otimização}

A otimização consiste na realização de uma busca sistemática de uma solução ótima dentre várias configurações possíveis através de um algoritmo numérico. Uma das áreas da engenharia em que a otimização tem sido intensivamente estudada desde o século XIX é a área de otimização estrutural. O objetivo comum é normalmente a redução do peso da estrutura mantendo o seu desempenho (rigidez, freqüência de ressonância, etc... $)^{33}$.

Em um problema de otimização genérico, existem algumas nomenclaturas normalmente utilizadas para a sua formulação ${ }^{33}$. Assim, os parâmetros que devemos atuar no problema são as chamadas variáveis de projeto, que podem ser classificadas nas categorias auto explicativas de contínuas ou discretas sendo as primeiras ainda classificadas em de parâmetro distribuído ou parâmetro discreto. No primeiro caso, a variável de projeto consistiria de uma função a ser utilizada no problema de otimização.

A solução de problemas práticos de engenharia requer normalmente a discretização do problema via método dos elementos finitos, por exemplo, antes da utilização do algoritmo de otimização adequado.

A chamada função objetivo é função das variáveis de projeto e representa o que queremos otimizar, sendo chamada de simples quando possuímos somente um objetivo e multi-objetivo no caso contrário.

As restrições são as condições que devem ser respeitadas na solução do problema de otimização. Elas podem ser classificadas em ${ }^{33}$ :

- Laterais: $\mathrm{x}_{\mathrm{i} \text { min }} \leq \mathrm{x}_{\mathrm{i}} \leq \mathrm{x}_{\mathrm{i} \text { máx }}$ com $\mathrm{i}=1,2 \ldots \mathrm{n}$

- De Desigualdade: $g_{j}(x) \geq 0, j=1,2 \ldots n_{g}$

- De lgualdade: $h_{k}(x)=0, k=1,2 \ldots n_{e}$

Torna-se válido mencionar a eventual necessidade de normalização das restrições visando evitar problemas com mal condicionamento numérico quando comparadas ordens de grandeza muito diferentes como, por exemplo, quando temos uma restrição de tensões em $\mathrm{MPa}$ e outra de deslocamentos em centésimos de milímetro. 
As restrições podem ainda ser classificadas em locais ou globais, e em ativa ou inativa. A segunda classificação é feita quando, no caso de uma restrição de desigualdade possui valor zero (ativa) ou maior que zero (inativa). Assim, as restrições que ao final da otimização estejam inativas são, a princípio, desnecessárias para o estudo.

Normalmente, a única forma de garantia da obtenção de um mínimo global em um problema de otimização seria a confirmação de que o mesmo é um problema convexo. Nos demais casos, é praticamente impossível classificar o mínimo como global ao invés de local.

Um problema é considerado convexo quando a sua função objetivo e o seu domínio viável (a parte do domínio em que as restrições são respeitadas) são convexos. Demonstra-se que uma função é convexa se sua Matriz Hessiana é positiva semidefinida (os seus auto-valores são positivos).

A Matriz Hessiana de uma função objetivo f genérica seria:

$$
\mathbf{H}=\left[\begin{array}{cccc}
\frac{\partial^{2} \mathrm{f}}{\partial \mathrm{x}_{1}{ }^{2}} & \frac{\partial^{2} \mathrm{f}}{\partial \mathrm{x}_{1} \partial \mathrm{x}_{2}} & \cdots & \frac{\partial^{2} \mathrm{f}}{\partial \mathrm{x}_{1} \partial \mathrm{x}_{\mathrm{n}}} \\
\frac{\partial^{2} \mathrm{f}}{\partial \mathrm{x}_{2} \partial \mathrm{x}_{1}} & \frac{\partial^{2} \mathrm{f}}{\partial \mathrm{x}_{2}{ }^{2}} & \cdots & \vdots \\
\vdots & \vdots & \ddots & \vdots \\
\frac{\partial^{2} \mathrm{f}}{\partial \mathrm{x}_{\mathrm{n}} \partial \mathrm{x}_{1}} & \cdots & \cdots & \frac{\partial^{2} \mathrm{f}}{\partial \mathrm{x}_{\mathrm{n}}{ }^{2}}
\end{array}\right]
$$

Os métodos de solução podem ser classificados em analíticos, gráficos ou numéricos, sendo possível separar o terceiro tipo em: específicos, quando uma formulação específica é desenvolvida para cada problema ou genéricos, normalmente implementados nos softwares comerciais.

Os métodos numéricos de otimização podem ser classificados em métodos de programação matemática e métodos probabilísticos.

Os procedimentos do primeiro tipo podem ser encontrados em programação linear, programação não linear, programação linear seqüencial, programação quadrática seqüencial, método de Lagrange, penalização, projeção de gradientes e outros. Exemplos para métodos probabilísticos seriam os algoritmos genéticos e "Simulated Annealing". Maiores detalhes sobre os métodos descritos podem ser encontrados em literatura específica ${ }^{13,14,33}$.

$\mathrm{Na}$ otimização estrutural do presente trabalho, devido à complexidade da geometria, 
a mesma foi modelada em um CAD 3D paramétrico, Pro/Engineer ${ }^{\circledR}$,que trabalha em interface com o software de análise estrutural ANSYS Workbench ${ }^{\circledR}$ cujo algoritmo de otimização utilizado consistiu no Goal Driven Optimization (GDO). Esta técnica traz uma relação de candidatos a melhor configuração de um problema de otimização multi-objetivo com restrições a partir de um conjunto de metas pré estabelecidas para as variáveis de projeto e para a função objetivo. O estudo de sensibilidade utilizado para encontrar os gradientes pode ser gerado por uma técnica de amostragem grosseira ou "peneiramento" ou uma opção avançada. A primeira abordagem é um método não iterativo de amostragem que usa um gerador de números quasi-aleatórios baseado no algoritmo de Hammersley. A abordagem avançada traz um algoritmo multi-objetivo genético (Multi-objective Genetic Algorithm - MOGA), que pode ser usado para otimizar somente problemas com variáveis de projeto contínuas.

Para a otimização da freqüência natural do componente, foi utilizado o método de Quasi-Newton.

\subsection{Delineamento/Projeto de Experimentos}

A indústria tem utilizado com freqüência em problemas de otimização a técnica do Delineamento ou Projeto de Experimentos (DOE - Design of Experiments) por vantagens de economia de recursos e precisão controlada.

Entende-se aqui por experimento: a manipulação de fatores controláveis (variáveis independentes) em diferentes níveis para analisar o efeito destes através de alguma resposta (variável dependente). O DOE nada mais é que uma técnica que se utiliza de métodos estatísticos como análise de variância para a experimentação.

Experimentos são feitos na prática há anos de diversos modos: por tentativa e erro, alterando-se um fator por vez, efetuando todas as combinações possíveis dos fatores em estudo, no chamado fatorial completo, ou parte delas, num fatorial fracionado, e outros. Obviamente, para cada combinação testada há um custo de tempo e dinheiro envolvidos, o que deve ser analisado antes da escolha do tipo de experimento. Ainda assim, as técnicas estatísticas aplicadas no DOE permitem ao experimentador analisar o erro envolvido nos resultados obtidos e procurar a solução ótima. 
A utilização de um experimento fracionado com o intuito de redução de custos obviamente traz erros envolvidos na medida em que não se poderão separar todos os efeitos das variáveis de projeto e suas iterações sem fazer todas as combinações possíveis. Chamamos de iterações as relações entre variáveis de projeto, ou seja, quando o efeito de uma variável na saída depende do nível ou valor de outra ou outras variáveis.

Pode-se calcular com esta ferramenta os efeitos individuais das variáveis de projeto, das iterações, o erro envolvido tanto no experimento em si quanto na utilização de um experimento fracionado e a significância estatística destes efeitos.

No presente trabalho esta ferramenta foi utilizada no estudo de sensibilidade para a otimização da freqüência fundamental da árvore de manivelas. Uma equação aproximada foi obtida com o uso desta ferramenta atrelado a um programa desenvolvido no MATLAB ${ }^{\circledR}$ para a então otimização da função objetivo citada, no mesmo software.

\subsection{Método de Quasi-Newton}

O método de Quasi-Newton assim como o método de Newton é um dos mais antigos e clássicos algoritmos de segunda ordem, ou seja, métodos que utilizam valores da função objetivo, suas derivadas e sua matriz Hessiana para a busca do valor ótimo. Este método foi utilizado no presente trabalho para otimização dinâmica do virabrequim. Ele foi desenvolvido com o propósito de evitar o cálculo da matriz Hessiana a cada iteração utilizando informações dos gradientes da função para construir uma aproximação para a matriz.

Considerando a expansão em série de Taylor dos gradientes da função objetivo f em $\mathrm{x}$ :

$$
\nabla f\left(x_{k+1}\right)-\nabla f\left(x_{k}\right) \cong H\left(x_{k+1}-x_{k}\right) \Rightarrow y_{k}=A_{k} \cdot p_{k} \text { e } B_{k+1} \cdot y_{k}=p_{k}
$$

Onde $p_{k}$ é o passo, $A_{k}$ é a aproximação da matriz Hessiana $H$ e $B_{k+1}$ a aproximação de $\mathrm{H}^{-1}$.

A relação $B_{k+1} \cdot y_{k}=p_{k}$ é chamada relação da secante ou Quasi-Newton.

Tanto $A_{k}$ quanto $B_{k+1}$ devem ser positivo-definidas para este método. Uma fórmula de aproximação para $B_{k+1}$ bastante utilizada e que garante que a matriz 
permanecerá simétrica e positivo-definida é a chamada BFGS:

$$
B_{k+1}=\left[I-\frac{p_{k} \cdot\left(y_{k}\right)^{T}}{\left(p_{k}\right)^{T} \cdot y_{k}}\right] \cdot B_{k} \cdot\left[I-\frac{\left(y_{k}\right)^{T} \cdot p_{k}}{\left(p_{k}\right)^{T} \cdot y_{k}}\right]+\frac{p_{k} \cdot\left(p_{k}\right)^{T}}{\left(p_{k}\right)^{T} \cdot y_{k}}
$$

$O$ algoritmo é iniciado fazendo $B_{k+1}=1$. Assim, primeiramente calcula-se o gradiente da função objetivo no ponto inicial $x_{0}$, obtendo a direção $s$ para a próxima iteração como paralela a este gradiente, porém com sinal oposto. $O$ valor da posição seguinte é dado por:

$$
\mathrm{x}_{\mathrm{k}+1}=\mathrm{x}_{\mathrm{k}}+\alpha \cdot \mathrm{s}
$$

Onde $\alpha_{i}$ é distancia na direção $\mathrm{s}$ em relação ao ponto inicial onde deverá ser calculado o próximo passo. Assim, o problema foi reduzido à chamada busca unidimensional onde a função objetivo é agora dependente somente de $\alpha_{i}$. Esta busca tem solução simples pela derivada da função $f\left(\alpha_{i}\right)=0$.

Com o novo valor de $\mathrm{x}$ da equação acima, se calcula o novo gradiente e o próximo passo. A fórmula de $B_{k+1}$ é utilizada e a nova direção s calculada de:

$$
S_{k+1}=B_{k+1} \cdot \nabla f\left(x_{k+1}\right)
$$

Segue-se neste processo iterativo até a solução ótima. 


\section{Estudo de Caso}

As análises do presente estudo de caso foram executadas com o objetivo de ilustrar as técnicas e cálculos discutidos nas seções anteriores. O foco no conceito e organização das análises dentro de uma metodologia pré-estabelecida justifica uma abordagem menos profunda do que a esperada para certas análises iterativas como a análise estrutural ou otimização. Nestes exemplos, outras regiões do virabrequim seriam estudadas para a garantia de obtenção da condição crítica de operação ou do valor ótimo objetivado para todo o componente. Estas análises adicionais seriam repetições dos métodos aqui apresentados e em razão disso não foram executadas. Para o presente trabalho, a teoria foi aplicada a um motor real, analisado inicialmente por $\mathrm{SCHALCH}^{32}$, que executou análises de vibrações torcionais no mesmo, obtendo a resposta em freqüência da árvore de manivelas além do balanceamento dinâmico e análise de tensões do modelo completo do componente. O cálculo da rigidez e inércia equivalente das seções conforme ilustrado no terceiro capítulo foi executado a partir dos modelos tridimensionais (Figuras 25 e 26) do mesmo motor estudado. As condições críticas de operação do motor foram obtidas das curvas de pressão do gás da mesma referência ${ }^{32}$, diferentemente da fonte citada, que utilizou condições de torque máximo do motor, potência máxima e máxima rotação para definição do carregamento aplicado em modelos do virabrequim completo montado no bloco do motor. 


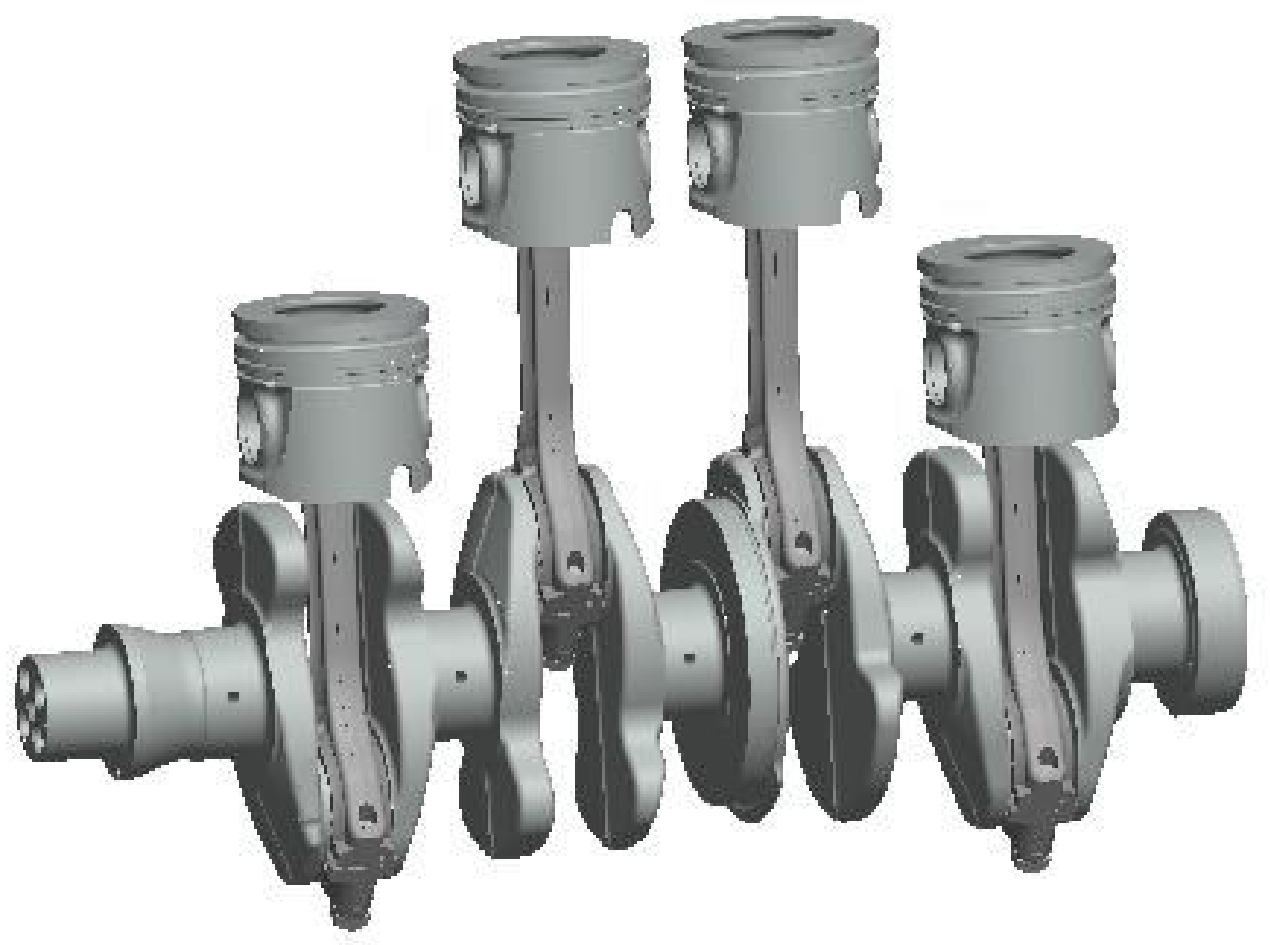

Figura 36: Modelos tridimensionais utilizados para aquisição de dados

\subsection{Dados}

Seqüência de ignição: 1-3-4-2

Sentido de rotação: Anti-horário, visto pelo volante.

Massa da biela: $1.705 \mathrm{~kg}$

Massa do conjunto do pistão: $1,910 \mathrm{~kg}$

Comprimento da biela: $207 \mathrm{~mm}$

Posição do centro de gravidade (L2): $61.5 \mathrm{~mm}$

Diâmetro do pistão: 105 mm

Meio curso da árvore de manivelas: $68,5 \mathrm{~mm}$

Rotação máxima do motor: 3000 rpm

Massas alternativas: $2,417 \mathrm{~kg}$

Inércias $\left[\mathrm{kg} \cdot \mathrm{m}^{2}\right]$ :

$11=0,0340 \quad$ (Polia)

$12=0,0438 \quad\left(1^{\text {a }}\right.$ manivela $)$

$13=0,0438 \quad\left(2^{\mathrm{a}}\right.$ manivela $)$

$14=0,0624 \quad\left(3^{a}\right.$ manivela $)$

$15=0,0448 \quad\left(4^{\mathrm{a}}\right.$ manivela $)$ 
$16=0,460 \quad$ (Volante)

Rigidez torcional [N.m/rad]:

$\mathrm{Kt} 1=1516000 \quad($ polia - moente 1$)$

$\mathrm{Kt} 2=1271000 \quad$ (moente $1-$ moente 2$)$

$\mathrm{Kt} 3=1612000 \quad$ (moente $2-$ moente 3$)$

$\mathrm{Kt} 4=1186000 \quad($ moente $3-$ moente 4$)$

$\mathrm{Kt} 5=2212000 \quad$ (moente $4-$ volante)

Diâmetro dos moentes: $63 \mathrm{~mm}$

Diâmetro dos munhões: 86 mm

Material da árvore de manivelas: SAE J403 - UNS

\subsection{Curvas de Pressão}

As curvas da pressão de gás pela posição angular utilizadas encontram-se na Figura 37 , onde podemos notar que a condição de máxima pressão neste caso ocorre quando a velocidade angular é 2200rpm.

\section{Pressão do Gás}

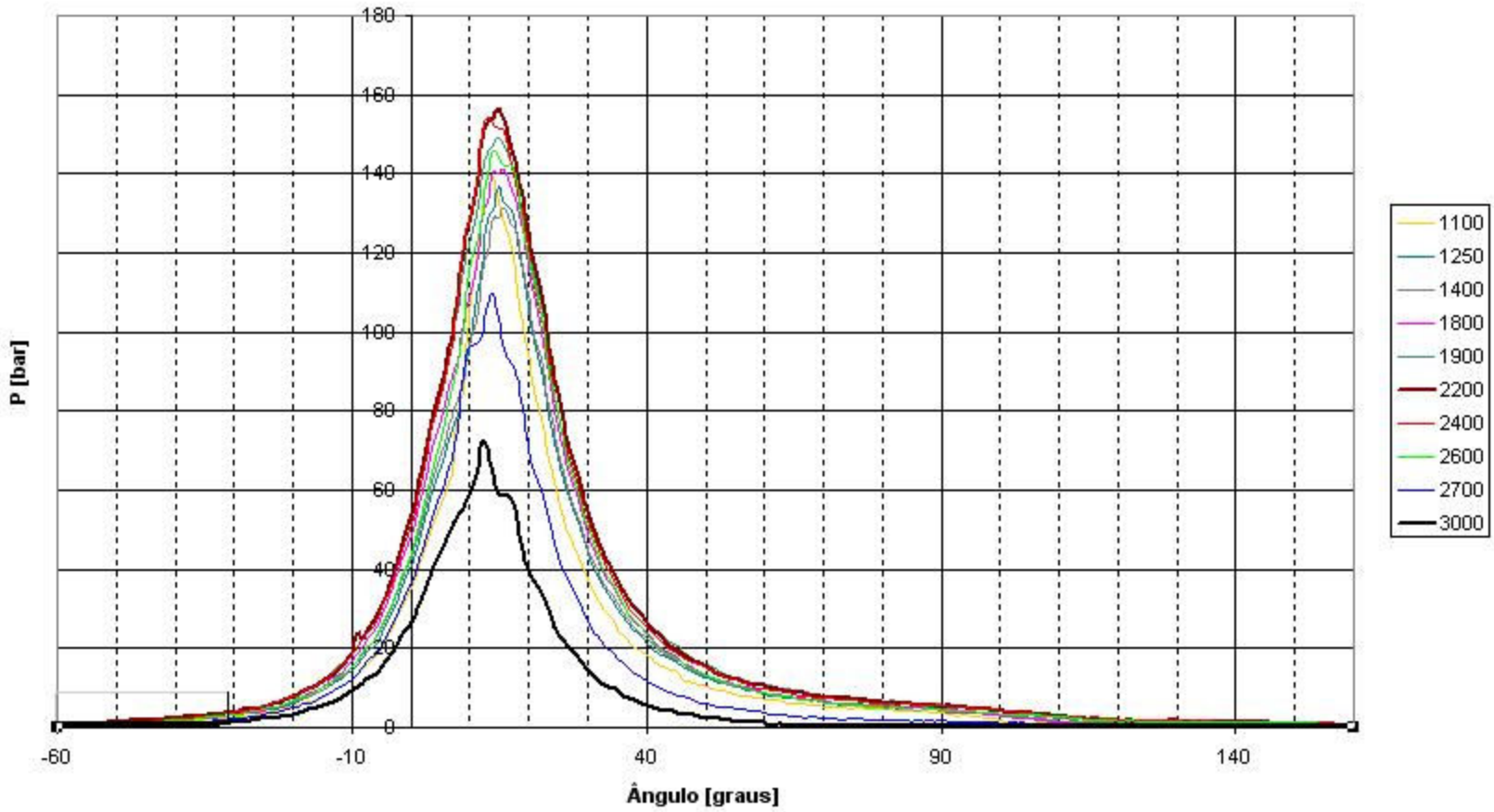

Figura 37: Curvas da pressão de gás pela posição angular do virabrequim em diferentes velocidades angulares ${ }^{32}$ 


\subsection{Carregamento}

Conforme os cálculos da seção 3.1, é apresentada nas Figuras 38 a 40 a cinemática do virabrequim. As Figuras 41 e 42 mostram as curvas de gás e de inércia para o estudo de caso. Finalmente, nas Figuras 43 e 44 observam-se respectivamente, as forças tangencial e radial, resultantes de acordo com os cálculos da seção 3.2. Para as Figuras 38 a 44 a rotação analisada foi de 2200rpm.

Deslocamento do Pistäo

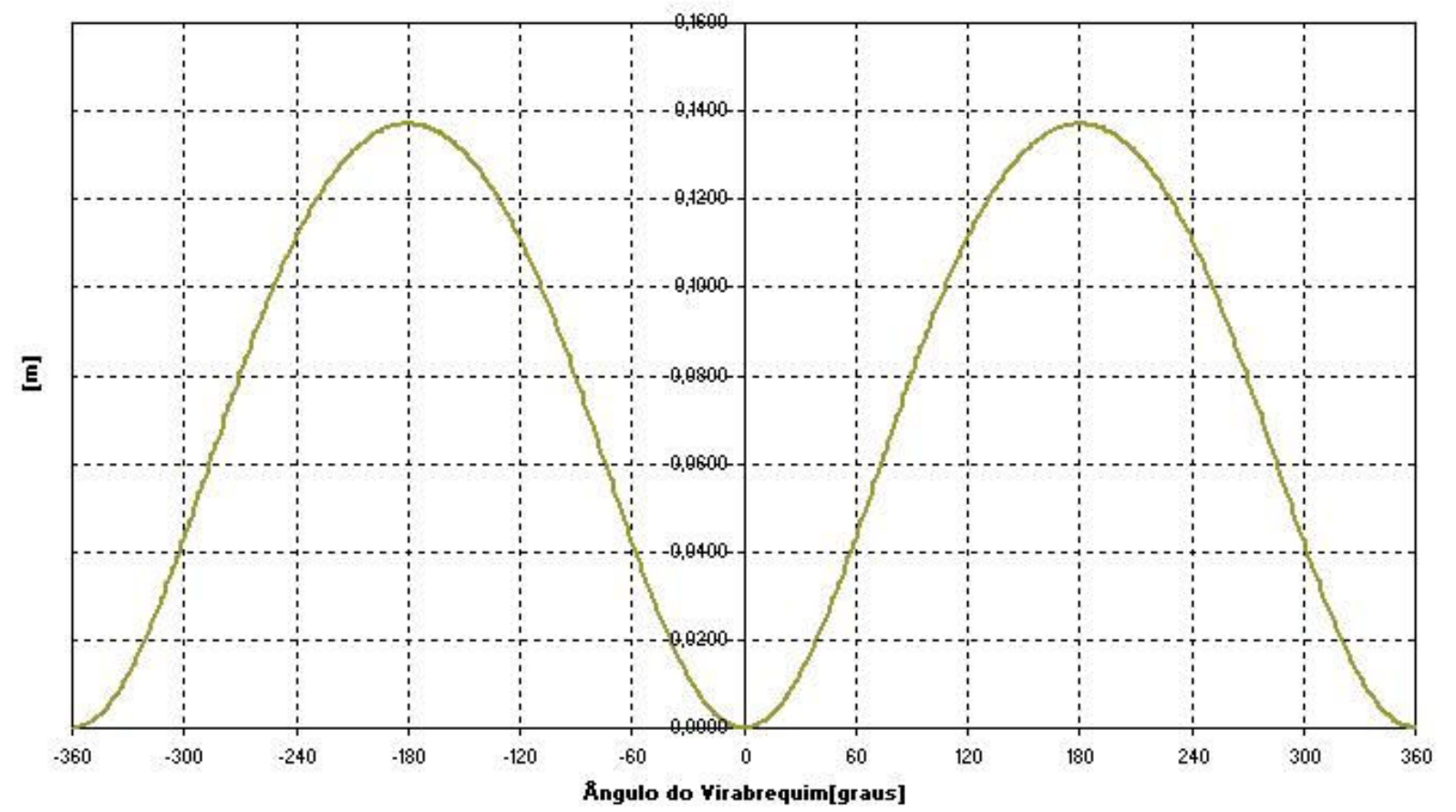

Figura 38: Deslocamento do pistão pelo ângulo do virabrequim 


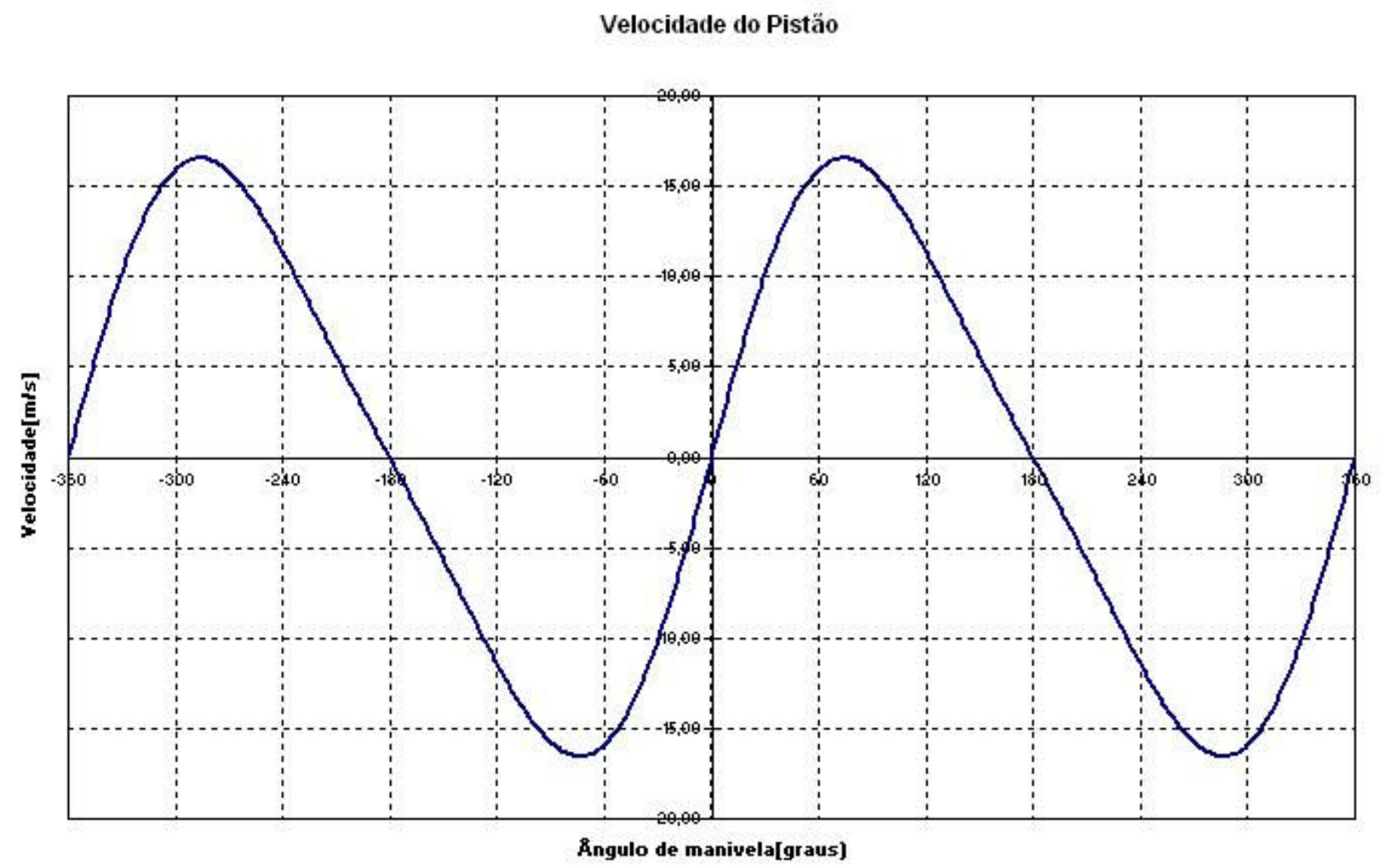

Figura 39: Velocidade do pistão pelo ângulo do virabrequim

Aceleração Total

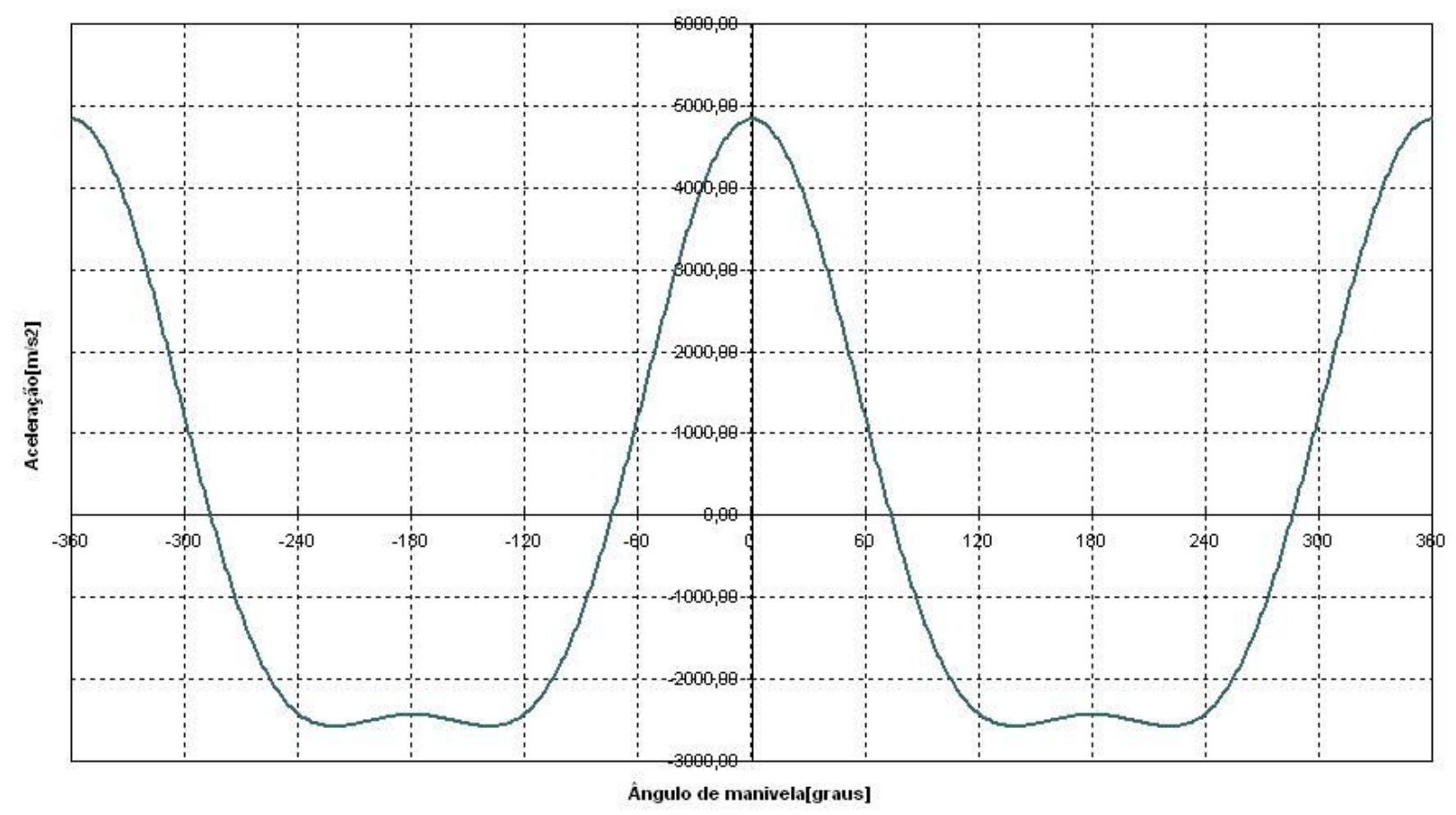

Figura 40: Aceleração do pistão pelo ângulo do virabrequim 


\section{Força de Gás}

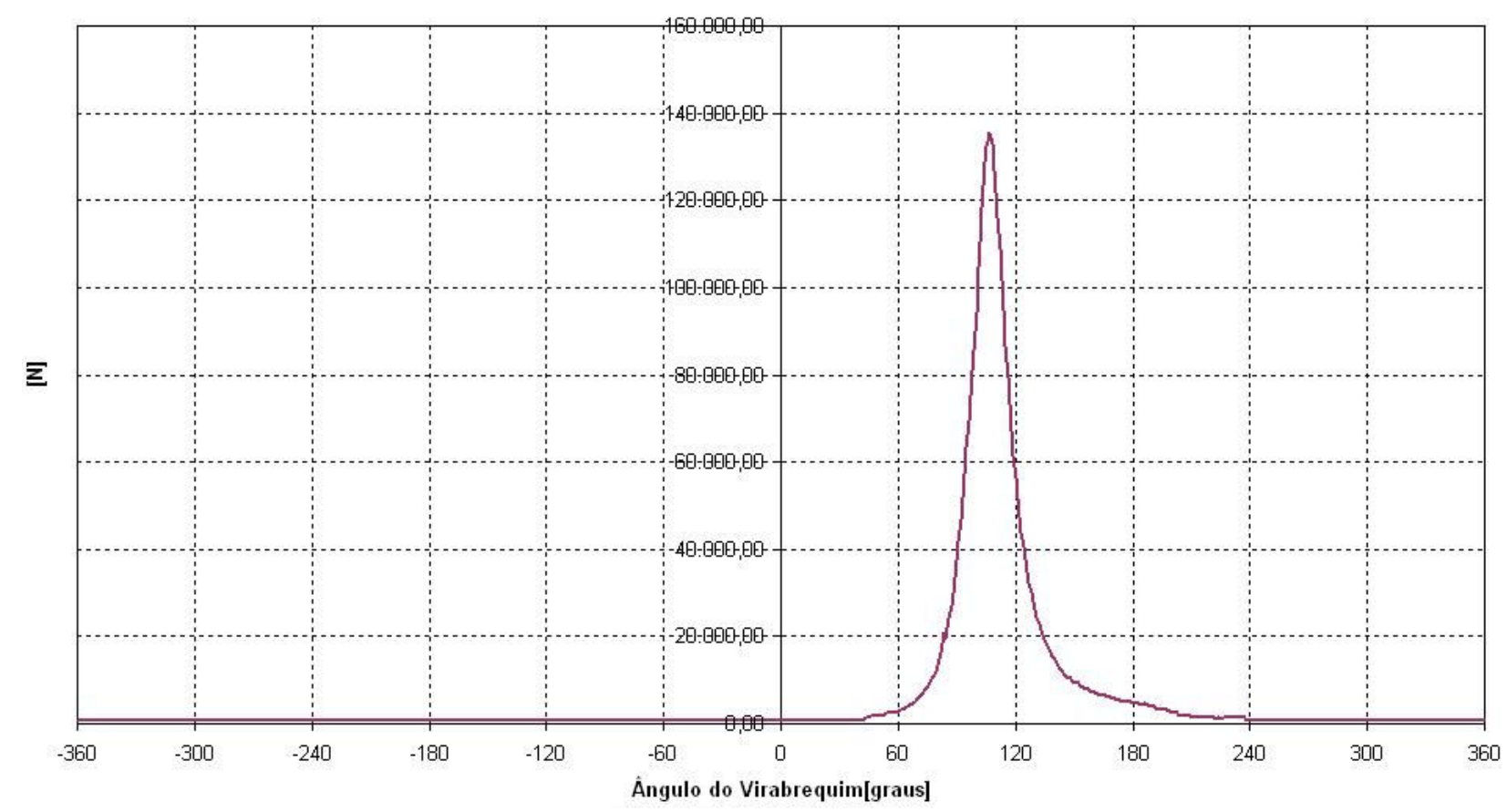

Figura 41: Força do gás pelo ângulo do virabrequim

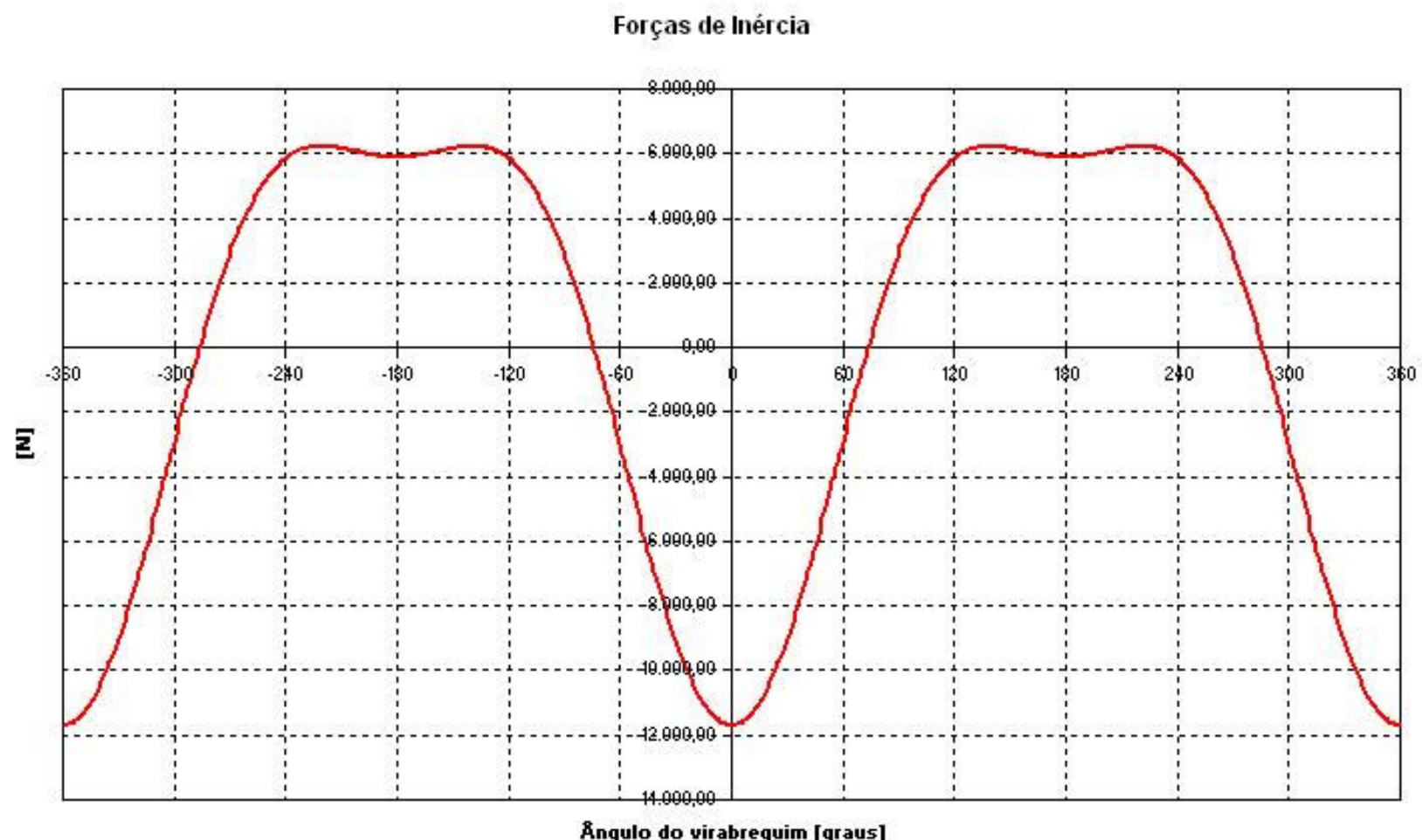

Figura 42: Força de inércia pelo ângulo do virabrequim 


\section{Força Tangencial}

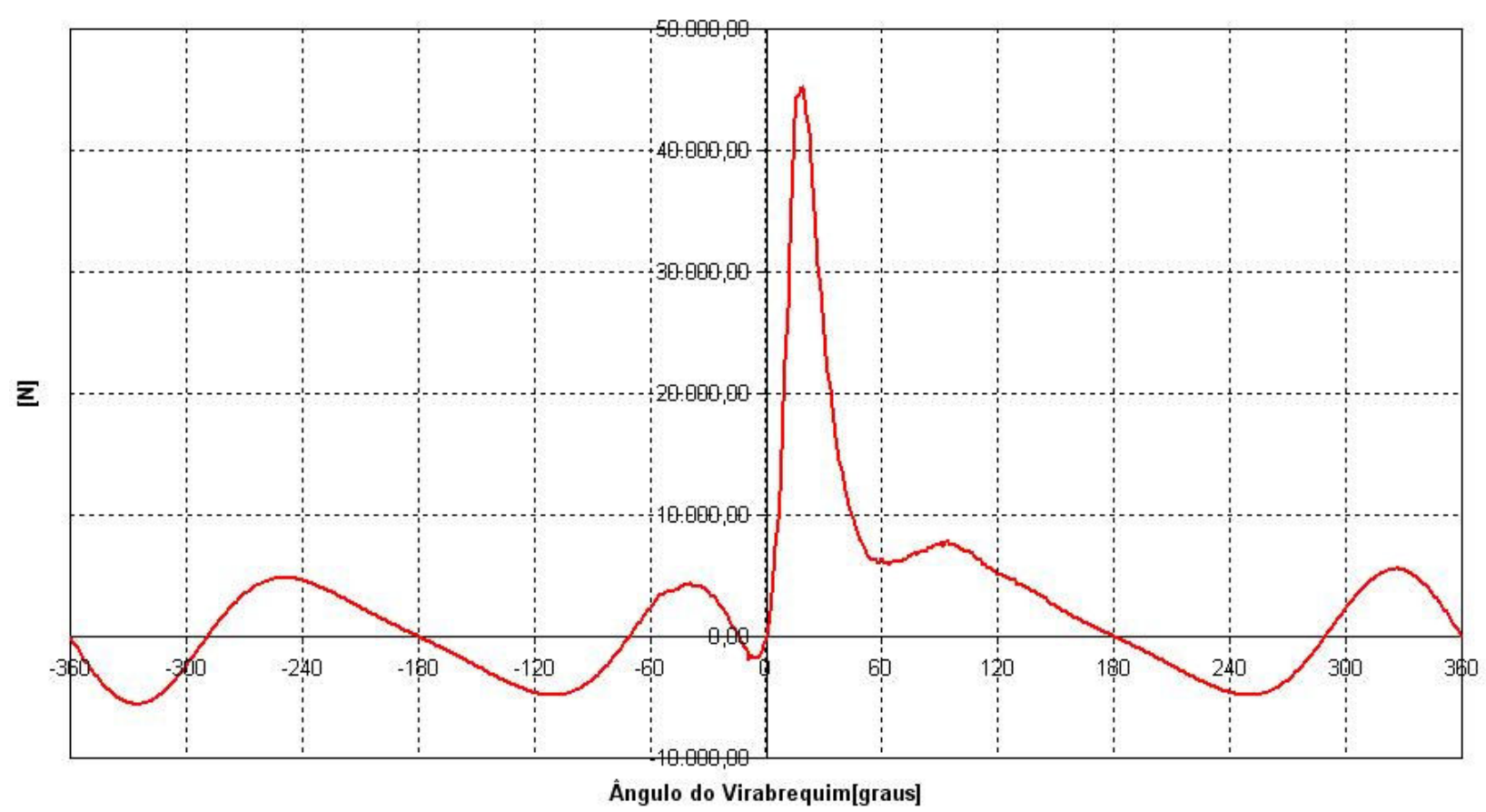

Figura 43: Força total tangencial pelo ângulo do virabrequim

\section{Força Radial}

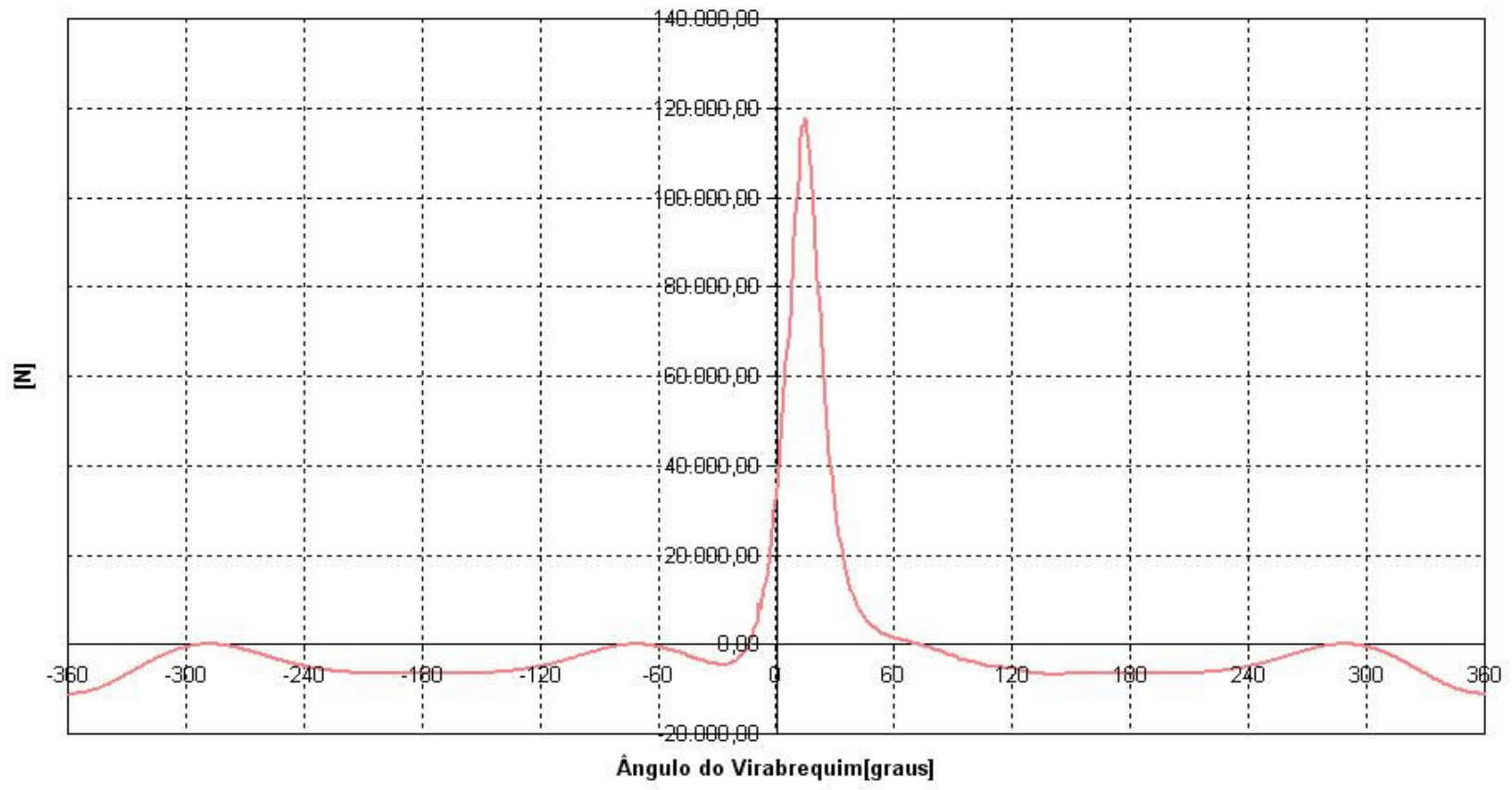

Figura 44: Força total radial pelo ângulo do virabrequim

Segundo a ordem de ignição para este estudo de caso (1-3-4-2), o carregamento total tangencial para a rotação especificada tem a forma da Figura 45. 


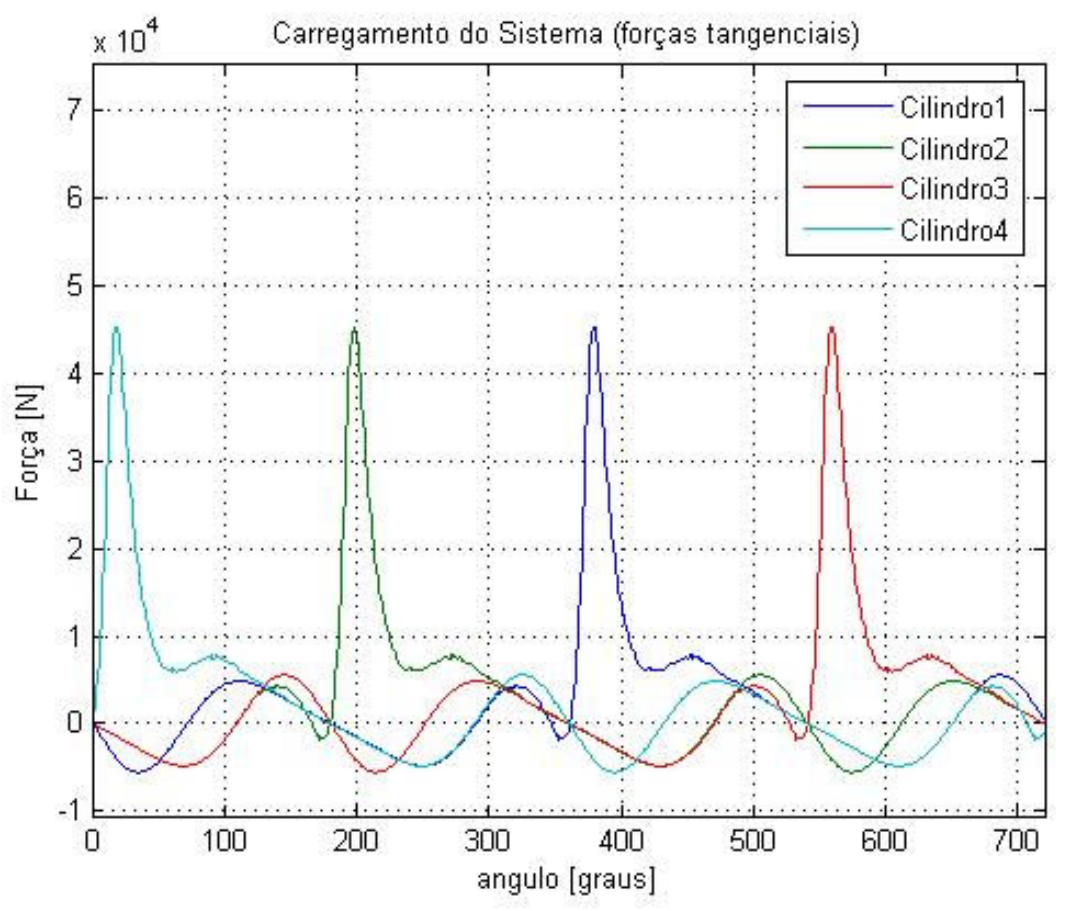

Figura 45: Força total tangencial pelo ângulo do virabrequim

\subsubsection{Carregamento atuante nos munhões}

Como comentado na seção 3.5, o cálculo do carregamento nos mancais foi elaborado neste estudo de caso, para ilustrar dados típicos de análise hidrodinâmica em mancais.

As Figuras 46 e 47 mostram o carregamento nos munhões nas direções vertical e horizontal, respectivamente de acordo com a ordem de ignição do estudo de caso (1-3-4-2). 


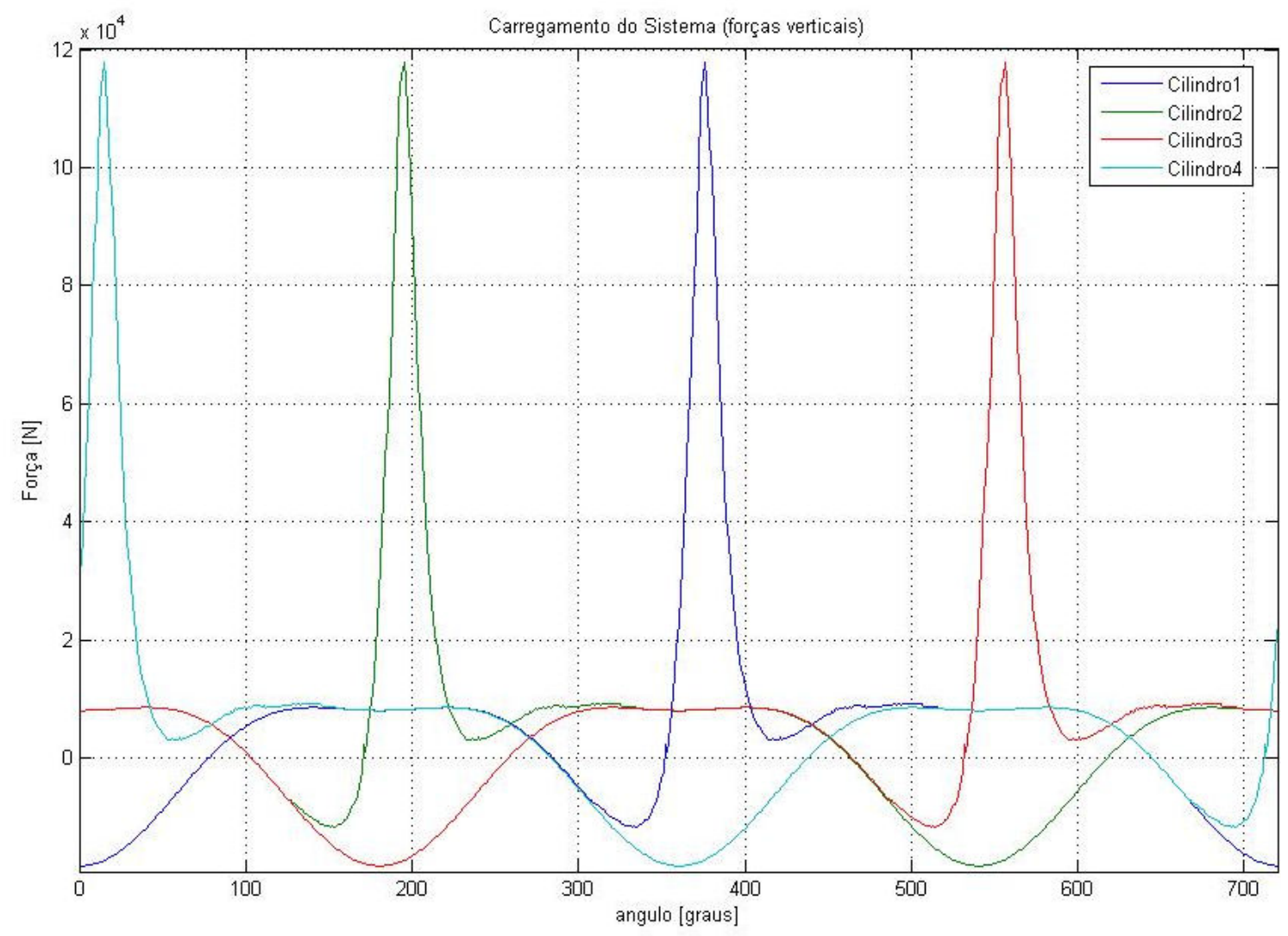

Figura 46: Forças verticais atuantes nos munhões

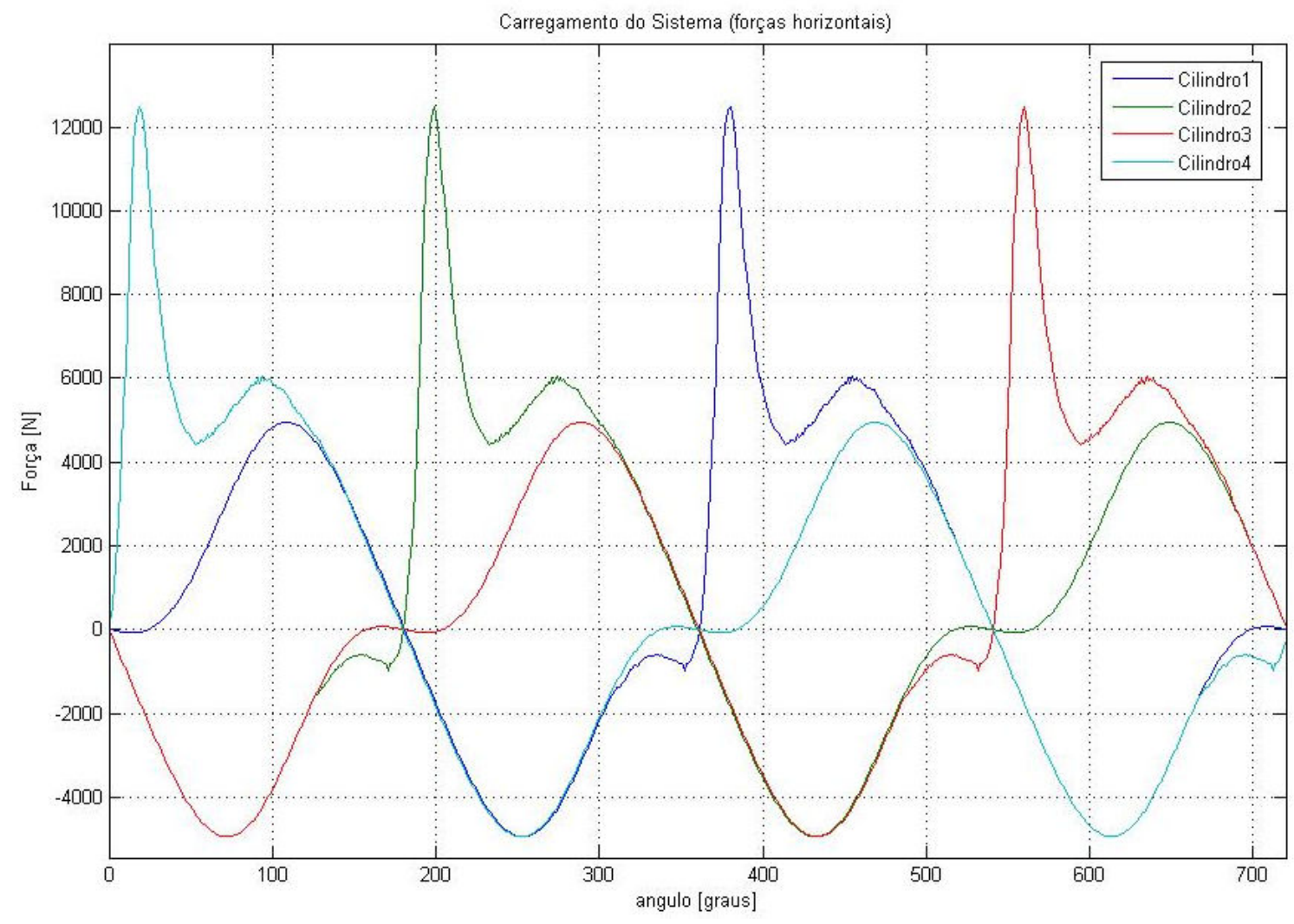

Figura 47: Forças horizontais atuantes nos munhões

As forças nos mancais do bloco do motor são, portanto, definidas conforme as 
Figuras 48 a 52, que como pode ser verificado, mostram para o primeiro e último munhões somente o efeito dos cilindros 1 e 4 respectivamente, ao passo que para os demais cilindros, a força resultante é dependente da metade da força atuante nos cilindros vizinhos, conforme ilustrado no capítulo 3.5 .

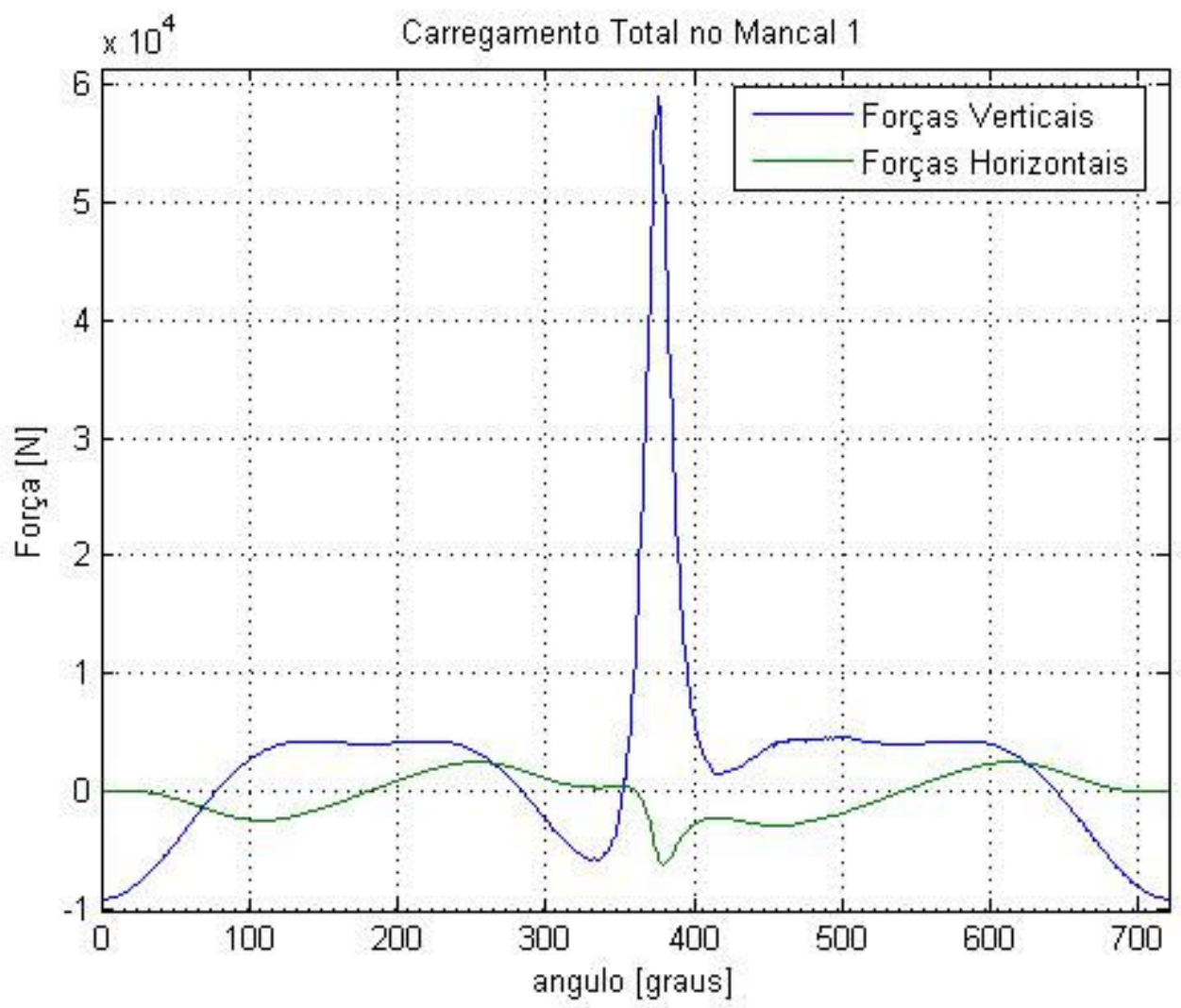

Figura 48: Forças totais atuantes no munhão 1 


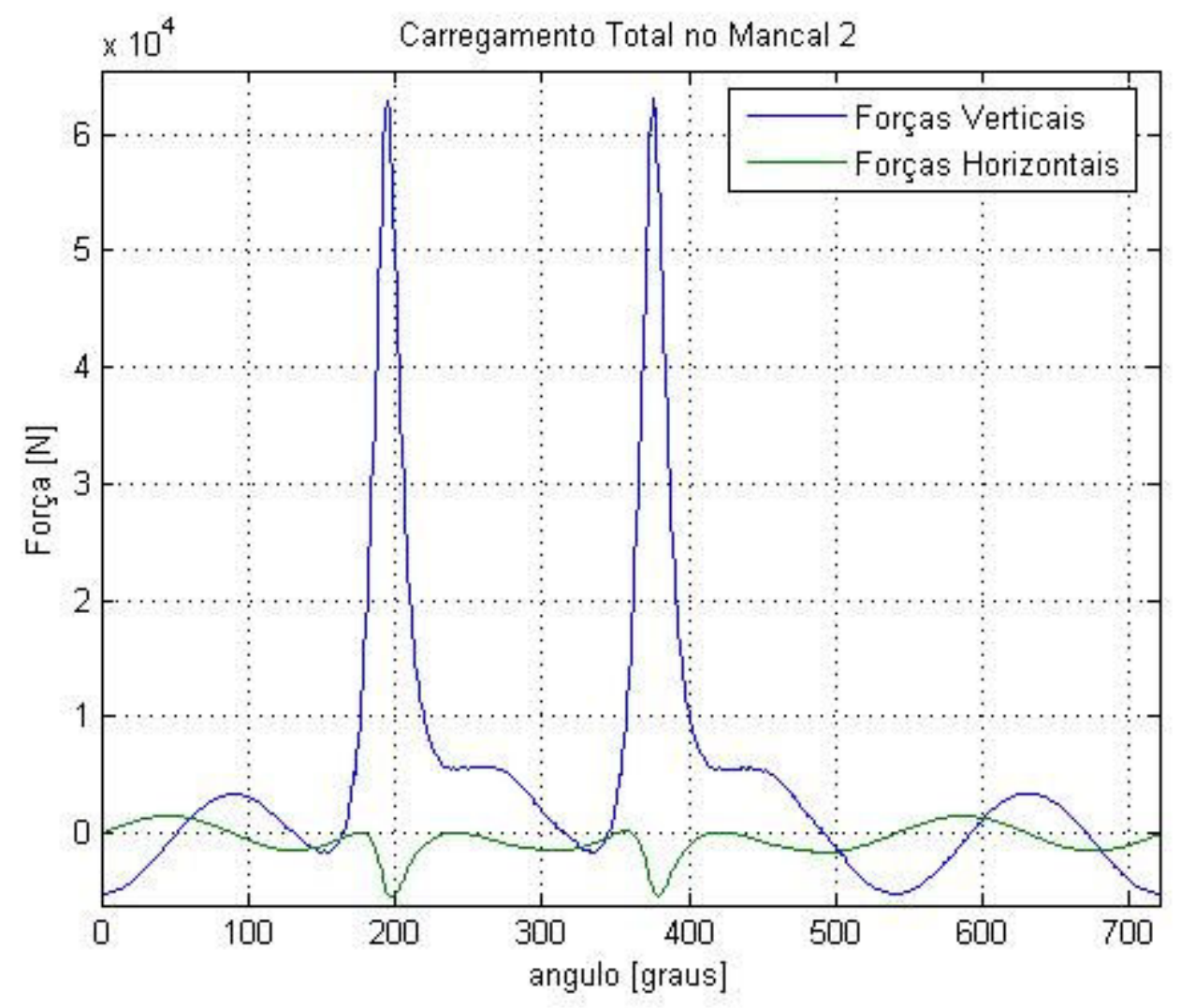

Figura 49: Forças totais atuantes no munhão 2

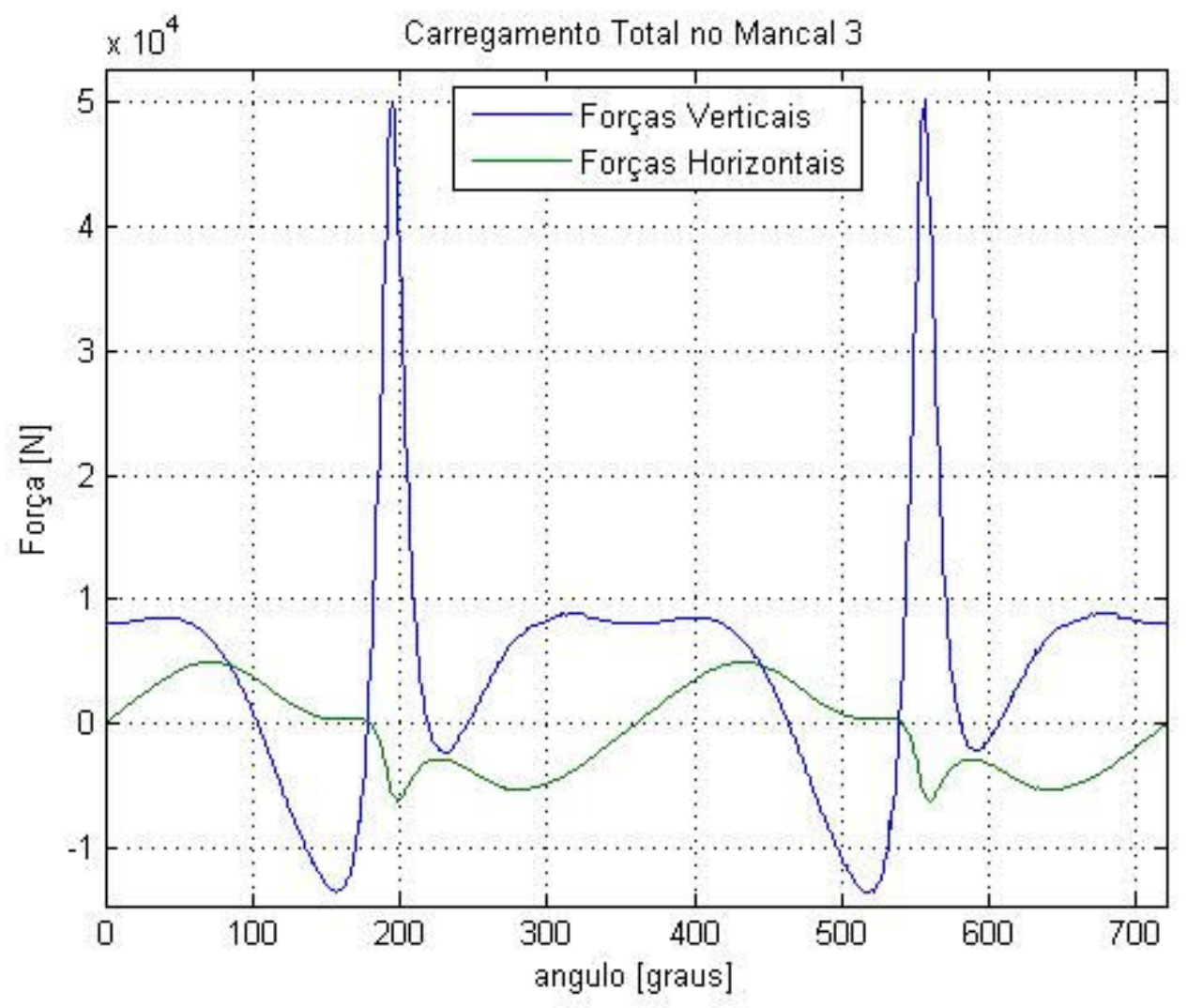

Figura 50: Forças totais atuantes no munhão 3 


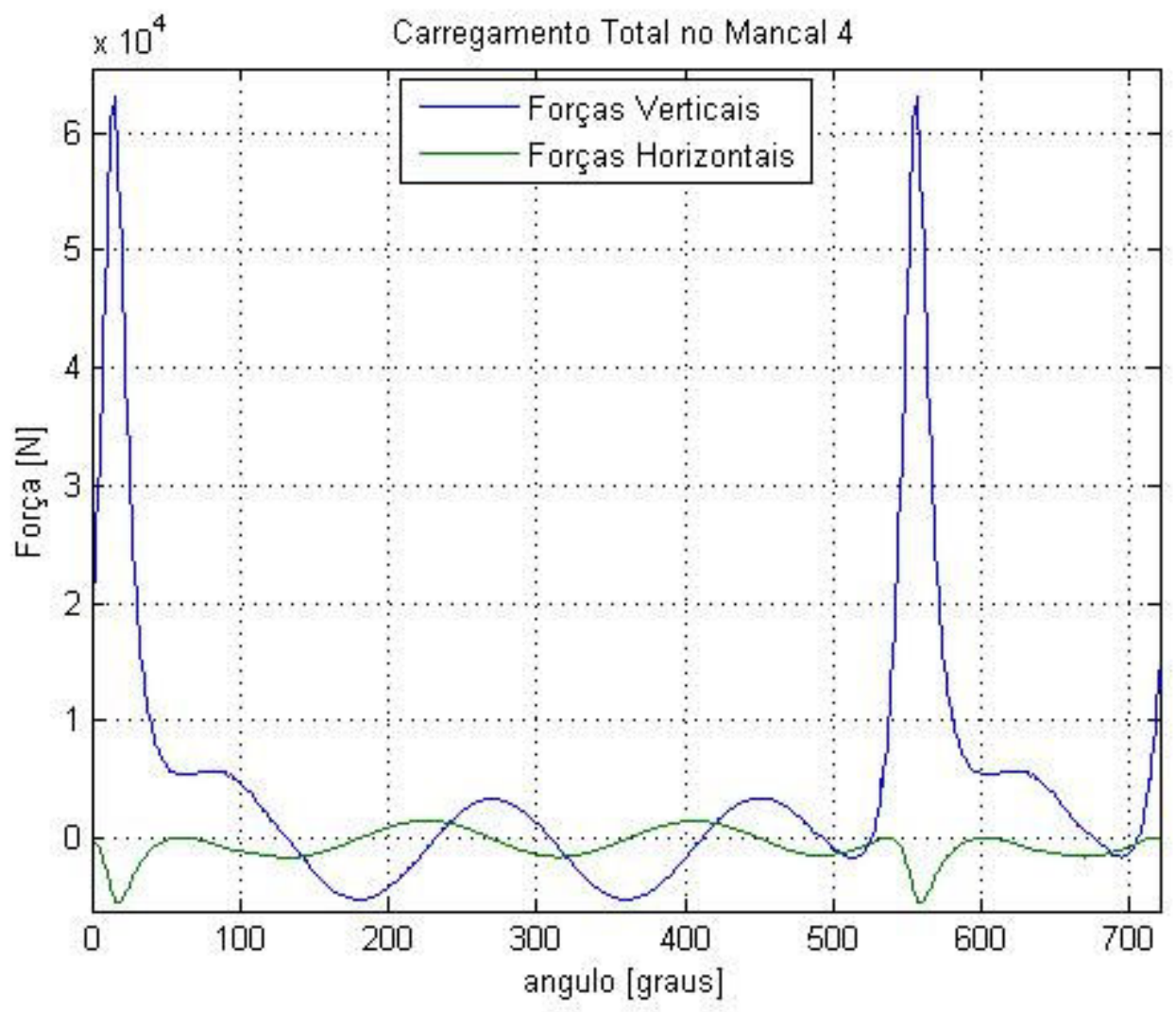

Figura 51: Forças totais atuantes no munhão 4

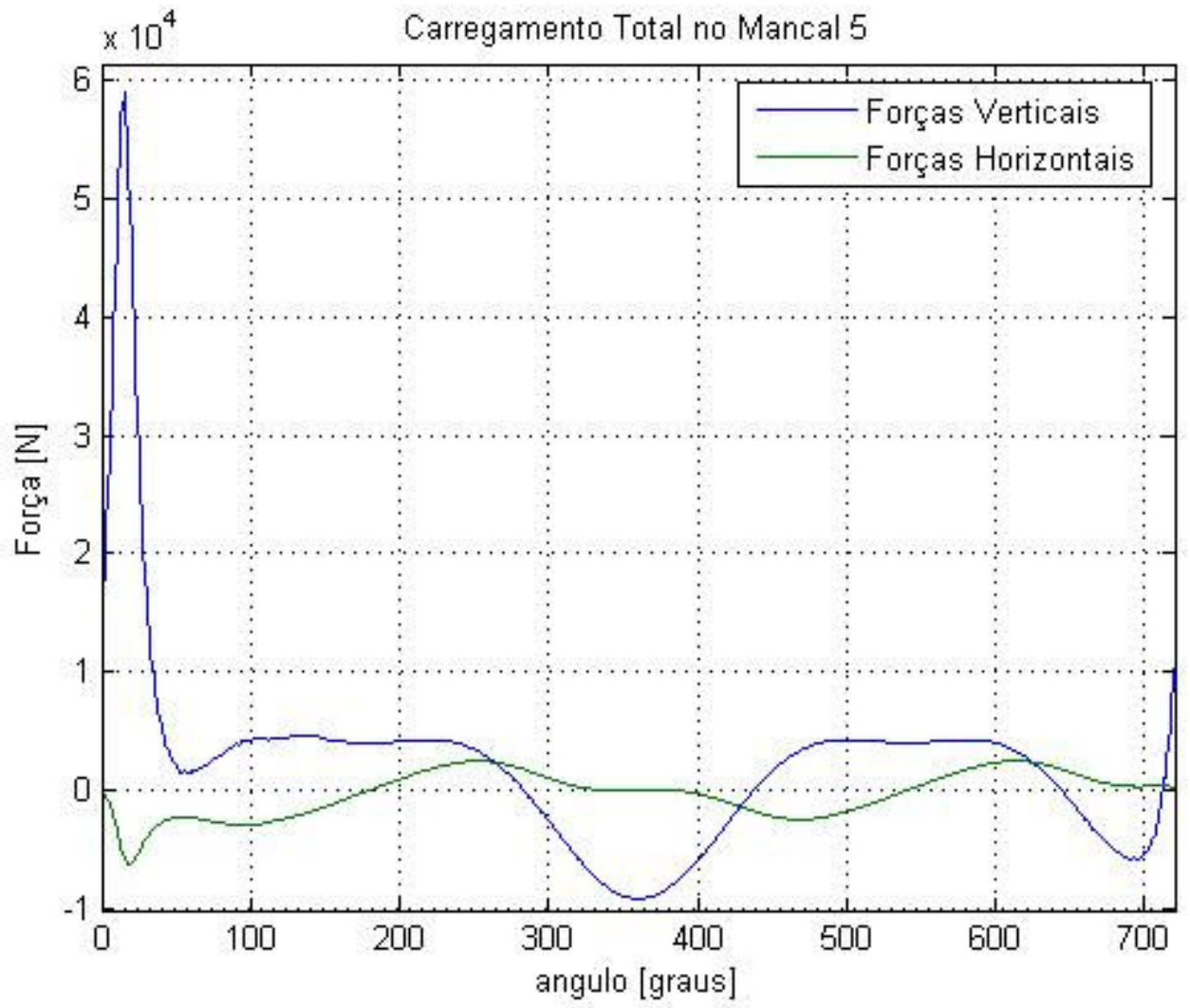

Figura 52: Forças totais atuantes no munhão 5 


\subsection{Cálculo de parâmetros hidrodinâmicos}

Apenas para ilustração de possíveis resultados obtidos com a análise hidrodinâmica, foi aplicado no presente trabalho um programa já disponível na literatura ${ }^{20} \mathrm{e}$ obtidos parâmetros básicos de lubrificação dos munhões a partir do máximo carregamento deduzido no capítulo 3.

Os dados de entrada para tal análise foram:

- Força aplicada ao mancal: $63000 \mathrm{~N}$

- Velocidade angular do eixo: 2200 rpm

- Folga radial: $50 \mu \mathrm{m}$

- Raio do mancal: $35 \mathrm{~mm}$

- Largura do mancal: $36 \mathrm{~mm}$

- Rugosidade da superfície: 0,2 $\mu \mathrm{m}$

- Temperatura de entrada do óleo: $80^{\circ} \mathrm{C}$

Os parâmetros básicos do mancal calculados pelo programa citado foram:

- Fator de Excentricidade: 0,975

- Força hidrodinâmica: $63000 \mathrm{~N}$

- Coeficiente de atrito: $0,782^{*} 10^{-3}$

- Potência de acionamento: $79,5 \mathrm{~W}$

- Vazão do fluido lubrificante: $0,78 \mathrm{l} / \mathrm{m}$

- Temperatura de saída do óleo: $103^{\circ} \mathrm{C}$

- Viscosidade média do fluido lubrificante: $10 \mathrm{mPa}{ }^{*} \mathrm{~s}$

- Pressão máxima do filme de óleo: 200,8 atm

- Espessura mínima do filme de óleo: 1,25 $\mu \mathrm{m}$

Como a espessura mínima de filme de óleo é maior que cinco vezes a rugosidade das superfícies, a lubrificação neste exemplo é hidrodinâmica, conforme definições apresentadas no Capítulo 3 . 


\subsection{Balanceamento}

Segue na Figura 53, o desbalanceamento residual do componente antes do seu balanceamento final. Numa situação real, um estudo de dispersão do processo de fabricação seria necessário para este componente. Dadas estas variações, o desbalanceamento residual projetado para o componente deve ser tal que minimize o tempo e retirada de material necessário durante o balanceamento final de cada componente fabricado. Esta remoção de material é realizada através da furação dos contrapesos para que o componente tenha desbalanceamento final próximo ao zero.

A Figura 53 mostra desbalanceamentos residuais com amplitudes de $404 \mathrm{gcm}$ a $475 \mathrm{gcm}$ e ângulo $180^{\circ}$ como indicado na Figura 53, quando a árvore de manivelas é vista pela espiga e o primeiro moente está posicionado na vertical, para cima.
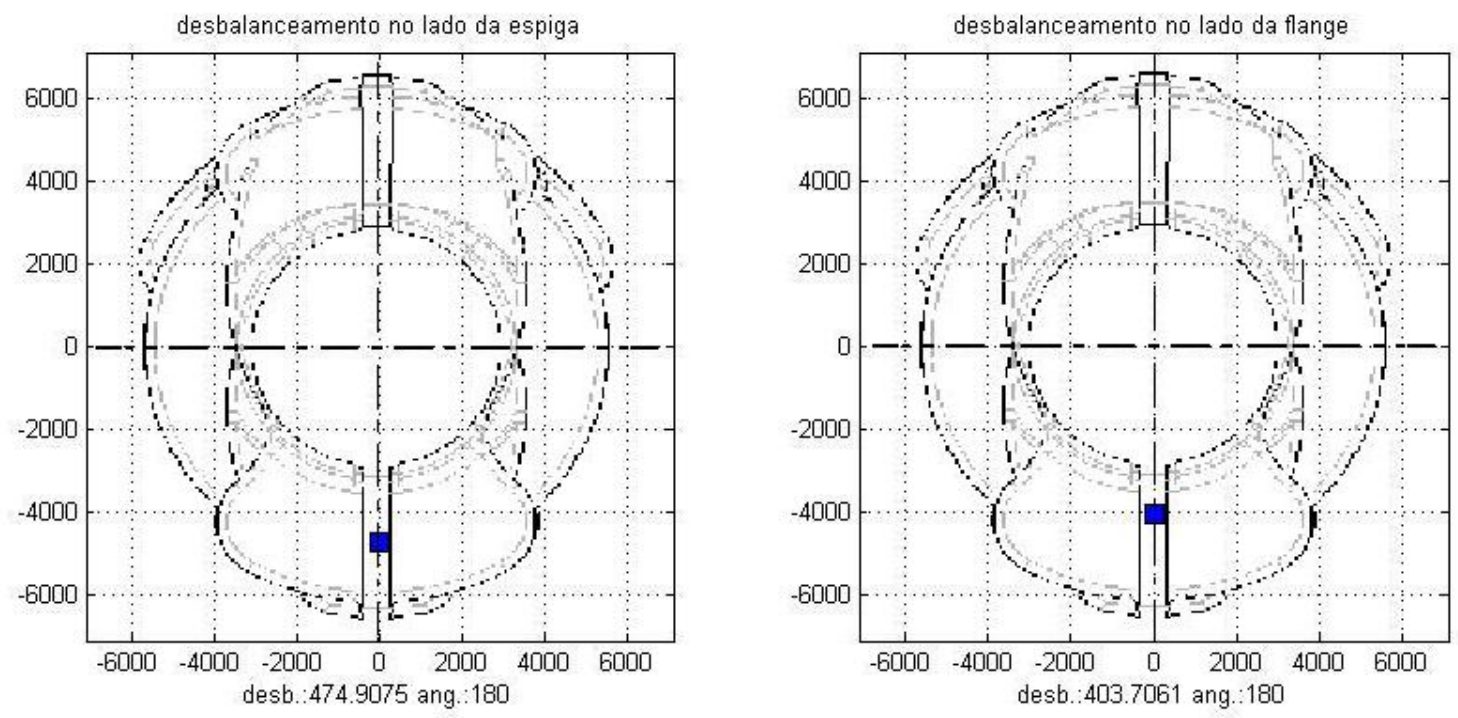

Figura 53: Desbalanceamento para o estudo de caso

\subsection{Análise Modal}

Os resultados para os três primeiros modos de vibrar do virabrequim, obtidos conforme programa em MATLAB ${ }^{\circledR}$ detalhado no apêndice $B$, encontram-se na Figura 54. 


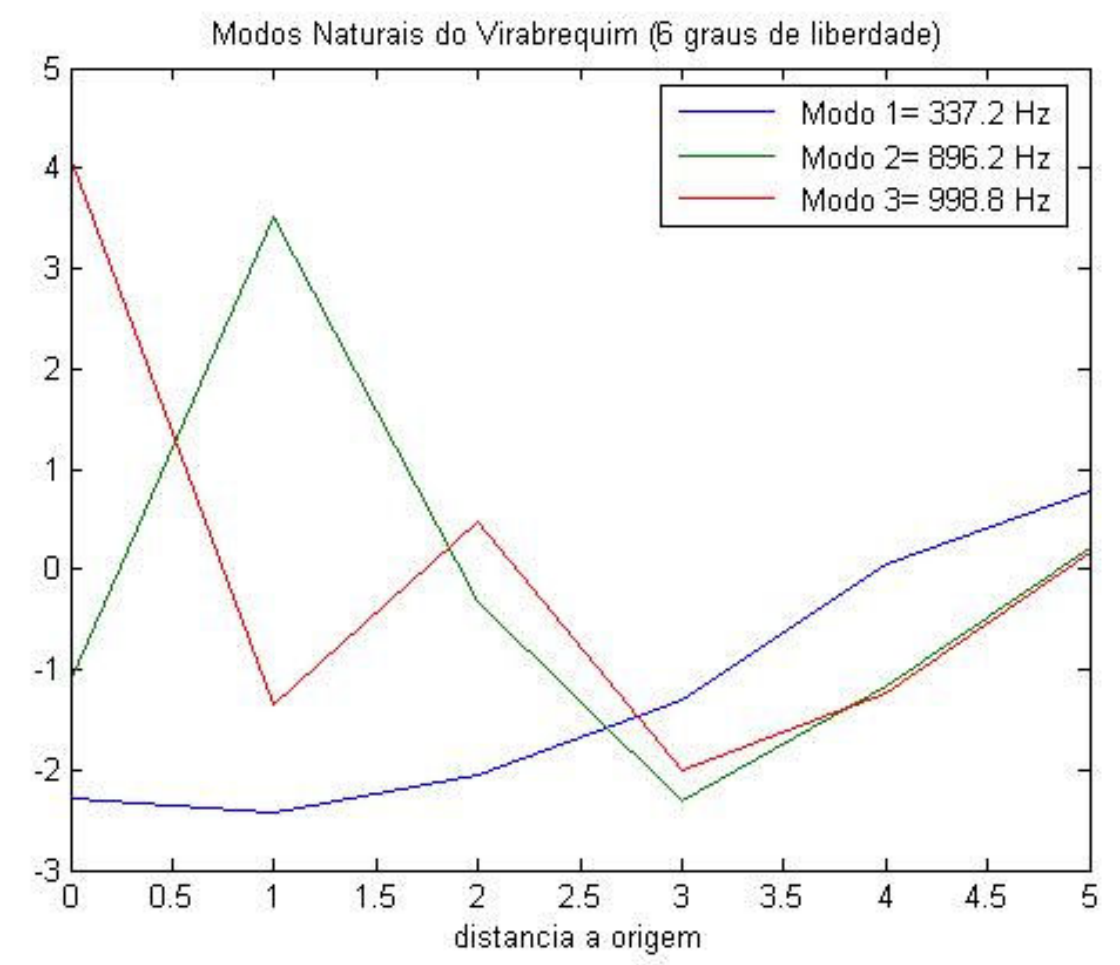

Figura 54: Modos e freqüências naturais de torção

Foi executada a análise modal para torção no software $A V L^{\circledR}$ para comparação dos dados obtidos no MATLAB ${ }^{\circledR}$, obtendo as curvas ilustradas na Figura 55. Neste software, mais divisões são feitas para o mesmo modelo tridimensional, separando munhões, moentes e braços, conforme mostra a legenda da Figura 55. Assim, com um maior número de graus de liberdade, os resultados são um pouco mais precisos que os encontrados pelo programa desenvolvido para este trabalho.

Como era de se esperar, o modelo simplificado do programa desenvolvido sendo mais rígido, apresenta freqüências naturais um pouco mais altas. A diferença entre os resultados tende a aumentar na medida em que se buscam valores de modos de ordens maiores.

Altas freqüências implicam em modos fora da faixa de operação do motor, o que justifica um foco somente nos primeiros modos. Por exemplo, no estudo de caso, a segunda freqüência natural já se encontra fora da faixa de operação do motor escolhido, com rotação máxima de 3000rpm, quando comparada com os harmônicos principais do carregamento nesta velocidade. 


\section{Modal Analysis Results}

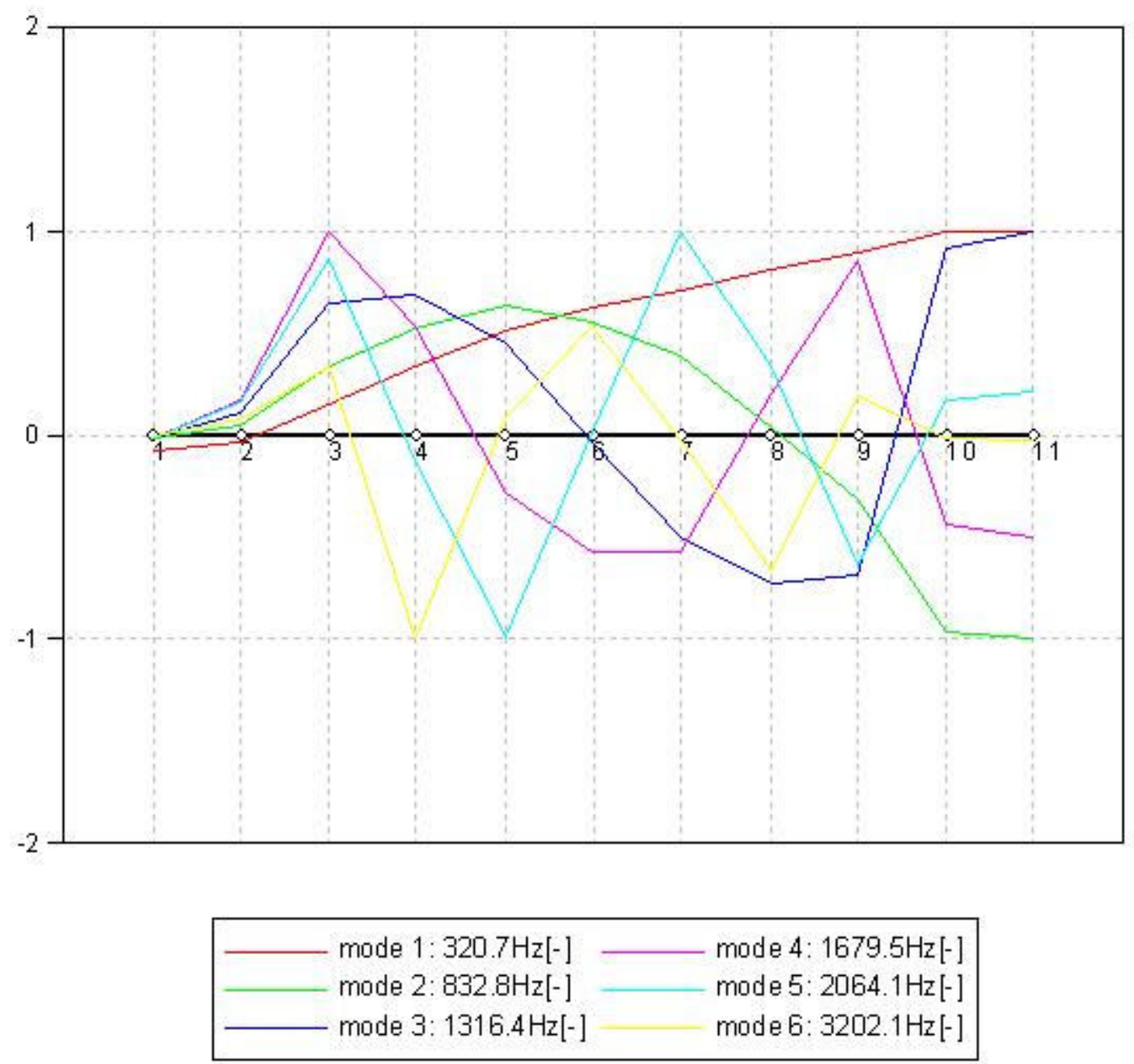

Nodes

Elements

\begin{tabular}{|l|l|}
\hline 1 Flywheel & 11 Pulley \\
2 MainJournal1 & \\
3 CrankPin1 & \\
4 Main.Journal2 & \\
5 CrankPin2 & \\
6 Main.Journal3 & \\
7 CrankPin3 & \\
8 MainJournal4 & \\
9 CrankPin4 & \\
10 Main.Journal5 &
\end{tabular}

1-2 Half_MainJournal1
2-3 Web1
3-4 Web2
4-5 Web3
5-6 Web4
6-7 Web5
7-8 Web6
8-9 Web7
9-10 Web8
10-11 Half_Main_Journal5

Figura 55: Modos e freqüências naturais de torção (AVL/EXCITE $\left.{ }^{\circledR}\right)$

Para a análise da presença de freqüências naturais dentro da faixa de operação do motor, deve-se avaliar o carregamento expandido em séries de Fourier. Os harmônicos da excitação para diferentes velocidades são então comparados com as freqüências naturais em gráficos como os da Figura 56, ou também em curvas de 
resposta em freqüência.

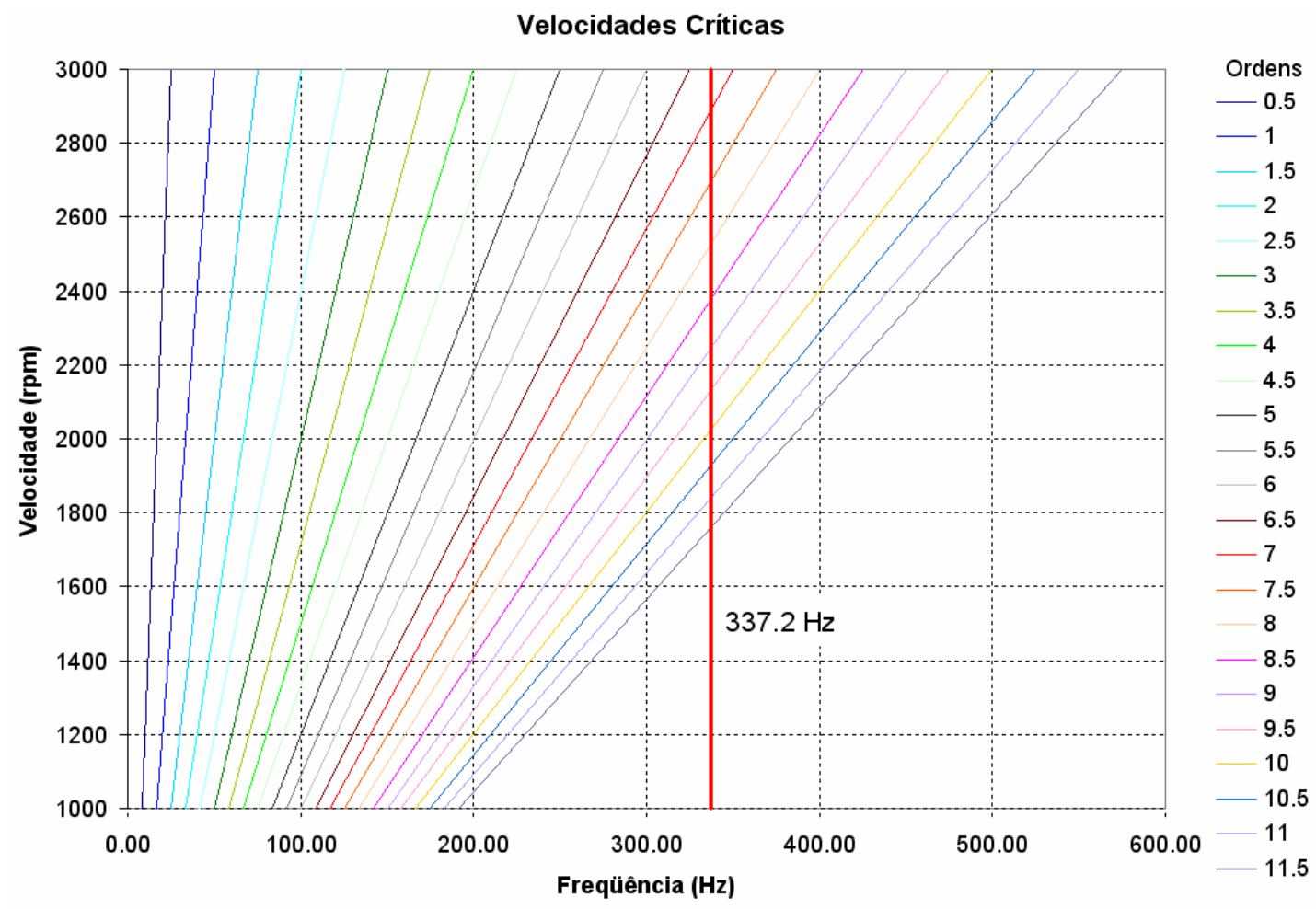

Figura 56: Velocidades críticas da árvore de manivelas

Pela Figura 56, pode-se verificar que as chamadas ordens do carregamento maiores que sete, excitam o primeiro modo de vibrar calculado.

As ordens são espaçadas de 0,5 a 0,5 pois, como o motor do estudo de caso é de quatro tempos, a cada ciclo completo de um determinado cilindro, são realizadas duas rotações da árvore de manivelas e, assim, um período completo da excitação. Deste modo, as ordens representadas na Figura 56 correspondem a meio harmônico do torque, sendo a ordem 0,5 correspondente ao primeiro harmônico, a 1 ao segundo harmônico e assim por diante.

Pode-se ainda executar a análise harmônica da resposta dinâmica para validar quais ordens são mais significativas. 


\subsection{Análise Dinâmica}

Nas Figuras 57 e 58, os gráficos de deslocamento, velocidade, e carregamento em função do tempo foram obtidos conforme os dois métodos detalhados no capítulo 5 (aceleração constante e linear) com condições de carregamento selecionadas na condição de máxima força do gás (rotação do virabrequim: 2200rpm).

Foi selecionado o nó correspondente ao da posição do Volante (nó 6) para visualizar o deslocamento e velocidade em função do tempo pois nele se concentra a maior inércia mas todos os nós podem ser estudados numa análise mais aprofundada. $O$ nó 5 , no caso, corresponde à posição do quarto moente.

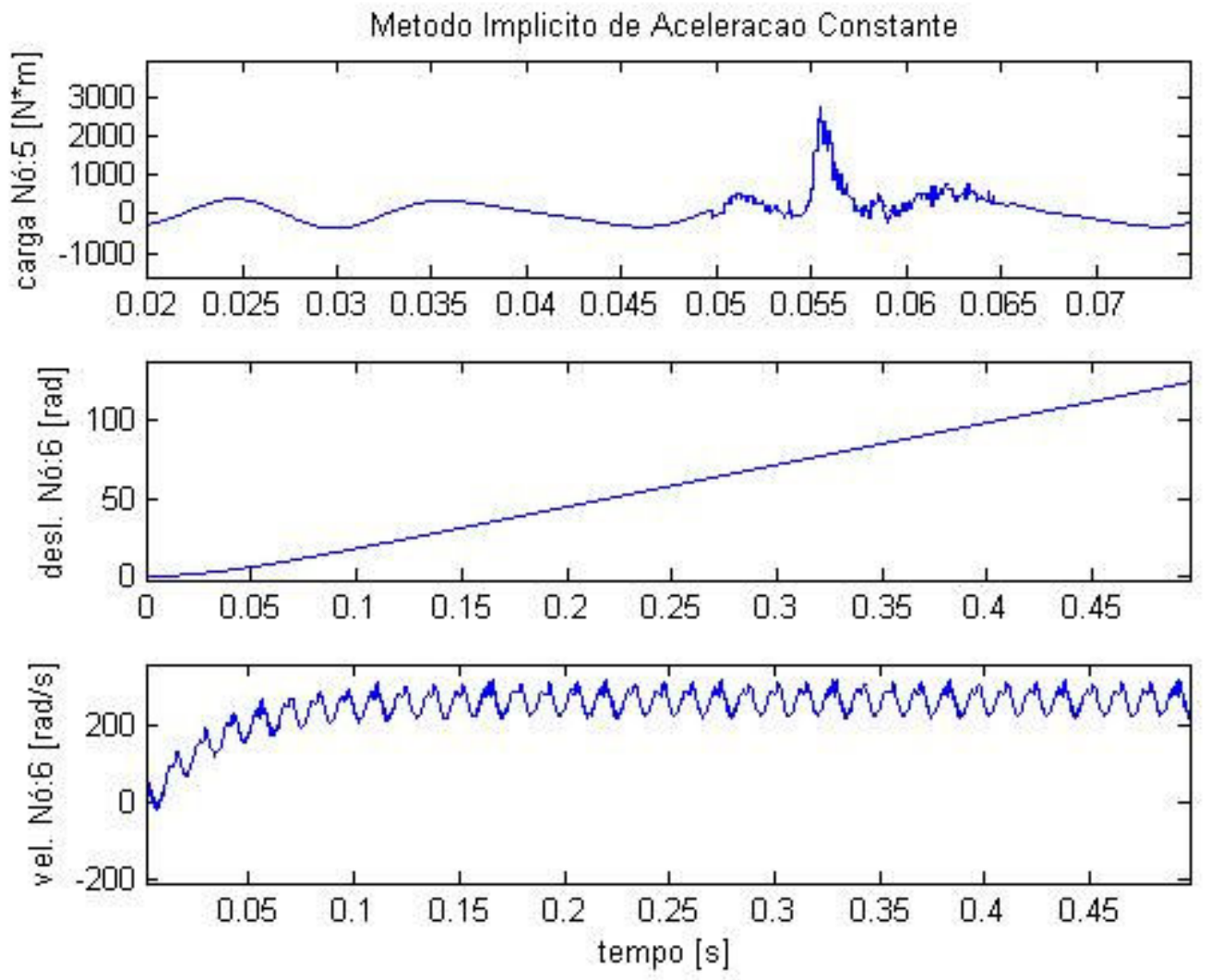

Figura 57: Resposta Dinâmica - Aceleração Constante 

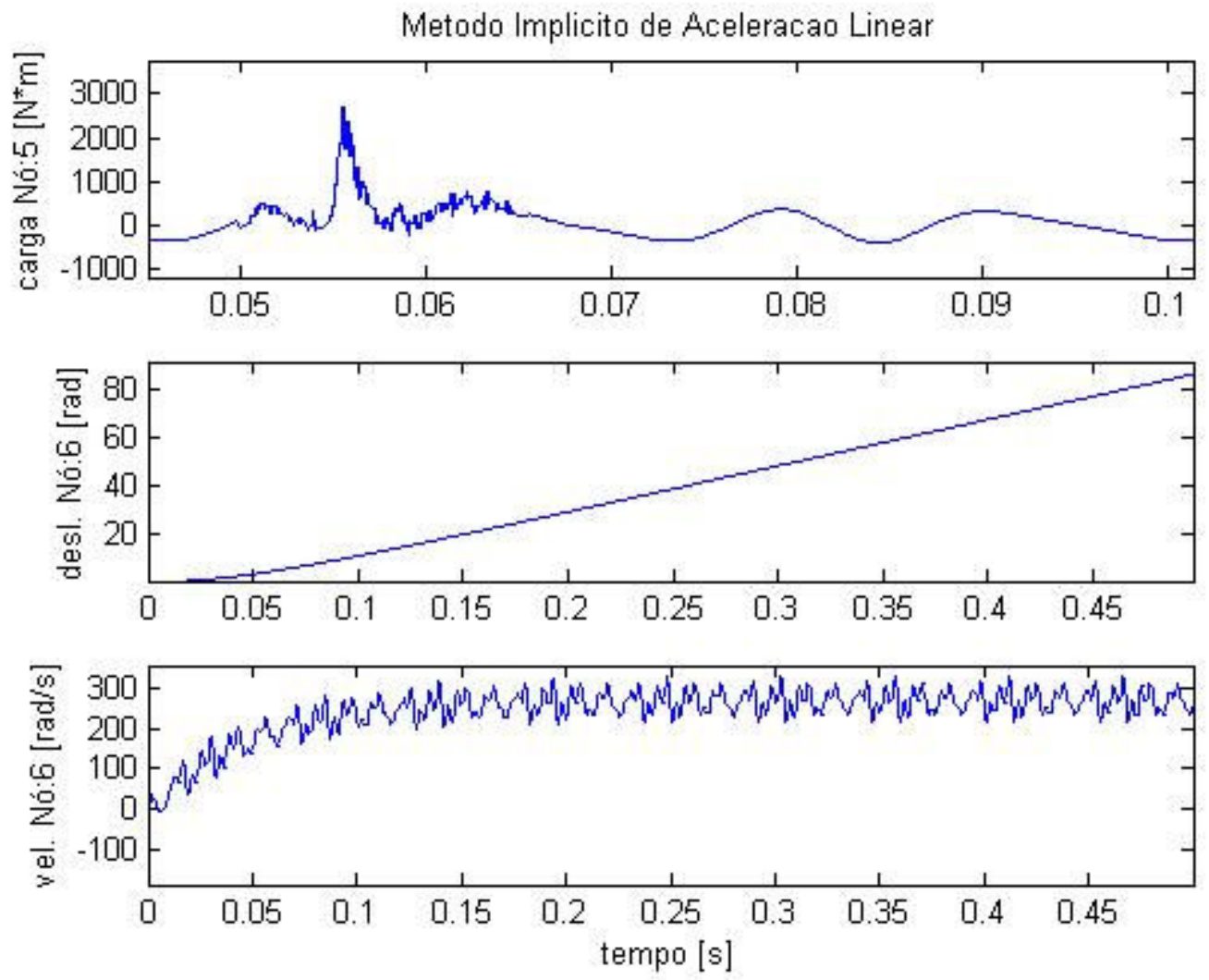

Figura 58: Resposta Dinâmica - Aceleração Linear

As Figuras 57 e 58 indicam consistência do algoritmo desenvolvido, pois resultam em velocidade média em regime de $\omega=246 \mathrm{rad} / \mathrm{s}$ próxima à esperada pelo carregamento, de 230rad/s (ou 2200rpm) e ilustram um comportamento de carregamento e deslocamento com perfis que nos permitem deduzir a amplitude de vibração torcional. Conforme ilustra a Figura 59, a amplitude pode ser calculada através da aproximação linear, pelo método dos mínimos quadrados, da curva de deslocamento no nó estudado (nó 6), na região de regime permanente.

A diferença máxima da curva de deslocamento em regime para a aproximação linear aplicada conforme mostrada na Figura 59, resulta na amplitude de vibração.

O valor para a amplitude de vibração, encontrado para este caso, foi de 0,00034rad (0,0195graus). Para o caso de máxima velocidade, obteve-se como saída a amplitude de vibração de 0,00025rad (0,0143graus). 


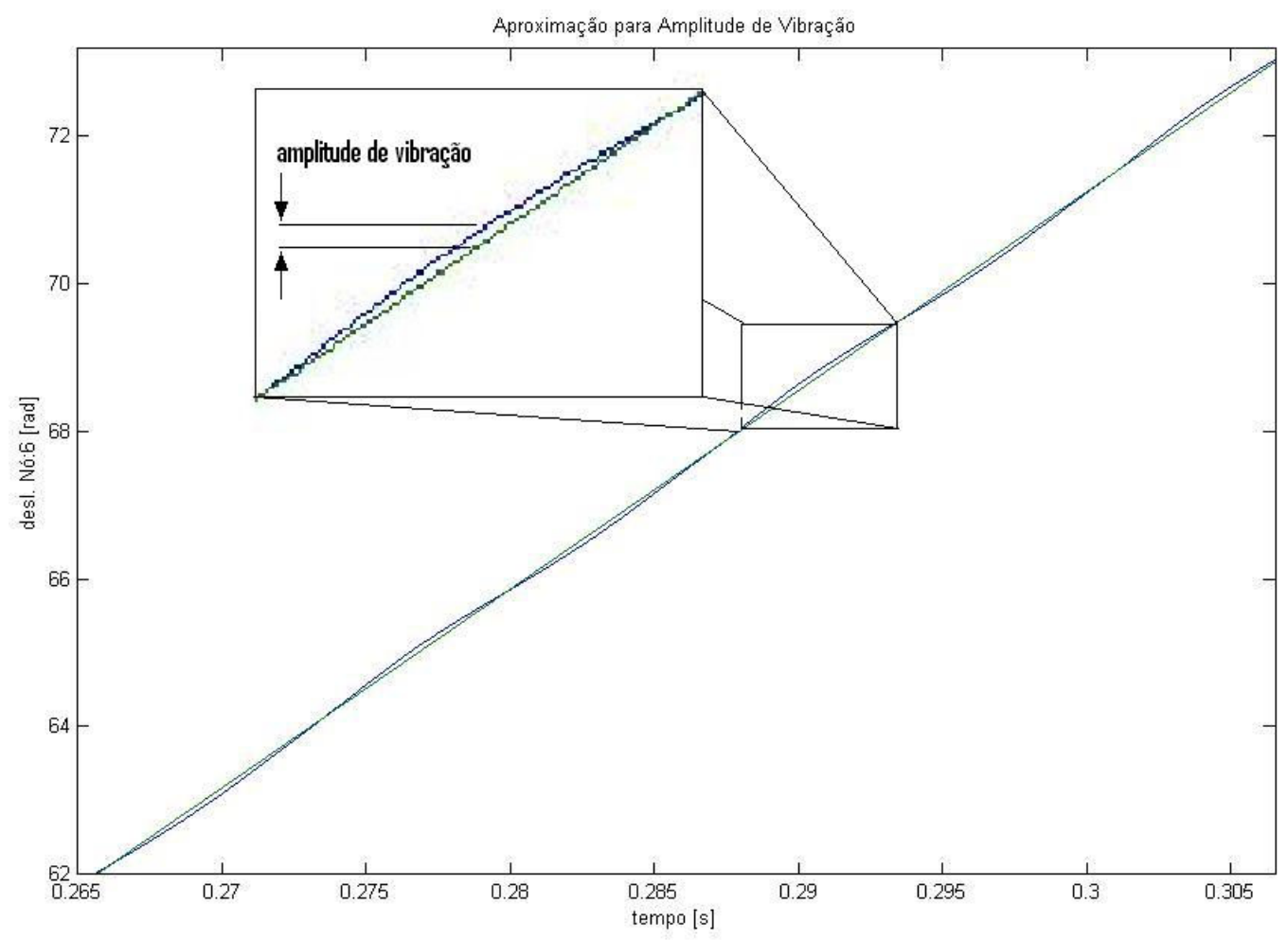

Figura 59: Resposta Dinâmica - Aproximação (MMQ) na região de regime permanente 


\subsection{Cálculo Estrutural}

Como já mencionado, para o dimensionamento de virabrequins, devemos executar no mínimo duas análises simulando as condições mais críticas de funcionamento: quando a força de gás é máxima e, portanto tendo maior compressão, e quando a força de inércia é máxima. Nos dois casos devem ser calculadas as tensões para $F_{p}$ máxima e $F_{p}$ mínima na mesma rotação obtendo assim as tensões alternadas e médias, conforme ilustrado no capítulo 6 .

Os valores para os carregamentos utilizados neste estudo foram obtidos do carregamento total, forças de inércia somadas às forças de gás, calculado conforme mostrado nas Figuras 43 e 44 para os dados numéricos resumidos no início deste capítulo. Para este caso específico, a condição de máxima força do gás ocorre, conforme já citado, a 2200rpm e a máxima força de inércia, ocorre a 3000rpm.

Para exemplificar a análise citada com o componente escolhido para o estudo de caso, as quatro análises descritas no capítulo 6 foram feitas, gerando perfis de distribuição de tensões como comumente observados na prática, concentrando seus valores máximos basicamente nos raios de transição entre os munhões e braços, entre moentes e braços e furos de lubrificação.

As condições de contorno utilizadas são mostradas na Figura 60. Foram dispostas nas Figuras 61 e 62 as condições críticas para o caso de $F_{p}$ e força do gás máximas (caso 1 ), e $F_{p}$ mínima na mesma rotação (caso 2 ).

Os valores de força utilizados na máxima força do gás e máxima força de inércia são resumidos na tabela 6 , de onde se pode observar o momento resultante da vibração torcional ( $\mathrm{Mt}_{\text {vibr }}$ ) na seção estudada (manivela 4, próxima ao volante) e os valores de momento de torção e força radial nos valores mínimos e máximos, para as condições de máxima força de gás e máxima força de inércia.

Nesta análise foram utilizados 36656 elementos sólidos tetraédricos totalizando 56000 nós.

\begin{tabular}{ccccccccc}
\hline Rotação [rpm] & \multicolumn{2}{c}{ Amplitude } & $\mathrm{Kt}[\mathrm{Nm} / \mathrm{rad}]$ & $\mathrm{Mt}_{\text {vibr }}[\mathrm{Nm}]$ & $\mathrm{M}_{\text {min }}$ & $\mathrm{Mt}_{\text {max }}$ & $\mathrm{Fr}_{\text {min }}$ & $\mathrm{Fr}_{\text {max }}$ \\
\hline 2200 & 0,00034 & 0,0195 & 1186000 & 403,2 & $-380,6$ & 3098,9 & -11087 & 117578 \\
3000 & 0,00025 & 0,0143 & 1186000 & 296,5 & $-733,3$ & 826,4 & -21138 & 40093 \\
\hline
\end{tabular}

Tabela 6: Carregamento utilizado no estudo 


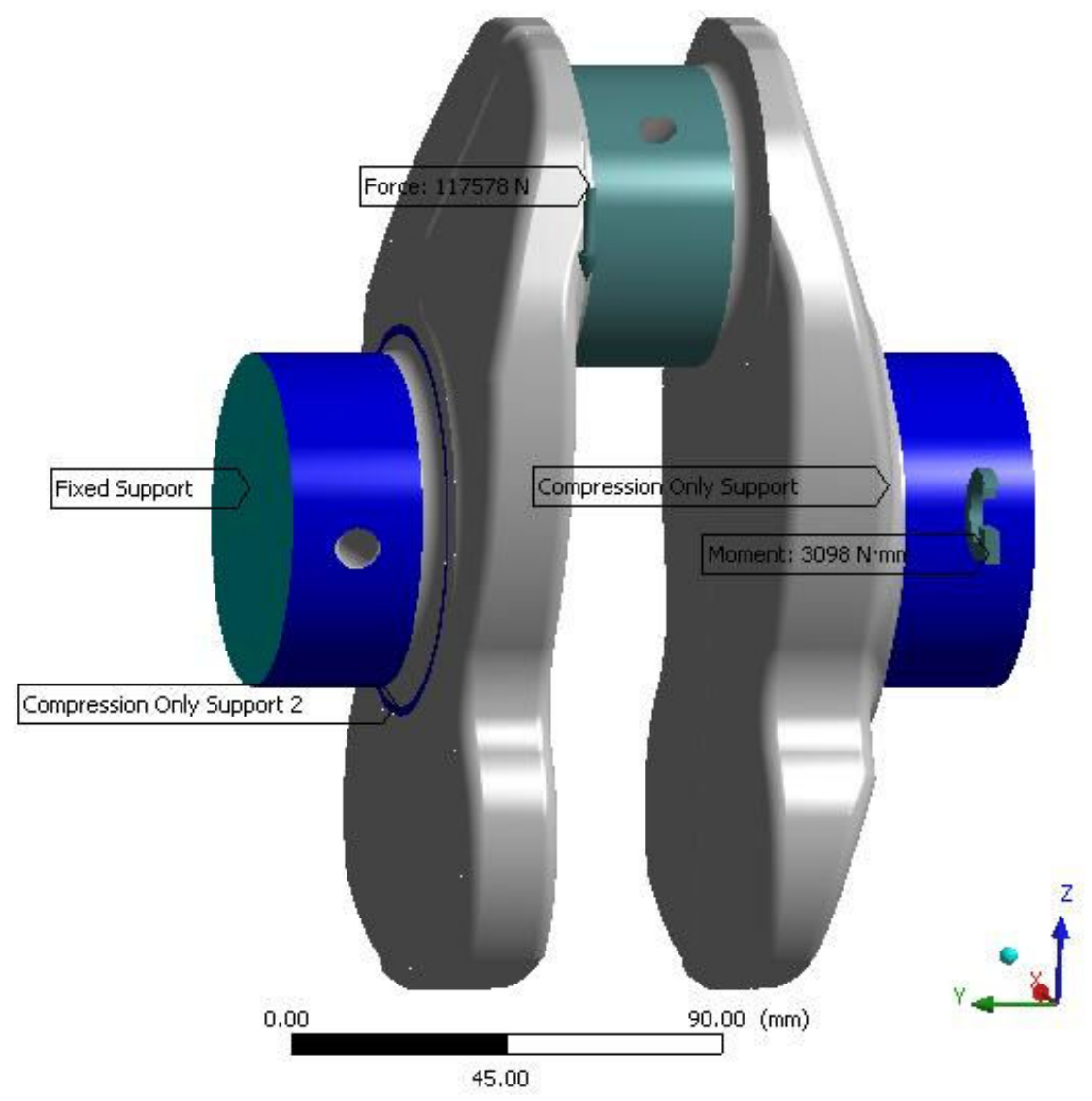

Figura 60: Condições de contorno para o exemplo estudado 
Maximum Principal Stress $\mathrm{MPa}$

Max: $1.123 \mathrm{e}+002$

Min: $-2.090 \mathrm{e}+001$

2007/12/9 18:49

\begin{tabular}{|l}
112,347 \\
97,541 \\
82,735 \\
67,929 \\
53,124 \\
38,318 \\
23,512 \\
8,707 \\
$-6,099$ \\
$-20,905$
\end{tabular}

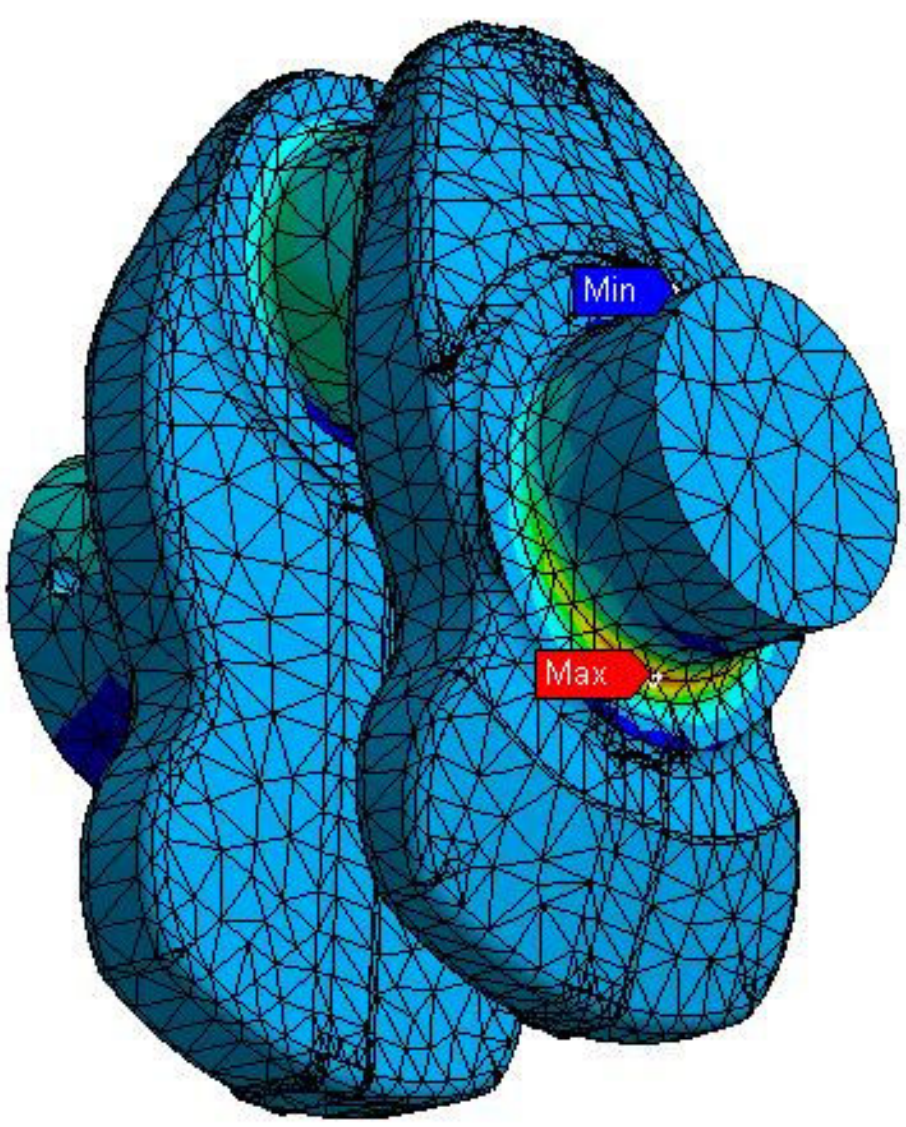

Figura 61: Máxima tensão principal para $F_{p}$ máxima no caso 1
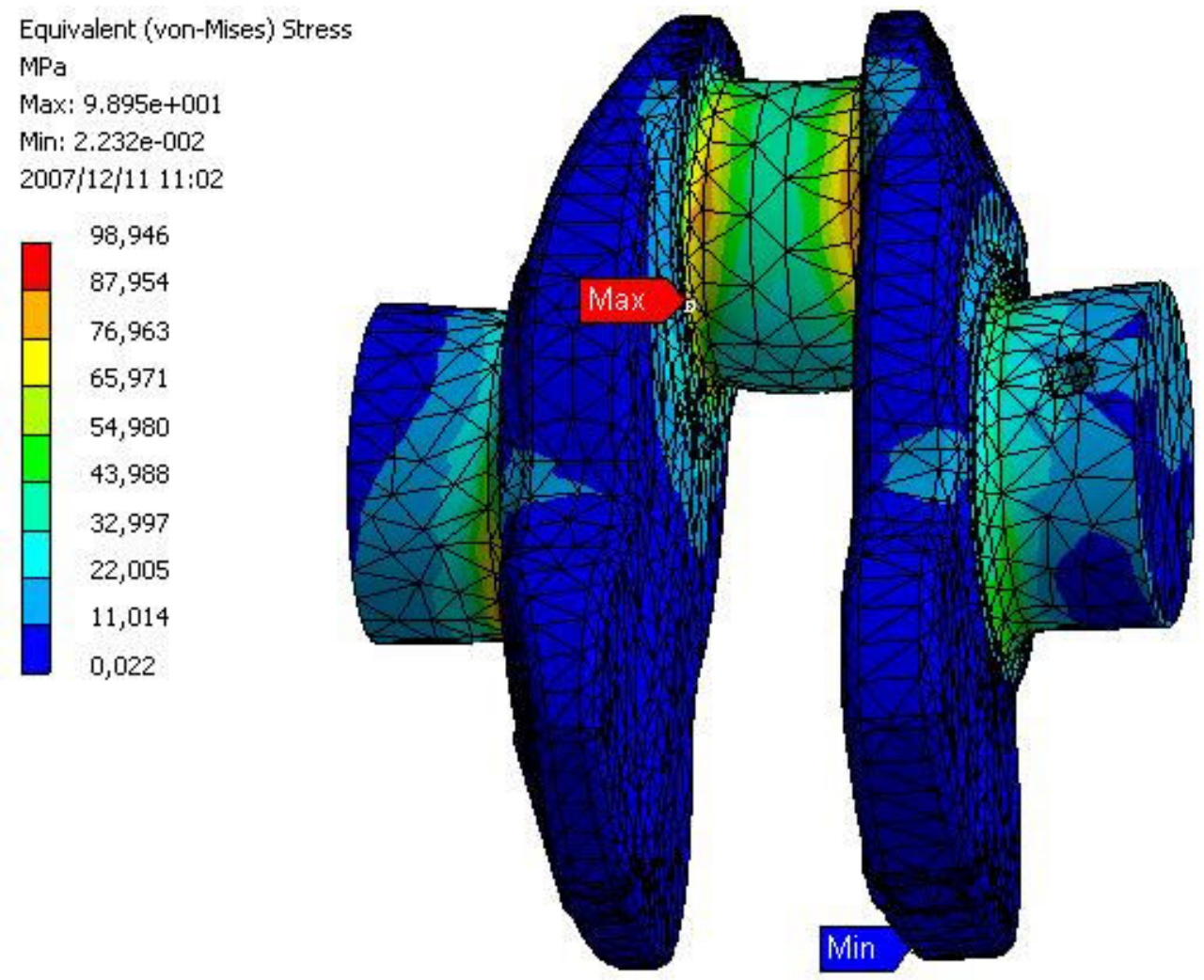

Figura 62: Tensão equivalente de Von Mises no caso 1 
Os componentes do tensor de tensões para o ponto crítico mostrado na Figura 61, com maior valor da tensão máxima principal, encontram-se na tabela 7. A tabela 8 mostra as tensões médias e alternadas calculadas. Tabelas como estas devem ser geradas para outras seções da árvore de manivelas, em estudos mais aprofundados. No presente trabalho foram feitos os cálculos baseados no ponto especificado na Figura 61 para ilustrar o cálculo dos coeficientes de segurança de falha por fadiga.

\begin{tabular}{llcccc}
\hline & & \multicolumn{2}{c}{ Máximo Carregamento } & \multicolumn{2}{c}{ Máxima Velocidade } \\
& & Fp máx & Fp mín & Fp máx & Fp mín \\
\hline$\sigma_{\mathrm{xx}}$ & {$[\mathrm{MPa}]$} & 20,24 & 0,11 & 4,37 & 0,19 \\
$\sigma_{\mathrm{yy}}$ & {$[\mathrm{MPa}]$} & 46,49 & 0,00 & 9,80 & 0,00 \\
$\sigma_{\mathrm{zz}}$ & {$[\mathrm{MPa}]$} & 52,42 & $-0,08$ & 14,95 & $-0,16$ \\
$\tau_{\mathrm{xy}}$ & {$[\mathrm{MPa}]$} & 0,64 & 0,00 & $-0,03$ & 0,00 \\
$\tau_{\mathrm{xz}}$ & {$[\mathrm{MPa}]$} & $-38,10$ & $-0,03$ & $-11,75$ & 0,03 \\
$\tau_{\mathrm{yz}}$ & {$[\mathrm{MPa}]$} & $-0,62$ & 0,00 & $-0,02$ & 0,00 \\
\hline
\end{tabular}

Tabela 7: Tensões para os dois casos no ponto crítico

\begin{tabular}{llcccc}
\hline & & \multicolumn{2}{c}{ Máximo Carregamento } & \multicolumn{2}{c}{ Máxima Velocidade } \\
& & alternada & média & alternada & média \\
\hline$\sigma_{\mathrm{xx}}$ & {$[\mathrm{MPa}]$} & 10,06 & 10,17 & 2,09 & 2,28 \\
$\sigma_{\mathrm{yy}}$ & {$[\mathrm{MPa}]$} & 23,24 & 23,25 & 4,90 & 4,90 \\
$\sigma_{\mathrm{zz}}$ & {$[\mathrm{MPa}]$} & 26,25 & 26,17 & 7,56 & 7,40 \\
$\tau_{\mathrm{xy}}$ & {$[\mathrm{MPa}]$} & 0,32 & 0,32 & $-0,02$ & $-0,02$ \\
$\tau_{\mathrm{xz}}$ & {$[\mathrm{MPa}]$} & $-19,04$ & $-19,07$ & $-5,89$ & $-5,86$ \\
$\tau_{\mathrm{yz}}$ & {$[\mathrm{MPa}]$} & $-0,31$ & $-0,31$ & $-0,01$ & $-0,01$ \\
\hline
\end{tabular}

Tabela 8: Tensões alternadas e médias para os dois casos no ponto crítico

\subsection{Coeficientes de Segurança}

Tendo as tensões equivalentes calculadas a partir dos dados da tabela 8 , pode-se calcular o coeficiente de segurança conforme ilustrado no capítulo 6 . O diagrama de Goodman para os dados do estudo de caso e a condição crítica de máximo carregamento nos casos 1 e 2 conforme a Tabela 5, encontram-se na Figura 63.

A tensão equivalente de resistência à fadiga $S_{e}$ foi calculada para o estudo de caso seguindo a teoria ilustrada no capítulo 6 .

A região onde se localiza o ponto crítico estudado é usinada. Assim, o fator de 
superfície definido pela equação 6.1 .1 tem coeficientes $a$ e $b$ tabelados ${ }^{34}$ respectivamente iguais a 4,51 e -0.265 resultando em $\mathrm{k}_{\mathrm{a}}=0.72$.

$$
\mathrm{k}_{\mathrm{a}}=\mathrm{a} \cdot\left(\mathrm{S}_{\mathrm{ut}}\right)^{\mathrm{b}}
$$

Pelo valor do diâmetro do munhão estudado $(70 \mathrm{~mm})$ o fator de forma utilizado foi: $\mathrm{k}_{\mathrm{b}}=0.6$.

Como o carregamento no virabrequim tem componentes de torção e cisalhamento o fator modificador de carga tem valor: $\mathrm{k}_{\mathrm{c}}=0.577$.

Finalmente, para os fatores de temperatura $\left(k_{d}\right)$ e efeitos miscelâneos $\left(k_{e}\right)$ foi utilizado valor unitário dado que o componente é estudado em condições de temperatura ambiente e a concentração de tensões já é tratada na análise via método dos elementos finitos.

Utilizando todos os fatores multiplicadores ilustrados e a tensão limite de resistência à compressão de $1000 \mathrm{MPa}$, obtemos um valor para a tensão equivalente $S_{e}$ de 250.3 MPa. Tendo então os valores da tensão limite de resistência à ruptura $\left(S_{u}\right)$ e a tensão limite de fadiga $\left(S_{e}\right)$ e a tensão limite de escoamento $\left(S_{y}\right)$, pode-se construir o diagrama de Goodman ilustrado nas Figuras 35 e 62.

Finalmente, obtém-se o coeficiente de segurança pela relação de B sobre A (Figura 62).

\begin{tabular}{llcccc}
\hline & & \multicolumn{2}{c}{ Máximo Carregamento } & \multicolumn{2}{c}{ Máxima Velocidade } \\
& alternada & média & alternada & média \\
\hline$\sigma_{\mathrm{vm}}$ & {$[\mathrm{MPa}]$} & 36.20 & 36.18 & 11.25 & 11.08 \\
\hline $\mathrm{SF}-$ & 6.38 & \multicolumn{3}{c}{21.98}
\end{tabular}

Tabela 9: Tensões equivalentes e fatores de segurança para os dois casos no ponto crítico 
Diagrama de Goodman Modificado

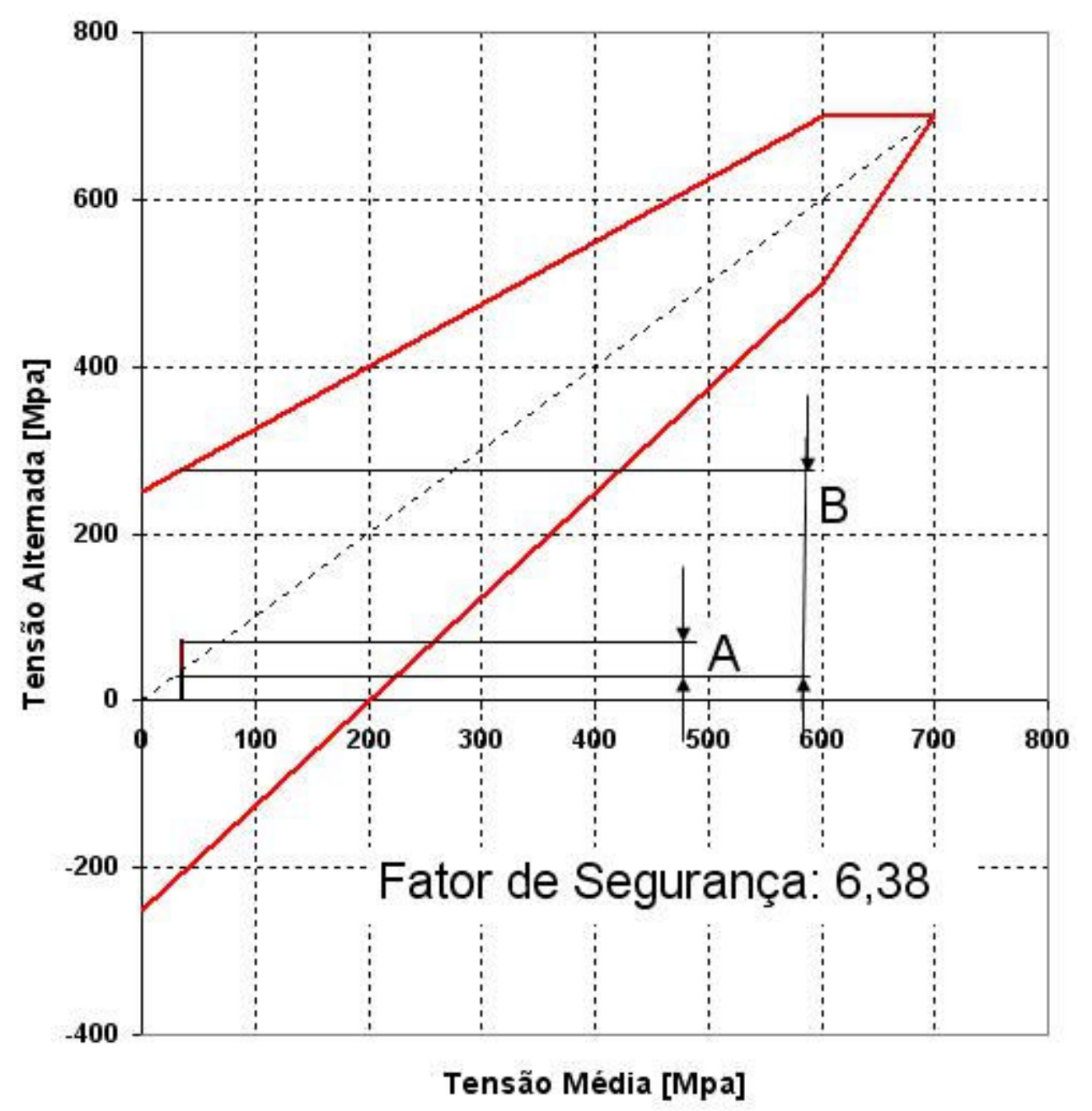

Figura 63: Diagrama de Goodman mdificado para o estudo de caso 


\subsection{Otimização}

\subsubsection{Otimização Estrutural}

Foi realizado um estudo de otimização visando minimizar a massa do componente, mantendo ou reduzindo os níveis de tensão do projeto corrente. O modelo tridimensional utilizado na análise estrutural foi simplificado para que o tempo de cada simulação necessária no estudo de sensibilidade fosse reduzido. Este modelo simplificado encontra-se na Figura 64 tendo seus índices de tensão variado pouco com a simulação mas o tempo necessário para a obtenção dos resultados reduzido drasticamente. Na simplificação foram utilizadas as propriedades de simetria e eliminados detalhes que influenciariam muito pouco no resultado final, tais como raios externos e parte do contrapeso.

Assim, para a condição de sobrecarregamento com força de Fp máxima idêntica à utilizada no caso 1 da tabela 5 do capítulo 6 , a distribuição de tensões para a máxima principal obtida foi muito semelhante à encontrada anteriormente para o modelo completo, antes em torno de $130 \mathrm{MPa}$ e no modelo simplificado, em torno de $110 \mathrm{MPa}$. 


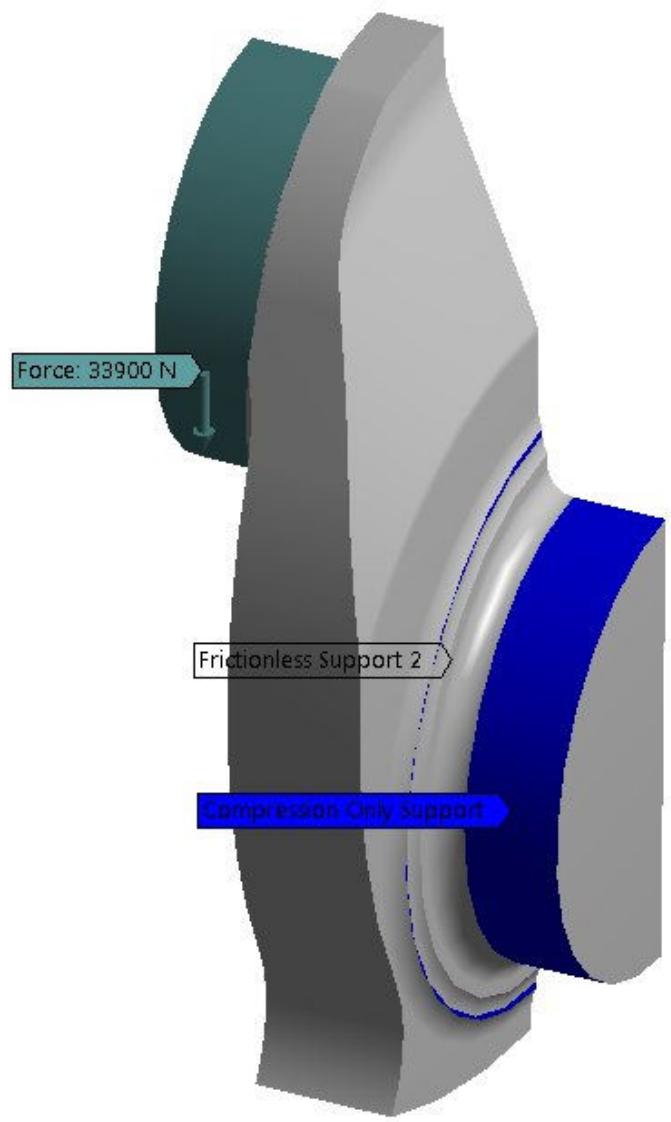

Figura 64: Condições de contorno para estudo de otimização

Foi feito o estudo de sensibilidade da tensão máxima principal no raio do munhão conforme análises anteriores, em função de dois parâmetros: largura do braço e distância da face do braço adjacente ao moente até o centro do quarto munhão, ou seja até o centro da árvore de manivelas. Este último parâmetro foi aqui denominado de comprimento (Figura 65). Estes dois fatores em questão foram selecionados para que, numa primeira abordagem, se objetive otimizar o componente sem a necessidade de alterar outros componentes do motor como ocorreria em caso de alteração dos diâmetros de moente e munhão ou dos raios de transição dos mesmos com o braço do virabrequim por exemplo, o que exigiria a alteração da biela ou do bloco do motor.

Neste estudo de sensibilidade, foi inicialmente executada uma análise de influência dos dois fatores atuando simultaneamente (Figura 66) tendo como saídas a tensão máxima principal, em sua região crítica no raio do munhão, e a massa do braço.

Gráficos de estudos de sensibilidade como este devem ser extensamente explorados para análise dos efeitos principais dos fatores nas saídas bem como de 
suas interações.

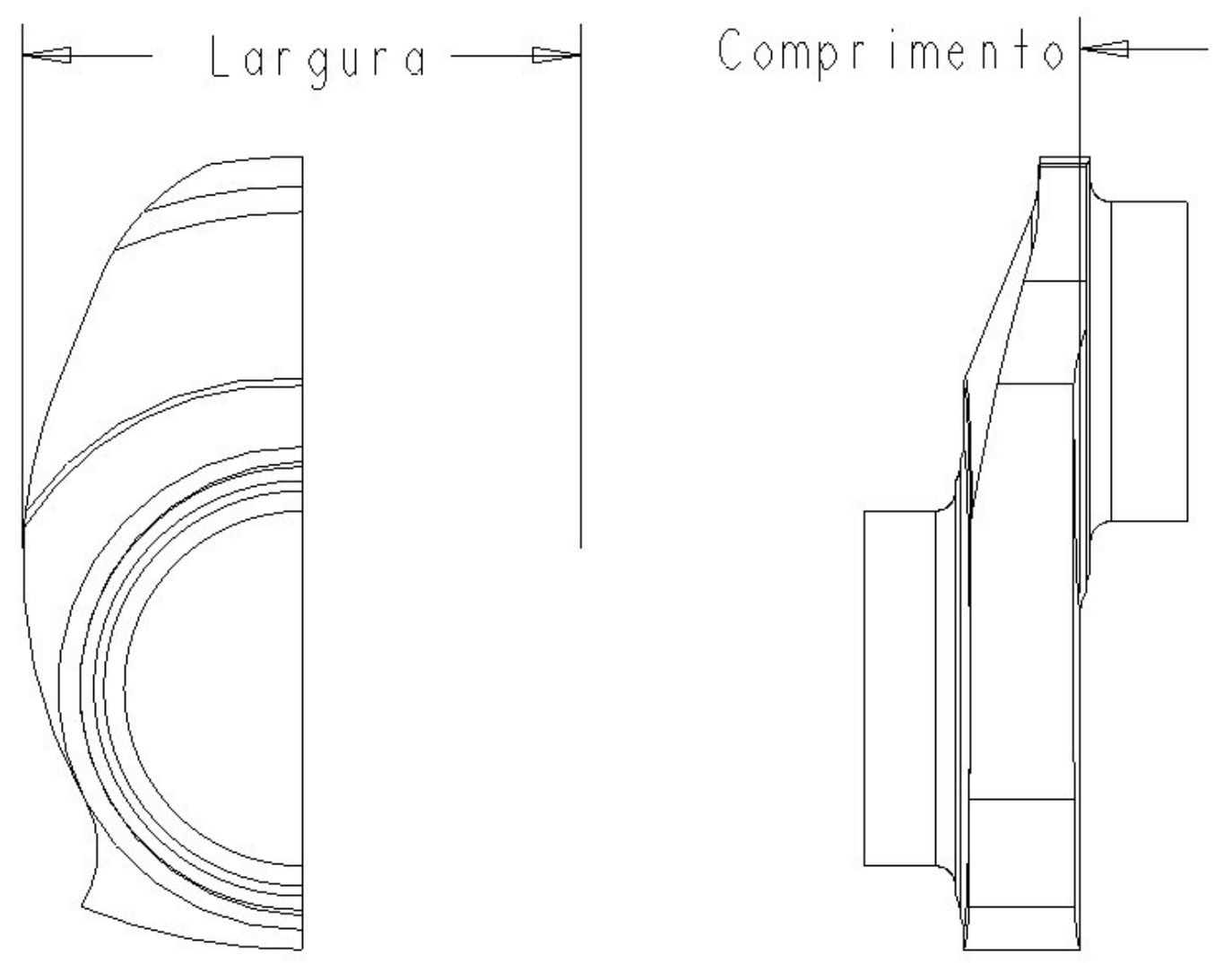

Figura 65: Dimensões analisadas na otimização 
Maximum Principal Stress 2 Maximum

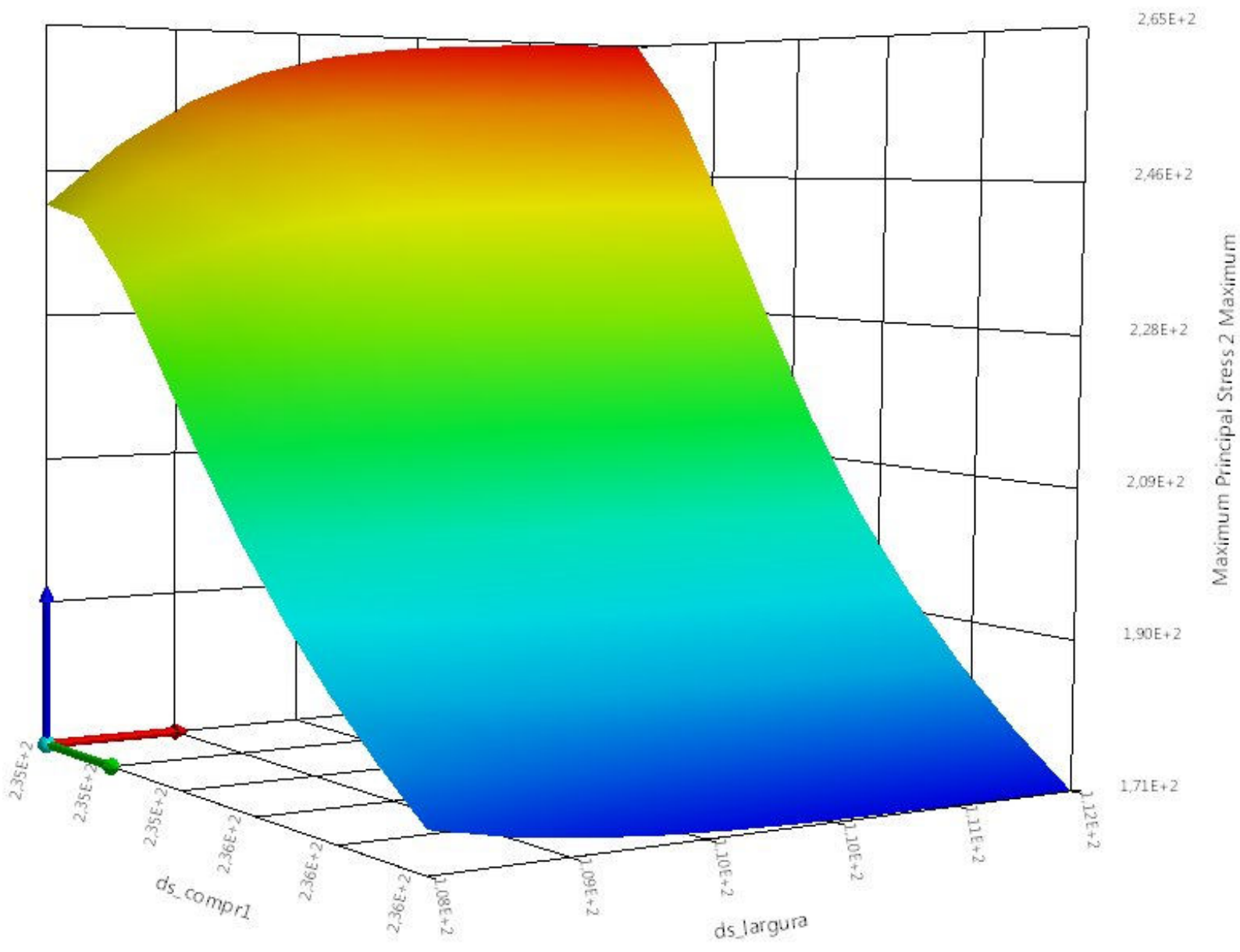

Figura 66: Estudo de sensibilidade $-\sigma_{1} \times$ comprimento $x$ largura

A Figura 66 confirma a não linearidade da resposta e uma forte interação entre comprimento e largura. Ou seja, quando o comprimento é máximo, o efeito da largura na saída é diferente de quando o primeiro fator se encontra no seu nível mínimo. O parâmetro que tem maior efeito na saída em questão é o comprimento. Já para a massa como saída, observa-se, na Figura 67, um efeito mais pronunciado da largura. 


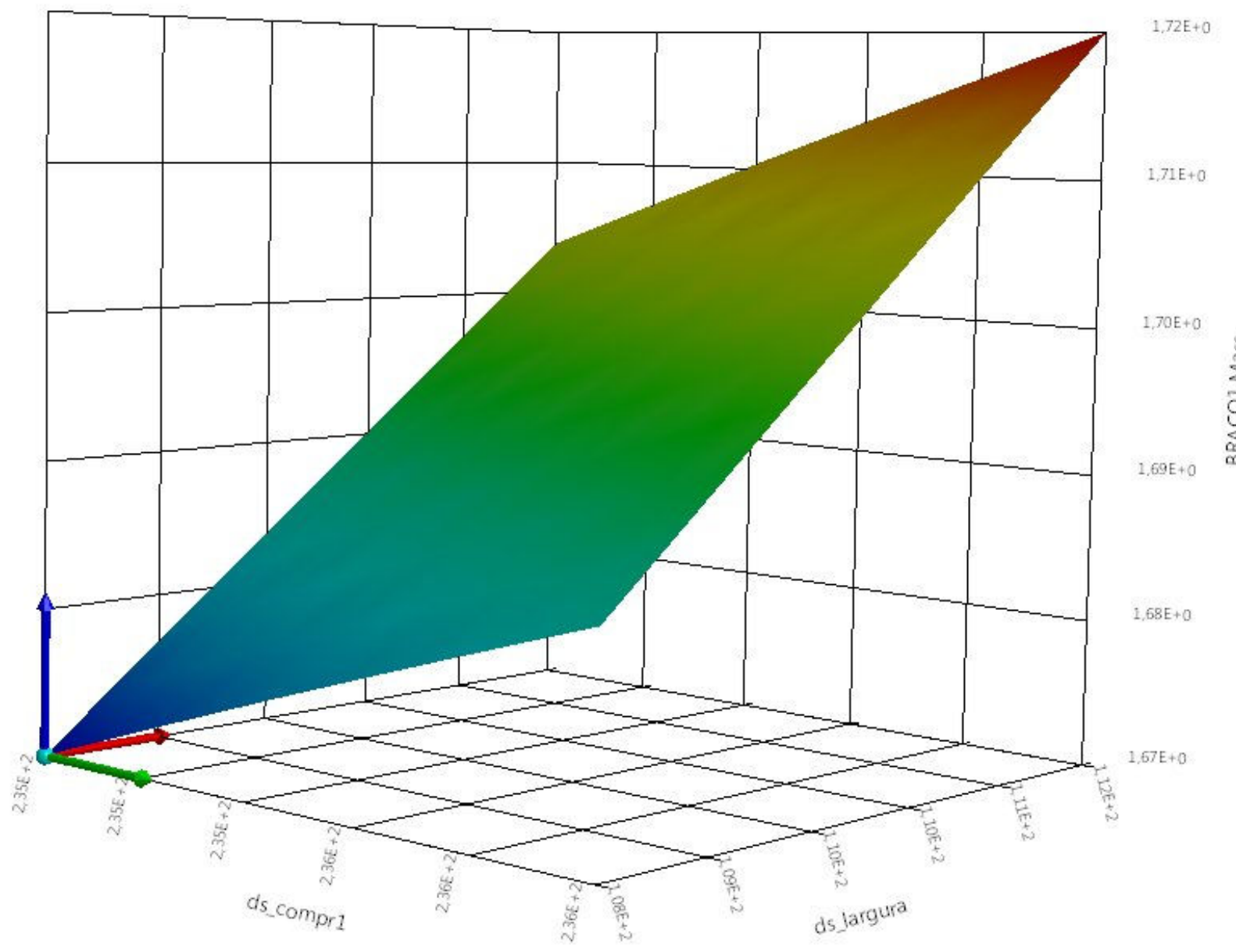

Figura 67: Estudo de sensibilidade - massa $x$ comprimento $x$ largura

$\mathrm{Na}$ Figura 68 segue a busca pelos valores de máximo e mínimo executada pelo software de análise dentro do espaço amostral especificado.

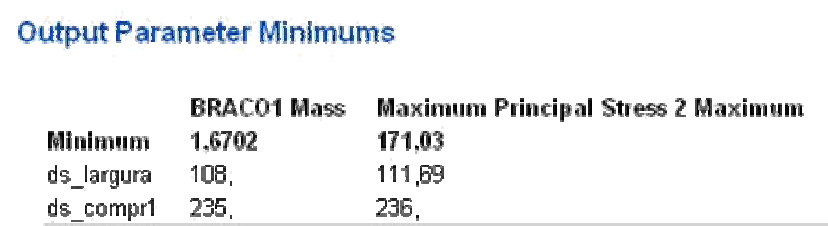

\section{Output Parameter Maximums}

$\begin{array}{lll} & \text { BRACO1 Mass } & \text { faximum Principal Stress } 2 \text { Maximum } \\ \text { Maximum } & \mathbf{1}, 7203 & 265,24 \\ \text { ds_largura } & 111,99 & 111,89 \\ \text { ds_compr1 } & 236, & 235,\end{array}$

Figura 68: Estudo de sensibilidade - massa $x$ comprimento $x$ largura Utilizando o algoritmo de otimização baseado numa amostragem quase-aleatória, obtem-se candidatos a valores ótimos de cada uma das saídas selecionadas, dependendo do peso e do objetivo proposto para as mesmas. Na Figura 69, propôs- 
se minimizar a massa do componente sem estabelecer algum obetivo específico para a tensão.

Input Parameter Goals

Click rows in this table to assign design goals 10 inpul parameters.

\begin{tabular}{|c|c|c|c|c|c|}
\hline $\begin{array}{l}\text { Hame } \\
\text { ds_largua } \\
\text { ds comprl }\end{array}$ & $\begin{array}{l}\text { Lower Bound } \\
108 \text {, } \\
235 \text {, }\end{array}$ & $\begin{array}{l}\text { Upper Bound } \\
112 \text {. } \\
236 \text {. }\end{array}$ & Target & $\begin{array}{l}\text { Desíad Value } \\
\text { No Preference } \\
\text { No Preference }\end{array}$ & $\begin{array}{l}\text { Impontance } \\
\text { Default } \\
\text { [lefault }\end{array}$ \\
\hline
\end{tabular}

\section{Response Parameter Goals}

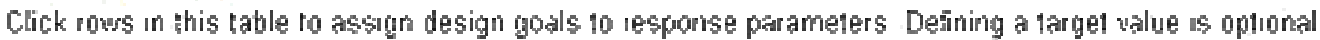

\begin{tabular}{|c|c|c|c|c|}
\hline Hame & Target & Desired Value & Imponançe & Tradeoff \\
\hline BRACO1 Mass & - & Minumum Posstale & Higher & On \\
\hline Maximun Prncipal Stress 2 Mayimum & - & No Preference & Defisult & - \\
\hline
\end{tabular}

\section{Candidate Designs}

(7) Gonerate or update candidate designs based on the current goals

\begin{tabular}{|c|c|c|c|c|c|c|}
\hline Parameter & - Candi & ate $A$ & Candid & te B & Candida & $\mathrm{C}$ \\
\hline ds_largura & 100. & - & 108,44 & - & 1008 & - \\
\hline 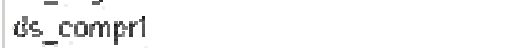 & 235 . & $=$ & 21 & $=$ & 235 & - \\
\hline Mass & 1 . $670 \mathrm{~kg}$ & औरे & 1,6 & 武事该 & $1,6776 \mathrm{~kg}$ & 齐光 \\
\hline Aasimurn Prncipal Stress 2 Mayimum & $242, M P$ & - & $249.8 \mathrm{MPa}$ & $=$ & $255,52 \mathrm{MPa}$ & - \\
\hline
\end{tabular}

Figura 69: Candidatos para os valores de mínima massa sem restrição para a tensão Input Parameter Goals

Click rows in this table to assign design goals 10 input garameters.

\begin{tabular}{|c|c|c|c|c|c|}
\hline $\begin{array}{l}\text { Name } \\
\text { ds_lagura } \\
\text { ds_corner } 1\end{array}$ & $\begin{array}{l}\text { Lower Bound } \\
108 \text {. } \\
235 \text {. }\end{array}$ & $\begin{array}{l}\text { Upper Bound } \\
112 \\
235\end{array}$ & Target & $\begin{array}{l}\text { Desired Value } \\
\text { Nó Preference } \\
\text { Nó Preference }\end{array}$ & $\begin{array}{l}\text { Impontames } \\
\text { Defoult } \\
\text { Defoult }\end{array}$ \\
\hline
\end{tabular}

Response Parameter Goals

Click rows in this table to assign design goals 10 response parameters Detinning a target value is optional

$\begin{array}{lllll}\text { Hame } & \text { Target } & \text { Desired Value } & \text { Impontance } & \text { Trade0f } \\ \text { BRACO1 Mass } & - & \text { Minimum Possible } & \text { Higher } & \text { On } \\ \text { Mamimum Principal Stress 2 Maximum } & - & \text { Minimum Possible } & \text { Lower } & \text { On }\end{array}$

\section{Candidate Designs}

Generate or undate candudate desians based on the currenl goals

\begin{tabular}{|c|c|c|c|c|c|c|}
\hline Parameter & (a Candid & ate $A$ & 5 Candidat & B & $C$ Candidat & $c$ \\
\hline ds_largura & 108, & $=$ & 108 & $=$ & 100,01 & $=$ \\
\hline ds_compr1 & 235, & $=$ & 235,5 & $=$ & 235,94 & $=$ \\
\hline BRACO1 Mass & $1,6702 \mathrm{~kg}$ & kt $k$ और & $1,6779 \mathrm{~kg}$ & स्र: & $1,6844 \mathrm{~kg}$ & औ \\
\hline Maximum Principal Stress 2 Maximum & 242, $\mathrm{MPg}$ & $x \times$ & $207,69 \mathrm{MPa}$ & 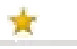 & $179,01 \mathrm{MPa}$ & tht \\
\hline
\end{tabular}

Figura 70: Candidatos para os valores de mínima massa com restrição para a tensão

Na figura 70, pôde-se observar um estudo de otimização da massa com a tentativa de minimizar concomitantemente a tensão, com a diferença que para a última foi estabelecido um peso menor que o definido para a massa.

Assim, analisando dos candidatos levantados pelo software quais saídas mostram valores viáveis e as tendências mostradas pelos candidatos apontados nota-se que a influência do fator largura na saída é praticamente desprezível. Numa análise de 
custo e benefício, verifica-se por exemplo que o candidato $A$ traz um ganho menor se comparado ao ganho de massa envolvido. Ainda assim, dado o valor grande do coeficiente de segurança de falha por fadiga calculado na análise estrutural, certamente este aumento de tensão não traz conseqüências no desempenho do componente.

Pode-se seguir num processo iterativo ou objetivar um valor específico de coeficiente de segurança mínimo para falha por fadiga do componente alcançando assim valores ideais. Dado que o objetivo do presente trabalho é a ilustração da metodologia envolvida com a otimização do componente, não foi executado o processo iterativo citado.

\subsubsection{Otimização dinâmica}

Numa segunda abordagem para ilustrar a utilização de algoritmos específicos na resolução de problemas de otimização, foi feito um estudo visando maximizar a freqüência fundamental de vibração torcional da árvore de manivelas. Para tanto, foram utilizadas como variáveis de projeto as larguras segundo mostrado na Figura 65 para todos os braços com exceção do quinto braço (contado à partir da espiga) que tem um formato arredondado para comportar um anel sensor, já explicado, com função em atuação nos efeitos de segunda ordem na vibração do componente. Assim, chamando de L1 a L8 as larguras dos braços e $\omega_{1}$ a freqüência fundamental de vibração, o problema de otimização proposto foi:

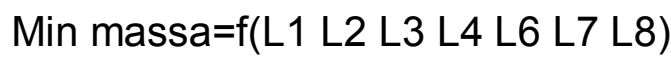

Tal que $\omega 1>0,99 \omega_{\max }$ e $108 \leq \mathrm{Li} \leq 112 \mathrm{~mm}$

Onde $\omega_{\max }$ representa a freqüência fundamental quando todas as larguras são máximas.

\section{Estudo de sensibilidade - função objetivo}

Para encontrar a função objetivo, foi feito um primeiro estudo de sensibilidade no CAD Pro/Engineer ${ }^{\circledR}$ alterando-se a largura de um dos braços em três níveis $(108 \mathrm{~mm}$, 
$110 \mathrm{~mm}$ e $112 \mathrm{~mm}$ ) e medindo-se a inércia e a massa. Para estes mesmos valores, foi calculada a rigidez torcional no software ANSYS ${ }^{\circledR}$. Na Figura 71 foram dispostos os gráficos das três saídas citadas pela largura do braço 1 da árvore de manivelas. Observa-se na faixa selecionada um comportamento linear das saídas em relação à entrada escolhida. O mesmo procedimento foi repetido para os demais braços.

Estudo de sensibilidade (K,M,I)

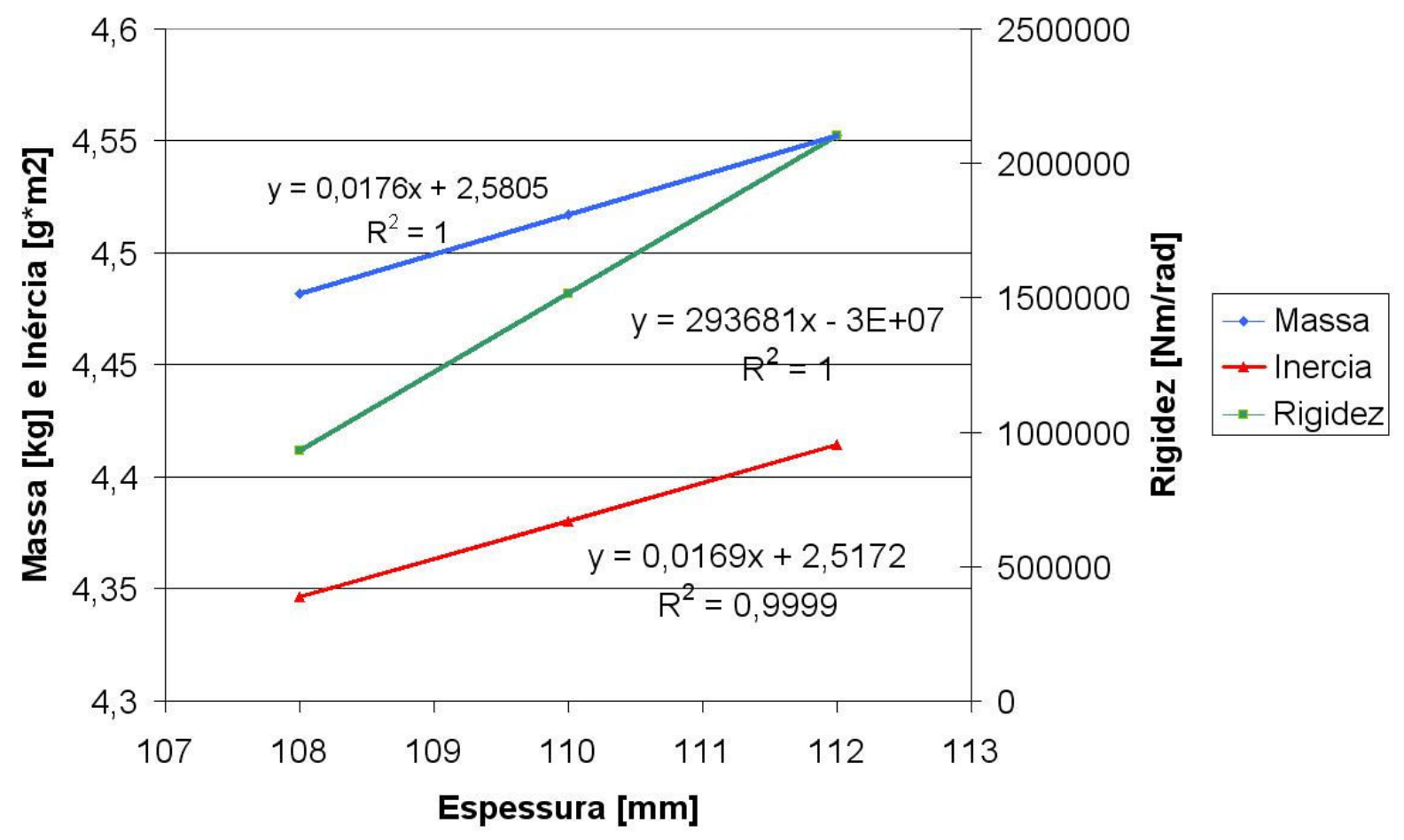

Figura 71: Estudo de sensibilidade Rigidez,Massa e Inércia x Espessura (largura do braço)

Para cada combinação das larguras dos braços, as curvas dos estudos de sensibilidade executados anteriormente foram utilizadas obtendo-se a rigidez e inércia equivalente que seriam então empregadas no programa citado (Apêndice $C$ ) para o cálculo da freqüência natural de vibração. A massa também foi armazenada para a análise de otimização.

A ferramenta DOE foi selecionada numa primeira abordagem para definir um experimento dos sete variáveis $\left(L_{1}, L_{2}, L_{3}, L_{4}, L_{6}, L_{7}\right.$ e $\left.L_{8}\right)$ em dois níveis (108mm e $112 \mathrm{~mm}$ ) que num fatorial completo (todas as combinações possíveis testadas) geraria um estudo com $2^{7}=128$ combinações. Foi feito um estudo fracionado onde apenas para 1/8 das rodadas necessárias foi calculada a freqüência fundamental pelo programa no Apêndice C. A matriz do experimento está ilustrada na Figura 72, 
no chamado Cube Plot, onde pode-se verificar os valores que foram calculados para somente 16 das 128 combinações possíveis. Apenas para ilustrar a interpretação do gráfico mencionado, por exemplo a freqüência natural destacada de $328,162 \mathrm{~Hz}$ é resultante quando $L_{1}=112, L_{2}=108, L_{3}=108, L_{4}=112, L_{6}=112, L_{7}=112$ e $L_{8}=108$. Já a freqüência natural destacada de $350,394 \mathrm{~Hz}$ é a resultante quando $L_{1}=112, L_{2}=112$, $L_{3}=108, L_{4}=108, L_{6}=108, L_{7}=112$ e $L_{8}=112$.

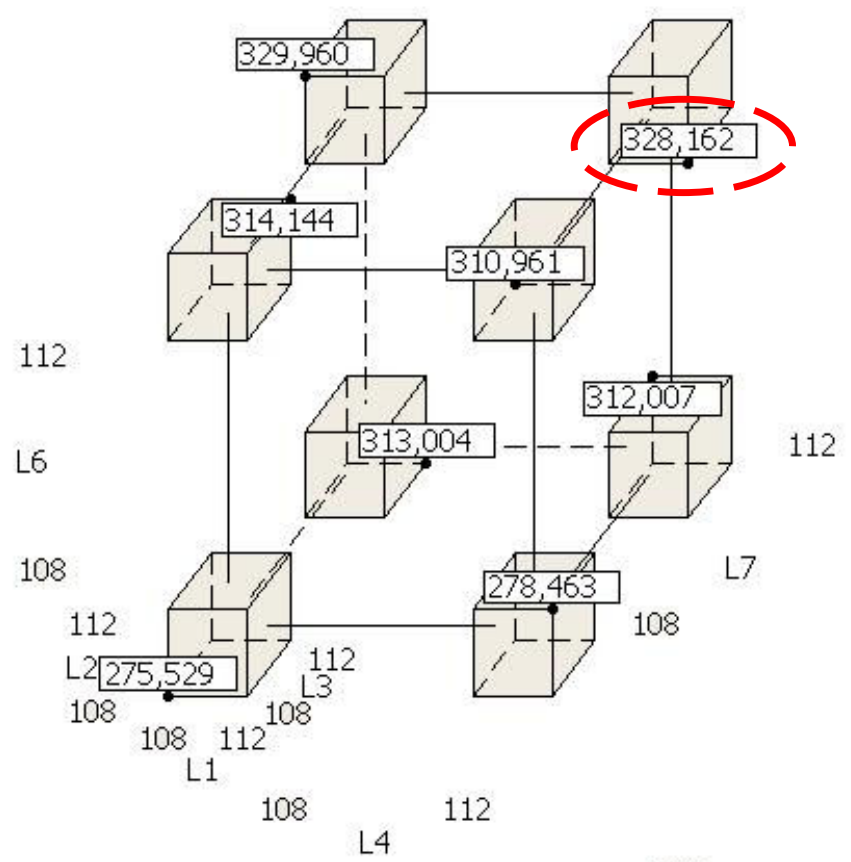

108

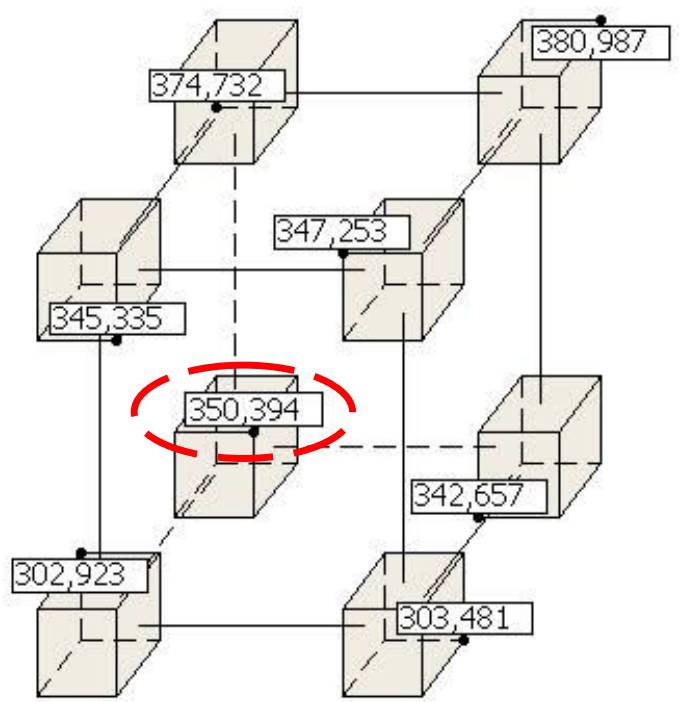

112

L8

Figura 72: Combinações estudadas na primeira abordagem com DOE

Os efeitos individuais de cada variável de entrada na saída $\omega_{1}$ aqui chamados de efeitos principais, e os efeitos das interações de segunda ordem, ou seja, $L_{i}{ }^{*} L_{j}$ com i diferente de j, e das demais interações (ABC, $A B C D$..) são ilustrados no diagrama de Pareto da Figura 73 onde podemos verificar a influência não uniforme dos efeitos principais e interações específicas na saída.

O diagrama da Figura 73 mostra que os efeitos das larguras dos braços mais próximos ao volante são mais significativos que os das demais larguras. Estes efeitos são, de fato, os coeficientes que multiplicam cada variável individual $\left(L_{i}\right)$ ou interação $\left(L_{i^{*}} L_{j}, L_{i^{*}} L_{j^{*}} L_{k}, \ldots\right)$. Apesar de simplificado, este estudo pode ser utilizado com grande valor agregado na otimização já que mostra onde atuar para obter resultados maiores com menor aumento de massa do componente. 


\section{Diagrama de Pareto Para os Efeitos}

(resposta: w1, Alfa $=, 05$ )

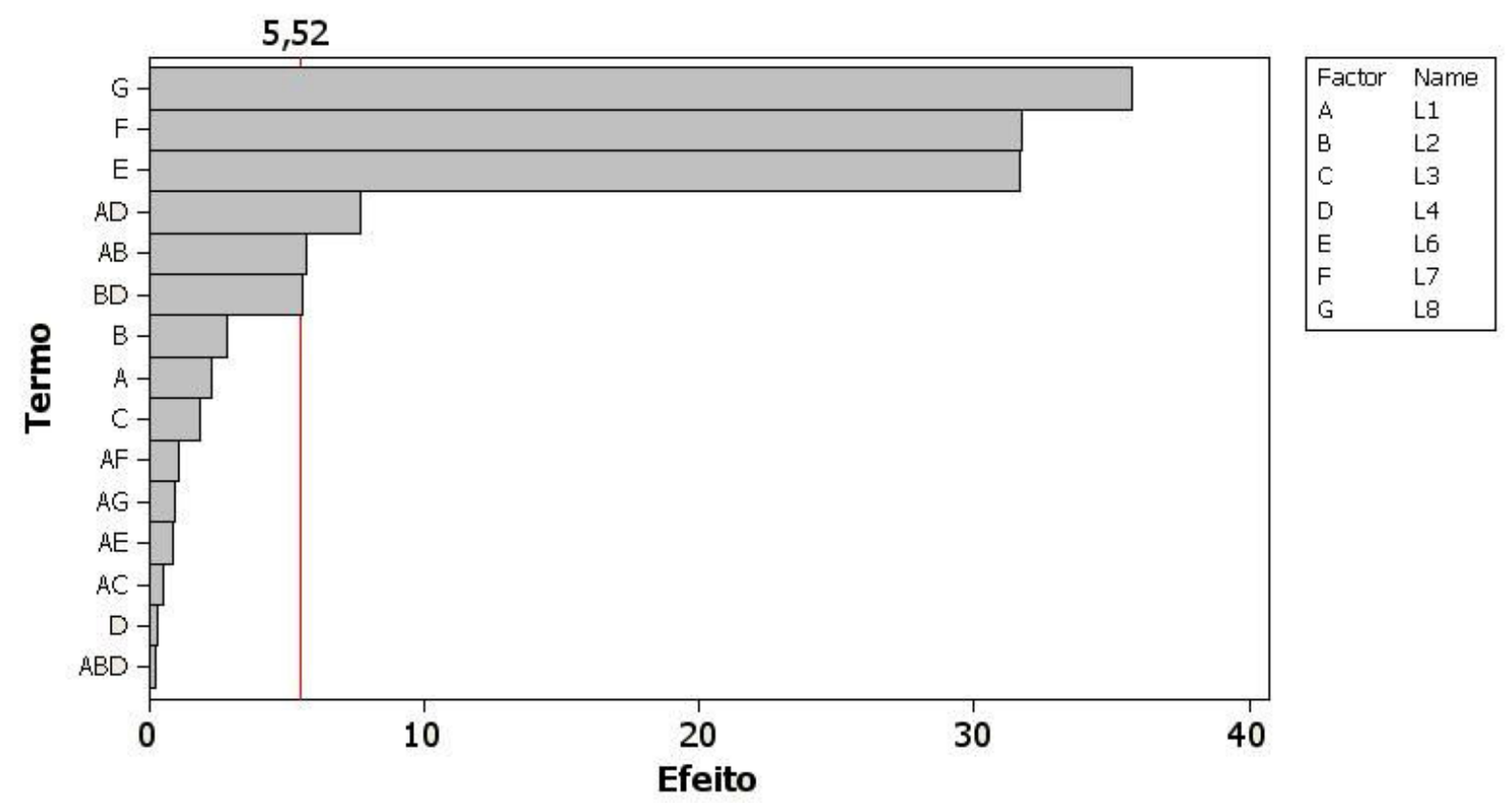

Lenth's PSE $=2,14881$

Figura 73: Diagrama de Pareto na primeira abordagem com DOE

Finalmente, podemos obter a equação para a freqüência fundamental:

$$
\begin{aligned}
& \omega_{1}=15609,7-97,40 \cdot \mathrm{L}_{1}-337,06 \cdot \mathrm{L}_{2}-11,68 \cdot \mathrm{L}_{3}-71,96 \cdot \mathrm{L}_{4}+0,23 \cdot \mathrm{L}_{6}-4,81 \cdot \mathrm{L}_{7}-9,22 \cdot \mathrm{L}_{8}+\text {, } \\
& \text { - }+2,43 \cdot \mathrm{L}_{1} \cdot \mathrm{L}_{2}+0,11 \cdot \mathrm{L}_{1} \cdot \mathrm{L}_{3}+0,013 \cdot \mathrm{L}_{1} \cdot \mathrm{L}_{4}-0,18 \cdot \mathrm{L}_{1} \cdot \mathrm{L}_{6}+0,14 \cdot \mathrm{L}_{1} \cdot \mathrm{L}_{7}+0,13 \cdot \mathrm{L}_{1} \cdot \mathrm{L}_{8}+\text { । } \\
& \text { - }+2,41 \cdot \mathrm{L}_{4} \cdot \mathrm{L}_{2}-0,016 \cdot \mathrm{L}_{1} \cdot \mathrm{L}_{2} \cdot \mathrm{L}_{4}
\end{aligned}
$$

Os cálculos estatísticos envolvidos podem ser mais bem estudados na literatura específica ${ }^{57}$. Análises mais profundas relacionadas ao cálculo da significância estatística dos efeitos, interações e da curvatura, quantificando efetivamente o erro potencial envolvido em assumir-se um modelo linear para este problema poderiam ser executadas em caso de custo excessivo para realização de experimentos mais complexos. Como não é este o caso do presente trabalho, onde se pôde executar com rapidez através do programa desenvolvido, um número grande de combinações, foi feito um estudo de sensibilidade mais completo.

No novo estudo executado, foram calculadas as freqüências fundamentais de vibração torcional para todas as combinações possíveis das sete larguras estudadas nos mesmos três níveis analisados no primeiro estudo de sensibilidade. Assim, foram calculadas $3^{7}=2187$ combinações das larguras dos sete braços nos níveis 
$108 \mathrm{~mm}, 110 \mathrm{~mm}$ e $112 \mathrm{~mm}$, resultando nos gráficos de efeitos principais e interações mostrados nas Figuras 74 e 75.

Efeitos Principais (médias) para w1

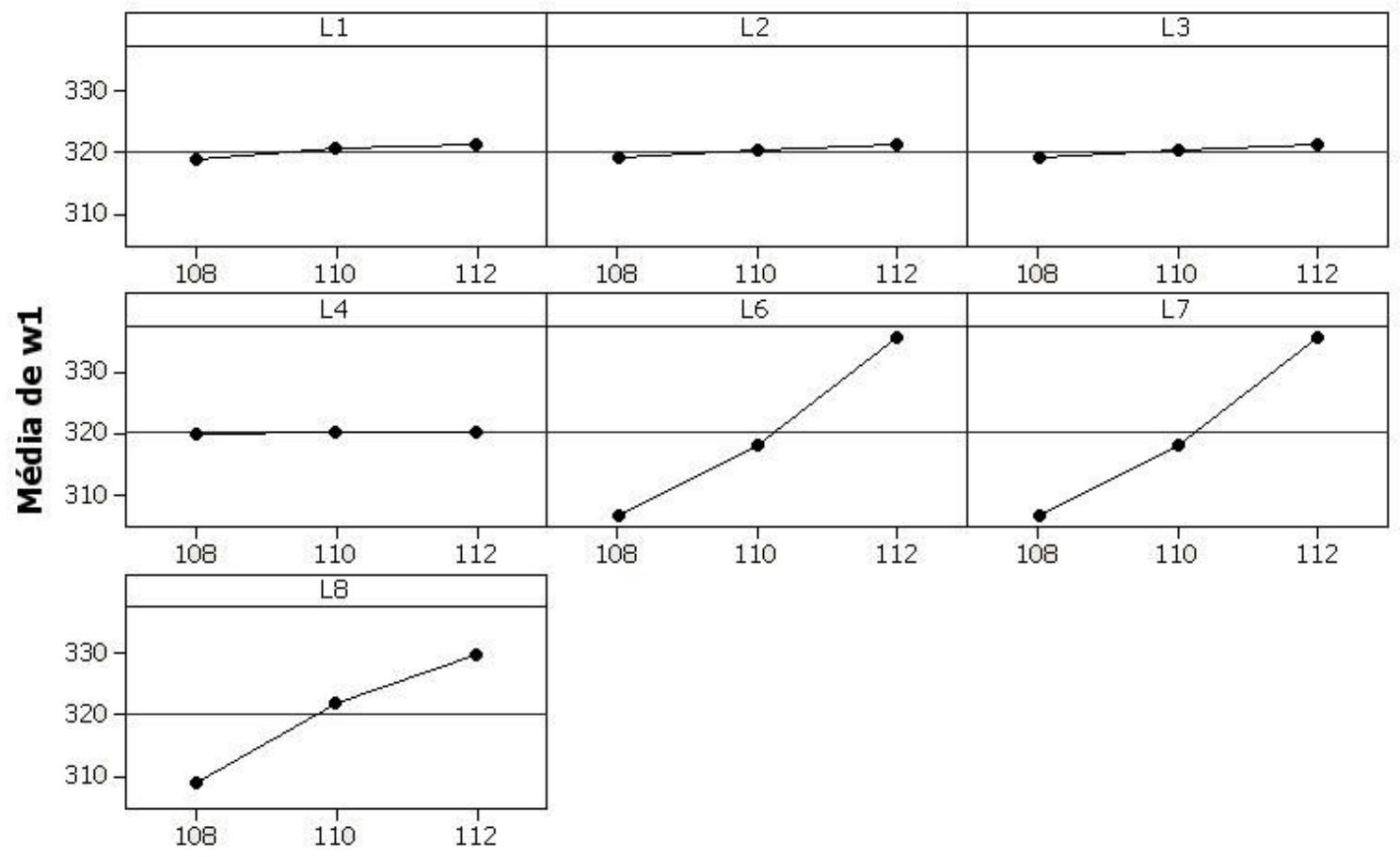

Figura 74: Efeitos principais na segunda abordagem com DOE

Iterações (médias) para w1

L1

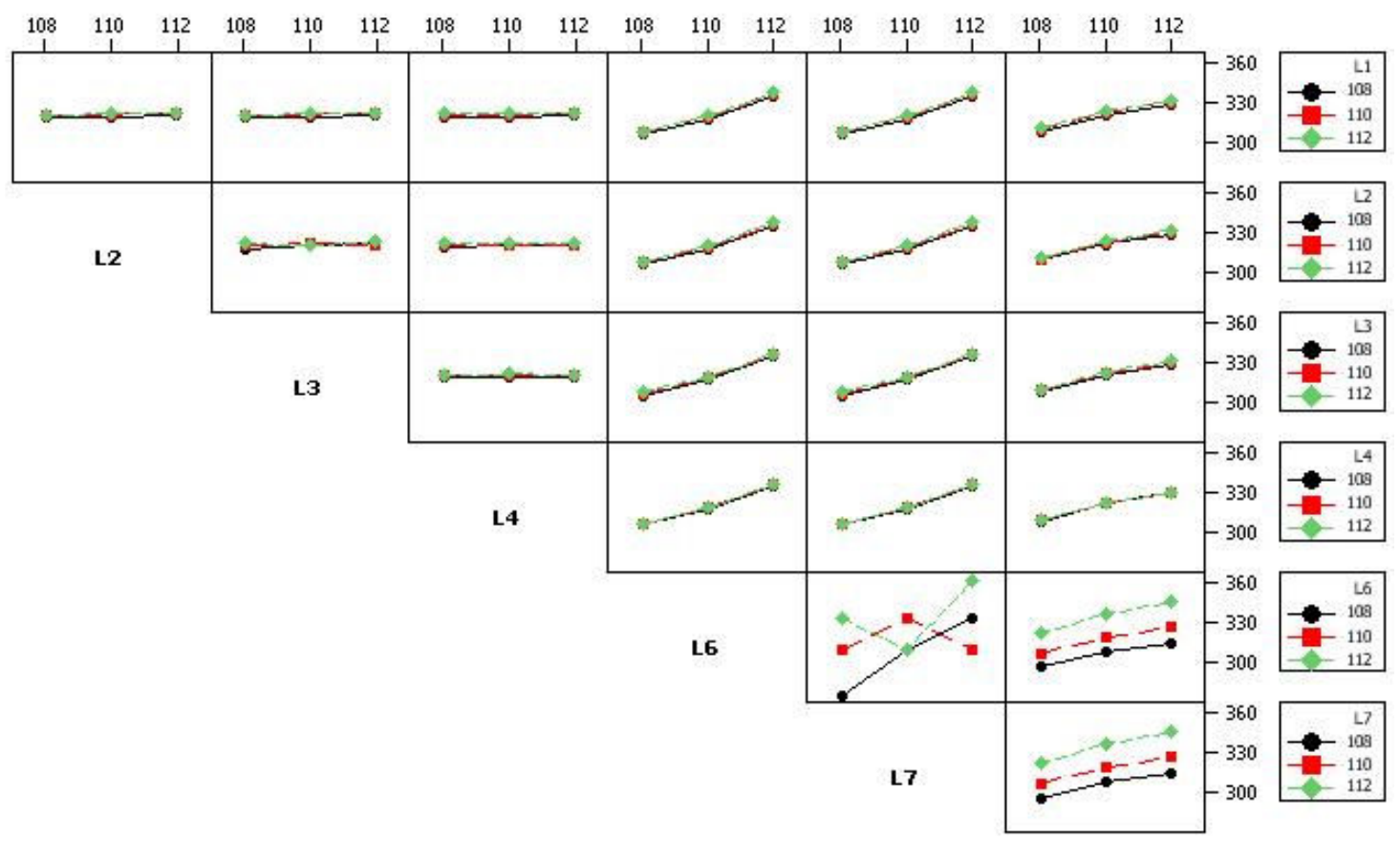

L8

Figura 75: Interações na segunda abordagem com DOE

Novamente, os resultados agora mais completos mostram maior influência individual 
das larguras dos braços próximos ao volante na freqüência natural. Uma nova equação aproximada foi obtida diretamente pelos dados do estudo, objetivo final desta análise de sensibilidade:

$$
\begin{aligned}
& \omega_{1}=-5236,90+15,081 \cdot \mathrm{L}_{1}+12,128 \cdot \mathrm{L}_{2}+10,451 \cdot \mathrm{L}_{3}+0,0962 \cdot \mathrm{L}_{4}-2,694 \cdot \mathrm{L}_{6}-5,656 \cdot \mathrm{L}_{7}+47,11 \cdot \mathrm{L}_{8}+\text { I } \\
& \text { ' }+0,011 \cdot \mathrm{L}_{1} \cdot \mathrm{L}_{2}+0,011 \cdot \mathrm{L}_{1} \cdot \mathrm{L}_{3}+0,0434 \cdot \mathrm{L}_{1} \cdot \mathrm{L}_{6}+0,0436 \cdot \mathrm{L}_{1} \cdot \mathrm{L}_{7}+0,0356 \cdot \mathrm{L}_{1} \cdot \mathrm{L}_{8}-0,221 \cdot \mathrm{L}_{3} \cdot \mathrm{L}_{2}+\text { I } \\
& \text { ' }+0,0481 \cdot \mathrm{L}_{6} \cdot \mathrm{L}_{2}+0,0483 \cdot \mathrm{L}_{2} \cdot \mathrm{L}_{7}+0,0393 \cdot \mathrm{L}_{2} \cdot \mathrm{L}_{8}+0,0492 \cdot \mathrm{L}_{3} \cdot \mathrm{L}_{6}+0,0494 \cdot \mathrm{L}_{3} \cdot \mathrm{L}_{7}+0,401 \cdot \mathrm{L}_{3} \cdot \mathrm{L}_{8}+\text { I } \\
& \text { ' }+0,0098 \cdot \mathrm{L}_{6} \cdot \mathrm{L}_{4}+0,0098 \cdot \mathrm{L}_{4} \cdot \mathrm{L}_{7}+0,0079 \cdot \mathrm{L}_{4} \cdot \mathrm{L}_{8}-1,834 \cdot \mathrm{L}_{7} \cdot \mathrm{L}_{6}+0,356 \cdot \mathrm{L}_{6} \cdot \mathrm{L}_{8}+0,355 \cdot \mathrm{L}_{7} \cdot \mathrm{L}_{8}+\text { I } \\
& \text { - }-0,138 \cdot\left(\mathrm{L}_{1}\right)^{2}-0,0153 \cdot\left(\mathrm{L}_{2}\right)^{2}-0,0094 \cdot\left(\mathrm{L}_{3}\right)^{2}-0,0137 \cdot\left(\mathrm{L}_{4}\right)^{2}+0,709 \cdot\left(\mathrm{L}_{6}\right)^{2}+0,708 \cdot\left(\mathrm{L}_{7}\right)^{2}-0,607 \cdot\left(\mathrm{L}_{8}\right)^{2}
\end{aligned}
$$

Foram calculadas as freqüências naturais a partir das equações obtidas no estudo fracionado e no estudo completo comparando com o resultado "exato"i obtido pelo programa em MATLAB ${ }^{\circledR}$. Para cada uma das freqüências calculadas pelas duas equações, foi calculado o erro percentual em relação à freqüência previamente calculada pelo programa do Apêndice C. Para todas as combinações possíveis, a fórmula da abordagem fracionada mostrou erro médio de $4,55 \%$ enquanto que a abordagem completa teve 3,90\% de erro médio.

Estes resultados mostram que com apenas 16 combinações de dimensões calculadas foi possível obter uma equação com erro próximo e satisfatório se comparado ao erro obtido com uma equação para a qual foram necessários 2187 cálculos de freqüência.

\section{Otimização}

Tendo disponível a equação que relaciona a freqüência fundamental de vibração com as larguras dos braços, e a equação da massa pelas mesmas variáveis, foi feito um estudo de otimização através do programa desenvolvido em MATLAB ${ }^{\circledR}$ descrito no Apêndice C, que utilizou o método de Quasi-Newton ilustrado na seção 7.2.

O objetivo neste estudo foi minimizar a massa do componente mantendo a freqüência fundamental de vibração torcional igual ou superior a $358 \mathrm{~Hz}$, sendo que o valor atual das variáveis $L_{1}$ a $L_{8}$ de $110 \mathrm{~mm}$ traz freqüência de $337 \mathrm{~Hz}$. A massa atual do componente é de $41,2 \mathrm{~kg}$ podendo chegar a $41,446 \mathrm{~kg}$ com as dimensões no nível máximo estabelecido.

' - Considera-se como exato o resultado da freqüência calculado pelo programa desenvolvido, dado que as freqüências calculadas pelas equações devem em tese ser semelhantes às obtidas pelo mesmo. 
Como mencionado no início do capítulo, os limites para as dimensões se encontram entre 108 e112mm.

O resultado de saída da otimização proposta foi:

\begin{tabular}{ll}
\hline L1 & 111,26 \\
L2 & 108,11 \\
L3 & 112,00 \\
L4 & 108,00 \\
L6 & 112,00 \\
L7 & 112,00 \\
L8 & 112,00 \\
\hline
\end{tabular}

Tabela 11: Dimensões para solução ótima

Freqüência fundamental resultante: $358,00 \mathrm{~Hz}$ (restrição ativa)

Massa total resultante: $41,294 \mathrm{~kg}$

A matriz Hessiana $(\mathrm{H})$ no ponto ótimo, é dada por:

$$
\begin{aligned}
& \mathrm{H}=\left[\begin{array}{llllllll} 
& 0.6794 & 0.3914 & 0.2199 & 0.2548 & -0.0091 & -0.0093 & -0.0816
\end{array}\right. \\
& \begin{array}{lllllll}
0.3914 & 0.4329 & 0.4526 & 0.2549 & -0.0138 & -0.0141 & -0.0853
\end{array} \\
& \begin{array}{llllllll}
0.2199 & 0.4526 & 0.5833 & 0.2546 & -0.0170 & -0.0173 & -0.0877
\end{array} \\
& \begin{array}{llllllll}
0.2548 & 0.2549 & 0.2546 & 0.2745 & 0.0146 & 0.0145 & -0.0608
\end{array} \\
& \begin{array}{lllllll}
-0.0091 & -0.0138 & -0.0170 & 0.0146 & 0.6862 & -0.3137 & -0.2782
\end{array} \\
& \begin{array}{lllllll}
-0.0093 & -0.0141 & -0.0173 & 0.0145 & -0.3137 & 0.6864 & -0.2775
\end{array} \\
& \begin{array}{lllllll}
-0.0816 & -0.0853 & -0.0877 & -0.0608 & -0.2782 & -0.2775 & 1.0692]
\end{array}
\end{aligned}
$$

Como os auto-valores da matriz $\mathrm{H}(0.00032,0.099,0.1969,0.4214,1.0000,1.1786 \mathrm{e}$ 1.5153) são positivos, o problema em questão é considerado convexo e, dentro dos limites especificados o valor encontrado para a massa é portanto um mínimo global. Assim, para o aumento da freqüência especificado, foi obtido o menor valor possível de aumento de massa.

Convém ressaltar que o projeto completo deve ser iterativo. Isto é, as análises: estrutural, dinâmica e de balanceamento devem ser reconsideradas. No caso apresentado, para a análise estrutural, por exemplo, foi verificado no próprio estudo executado na seção 8.10.1 que a influência da largura nos valores de tensões não é significativa. 


\section{Conclusões}

A tecnologia envolvida com o desenvolvimento de componentes tem evoluído com uma velocidade muito grande, tendo qualidade e quantidade de informações obtidas relacionadas ao desempenho e processo de componente aumentado em proporção semelhante. A organização do projeto em torno de uma metodologia suficientemente bem elaborada auxilia a utilização sensata destas informações e de novas ferramentas. Conhecimentos difundidos na engenharia há anos podem ser aliados a softwares e organizados de forma estruturada acelerando o projeto de componentes, tornando o mesmo mais eficiente e competitivo.

O presente trabalho exemplificou a aplicação de tais ferramentas em um estudo de caso onde foi analisado o desempenho de uma árvore de manivelas de um motor de quatro cilindros em linha real, com o cálculo de propriedades dinâmicas e estruturais do componente.

As análises dos resultados numéricos do estudo de caso foram executadas ao longo do capítulo 8. Cabe mencionar que na análise de falha por fadiga, os coeficientes de segurança calculados mostraram um projeto um tanto conservador, viabilizando uma potencial redução de massa como visto na seção referente à otimização estrutural do componente. Por outro lado, há a presença da freqüência natural fundamental na faixa de operação do motor estudado.

Foi verificada a relação totalmente interligada dos estudos de desempenho diversos. Assim, em quaisquer alterações executadas em componentes como o do estudo do presente trabalho, deve-se verificar potenciais efeitos em outros parâmetros de comportamento.

Como sugestões para próximos trabalhos, podem-se desenvolver estudos específicos sobre cada análise executada, seja modal, dinâmica, estrutural ou de otimização. Há ainda a possibilidade de execução de análise experimental para todos os estudos numéricos descritos. 


\section{Referências Bibliográficas}

[1] BACK, N. Metodologia de projeto de produtos industriais. Rio de Janeiro: Guanabara Dois, 1983.

[2] ASIMOV, M. Introdução ao projeto. 1 ed. São Paulo: Mestre Jou, 1968.

[3] PAHL, G.; BEITZ, W. Engineering design: a systematic approach. 2 ed. London: Springer, 1996.

[4] HUBKA, V. ; EDER, W. E., Theory Technical Systems: A Total Concept Theory for Engineering Design, New York: Springer Verlag, 1988;

[5] MOURELATOS, Z. P. An efficient crankshaft dynamic analysis using substructuring with Ritz vectors. Journal of Sound and Vibration 238(3), p. 495527, (2000).

[6] FONSECA, M.L.. Procedimento Metodológico para o Projeto de Virabrequins. 2003, 133p. Dissertação (Mestrado) - Universidade Federal de Santa Catarina, Florianópolis, 2003.

[7] MOURELATOS, Z. P. A crankshaft system model for structural dynamics analysis of internal combustion engines. Computers and Structures 79 , p. 2009-2027, (2001).

[8] TAYLOR, C. F. The Internal-Combustion Engine in Theory and Practice. Vol. 2. Cambridge MA : MIT Press, 1985

[9] AVL EXCITE. EXCITE Designer Theory, Version 6.1, AVL LIST GMBH. 2004

[10] BOSCH, Automotive handbook. $5^{\text {th }}$ edition. USA: SAE, 2000.

[11] BRITISH INTERNAL COMBUSTION ENGINE RESEARCH ASSOCIATION., A handbook on torsional vibration compiled by E. J. Nestorides, of the B. I. C. E. R. A. Research Laboratory. Cambridge [ENG]: University Press. 1958

[12] KER WILSON, W., Practical solution of torsional vibration problems. New York: 
John Wiley \& Sons Inc. 1963

[13] HAFTKA, R. T.; GÜRDAL,Z., Elements of Structural Optimization, Solid Mechanics and its Applications, Dordrecht, The Netherlands: Kluwer Academic Publishers, 1995.

[14] RAO, S.S., Engineering Optimization ,Theory and Practice $3^{\text {rd }}$ Edition, New York, EUA: Wiley Interscience, 1996

[15] DURELLI, A.J.; PHILLIPS, E.A.; TSAO C.H. Introduction to the Theoretical and Experimental Analysis of Stress and Strain, New York: McGraw-Hill, 1958

[16] VANDERPLAATS, G. N., Numerical Optimization Techniques for Engineering Design With Applications, New York: Mcgraw-Hill, 1984.

[17] WRIGHT, C. P. Applied Measurement Engineering, How to Design Effective Mechanical Measurement Systems, Englewood Cliffs, N.J. : Prentice Hall PTR, 1995

[18] EWINS, D. Modal Testing: Theory and Practice, Letchworth, Hertfordshire, England; New York : Research Studies Press: Wiley, 1984.

[19] MEIROVITCH L., Principles and techniques of vibration, Upper Saddle River, N.J. : Prentice Hall, 1997

[20] DUARTE Jr, D., Tribologia,lubrificação e Mancais de Deslizamento, 1 Ed. Editora Ciência Moderna, 2005

[21]KALPAKJIAN,S.; SCHMID,S.R. Manufacturing Engineering and Technology $5^{\text {th }}$ Edition, Upper Saddle River, NJ : Prentice Hall. 2005

[22] ASM Intl.,Metals Handbook Volume 14 - Forming and Forging, 9th Edition, Metals Park, Ohio: ASM International, 1988

[23] PROJECT MANAGEMENT INSTITUTE, PMBOK - Project management body of knowledge Pennsylvania: Project Management Institute, 200 
[24] Car Bibles The Fuel and Engine Bible - Informações básicas sobre motores. Disponível em: <http://www.carbibles.com/fuel_engine_bible.html> Acesso em: 15 out. 2006

[25] BRUNETTI F., GARCIA O. Motores de Combustão Interna 2 ed. EPUSP 1992

[26] WHYLEN, V., SONNTAG, R., BORGNAKKE,C.Fundamentos da Termodinâmica Clássica, Tradução de ZERBINI,E.J.;SIMỐES,R.S.E. $4^{a}$ Edição, São Paulo: Editora Edgard Blücher,1995

[27] AMSTRONG, L.V.,HARTMAN, J.B. The Diesel Engine - Its Theory, Basic Design and Economics, New York: The Macmillan Company, 1959

[28] - CALCOM SA - Casting vs. Forging Disponível em: <http://www.calcom.ch> Acesso em: 15 out. 2006

[29] FUJIKAWA, S. Application of CAE for hot-forging of automotive components. Journal of Materials Processing Technology 98 p.176 -181 (2000)

[30] DARLOW, M.S. Balancing of Hogh-Speed Machinery: Theory, Methods and Experimental Results. Mechanical Systems and Signal Processing 1(1), p. 1051341987

[31] DARLOW, M. S. A unified approach to the mass balancing of rotating flexible shafts. Ph.D. Disseration, Florida: University of Florida, 1980

[32] SCHALCH, A. S. Desenvolvimento e Validação de Metodologia para Análise de Vibrações Torcionais em Motores de Combustão Interna 2005, 82p. Dissertação (Mestrado) - Universidade Estadual de Campinas, Campinas, 2005.

[33] SILVA, E.C.N. Apostila - Otimização Aplicada ao Projeto de Sistemas Mecânicos EPUSP

[34] SCHIGLEY, J. E.,MISCHKE, C. R. Mechanical Engineering Design $5^{\text {th }}$ Edition, Mcgraw-Hill, 1989.

[35] PANDEY, P. K. Failure of diesel-engine crankshafts Engineering Failure Analysis 10 p. $165-1752003$

[36] BATHE, K.J., Finite Element Procedures Englewood Cliffs, N.J. : Prentice Hall PTR, 1996 
[37] OGATA, K. System Dynamics $3^{\text {th }}$ Edition, Upper Saddle River, NJ : Prentice Hall. 1998.

[40] OBERT, E.F. Internal Combustion Engines $2^{\text {nd }}$ Edition, Scranton, PA : Intl. Textbook 1950

[41] WERKEMA, C. Design For Six Sigma Ferramentas básicas usadas nas etapas D e M do DMADV $1^{\text {a }}$ Edição, Belo Horizonte, MG : Werkema Editora. 2005.

[42] ZIENKIEWICZ, O.C., The Finite Element Method Maidenhead Berkshire, England; $3^{\text {rd }}$ Edition, Mcgraw-Hill, 1977

[43] SHIAO, Y., PAN, C.-H., MOSKWA, J. J., Advanced Dynamic Spark Ignition Engine Modeling for Diagnostics and Control, Int. Journal of Vehicle Design, Vol. 15, No. 6, 1994.

[44] HOFFMAN, D. M. W. ,DOWLING D. R., Fully Coupled Rigid Internal Combustion Engine Dynamics and Vibration-Part I: Model Development, Journal of Engineering for Gas Turbines and Power, Vol.123, pp. 677-684, July 2001.

[45] MOURELATOS, Z. P. An efficient crankshaft dynamic analysis using substructuring with Ritz vectors. Journal of Sound and Vibration Vol. 238 (3), p. 495-527, 2000.

[46] COUDERC, J., CALLENAERE, J., DER HAGOPIAN, FERRARIS, G. Vehicle Driveline Dynamic Behaviour:Experimentation and Simulation Journal of Sound and Vibration Vol. 218 (1), p. 133-157, 1998.

[47] SZADKOWSKI, A., Mathematical model and computer simulation of idle gear rattle International Congress and Exposition Detroit Michigan SAE Technical Paper Series 910641, p. 81-97, 1991

[48] . A. LASCHET, Computer simulation of vibrations in vehicle powertrains considering nonlinear efects in clutches and manual transmissions. SAE Technical Paper Series 941011 p. 221-227, 1994

[49] CROLLA, D. A.,Torsional Vibration Analysis of Tractor and Machine P. t.o. Drivelines Journal of Agricultural Engineering Research Vol. 23,p. 259-272, 1978.

[50] ZHANG, G.,FILIPI Z.S.m ASSANIS, D.N., A Flexible, reconfigurable, transient multi-cylinder diesel engine simulation for system dynamics studies Mech. Struct. \& Mach. Vol. 25(3), p. 357-378, 1997

[51] ASSANIS, D.,BRYZIK, W., CHALHOUB, N.,FILIPI, Z.,HENEIN, N., JUNG, D. , LIU, X., LOUCA, L., MOSKWA, J.,MUNNS, S., OVERHOLT, J., PAPALAMBROS, P., RILEY, S., RUBIN, Z., SENDUR, P.,STEIN, J., ZHANG, G., Integration and Use of Diesel Engine,Driveline and Vehicle Dynamics Models for Heavy Duty Truck Simulation International Congress and Exposition Detroit Michigan SAE Technical Paper Series 1909-01-0970, March 1999 
[52] AVL EXCITE. EXCITE Designer Primer, Version 7.0.2, AVL LIST GMBH. May 2007

[53] CROWTHER,A.R.,ZHANG,N.Torsional finite elements and nonlinear numerical modelling in vehicle powertrain dynamics Journal of Sound and Vibration Vol. 284 p. $825-849,2005$

[54] BITTENCOURT, M. L., DUARTE JR, D., PIEROTTI,R., ZOTTIN, W. Modelagem Matemática e Simulação do Circuito de Lubrificação de um Motor de Combustão Interna CONSICAE Mahle Metal Leve S.A. - DPM FEA Unicamp, AEA - SIMEA, 2007

[55] NORTON, R. L. Projeto de Máquinas - Uma abordagem integrada Tradução $2^{\mathrm{a}}$ Ed. Bookman, Porto Alegre, RS

[56] MARIN, J. Mechanical Behavior of Engineering Materials Prentice-Hall, Englewood Cliffs, N.J., 1962

[57] BOX, G. E. P., HUNTER, J.S., HUNTER, W.G. Statistics for Experimenters Design, Innovation, and Discovery Hoboken, $\mathrm{NJ} ; 2^{\text {nd }}$ Edition, Wiley-Interscience, 2005

[58] CREVELING, C.M., SLUTSKY, J.L., ANTIS JR, D. Design for Six Sigma in Technology and Product Development, Prentice-Hall, Upper Saddle River, New jersey, 2003

[59] VILLALVA, S. G. , SILVA, R. A. , OLIVEIRA, F. L., KURKA, P. R. , SANTOS, I. F. , BITTENCOURT, M. L. Determinação de esforços dinâmicos, vibração torcional e análise de tensões em virabrequins de motores de combustão interna. Relatório CONSICAE, Universidade Estadual de Campinas, Campinas, 2006.

[60] COELHO, T. A. H. Otimização no balanceamento de mecanismos tridimensionais do tipo RSSR. Tese (Doutorado) - ESCOLA POLITÉCNICA, Universidade de São Paulo, São Paulo, 1997

[61] DEN HARTOG, J. P. Mechanical Vibrations, Mc Graw Hill, New York, 1956

[62] PIRANER, I. , PFLUEGER, C. ,BOUTHIER, O. , Cummins Crankshaft and Bearing Analysis Process 2002 North American MDI User Conference, 2002 


\section{APÊNDICE A: PROGRAMA EM MATLAB PARA BALANCEAMENTO}

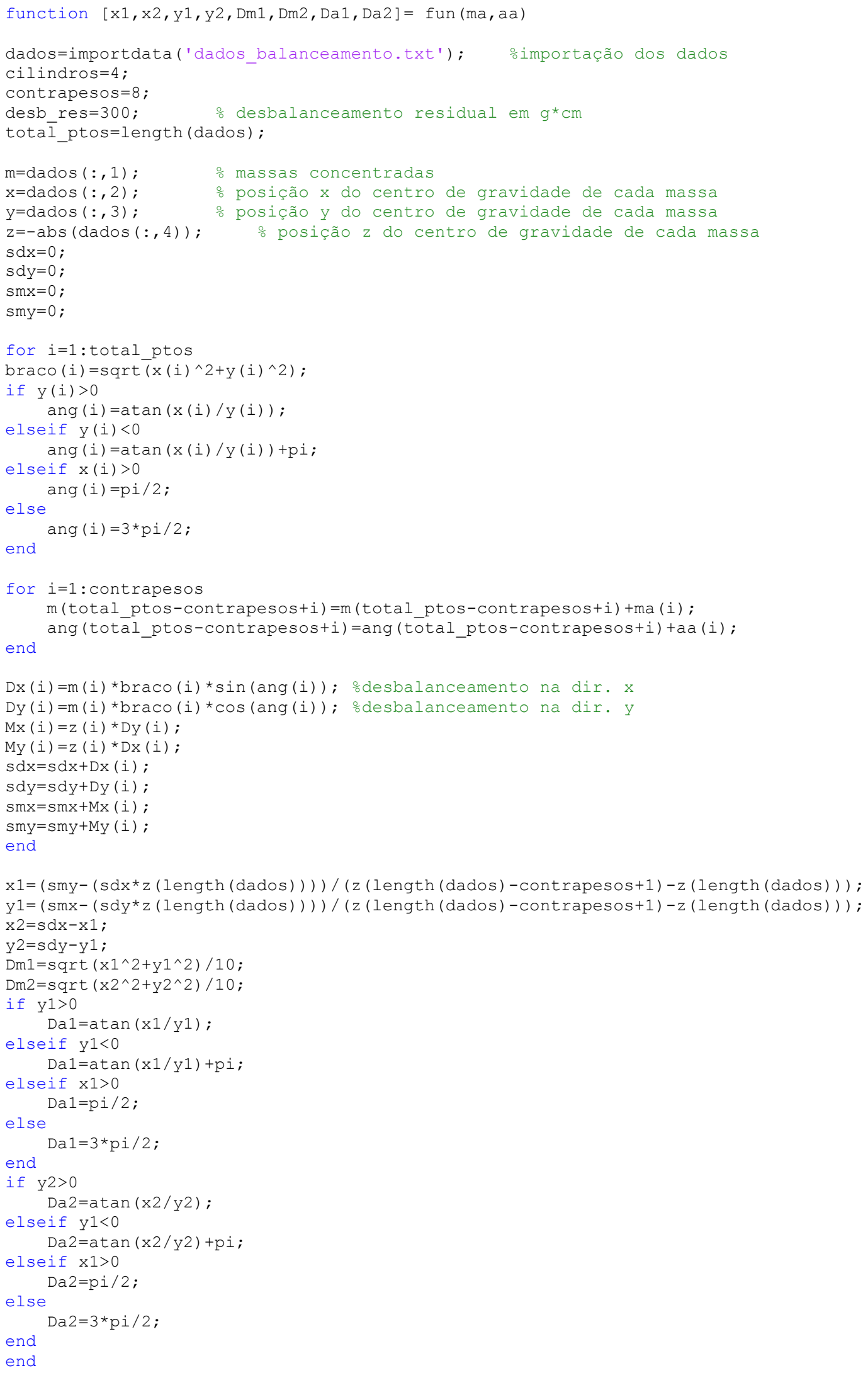




\section{APÊNDICE B: PROGRAMA EM MATLAB PARA CÁLCULO DO CARREGAMENTO, ANÁLISE MODAL E ANÁLISE DINÂMICA}

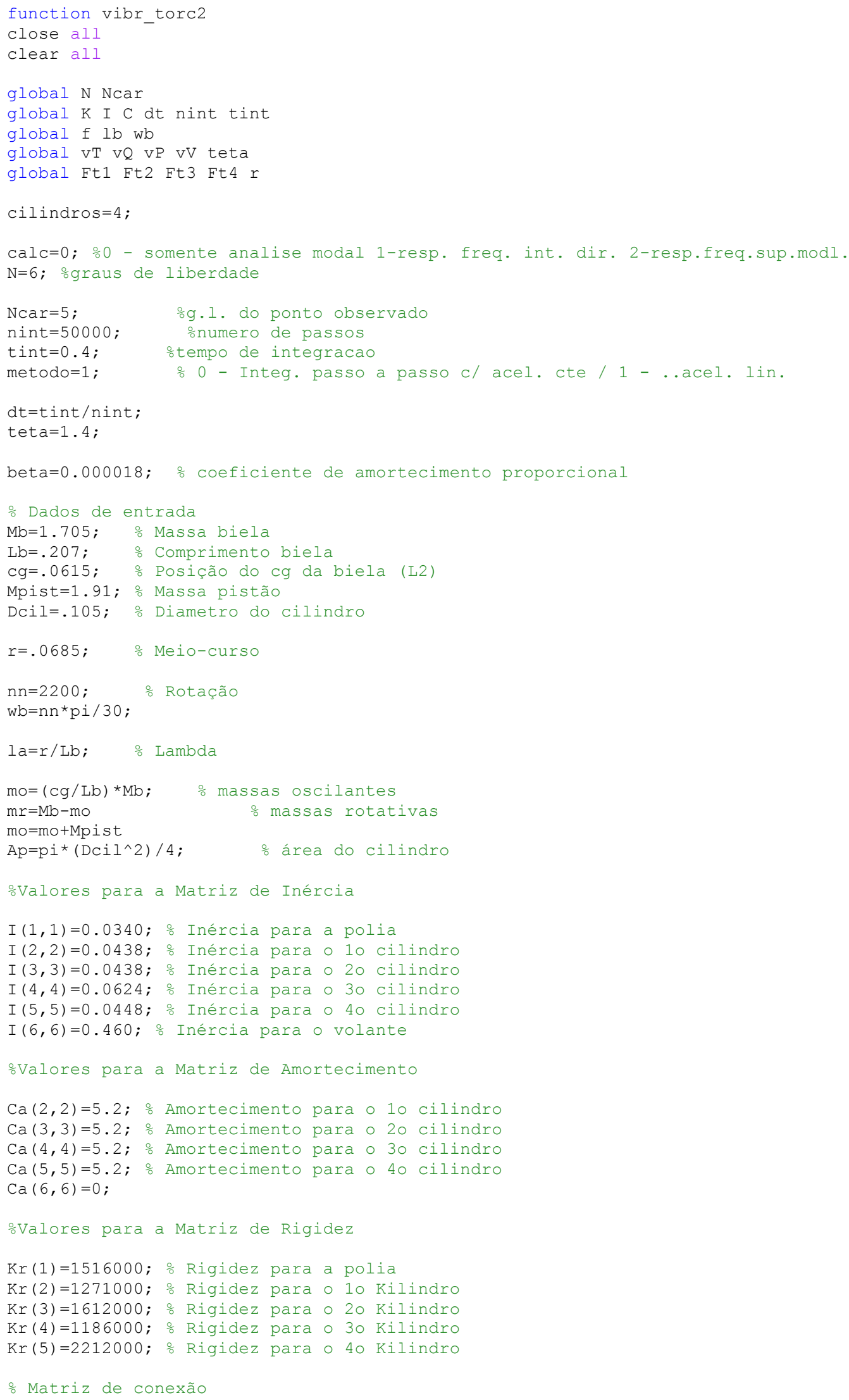




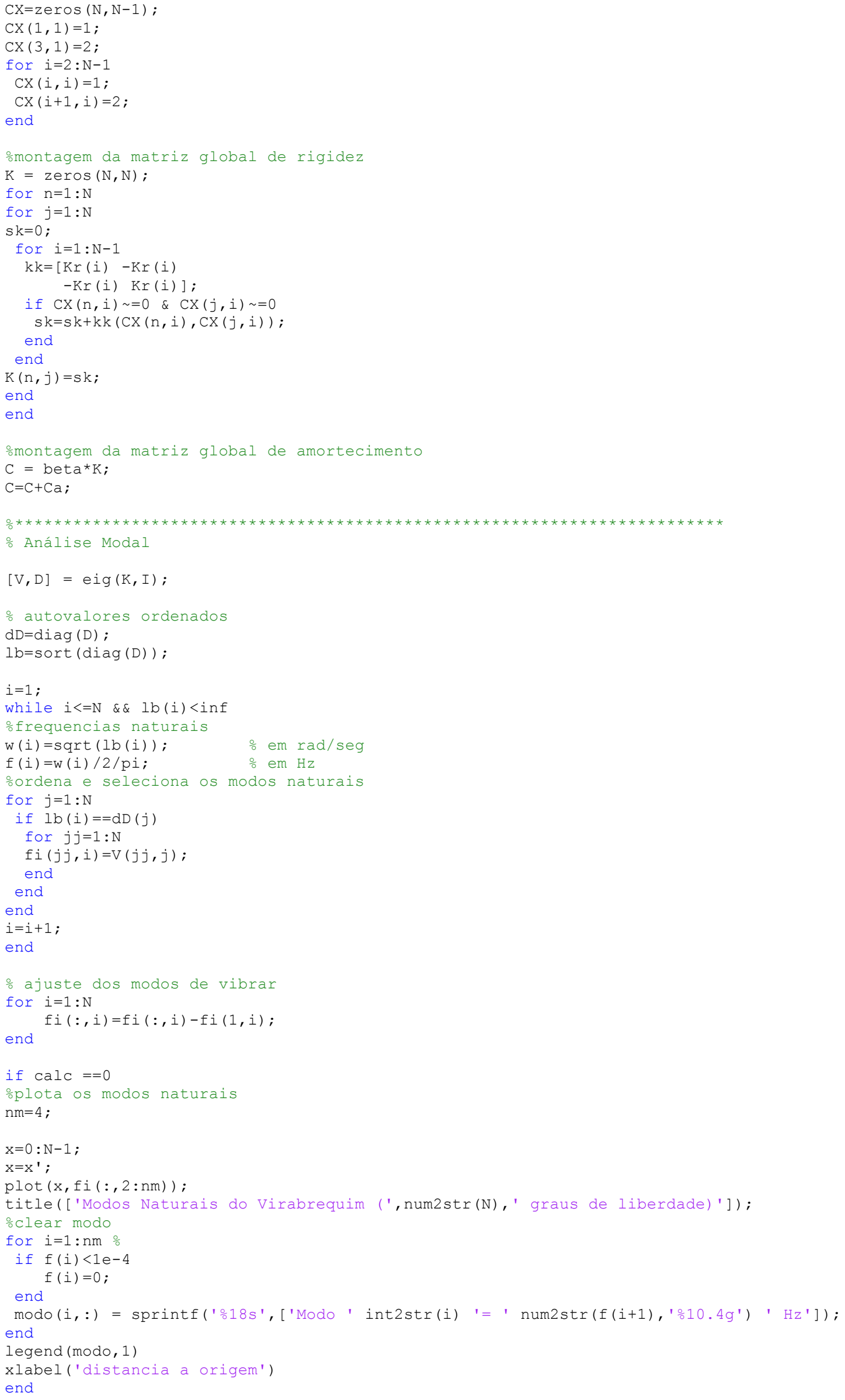




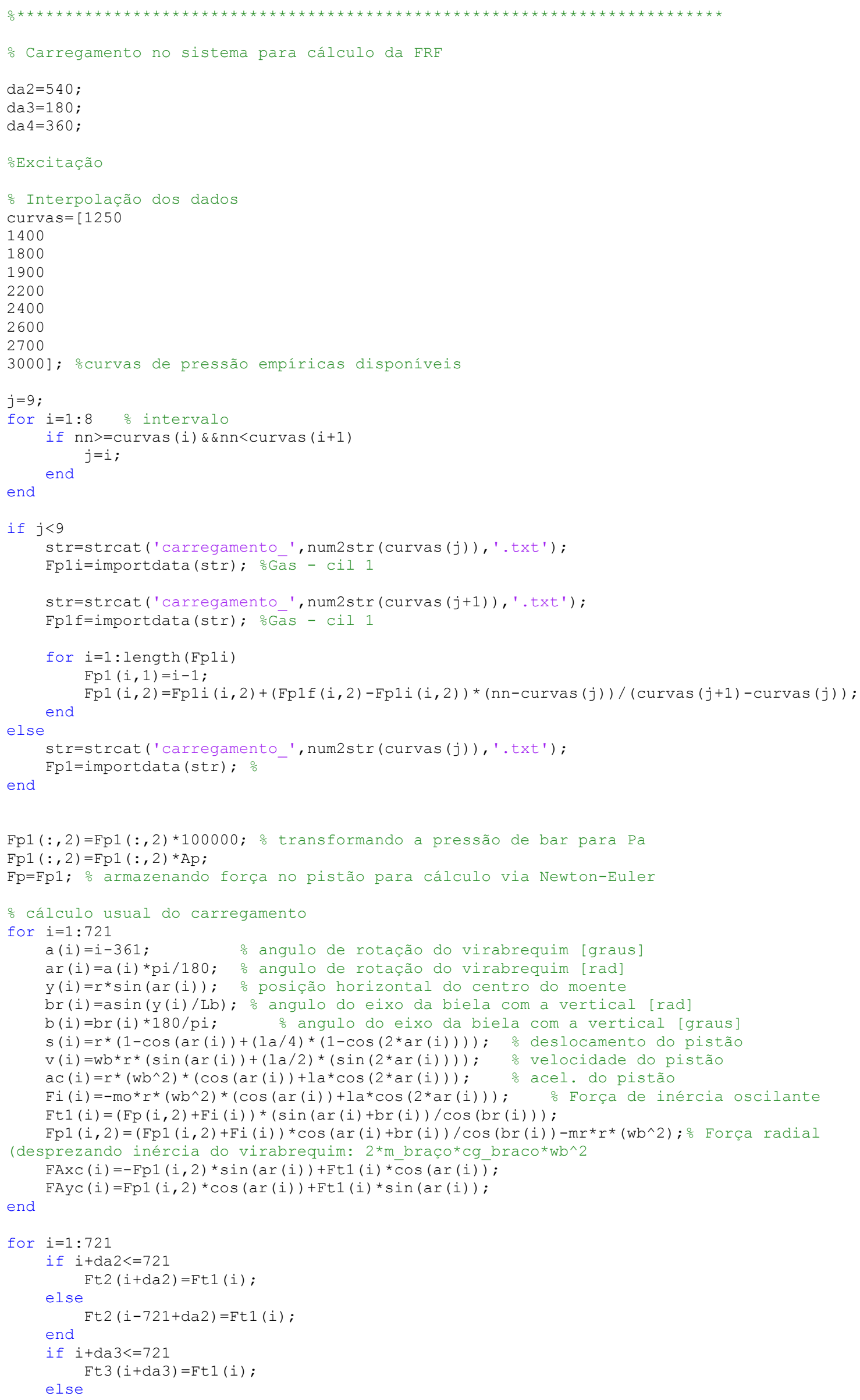




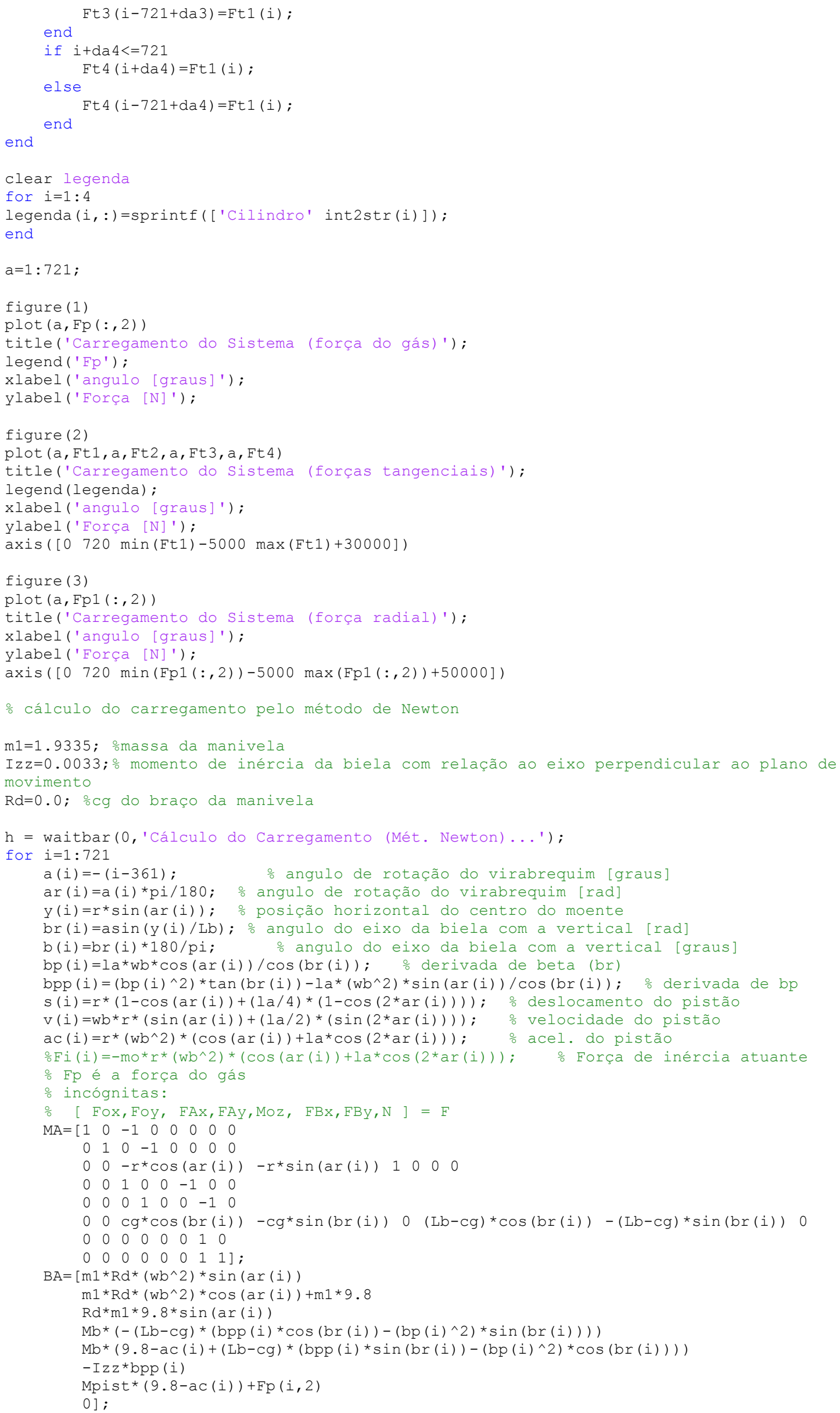




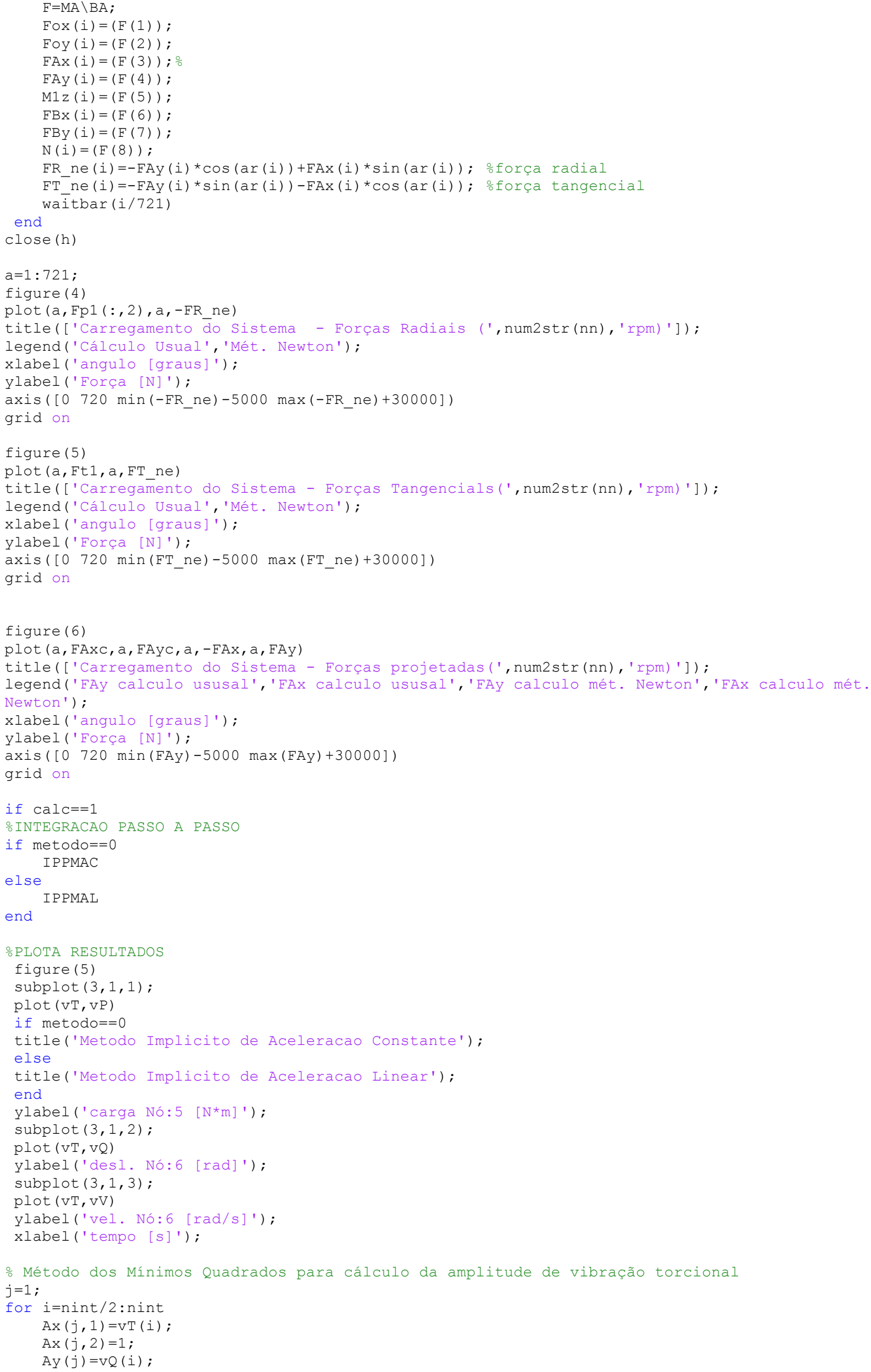




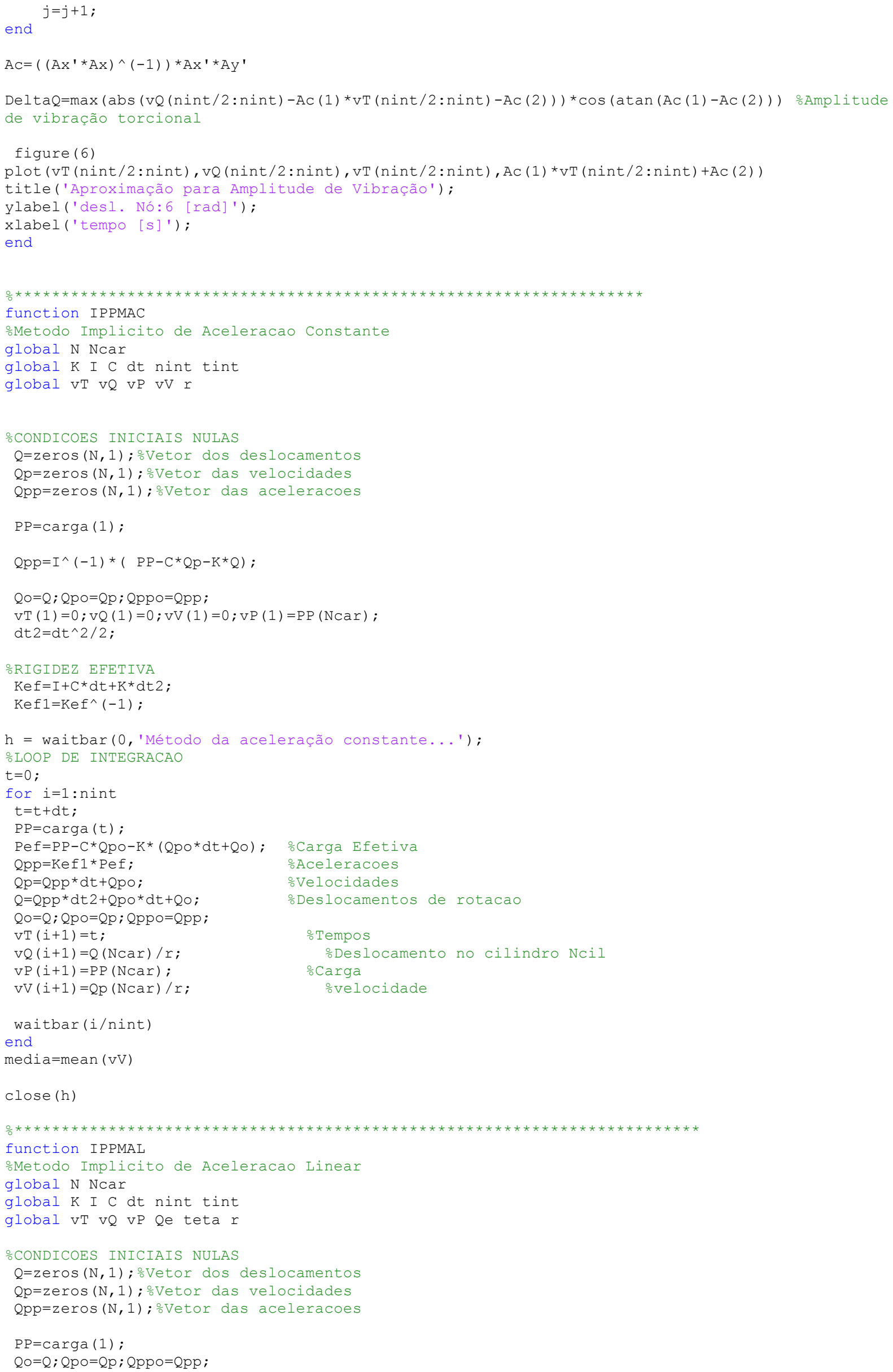




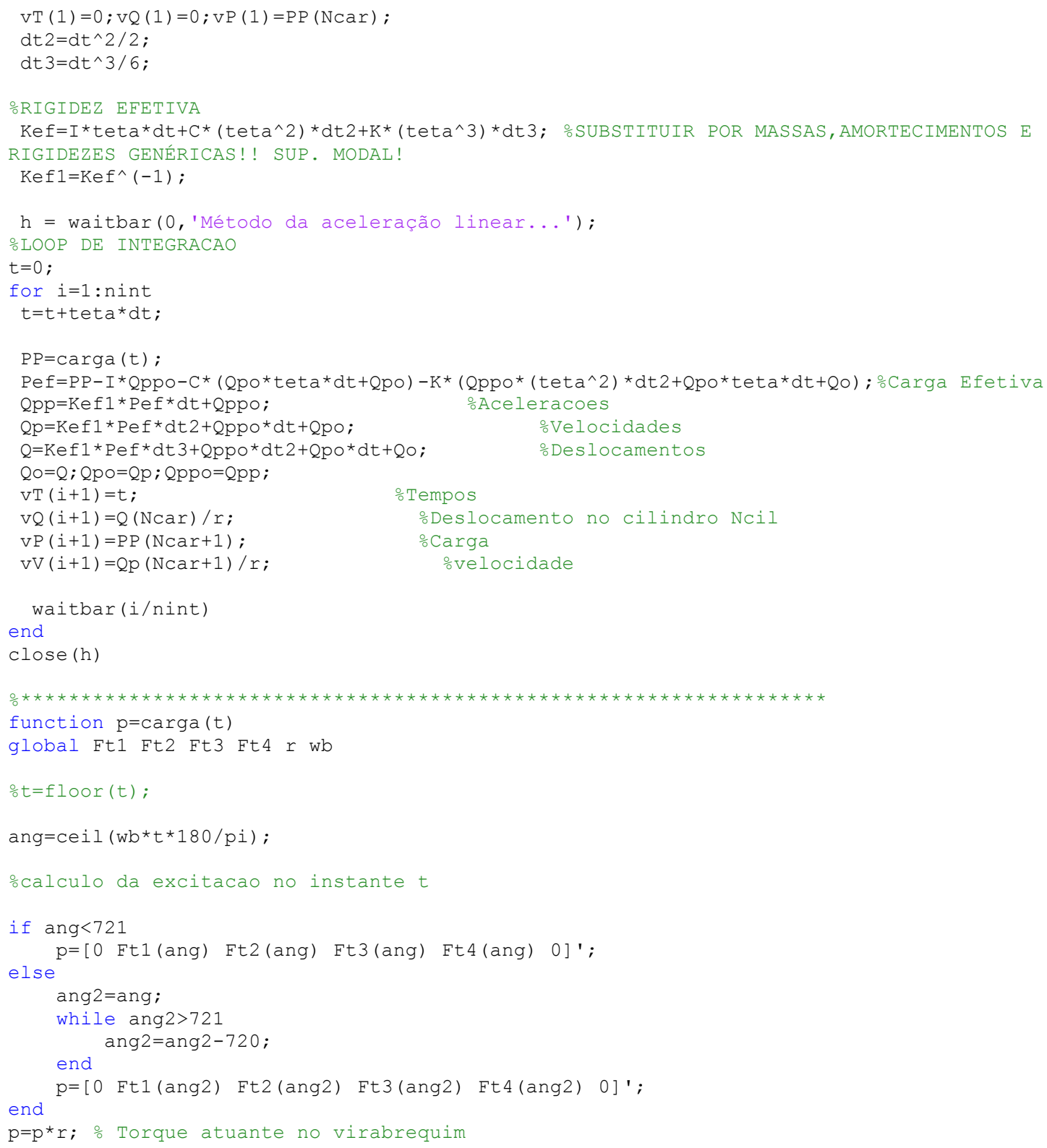




\section{APÊNDICE C: PROGRAMA EM MATLAB PARA OTIMIZAÇÃO}

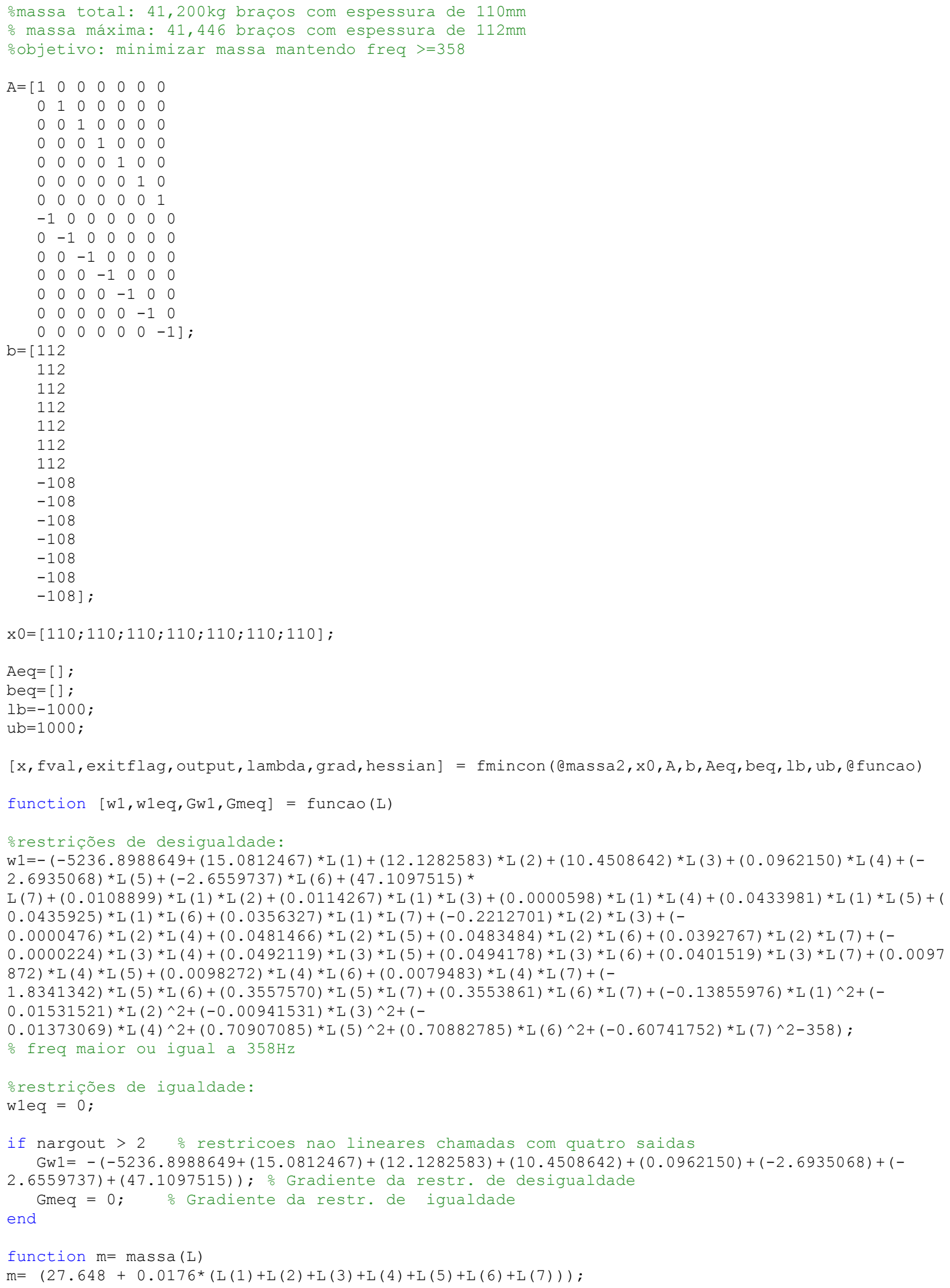

